NBSIR 84-3008

\title{
A CALORIMETER FOR MEASURING HIGH-ENERGY OPTICAL PULSES
}

National Bureau of Standards

U.S. Department of Commerce

Boulder, Colorado 80303

October 1984 



\section{A CALORIMETER FOR MEASURING HIGH-ENERGY OPTICAL PULSES}

\section{P.A. Simpson}

E.G. Johnson, Jr.

S.M. Etzel

Electromagnetic Technology Division

National Engineering Laboratory

National Bureau of Standards

U.S. Department of Commerce

Boulder, Colorado 80303

October 1984

Sponsored by

Newark Air Force Base, Ohio

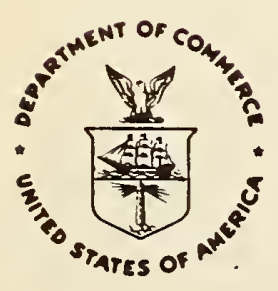

U.S. DEPARTMENT OF COMMERCE, Malcolm Baldrige, Secretary 

List of Figures.

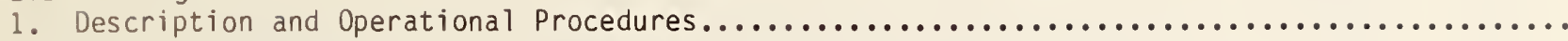

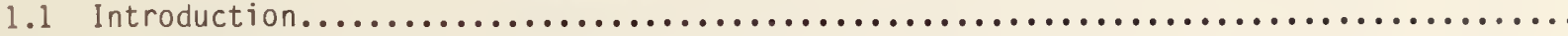

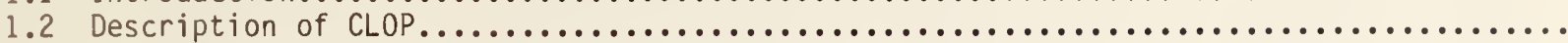

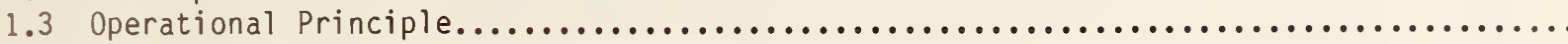

1.3.1 Main Calorimeter Principles.

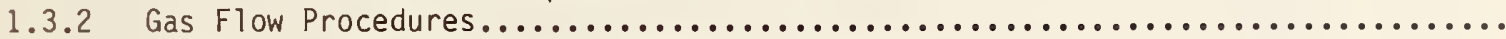

1.3.3 Functional Description of Modules Preceding

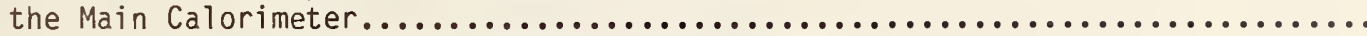

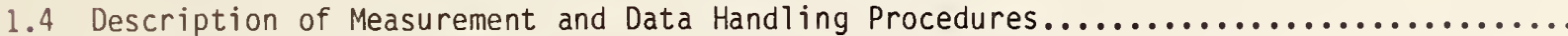

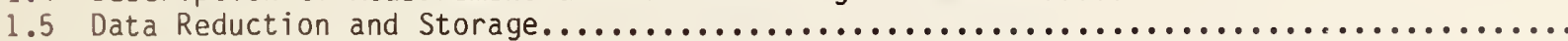

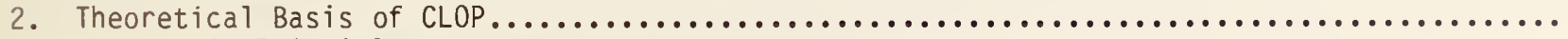

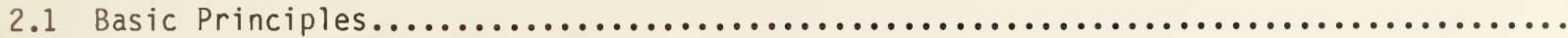

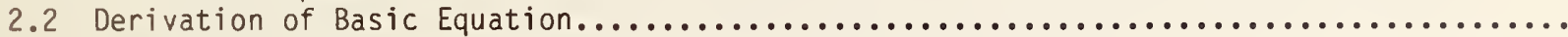

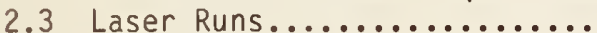

3. Description of Components.

3.1 Blast Shield.

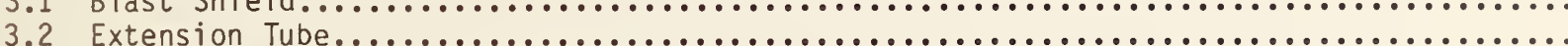

3.3 Overspill Monitor/Backscatter Monitor

3.3.1 General Features.

3.3.2 Overspill Monitor.

3.3.3 Backscatter Monitor

3.3.4 OSM/BSM Shutter.

3.4 Separation Tube

3.5 Mirror Reflector Surface.

3.5.1 Description of Module Supporting Frame

3.5.2 Deflecting Plate.

3.5.3 Foil Reflector.

3.6 Main Calorimeter.........

3.6.1 General Features.

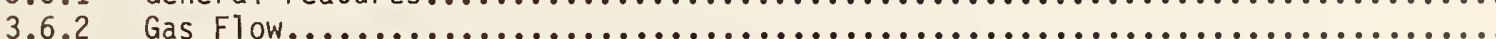

3.6.3 Electrical Instrumentation.

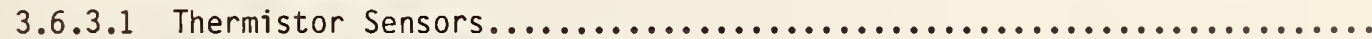

3.6.3.2 Resistance Thermometer Detector

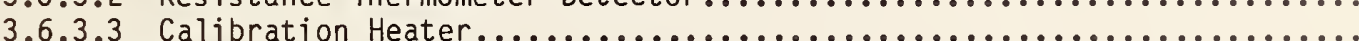

3.6.4 Main Calorimeter Shutter.

3.7 Data Acquisition Rack.

3.7.1 General Description.

3.7.2 Main Power Switch Panel

3.7 .3

3.7 .4

Scanner

3.7 .5

Status Light Panel.

3.7.7 Digital Voltmeter.

3.7.8 Pacer Unit (System T Only)

3.7.9 Input Gas Temperature Controller

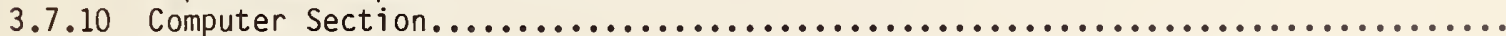

3.7.11 Power Supply Section

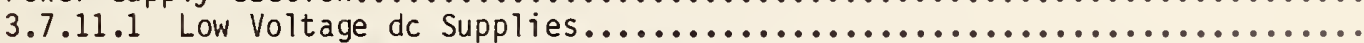

3.7.11.2 Calibration Power Supply Interface Unit.

3.7.12 Calibration Power Supply Status Circuit.

3.7.13 Preheater Control Circuit

3.7.14 Calibration Power Supply

3.7.15 Alternating Current Input Panel

3.7.16 CLOP Module Connection Panel.

3.7.17 Gas Valve Control Output Panel.

4. Computer Programs and Data Storage Files.

4.1 Introduction.

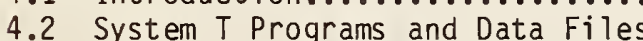

4.2.1 Index (FILE 1)

4.2.2 CLOP (FILE 2).

4.2.3 CHANNEL MONITOR (FILE 3 )

4.2.4 READ RUN DATA FILES (FILE 4)

4.2.5 CALCULATE RESULTS (FILE 5).

4.2.6 READ ELECTRICAL SUMMARY FILE (FILE 6). 


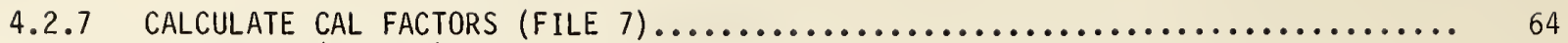

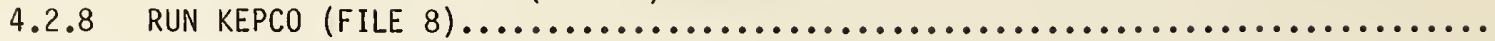

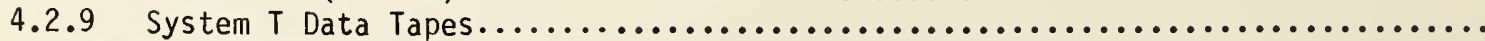

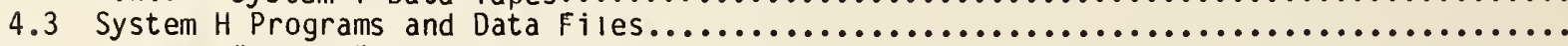
4.3.1 "Autost".

4.3 .2 "CLOP2"

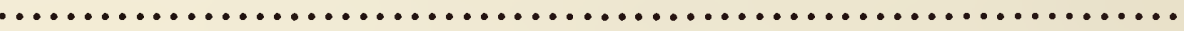

"CALC"

"ELSCAN"

4.3 .5

"FACTOR"

".

4.3 .6

4.3 .7

4.3 .8

4.3 .9

"FILEXM"

"CHMON"

"КЕPC

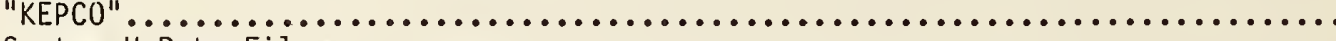

5. References.

System H Data Files.

Appendix A. Conversion Routines Between Decimal and Hexadecimal

Based Number Systems............................................ 71

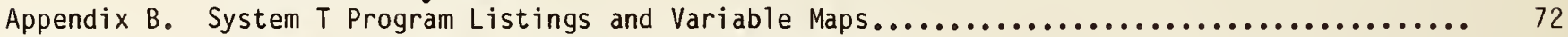

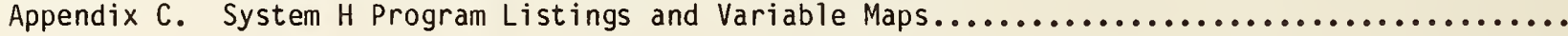


Figure 1-1. Figure 1-2. Figure 1-3. Figure 3-1. Figure 3-2. Figure 3-3. Figure 3-4. Figure 3-5. Figure 3-6. Figure 3-7. Figure 3-8. Figure 3-9. Figure 3-10. Figure 3-11. Figure 3-12. Figure 3-13. Figure 3-14. Figure 3-15.

Figure 3-16. Figure 3-17. Figure 3-18. Figure 3-19. Figure 3-20. Figure 3-21. Figure 3-22. Figure 3-23. Figure 3-24. Figure 3-25. Figure 3-26. Figure 3-27. Figure 3-28. Figure 3-29. Figure 3-30. Figure 3-31. Figure 3-32.

Figure 3-33. Figure 3-34. Figure 3-35. Figure 3-36. Figure 3-37. Figure 3-38.

Figure 3-39.

Figure 3-40. Figure 3-41. Figure 3-42. Figure 3-43.

Figure 3-44.

Figure 3-45.

Figure 3-46. Figure 3-47. Figure 3-48.

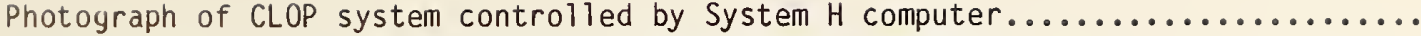

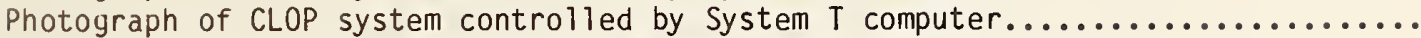

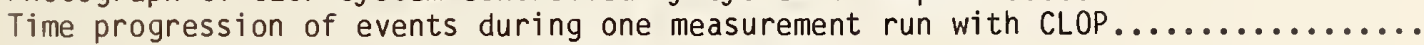

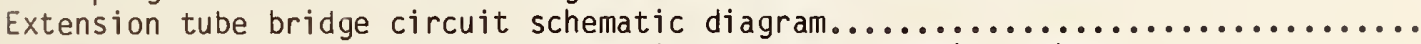
Schematic diagram of the heater circuit for the extension tube..................

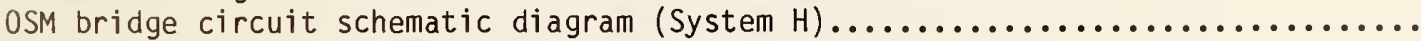

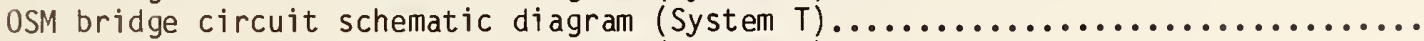

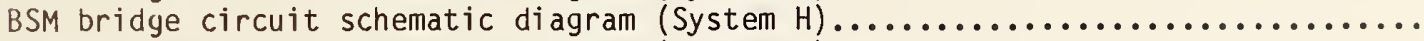

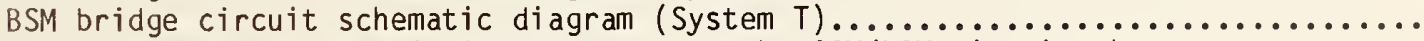
Wiring diagram of the 24-pin connector on the OSM/BSM circuits box..............

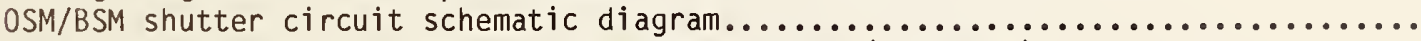

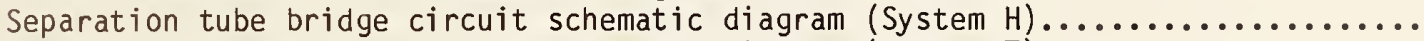

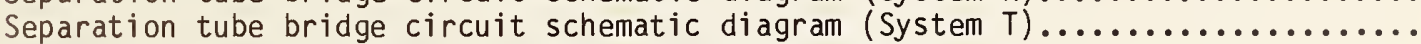

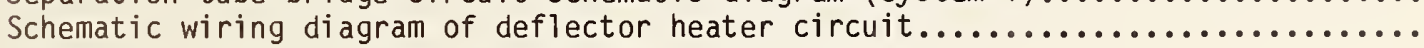

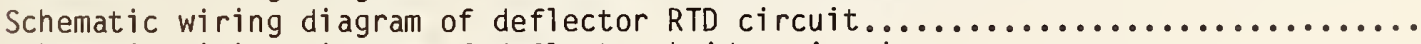

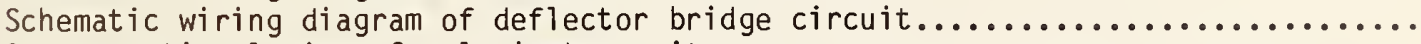

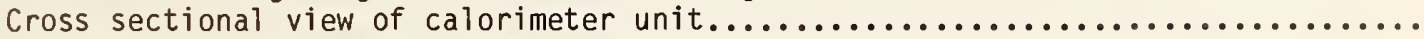
Total gas flow system for CLOP. Either the output from the high pressure manifold may be connected to an electrically operated valve on the low pressure manifold or individual cylinders with PRV's may be connected to

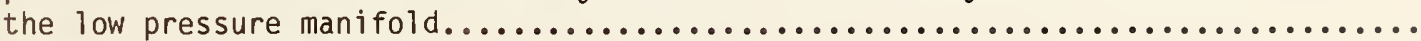

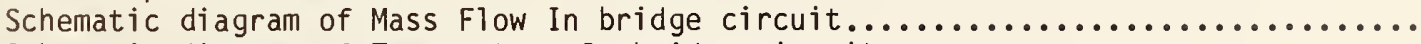

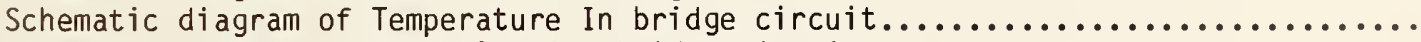

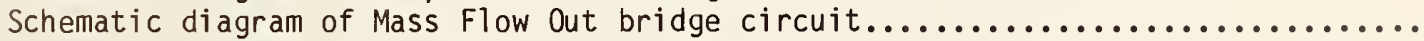

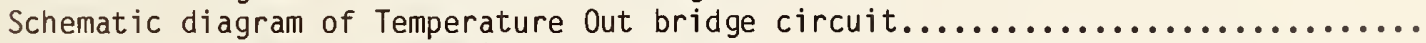

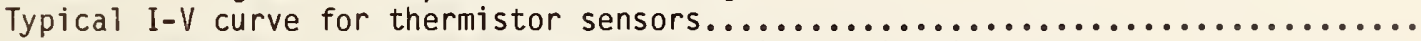

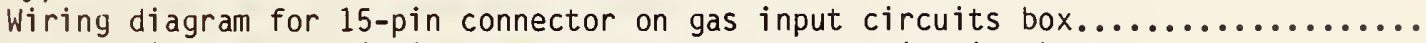

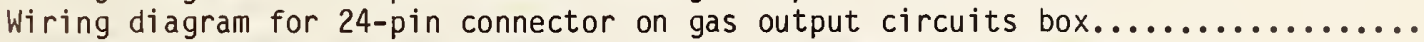
Schematic diagram for the bridge circuit for the main calorimeter RTD...........

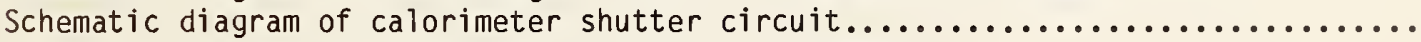

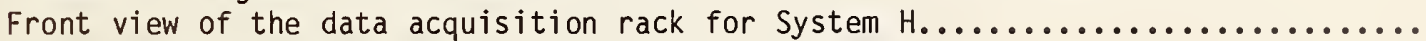

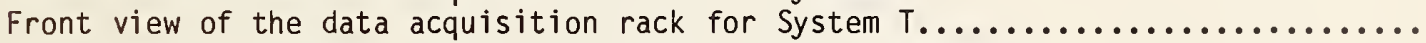

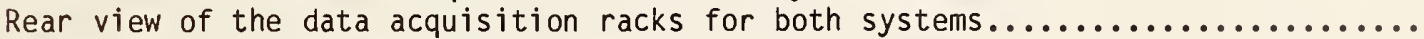

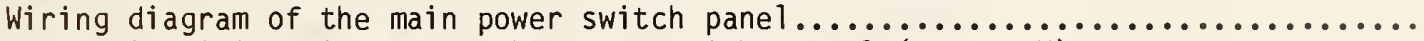

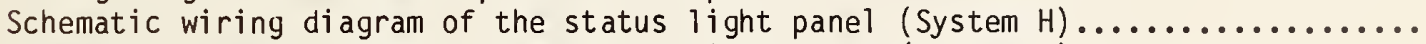

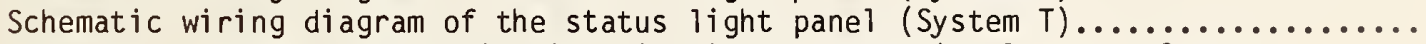
Schematic diagram of the switching circuit for measuring low dc voltage.......... Schematic diagram of the circuit for measuring the dc electrical voltage

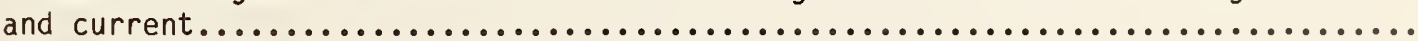

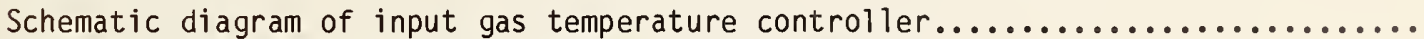

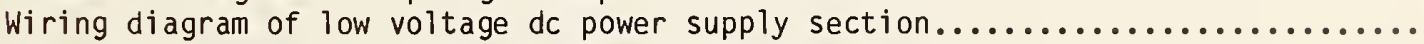

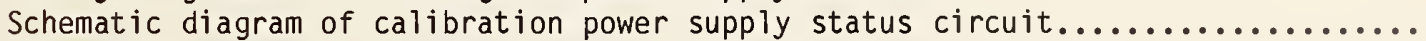

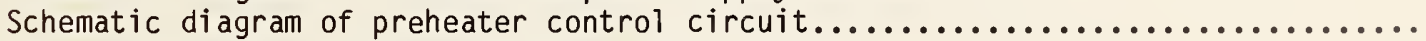

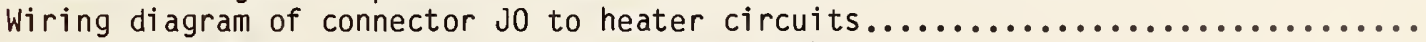
Wiring diagram of connector $\mathrm{Jl}$ to extension tube

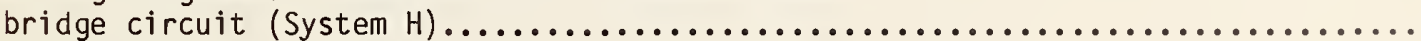
Wiring diagram of connector $j l$ to extension tube

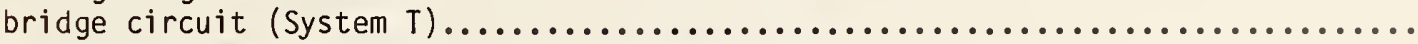

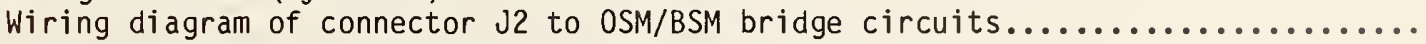
Wiring diagram of connector 33 to separation tube bridge circuits................

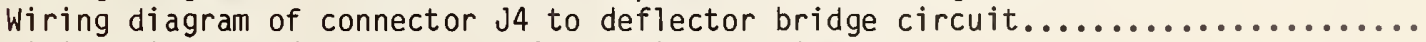
Wiring diagram of connector J5A to main calorimeter

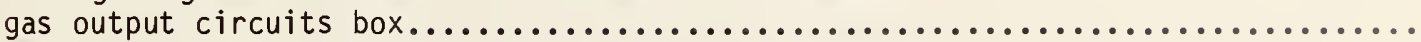
Wiring diagram of connector J5B to main calorimeter

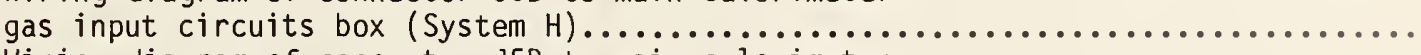
Wiring diagram of connector J5B to main calorimeter

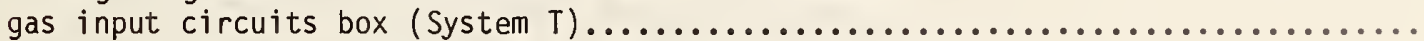

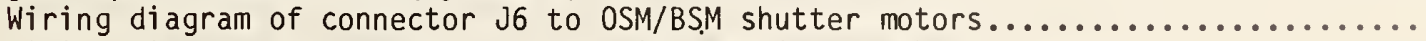

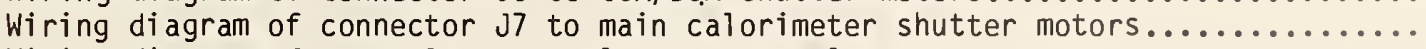

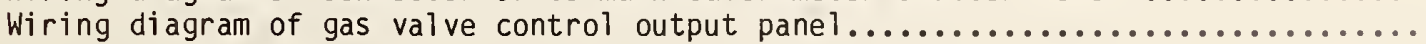



A Calorimeter for Measuring High-Energy Optical Pulses

P. A. Simpson, E. G. Johnson, Jr., and S. M. Etzel

National Bureau of Standards

Electromagnetic Technology Division

Boulder, Colorado 80303

Two similar calorimeters for measuring laser pulses in the range $1 \mathrm{~kJ}$ to $15 \mathrm{~kJ}$ are described. The calorimeters, which are electrically calibrated, can be operated anywhere from the ultraviolet to infrared by selecting the proper materials for the volume absorber and deflecting mirror. Operation of each calorimeter is controlled by a dedicated desktop computer. The theoretical basis for the calorimeters is given as are the constructional and operational details. The computer programs that are used are included in the appendices .

Key words: calorimeter; electrically calibrated calorimeter; high energy calorimeter; laser pulse; volume absorbing calorimeter.

\section{Description and Operational Procedures}

\subsection{Introduction}

This publication describes two reference standard calorimeters for laser optical pulses (CLOP). The instruments are designed to measure pulses having energies from 1 to $15 \mathrm{~kJ}$ at wavelengths from ultraviolet to infrared. Beam size can be as big as $30 \mathrm{~cm}$ by $15 \mathrm{~cm}$. They are presently set up for measurements at $340 \mathrm{~nm}$ and $10.6 \mu \mathrm{m}$ but can be rather simply adapted for other wavelengths by merely selecting the appropriate materials for a new volume absorber and mirror. The two entire units can be electrically calibrated and hence may be referred back to the basic SI measurement system. The two calorimeter systems have been built to be quite similar, but do possess minor differences because they are controlled by computers from different manufacturers.

\subsection{Description of CLOP}

CLOP consists of five modules designed to trap the laser radiation and convert it to heat. The normal configuration of CLOP, from input to beam termination, is (1) extension tube, (2) overspil1 monitor, (3) backscatter monitor, (4) separation tube, (5) deflecting mirror, and (6) main calorimeters, hence five modules contain six energy-measuring units. The overspill monitor and backscatter monitor share the same module. CLOP is so designed that the order of the modules may be rearranged or any of the modules may be omitted if so desired. The major portion of the radiation is absorbed in the main calorimeter which is housed in a thermally isolated enclosure. The other four modules are designed to reduce ambient effects on the main calorimeter, steer the beam into the main calorimeter, and estimate the radiation reflected back out of the main calorimeter. All of the modules are ins: mented to measure their temperature rise and have provision for individual electrical calibration.

A blast shield is provided to be placed around the entrance aperture of CLOP to protect it from damage caused by errant laser shots. This unit is not instrumented. It is so designed to direct the reflected laser beam downward at a shallow angle. 
Operation of one of the calorimeters is controlled by an HP $85^{*}$ computer (System H) contained in a data acquisition rack. The other calorimeter is controlled by a Tektronix 4052A (System T) located outside the data acquisition rack. The data acquisition rack contains the necessary equipment to record the output of the various sensors and contains the power supplies required to operate the electronics associated with CLOP and perform the electrical calibrations. Finally, a gas supply system consisting of a high-pressure manifold for connecting nitrogen gas cylinders to CLOP, a pressure reducing valve (PRV), an electrically operated off-on valve on a low-pressure manifold, and a gas preheater is also supplied. The high-pressure manifold is mounted on a stand which also serves as a base for sturdy mounting of the gas cylinders. This manifold has been tested for safe operation and leakfree integrity at pressures of $15168472 \mathrm{~Pa}$ (2200 psi). Pictures of the two versions of CLOP are shown in figures $1-1$ and $1-2$.

\subsection{Operational Principle}

\subsubsection{Main Calorimeter Principles}

CLOP uses a volume-absorbing material to capture the laser radiation, thus avoiding the damage effects possible with surface absorbers. For $340 \mathrm{~nm}$, the material used is common soda glass since this material has an absorption coefficient compatible with present-day, high-energy uv lasers ( $\sim \mathrm{kJ})$ [1]. If, in the future, higher energy lasers are to be measured, a more transparent material will have to be used and small chunks ( l cm size) substituted for the glass plates to avoid fracturing due to thermal stress. For $10.6 \mu \mathrm{m}$ radiation, calcium fluoride pieces are used as the absorber [2].

Even though the bulk of the laser radiation is absorbed in the volume absorber and the resultant temperature rise is associated with this material, the temperature sensors cannot be located in the absorber. The radiation might damage or destroy the sensors. Consequently, dry nitrogen gas is blown through the porously stacked absorber and the temperature rise of the gas measured. Thus, the calorimeter is instrumented with expediently located thermistors to measure the mass and temperature of the gas entering and leaving the main calorimeter. A copper resistance thermometer is also included to measure the gas temperature just before it flows through the volume absorber. The PRV maintains the gas flow sufficiently constant for the measurements and a feedback circuit from the temperature in thermistor to the preheater maintains the gas input temperature constant, offsetting the cooling of the gas due to expansion.

Since the gas is the vehicle for transferring the temperature rise information, none must be allowed to escape through leaks. It must all flow past the temperature out thermistor. Thus, the main calorimeter is a sealed unit with just a single gas exit area. Just before the laser pulse is to be shot into the main calorimeter the gas is turned off and a trapdoor that seals the main calorimeter entrance aperture is opened. After the laser shot the trapdoor is closed again and the gas flow resumed. In system $H$ this time window is $14 \mathrm{~s}$; in system $T$ it is $33 \mathrm{~s}$.

*Certain commercial equipment, instruments, or materials are identified in this paper in order to adequately specify the experimental procedure. Such identification does not imply recommendation or endorsement by the National Bureau of Standards, nor does it imply that the materials or equipment identified are necessarily the best available for the purpose. 


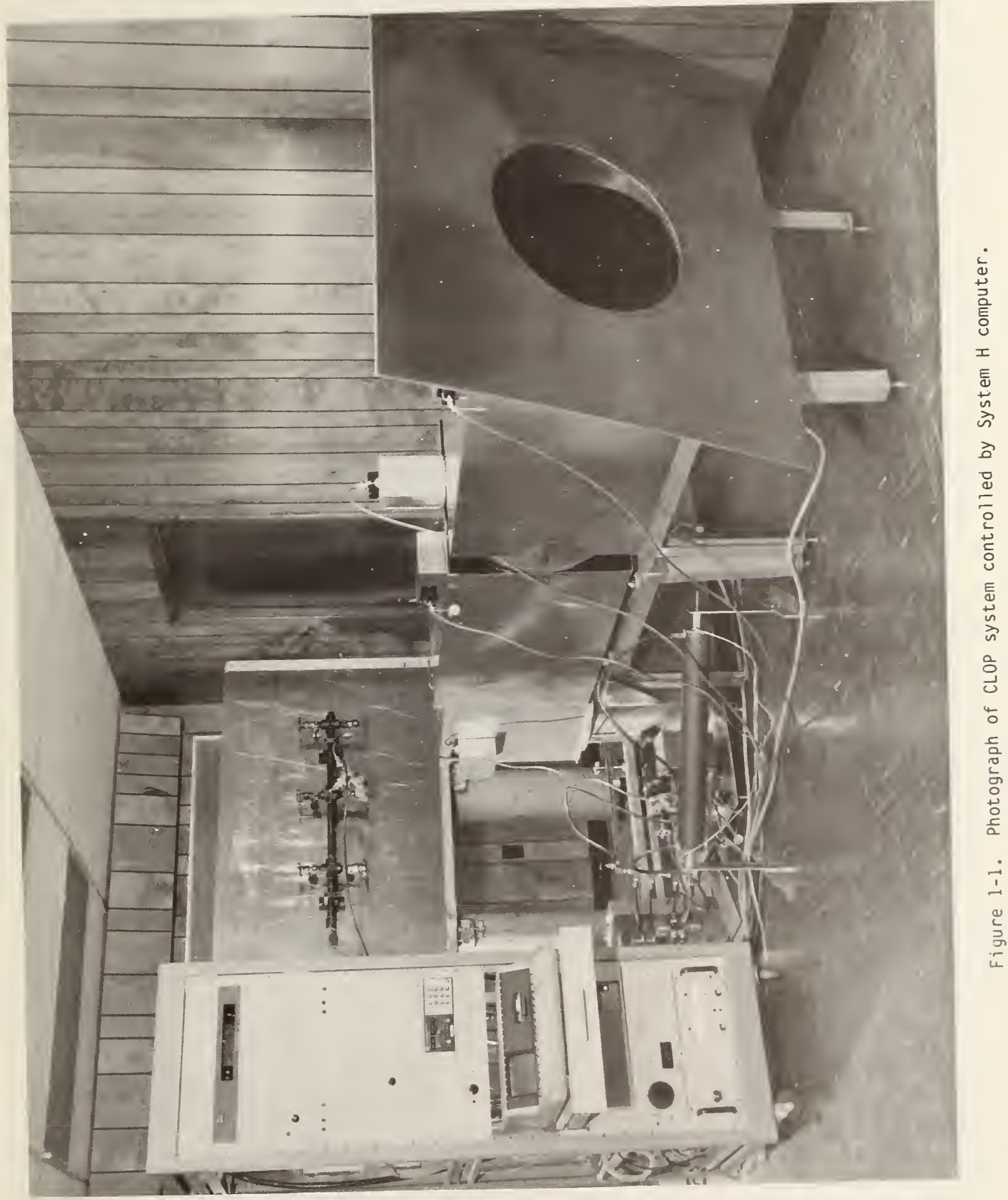




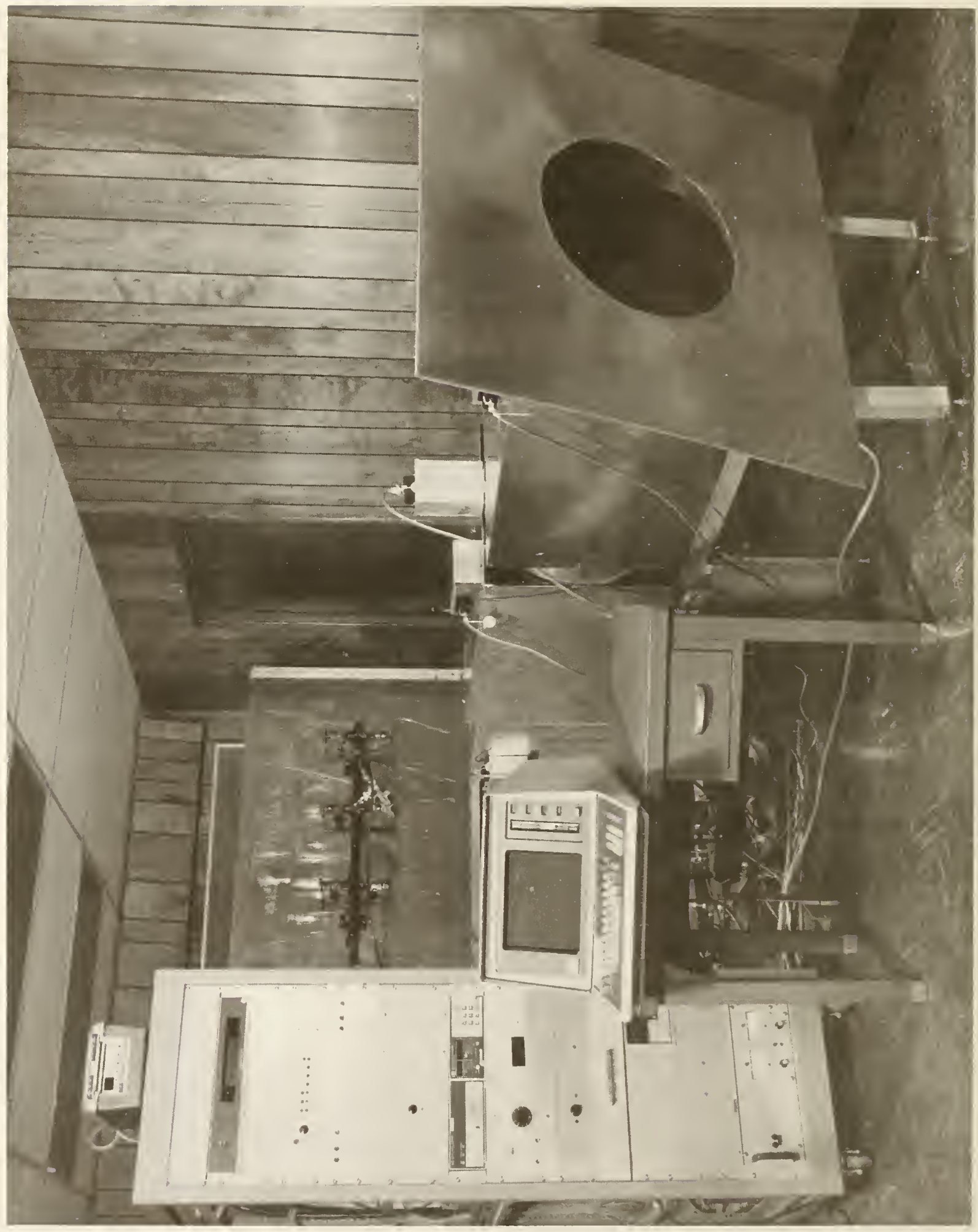

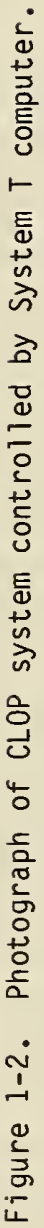




\subsubsection{Gas Flow Procedures}

Gas flow is furnished from cylinders of dry nitrogen gas. At the flow conditions enumerated in the computer program, one cylinder at $15168472 \mathrm{~Pa}(2200 \mathrm{psi})$ will be just insufficient for a single run. Thus, provisions are made for two different methods of uninterrupted gas flow during a run.

The first method, although inferior to the second, can be used if conditions preclude the preferred method. This first method uses two to four cylinders, each with its own PRV connected to the separate electrically operated valves on the low-pressure manifold. During the setup procedure for the run, each PRV is adjusted one at a time to produce the prescribed reading from the mass flow in thermistor. In practice, this is quite difficult and a slight discontinuity results whenever gas cylinders are changed.

The second and preferred method uses three or more cylinders connected to the high-pressure gas manifold. One PRV outputs gas from the manifold at low pressure to a single electrically operated valve on the low-pressure manifold. Two gas cylinders are used to charge the high-pressure manifold and the rest is held in reserve. When the first two cylinders are nearly empty (at $\sim 6894.76 \times 10^{3} \mathrm{~Pa}$ [100 psi]), one cylinder is shut off from the manifold and a reserve cylinder opened up to the manifold. During this manual switching process the second of the two original cylinders has sufficient capacity to maintain the required flow conditions. This second method produces a much more constant gas flow than the first, and is the preferred method.

\subsubsection{Functional Description of Modules Preceding the Main Calorimeter}

As mentioned in section 1.2, the four modules preceding the main calorimeter have three functions. These are: steering the beam, isolation of the main calorimeter from the ambient conditions, and measurement of energy reflected back out of the main calorimeter.

The main calorimeter, because of the fact the volume absorber does not lend itself to vertical stacking, must have its entrance aperture facing upward. Thus, directly above the main calorimeter is a module with a mirror-like surface used to deflect a horizontal beam downward into the main calorimeter. This surface need not be an optically flat, aberration-free surface but it must be shiny and free from any blemishes or other imperfections that could possibly cause plasma ignition or high absorption with its associated burning.

Two different kinds of surfaces have been furnished. The first uses highly polished copper surfaces to which a thin plate containing the electrical instrumentation sensors is attached on the backside. These mirrors were originally acquired for use at $\mathrm{CO}_{2}$ wavelengths and should not be used in the uv because of their low reflectivity.

The preferred deflecting surface consists of a foil reflector stretched over an instrumented back piece. The foil is stretched tight and a slight negative pressure applied to maintain the shape. When the foil is eventually damaged it is merely thrown away and a new piece used. Highly polished thin aluminum sheets may be used in place of the foil but the material should be rolled since this method of manufacturing greatly reduces the occurrence of possible damage center sites in the metal.

Preceding the mirror module is the separation tube module. This unit is a tube $91.5 \mathrm{~cm}$ long with an i.d. of $43 \mathrm{~cm}$. The inside is black anodized aluminum to absorb scattered laser radiation. The length of the unit helps reduce the solid angle of the ambient seen by the main calorimeter. 
In front of the separation tube is a disc-shaped module containing a backscatter monitor (BSM) and an overspill monitor (OSM). The BSM is used to measure the reflected energy from the main calorimeter, while the purpose of the OSM is to indicate poorly directed laser shots in which only part or none of the energy enters the main calorimeter. In the center of the module is a $15 \mathrm{~cm}$ by $30 \mathrm{~cm}$ aperture similar in shape to the aperture of the main calorimeter. A dual shutter closes this aperture to block out ambient effects except for a short time window when the main calorimeter trap door is also opened for the laser shot.

In front of the BSM/OSM module is the extension tube module. The module is a duplicate of the separation tube and is used to further reduce the effects of the external environment.

\subsection{Description of Measurement and Data Handling Procedures}

Operation of CLOP is controlled completely by the desktop computer. The operator inputs the run conditions and the computer takes over. When the run is completed the operator indicates what he wants done to the data. All computer programs are discussed in detail in section 4 and listed in appendices $B$ and $C$. This section will give just a general outline of the steps.

There are two $\mathrm{Classes}$ of cassette tapes furnished with each CLOP system. These are program tapes and data tapes. All of the programs necessary for operating each CLOP system is on the one proyram tape for that system. A duplicate copy of each of the two different program tapes (System $T$ and System $H$ ) is also furnished. As good practice, the program tapes are kept in the write-protected condition.

The first program used is the data-taking program. This is accessed somewhat differently in the two systems because of the different type computers. In System $T$ it is most easily accessed by using the AUTO LOAD button, that loads the tape index from which the desired program can be called up. In the System $\mathrm{H}$ the computer memory space requires that the program be split into two parts and chained together for operation. The first part is labeled "Autost". This program name will automatically load and run, if the tape is fully inserted before System $H$ is first turned on. Of course, these programs can be loaded and run using the ordinary commands from the keyboard as described in the computer instruction manuals.

The data-taking program first initializes the equipment and then goes through a pre-run checklist including a 45 min warm-up period if that is required. Next, the run parameters are input. Table 1.1 lists the various parameters and the format to be used. In addition to acquiring these parameters, the program also leads the operator through the various steps to set up the gas flow if the main calorimeter is to receive energy (laser or electrical). When all this is accomplished a final check list is presented in anticipation of starting the data-taking. It is at this point that the System $H$ performs the previously mentioned CHAINing operation.

Figure 1-3 shows the time progression of events during a run. During the 2 min adjustment period and the 8 min monitor period, the output from all 10 sensors is measured at $3 \mathrm{~s}$ intervals and displayed on the computer screen. The 2 min adjustment period allows the operator to set the zero reading (i.e., the baseline reading before laser or electrical energy injection) of any sensors he so desires; the 8 min monitor period allows him to verify that all relevant sensor outputs are stable to within acceptable limits. The operator can abort the run any time during these two periods with a user-defined key on the computer. An abort in the 2 min adjustment period stops the program which can 


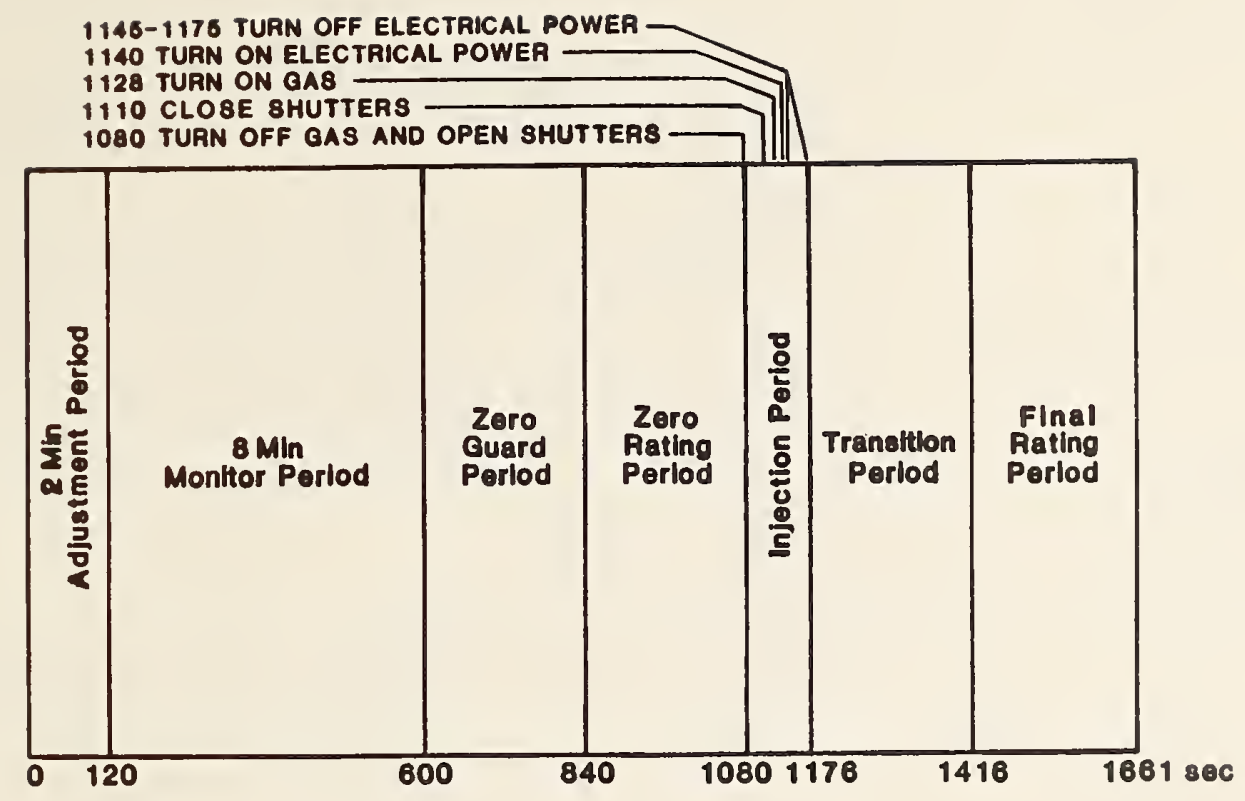

Figure 1-3. Time progression of events during one measurement run with CLOP.

be restarted at the beginning of the 2 min adjustment by pressing the CONT key. An abort during the 8 min monitor period restarts the program at the beginning of the 2 min adjustment period.

When the 8 min monitor period is completed the run enters the data-taking stage.

\section{WARNING}

During the data-taking period of laser (L) and combination (C) runs, all personnel should leave the area for a place safe from the laser. After the laser shot when the CLOP area is again safe they may return. For electrical (E) runs the personnel can remain with CLOP.

Here the output of all the sensors is measured every second. Every $6 \mathrm{~s}$ the values are summed and stored in the appropriate location of a 10 column by 176 row matrix (Vø). The first 8 min of the data-taking period are to record the zero readings of the sensors. For mathematical purposes this 8 min interval as well as a final one are divided into two 4-min intervals each. These four periods are referred to as the Zero Guard Period, the Zero Rating Period, the Transition Period, and the Final Rating Period.

Interposed between the two 8-min periods is a 96-s Injection Period. During this time the gas flow is stopped and shutters opened. The laser shot is now made into CLOP (unless the run is an electrical calibration). Next, the shutters are closed and gas flow resumed. Finally, electrical energy is injected if the run is an $E$ or $C$ type (see table 1.1).

When the run is completed, all appropriate functions of CLOP are shut down and a run-end checklist presented. When the checklist is completed, some preliminary mathematical manipulations are performed and the run data is stored in a temporary data file selected by the operator. Finally, the mathematical processing program is called up. 
1. Run number

2. Run type

3. Calorimeter configuration

4. Mirror device

5. Room temperature

6. Barometric pressure

7. Electrical energy
1. YYMMDD.RR $Y=$ year; $M=$ month; $D=$ day; $R=$ run no. for that day; e.g., 830217.03 is the third run on February 17, 1983

2. $L=$ Laser

$E=$ Electrical

$\mathrm{G}=$ Combination (laser and electrical energy injected into the main calorimeter)

3. DDDDDD $D=$ digit; 1 = extension tube; $2=0 \mathrm{SM} ; 3=\mathrm{BSM} ; 4=$ separation tube; $5=$ deflector or foil reflector; $6=$ main calorimeter; $\emptyset=$ no module

4. $D \quad D=$ digit; 1 = deflector; 2 = foil reflector

5. Degrees centigrade

6. Millimeters of mercury

7. Joules ( $E$ and $C$ runs only)

\subsection{Data Reduction and Storage}

The data reduction are performed by program "CALC" on System $H$ and by file 5 on System T. These programs calculate the zeroth, first, and second moments for each sensor's voltage output curve in the zero rating period, the transition period, and the final rating period. For a detailed description of the mathematics involved see section 2.2 .

For laser and combination runs, the moments for all the sensors along with other pertinent information are stored in data files. No provisions for further mathematic manipulations of this type data have been developed at this time as no experience with laser shots has yet been acquired. As this experience is gained it is expected that the routines will be developed. Section 2.3 offers some thoughts for consideration for a first approach to this development. In System $H$ the data storage files are on tape LASER RUNS 1; for System $T$ they are files 24 through 33 on each data tape.

For electrical calibration runs, calibration factors are calculated for the Temperature Out sensor and the main calorimeter resistance thermometer detector (RTD) as also for the RTD of each of the ancillary modules. A stability factor is calculated for the Mass Flow In, Mass Flow Out, and Temperature In sensors. The moments, calibration factors, stability factors, and other pertinent data are stored in the appropriate electrical summary file. There is one summary file for each sensor. For the system $H$ these files are on the tape labeled ELECTRICAL SUMMARY. In System $T$ these are files 12 through 22 on the data tapes.

Finally, one more operation is performed on the results of the electrical runs. A "best" estimate of the calibration factor for each temperature sensor is derived. This is done by still another program ("FACTOR" on System H, file 7 on System T). These programs calculate the mean and standard deviation for the RTD of each ancillary module. For the main calorimeter RTD and Temperature Out sensor, the program performs a linear least squares fit of calibration factor as a function of the first moment (drift) during the zero rating period. The reason for this is discussed in section 2 .

The results are stored in the form of an $8 \times 4$ matrix in data file "CALFAX" on System $H$ and file 23 on the System $T$ along with an operator-input descriptive information note for each sensor. Table 1.2 shows the storage scheme used for the data. 
Table 1.2. Array $F \emptyset$ for storing CLOP calibration factors.

\begin{tabular}{|c|c|c|c|c|}
\hline & 1 & 2 & 3 & 4 \\
\hline 1 & $\begin{array}{c}\text { KO } \\
\text { main cal. } \\
\text { RTO }\end{array}$ & $\begin{array}{c}\% \text { std. dev. } \\
\text { of KO } \\
\text { main cal. } \\
\text { RTD }\end{array}$ & $\begin{array}{c}\text { No. of points } \\
\text { main cal. } \\
\text { RTD }\end{array}$ & $\begin{array}{c}\text { Al } \\
\text { main cal } \\
\text { RTD }\end{array}$ \\
\hline 2 & $\begin{array}{c}\text { Ko } \\
\text { temp. out }\end{array}$ & $\begin{array}{l}\text { \% std. dev. } \\
\text { of KO } \\
\text { temp. out }\end{array}$ & $\begin{array}{c}\text { No. of points } \\
\text { temp. out }\end{array}$ & $\begin{array}{l}\text { Al } \\
\text { temp. out }\end{array}$ \\
\hline 3 & $\begin{array}{c}\text { Ko } \\
\text { foil refl. }\end{array}$ & $\begin{array}{c}\text { \% std. dev. } \\
\text { of KO } \\
\text { foil refl. }\end{array}$ & $\begin{array}{l}\text { No. of points } \\
\text { foil refl. }\end{array}$ & $\begin{array}{c}\text { \% std. dev. } \\
\text { of Al for } \\
\text { main cal. } \\
\text { RTD }\end{array}$ \\
\hline 4 & $\begin{array}{c}\text { Ko } \\
\text { mirror } \\
\text { deflector }\end{array}$ & $\begin{array}{c}\text { \% std. dev. } \\
\text { of KO } \\
\text { mirror } \\
\text { deflector }\end{array}$ & $\begin{array}{l}\text { No. of points } \\
\text { mirror } \\
\text { deflector }\end{array}$ & $\begin{array}{l}\% \text { std. dev. } \\
\text { of Al for } \\
\text { temp. } \\
\text { out }\end{array}$ \\
\hline 5 & $\begin{array}{l}\text { Ko } \\
\text { separation } \\
\text { tube }\end{array}$ & $\begin{array}{l}\% \text { std. dev. } \\
\text { of ko } \\
\text { separation } \\
\text { tube }\end{array}$ & $\begin{array}{l}\text { No. of points } \\
\text { separation } \\
\text { tube }\end{array}$ & $\begin{array}{c}0 \\
\text { (not used) }\end{array}$ \\
\hline 6 & $\begin{array}{l}\text { KO } \\
\text { BSM }\end{array}$ & $\begin{array}{c}\text { \% std. dev. } \\
\text { of KO } \\
\text { BSM }\end{array}$ & $\begin{array}{l}\text { No. of points } \\
\text { BSM }\end{array}$ & $\begin{array}{c}0 \\
\text { (not used) }\end{array}$ \\
\hline 7 & $\begin{array}{l}\text { KO } \\
\text { OSM }\end{array}$ & $\begin{array}{c}\% \text { std.dev. } \\
\text { of KO } \\
\text { OSM }\end{array}$ & $\begin{array}{c}\text { No. of points } \\
\text { OSM }\end{array}$ & $\begin{array}{c}0 \\
\text { (not used) }\end{array}$ \\
\hline 8 & $\begin{array}{l}\text { Ko } \\
\text { extension } \\
\text { tube }\end{array}$ & $\begin{array}{c}\% \text { std. dev. } \\
\text { of } \mathrm{KO} \\
\text { extension } \\
\text { tube }\end{array}$ & $\begin{array}{c}\text { No. of points } \\
\text { extension } \\
\text { tube }\end{array}$ & $\begin{array}{c}0 \\
\text { (not used) }\end{array}$ \\
\hline
\end{tabular}

No "best" values are calculated for the Mass Flow In, Mass Flow Out, and Temperature In sensors, since these readings may vary from run to run and the constancy of the value during the run is the important factor.

2. Theoretical Basis of CLOP

\subsection{Basic Principles}

Ordinarily, laser calorimetry involves the injection of energy into the calorimeter and after a suitable time period to allow high-order heat modes to decay, fitting a single-mode exponential curve to the data to determine the magnitude of injected energy [3]. CLOP, however, is a dynamic, gasflowing system and as such does not lend itself readily to the above method. That method is based on isoperibol conditions; CLOP is a non-isoperibol system.

A method of moments has been developed to reduce the sensor voltage output data and establish a procedure for summarizing the results. As mentioned in section 1.4 and shown in figure $1-3$, there are four 4-min periods of rapid data taking: the zero guard period, the zero rating period, the transition period, and the final rating period. Interposed between the zero rating period and the transition period is a $96 \mathrm{~s}$ injection period. For the latter three 4 -min periods the zeroth, first, and 
second moments are calculated as described in section 2.2. These moments correspond to the dc value, the drift, and the curvature of the sensor output voltage curve. They are calculated in such a manner that they are orthogonal to each other.

This is the primary data reduction method. The zero guard and the zero rating periods provide the baseline information to confirm that the system is operating in a reproducible way, namely that the drift is constant. Once this is so, energy is injected into that calorimeter to create a differential change from the nominal baseline conditions. This change is a measure of the amount of injected energy and is determined by subtracting the zeroth and first moments of the zero rating period from the zeroth and first moments of the transition period. This method assumes that while the shutters are open heat flow into and out of the calorimeter is negligible. Maximum accuracy is achieved by making the mass flow in and temperature in of the nitrogen gas the same for laser shot runs and electrical calibration runs. Also, the shutters are opened and closed in like manner for both type runs.

In section 2.2 we shall define the calculation of the moments and then define how the temperature differential is computed based on these moments. We have found that there is a drift term present in temperature out sensor signal and, while it may not be the same value from one run to the next, it can be made constant for any one run. Thus, for each run the drift can be subtracted out of the data to determine quite precisely the differential change from the baseline conditions. We believe the drift terms arise from the fact that the absorber material is at a cooler temperature than the flowing gas and is absorbing heat from the gas as it is being raised toward the temperature of the gas.

The second moment is used basically as an indicator that the drift is constant. When this is so the second moment is insignificant.

Thus, the calibration procedure for the main calorimeter requires the determination of two constants. The first is a fundamental energy constant and the second is a linear correction factor based on the drift (e.g., the first moment in the zero rating period). This determination is accomplished by performing a linear least squares fit of calibration factor versus first moment as measured from a number of different runs [4]. The $Y$ intercept is the fundamental constant and the slope of the line is the drift coefficient or linear correction factor.

For the ancillary modules we determine just the fundamental energy constant. Here we assume that the drift term is insignificant which is quite valid since these modules will be absorbing only a small portion of the total energy of a laser shot and the drift term will be a second-order correction. For these calibration factors only an average and standard deviation need be calculated.

For the mass flow in, mass flow out, and temperature in data a stability factor is calculated based on the zeroth and first moments of the zero rating period and the transition period. No further mathematical operations are performed on these data but the data are saved if needed for future use.

\subsection{Derivation of Basic Equation}

In deriving the basic equations we shall endeavor to use the same designation for each particular quantity as is used in the computer programs for performing calculations. First, we must consider how the data are taken. Voltage readings of a sensor output are taken at $1 \mathrm{~s}$ intervals for $1056 \mathrm{~s}$ (four 4-min periods and a $96 \mathrm{~s}$ injection period). During the data-taking process these are averaged on a 
Table 2.1. Numerical indicator for CLOP sensors.

\begin{tabular}{ccl}
\hline \multicolumn{2}{c}{ Numbers } & \multicolumn{1}{c}{ Sensor } \\
\hline 0 & 1 & Main calorimeter RTD \\
1 & 2 & Main calorimeter mass flow out \\
2 & 3 & Main calorimeter temperature out \\
3 & 4 & Main calorimeter mass flow in \\
4 & 5 & Main calorimeter temperature in \\
5 & 6 & Foil reflector or deflector \\
6 & 7 & Separation tube \\
7 & 8 & Backscatter monitor \\
8 & 9 & Overspill monitor \\
9 & 10 & Extension tube \\
\hline
\end{tabular}

$6 \mathrm{~s}$ basis to reduce noise in the readings and because of computer memory space limitations. Thus, we have for each sensor 176 values representing its output over the time period $t=0$ to $t=1055 \mathrm{~s}$. These are stored in the array $V(I, J)$, where $0 \geqslant I \geqslant 175$ and $0 \leqslant J \leqslant y,(J=$ sensor index, see table 2.1). Note that for System $T$ the index limits are increased by 1 since that computer does not allow an array index of 0 .

In terms of the actual time expressed in seconds, we can say,

$X 1=237$ starting time of the zero rating period,

$X_{2}=477$ ending time of the zero rating period,

$X_{3}=573$ starting time of the transition period,

$X 4=813$ ending time of the transition period and the starting time of the final rating period, and

$X 5=1053$ ending time of the final rating period.

Also,

$X 7=\left(X_{1}+x_{2}\right) / 2$ midpoint of the zero rating period,

$x_{8}=\left(x_{4}+x_{5}\right) / 2$ midpoint of the final rating period, and

$x_{9}=\left(x_{3}+x_{4}\right) / 2$ midpoint of the transition period.

Now we set $N=20$, which represents the half width of the stored values in array $V(I, J)$ for any one sensor during any of the three periods of interest. Also $X \emptyset=\left(X_{2}-X_{1}\right)$, the duration in seconds of each of the time periods of interest, so that we derive $Z \emptyset$, the number of measurements represented by each value in $V(I, J)$, as

$$
Z \emptyset=X \emptyset / 2 N \text {. }
$$

Because we will be using a finite number of terms in the integrals that will calculate the moments, we need to introduce a first-order correction factor to get true orthogonality. This term, $A \emptyset$, is

$$
A \emptyset=1-1 / 4 N^{2} .
$$


Normalization constants for the moments are

$$
\begin{array}{ll}
C \emptyset=1 / \sqrt{X \emptyset} & \text { (zeroth moment), } \\
C 1=\sqrt{12 / A \emptyset} /(X \emptyset)^{3 / 2} & \text { (first moment), } \\
C 2=\sqrt{180} /(X \emptyset)^{5 / 2} & \text { (second moment). }
\end{array}
$$

Using the above terms we can now calculate the moments for the output from any sensors as

$$
Y \emptyset(n, J)=\sum_{I=-N}^{N-1} P \emptyset \cdot V((K 1+Z 1) / Z \emptyset, J)
$$

where

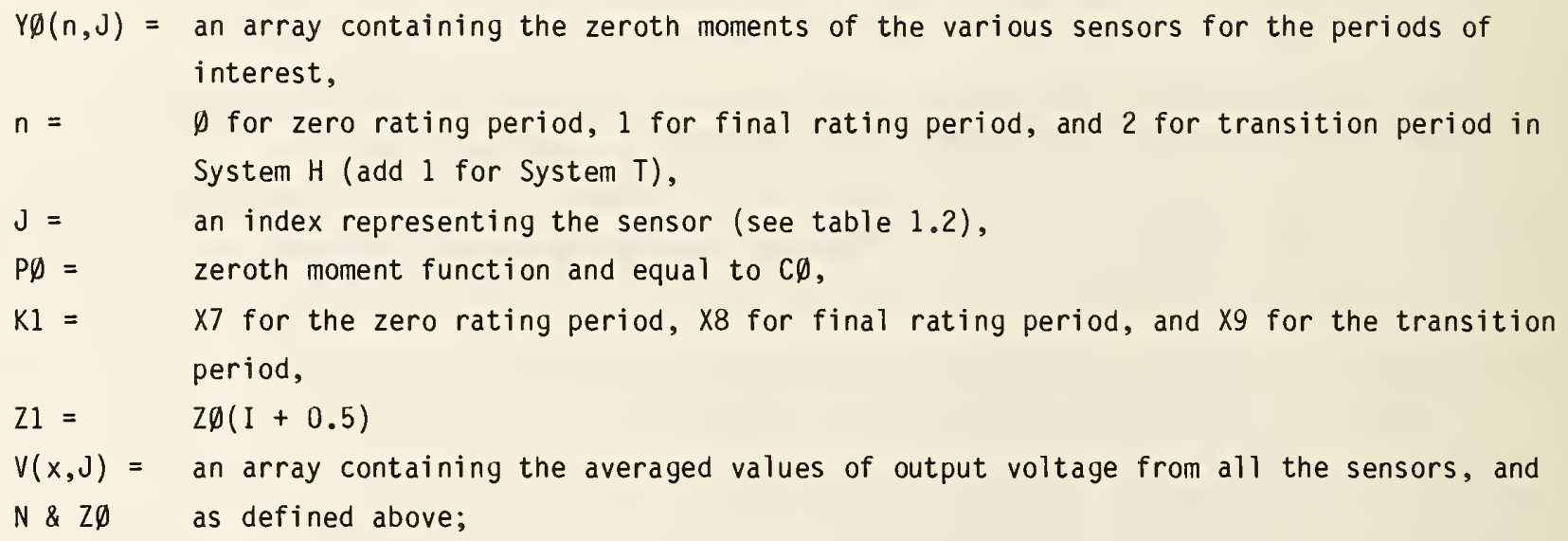

$$
Y 1(n, J)=\sum_{I=-N}^{N-1} P 1 \cdot V((K I+Z 1) / Z \emptyset, J),
$$

where

$Y 1(n, J)=$ an array containing the first moments of the various sensors for the periods of interest,

$P 1=\quad$ the first moment function and equal to $\mathrm{Cl} \cdot \mathrm{Zl}$, and $\mathrm{n}, \mathrm{J}, \mathrm{V}(\mathrm{x}, \mathrm{J}), \mathrm{N}, \mathrm{K} 1, \mathrm{Zl}, \mathrm{Z \emptyset}$, and Cl are as previously defined; and

$$
Y 2(n, J)=\sum_{I=-N}^{N-1} P 2 \cdot V((K 1+Z 1) / Z \emptyset, J),
$$

where

$Y 2(n, J)=$ an array containing the second moments of the various sensors for the periods of interest,

P2 $=\quad$ the second moment function and equal to $C 2\left(Z 1^{2}-\left(A \emptyset \cdot x \emptyset^{2}\right) / 12\right)$, and $n, J, V(x, J), N$, $\mathrm{K} 1, \mathrm{Z1}, \mathrm{Z \emptyset}, \mathrm{X} \emptyset, \mathrm{A} \emptyset$, and $\mathrm{C} 2$ are previously defined.

We can now define a calibration factor, $k \emptyset$, as

$$
K \emptyset(J)=\frac{Y \emptyset(2, J)-Y \emptyset(\emptyset, J)-\sqrt{12} \cdot T 2 \cdot Y 1(\emptyset, J)}{J \emptyset},
$$


$K \emptyset(J)=$ calibration constant for the particular sensor,

$J=\quad$ index of the sensor as given in table 1.2 ,

$Y \varphi(x, J)=$ the zeroth moment as defined above,

$Y l(x, J)=$ the first moment as defined above,

$T_{2}=$ the ratio of the sensor output voltage after the shutter closes to that before the shutter opens (assume $T 2=1$ ), and

$J \emptyset=\quad$ injected electrical energy in joules.

For the mass flow in, mass flow out, and temperature out, we wish to calculate a stability factor which will give us a measure of how constant the input conditions are for a particular run. This we define as

$$
K \emptyset(J)=Y \emptyset(2, J)-Y \emptyset(\emptyset, J)-\sqrt{12} \cdot T 2 \cdot Y 1(\emptyset, 1),
$$

where

$K \emptyset=$ the stability factor, and all the rest of the terms are as defined above for the calibration factor.

Now there remains the task of determining a "best" value of calibration factor. As mentioned in section 2.1, we found that the calibration factor is a linear function of temperature. Thus, we perform a series of electrical calibrations on the main calorimeter which have various drift rates and for the temperature out and main calorimeter RTD we perform a least squares fit on the following equation

$$
\frac{Y \emptyset(2, J)-Y \emptyset(\emptyset, 1)-\sqrt{12} \cdot T 2 \cdot Y 1(\emptyset, J)}{J \emptyset}=K \emptyset(n)+A 1 \cdot Y 1(\emptyset, J),
$$

where

Al = drift coefficient, and all the rest of the terms are as previously defined.

For all the modules other than the main calorimeter, we assume $A 1=0$ and simply calculate an average calibration factor $(K \emptyset)$ and its standard deviation. These "best" values are stored in an $8 \times 4$ array, $F \emptyset$, in a data file. Table 2.1 shows the organization of $F \emptyset$. Note no "best" values are determined for the mass flow in, mass flow out, and temperature in.

\subsection{Laser Runs}

Since no experience using lasers on CLOP has been acquired as yet, this section will only offer various points as a guide to developing future procedures and computer programs for processing the data from laser and combination runs. As experience is acquired, first procedures (and the related computer programs) should be refined.

In order to calculate the injected energy for a laser run, we need to transpose the terms in eq (2-11) for the temperature out sensor in the main calorimeter and eq (2-9) for the sensors in the ancillary modules. Thus, for the temperature out we get from eq (2-11)

$$
E=\frac{Y \emptyset(i+2, J)-Y \emptyset(i, J)-\sqrt{12} \cdot T 2 \cdot Y 1(i, J)}{K \emptyset+A 1 \cdot Y 1(i, J)},
$$




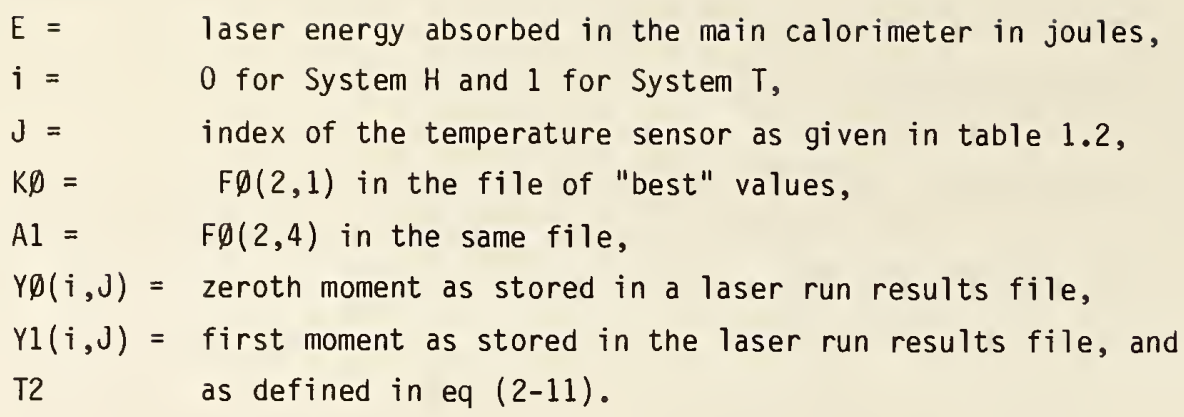

For the ancillary modules eq (2-9) transposes to become

$$
E=\frac{Y \emptyset(i+2, J)-Y \emptyset(i, j)-\sqrt{12} \cdot T 2 \cdot Y 1(i, j)}{K \emptyset},
$$

where

$E=$ the energy in joules absorbed by the module,

$K \emptyset=F \emptyset(1, a)$ with a being determined for the particular module from table 2.1 , and the rest of the terms are as in eq (2-12).

It should be noted that the OSM has a high reflectance and the value of $E$ in eq (2-13) is actually $E_{A}$ in eq (3-1). The actual laser energy incident upon the OSM should be modified accordingly.

Now the total laser energy is the sum of the energies measured by the various units of CLOP. However, there are two more important factors to be considered, backscatter and inequivalence. Considering the index of refraction for the glass and calcium fluoride ( $n=1.5$ or less), the reflection should be of the order of 4 percent or less. Also, the orientation of the surfaces of the absorbing material is such that the reflected light must experience additional reflections (with some associated absorption) before escaping through the calorimeter trapdoor opening. The light will then experience more reflections off of the surfaces of the deflecting unit and the separation tube before arriving at the BSM. The surface of the separation tube is quite black. At the BSM some of the energy will be absorbed by its black surface but some will escape through the open aperture where more will be absorbed by the extension tube. This untrapped (and unmeasured) backscatter should be quite small but it would be prudent to confirm this analysis.

The inequivalence arises from differences in the way the laser energy is injected as compared to the way the electrical energy is injected. The laser energy is absorbed (and converted to heat) throughout the entire volume of the absorber. The electrical energy heats the moving nitrogen gas by conduction and convection which must then transfer the heat to the surface of the absorbing materials. Some of the electrical energy also heats the walls of the calorimeter by radiation. With the large ratio of surface area to volume for the glass plates there should be very little difference when extracting the heat from that absorber, whether it was deposited by optical or electrical energy. The same should hold true for the calcium fluoride for pieces up to $1 \mathrm{~cm}$ on a side. Larger pieces may have to be broken down. Thus, the major contributor to inequivalence in the main calorimeter will probably be the less efficient way of transferring the electrical energy to the volume absorbing material. 
The deflector unit receives the full energy of the laser beam but should absorb only 1 or 2 percent of it. Thus, inequivalence here should not be as serious as in the main calorimeter. The foil reflector with its air space between the foil and the plate on which the sensor and heater are mounted should have a yreater inequivalence than the mirror deflecting unit. However, an inequivalence of 50 percent should only introduce a 0.5 to 1.0 percent error in the total energy measurement.

The same holds true for the other ancillary modules. Here we are talking about measuring only 4 percent of the total energy so we can tolerate inequivalences of 50 percent. This would yield an additional error of 2 percent in the total energy measurement. The close, intimate contact of the electrical heaters and sensors for these units plus the black surfaces and thin walls should result in a much greater equivalence than 50 percent.

\section{Description of Components \\ 3.1 Blast Shield}

The blast shield is a piece of aluminum $99 \mathrm{~cm}$ by $99 \mathrm{~cm}$ and $1.6 \mathrm{~mm}$ thick. This shield leans forward at an angle of approximately 20 degrees from the vertical so that any radiation reflected from it is directed downward and absorbed at some remote place. In the center is a $42 \mathrm{~cm}$ diameter tube which mates with the inside of the next section, the extension tube. The blast shield is held in place by two aluminum straps which connect to supports on the mounting stand for the extension tube.

No electrical instrumentation is associated with the blast shield; its sole function is to provide some measure of protection for CLOP in the event there is a gross misalignment of the laser beam.

\subsection{Extension Tube}

The extension tube is made from black anodized aluminum. It is $92 \mathrm{~cm}$ long by $43 \mathrm{~cm}$ in diameter and $1.6 \mathrm{~mm}$ thick. It is enclosed in an insulating jacket made from aluminum which is lined on the inside with $2.54 \mathrm{~cm}$ foamed polystyrene to isolate the unit from ambient effects. The outer dimensions of the insulating jacket are $90 \mathrm{~cm}$ long by $50 \mathrm{~cm}$ square. The extension tube protrudes $1 \mathrm{~cm}$ beyond each end of the insulating jacket to permit connecting to adjacent sections.

Instrumentation is provided to measure the temperature change of the unit and thus the amount of absorbed backscattered energy from the laser shot. The instrumentation consists of two insulated, bifilar windings of \#40 copper wire which are wrapped in a coincident spiral around the outside of the extension tube. Pitch of the spiral is $2 \mathrm{~cm}$ per turn. Nominal resistance of each winding is $440 \Omega$ and the two are equal to within $0.5 \Omega$. The two windings are designated RT1 and RT2 and form opposite arms of a bridge circuit.

This bridge circuit is shown in figure 3-1. It is mounted on a printed circuit board which is housed in an aluminum circuit box located on the outside of the insulating jacket. Zeroing of the bridge output is accomplished with the 10 turn wirewound pot, R16, that is mounted on the side of the circuit box. All power and signal connections to the bridge circuit are via a 10-pin connector mounted on the circuit box. 


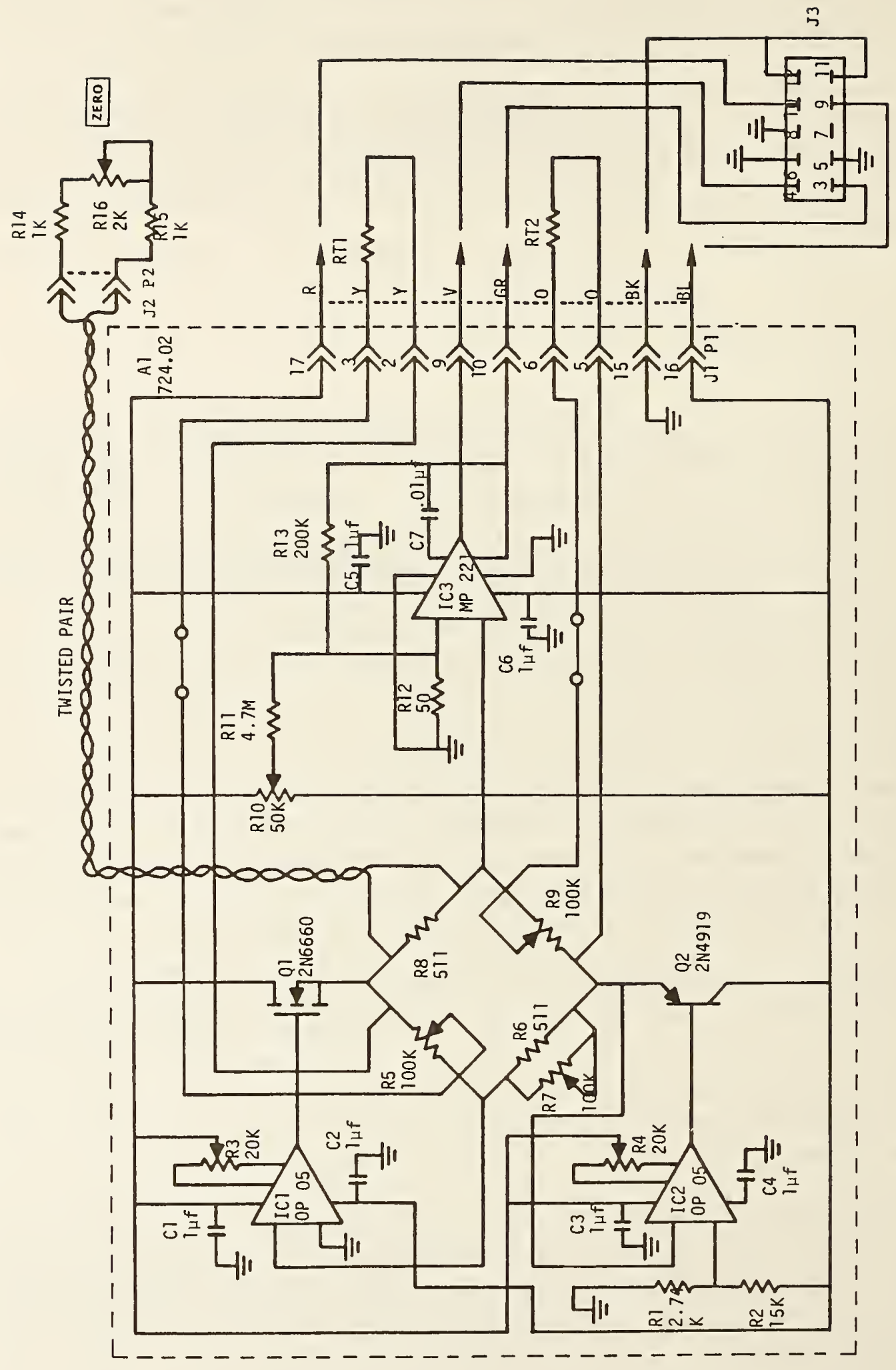




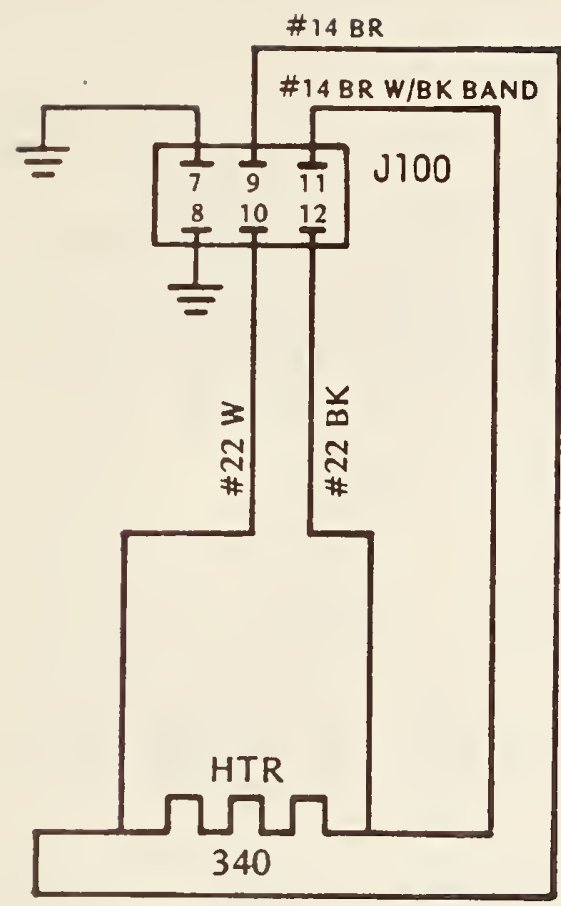

Figure 3-2. Schematic diagram of the heater circuit for the extension tube.

Electrical calibration is performed using a heater wire of bare \#24 nickel chromium wire. The wire is insulated from the metal tube by a layer of $76 \mu \mathrm{m}$ Teflon tape. Both the heater wire and resistance thermometers are covered with a layer of polystyrene coil dope which serves to anchor the wires in place and maintain good thermal contact with the metal tube.

The heater wire is also wound on a $2 \mathrm{~cm}$ pitch spiral and is centered between the turns of the resistance thermometers. Thus, the heater is separated from the temperature sensor by $1 \mathrm{~cm}$ on each side. The resistance of the heater is approximately $340 \Omega$ at room temperature.

The ends of the nickel chromium heater wire are secured on ceramic standoff insulators from which leads are brought out to a six-pin connector on the same circuit box that contains the bridge printed circuit board. The voltage across the heater is measured via a twisted pair of black and white \#22 wires connected to lugs on the ceramic insulators. The two leads are brought out to the same connector as the power leads. A schematic diagram of the heater circuit is shown in figure 3-2.

\subsection{Overspill Monitor/Backscatter Monitor}

\subsubsection{General Features}

The overspill monitor (OSM) and backscatter monitor (BSM) share the same section of CLOP. The dimensions of this section are $50 \mathrm{~cm}$ in diameter by $9.5 \mathrm{~cm}$ long. The outer skin is made of $1.6 \mathrm{~mm}$ thick aluminum and is lined on the inside with foamed polystyrene $3.5 \mathrm{~cm}$ thick for environmental insulation. Inside the insulation is another aluminum wal1, $1.6 \mathrm{~mm}$ thick, which forms a compartment for certain electrical circuits.

Along the centerline of the OSM/BSM section is a $30 \mathrm{~cm}$ by $15 \mathrm{~cm}$ aperture through which the laser beam is directed. A motor-driven shutter blocks this aperture for all measurement phases except laser energy injection, thereby helping to isolate the inner parts of CLOp from external ambient temperature 
effects and also inhibiting thermal radiation losses to the outside during the post-injection measuring period. Provision has been made to orient the aperture with the long dimension either horizontal or vertical.

\subsubsection{Overspil1 Monitor}

The function of the OSM is to measure how much energy misses going into the calorimeter. The absorbing surface is a piece of aluminum $43 \mathrm{~cm}$ in diameter and $3.2 \mathrm{~mm}$ thick. Since aluminum is quite reflective at most wavelengths, the reflectance must be considered when determining the amount of energy incident upon the OSM. Thus, the incident energy should be calculated by eq (3-1),

$$
E_{I}=\frac{E_{A}}{1-R},
$$

where

$E_{I}=$ the energy, in joules, incident upon the OSM,

$E_{A}=$ the energy, in joules, absorbed by the OSM, and

$R=$ the reflectance of the OSM which is equal to the ratio of the reflected energy to the incident energy.

Table 3.1 gives the reflectance of aluminum at certain selected wavelengths. The values given are from Bennett et al. [5] and are for "aged evaporated" films.

OSM temperature changes are sensed with two windings of \#40 copper wire, each of $50 \Omega$ resistance. They are wound in a hexagonal shape around the inside of the periphery of the back side of the OSM and are separated from the metallic surface by a layer of 89 um mylar tape. This tape, which has an adhesive on both sides, serves to hold the windings in place. A second layer of mylar tape covers the windings and in turn is covered by $89 \mu \mathrm{m}$ copper foil tape.

The sensors form the opposite arms of the bridge circuit shown in figure 3-3 for System $\mathrm{H}$ and figure 3-4 for System T system. Except for the sensors (RT1 and RT2) and R16 the zero adjustment, these circuits are contained on printed circuit boards located in a circuit box on the outside of the section. R16 is mounted on the circuit box for convenient access. All connections from the PC board to the data acquisition rack are via pins 1 through 12 of a 24-pin connector. This connector is shared with the output from the BSM PC board.

Two commercially available heaters are used to electrically calibrate the OSM. The heaters are $7.62 \mathrm{~cm}$ by $10.16 \mathrm{~cm}$ and are located next to the center portion along the $30 \mathrm{~cm}$ edge of the entrance aperture. The two heaters are each $3.93 \Omega$ and are connected in series. Total power dissipation is limited to $336 \mathrm{~W}$ by the computer program to prevent possible damage to the heaters. Leads to the heater are brought out to a six-pin connector on the circuit box. This connector is wired the same as the connector on the extension tube (see fig. 3-2).

\subsubsection{Backscatter Monitor}

The BSM is used to measure the energy that enters the calorimeter and is not absorbed but instead is reflected back out and hence not measured by the main calorimeter. It is made of black anodized aluminum $43 \mathrm{~cm}$ in diameter and $1.6 \mathrm{~mm}$ thick. In the center is a $15 \mathrm{~cm}$ by $30 \mathrm{~cm}$ aperture through which the laser beam passes. 


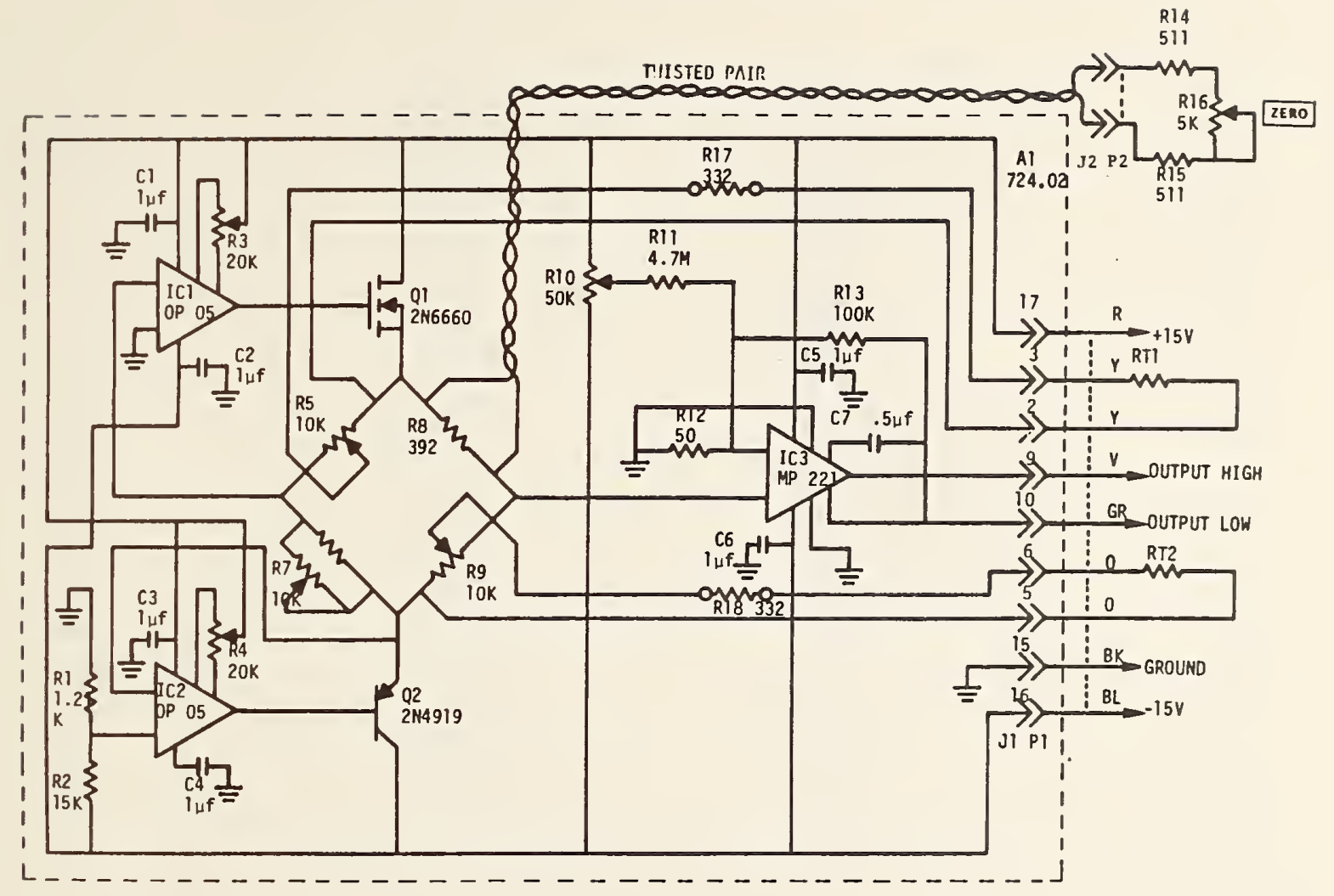

Figure 3-3. OSM bridge circuit schematic diagram (System H).

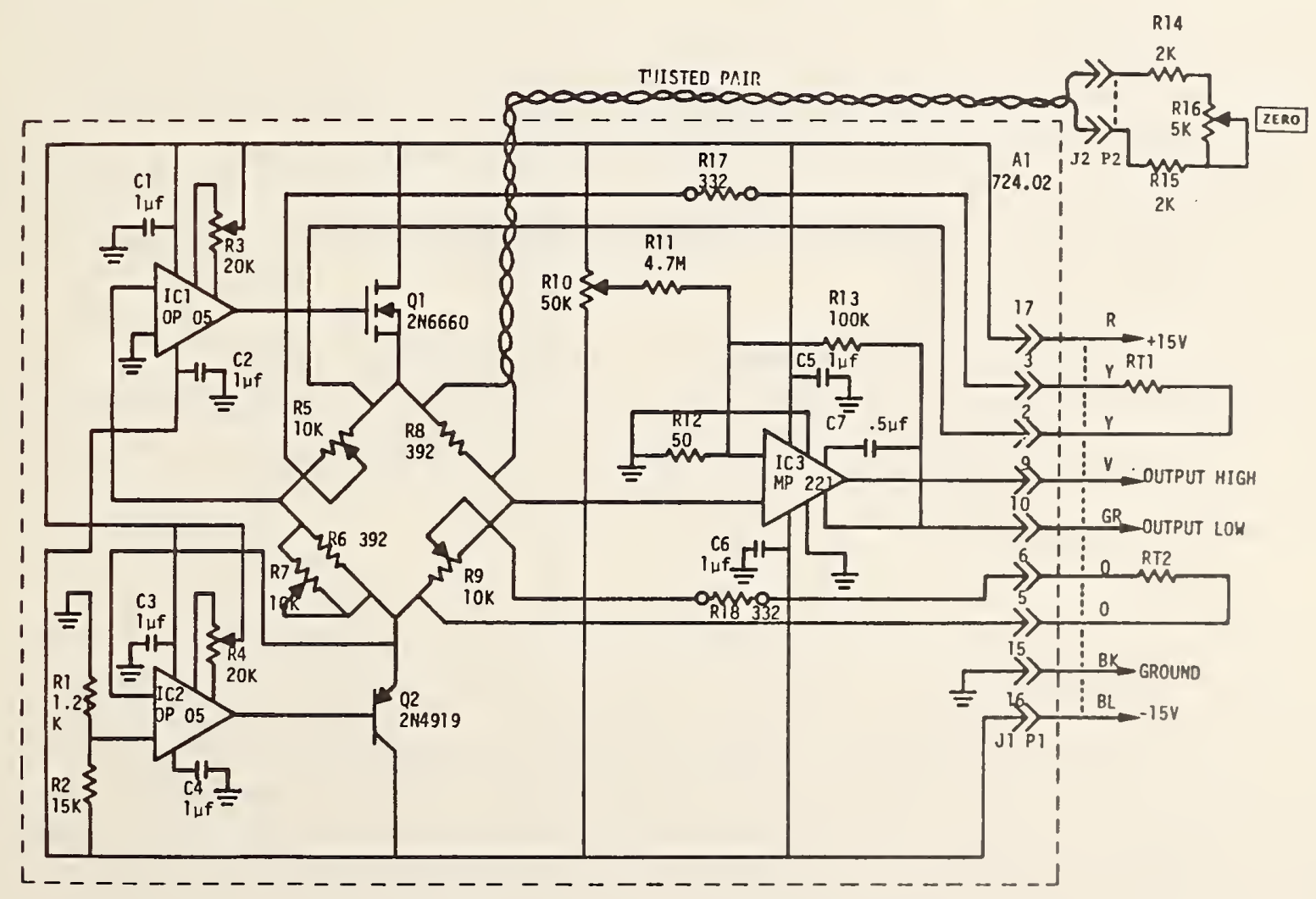

Figure 3-4. OSM bridge circuit schematic diagram (System T). 
Table 3.1. Reflectance of aged, evaporated aluminum films.

\begin{tabular}{llll}
\hline$\lambda \mu \mathrm{m}$ & $\mathrm{R}$ & $\lambda, \mu \mathrm{m}$ & $\mathrm{R}$ \\
\hline 0.400 & 0.9076 & 4.000 & 0.9758 \\
0.450 & 0.9061 & 5.000 & 0.9772 \\
0.500 & 0.9034 & 6.000 & 0.9784 \\
0.550 & 0.9032 & 7.000 & 0.9794 \\
0.600 & 0.9027 & 8.000 & 0.9801 \\
0.650 & 0.8976 & 9.000 & 0.9807 \\
0.700 & 0.8886 & 10.000 & 0.9812 \\
0.750 & 0.8761 & 11.000 & 0.9816 \\
0.775 & 0.8678 & 12.000 & 0.9821 \\
0.800 & 0.8596 & 13.000 & 0.9826 \\
0.825 & 0.8556 & 14.000 & 0.9830 \\
0.850 & 0.8596 & 16.000 & 0.9838 \\
0.875 & 0.8730 & 18.000 & 0.9845 \\
0.900 & 0.8894 & 20.000 & 0.9852 \\
0.925 & 0.9030 & 22.000 & 0.9856 \\
0.950 & 0.9154 & 24.000 & 0.9861 \\
1.000 & 0.9324 & 26.000 & 0.9864 \\
1.200 & 0.9585 & 28.000 & 0.9867 \\
1.500 & 0.9658 & 30.000 & 0.9870 \\
2.000 & 0.9699 & 32.000 & 0.9872 \\
3.000 & 0.9736 & &
\end{tabular}

Two $56 \Omega$ RTDs made of \#40 copper wire are used to measure the temperature rise of the BSM. They are wound in a rectangular shape around the central aperture leaving two spaces $2.54 \mathrm{~cm}$ wide along each $30 \mathrm{~cm}$ edge of the aperture. These two spaces are for the calibrating heaters (see below). The RTDs form the opposite arms of the bridge circuit in figure 3-5 for System $H$ and figure 3-6 for System T. This circuit is on a PC board in the same circuit box with the OSM PC board. As with the OSM circuit, the zero adjust pot, R16, for the BSM is located on the circuit box. Leads from the PC board to the data acquisition rack are via pins 13 through 24 of the 24-pin connector. A diagram of the 24-pin connector is shown in figure 3-7.

The two calibrating heaters are commercially available. They are each $30.5 \mathrm{~cm}$ long and $2.54 \mathrm{~cm}$ wide. Each has a resistance of $11.1 \Omega$ and they are connected in series. Maximum power dissipation for the total series combination is limited to $336 \mathrm{~W}$ to prevent possible damage. Connections to these heaters is via a six-pin connector on the circuit box. The connector in figure 3-2 also serves for this circuit.

\subsubsection{OSM/BSM Shutter}

As mentioned in section 3.3.1, a shutter is used to block the aperture in the OSM/BSM section. Normally, this shutter is closed for all phases of electrical and laser runs except for those time periods corresponding to laser energy injection. The shutter is made from two pieces of electropolished stainless steel that are opened and closed by individual motors which drive them through rack and gear arrangements. The "open" and "closed" positions of each shutter section are sensed by miniature roller-action switches. Each shutter section is powered independently of the other and thus a 


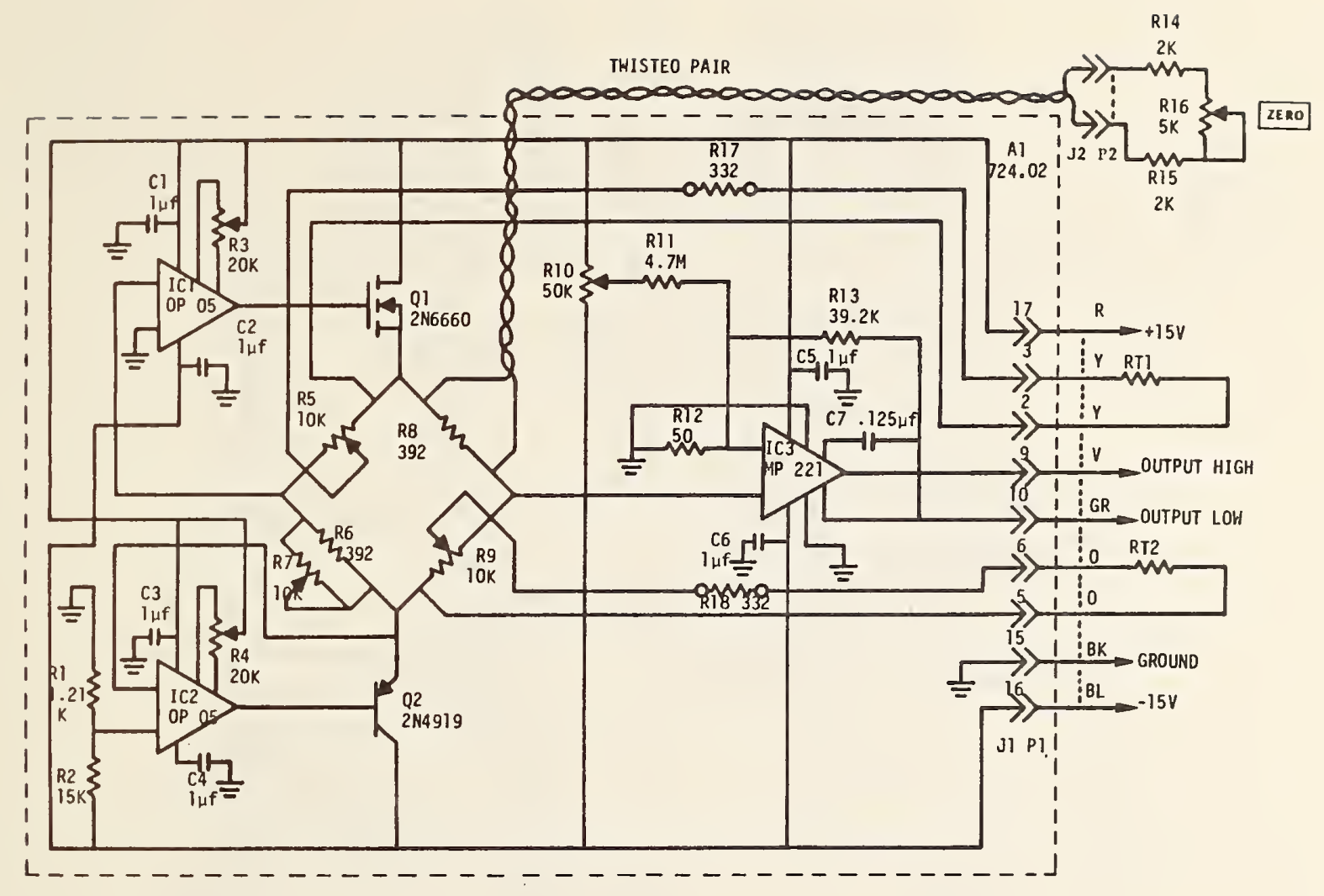

Figure 3-5. BSM bridge circuit schematic diagram (System $H$ ).

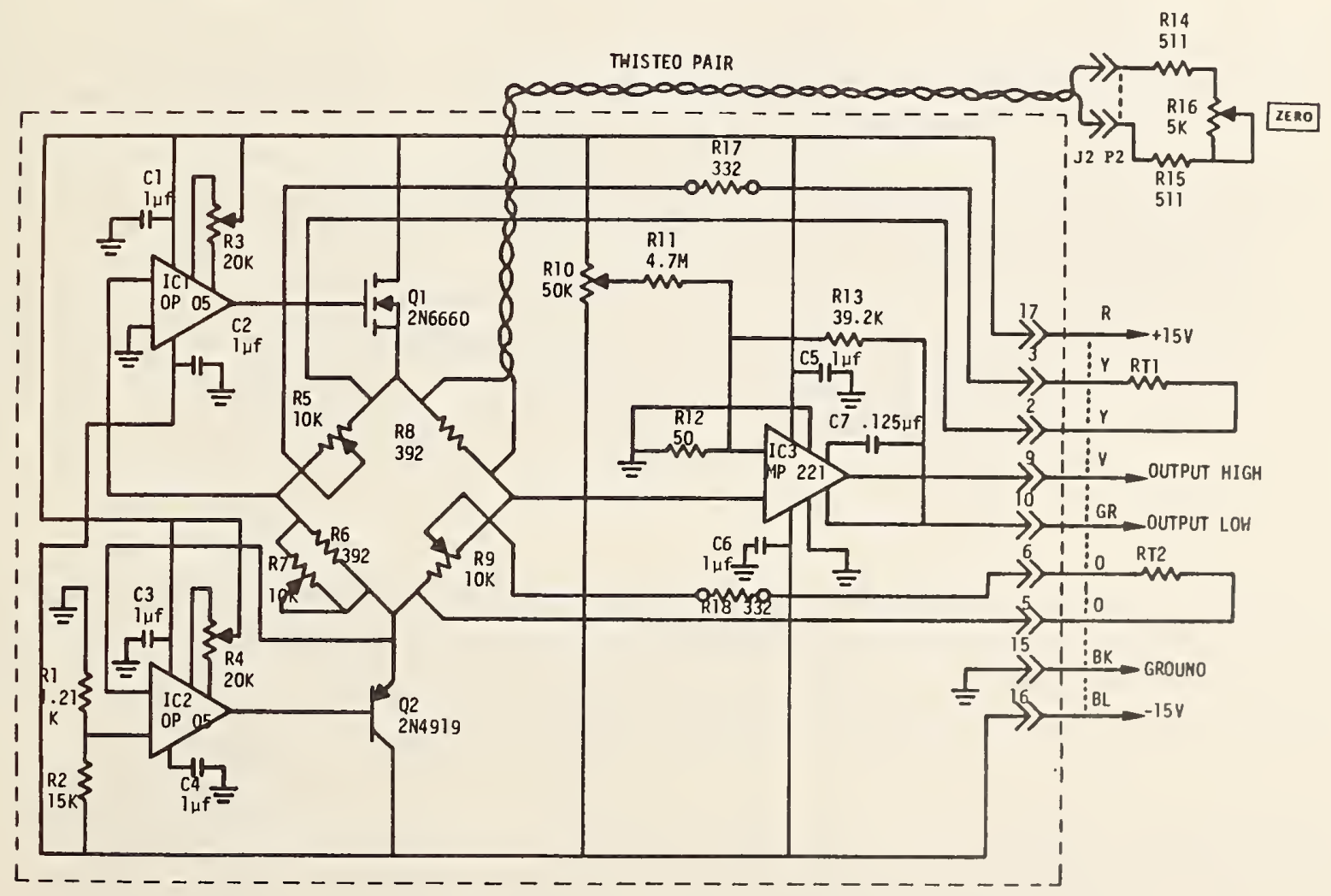

Figure 3-6. BSM bridge circuit schematic diagram (System T). 


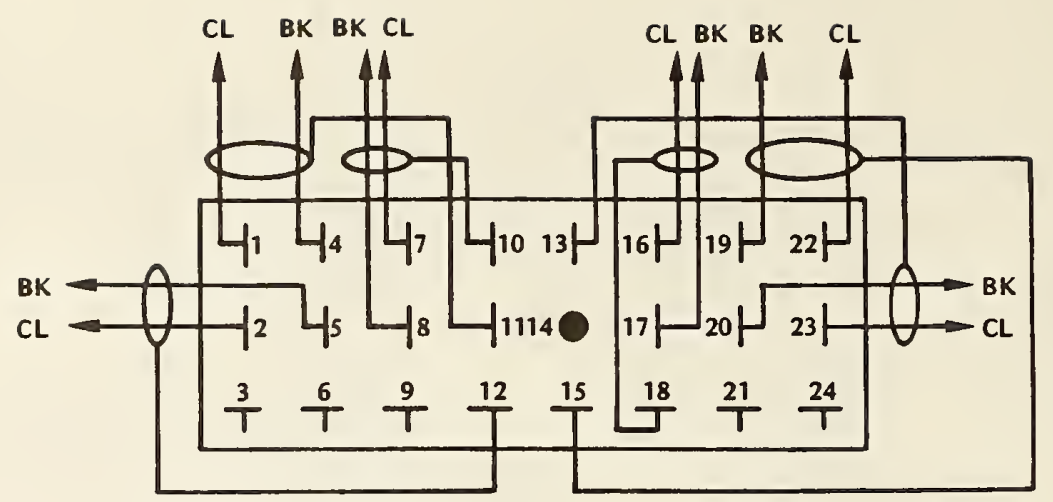

\begin{tabular}{|c|l|l|l|}
\hline PIN & ACQUISITION RACK CONNECTION & PIN & ACQUISITION RACK CONNECTION \\
\hline 1 & +15 VC POWER SUPPLY DECK & 13 & -15 V SHIELD \\
2 & -15V DC POWER SUPPLY DECK & 14 & NC \\
3 & NC & 15 & $+15 V$ SHIELD \\
4 & GROUND POWER SUPPLY DECK & 16 & SCANNER CONTACT 07 H \\
5 & GROUND POWER SUPPLY DECK & 17 & SCANNER CONTACT 07 L \\
6 & NC & 18 & SCANNER CONTACT 07 SHIELD \\
7 & SCANNER CONTACT 08 H & 19 & GROUND POWER SUPPLY DECK \\
8 & SCANNER CONTACT 08 L & 20 & GROUND POWER SUPPLY DECK \\
9 & NC & 21 & NC \\
10 & SCANNER CONTACT 08 SHIELD & 22 & +15 DC POWER SUPPLY DECK \\
11 & +15V SHIELD & 23 & $-15 V$ DC POWER SUPPLY DECK \\
12 & -15V SHIELD & 24 & NC \\
\hline
\end{tabular}

Figure 3-7. Wiring diagram of the 24-pin connector on the OSM/BSM circuits box.

slower moving one will complete its operation even after the other has terminated its movement. Position of the shutter is indicated by a red or green LED on the status light panel on the data acquisition rack. Red indicates "closed" and green "open."

Operation of the shutter is controlled by relays KI through $K 9$ in the circuit shown in figure 3-8. Commands to open or close the shutter may be initiated manually or by computer control. The manual pushbuttons OPEN, CLOSE, and STOP can be used during a computer controlled run to override computer commands if so desired. The computer uses scanner contacts 32 to open and 33 to close the shutter. Connection for operating the shutter is made via a 14-pin connector mounted on a $10.16 \mathrm{~cm}$ by $5.08 \mathrm{~cm}$ by $5.08 \mathrm{~cm}$ aluminum circuit box.

\subsection{Separation Tube}

The separation tube is similar to the extension tube (see section 3.2) except for values of components in the bridge circuit. Figure 3-9 is a schematic diagram of the bridge circuit for System $\mathrm{H}$ and figure 3-10 is for System T. All constructional details of the two tubes were made as close as possible to be alike, including sensor resistance and heater resistance.

\subsection{Mirror Reflector Surface}

\subsubsection{Description of Module Supporting Frame}

The mirror reflecting surface module is used to direct the incoming horizontal laser beam downward at a $90^{\circ}$ angle into the volume absorbing material in the main calorimeter. This beam steering is 


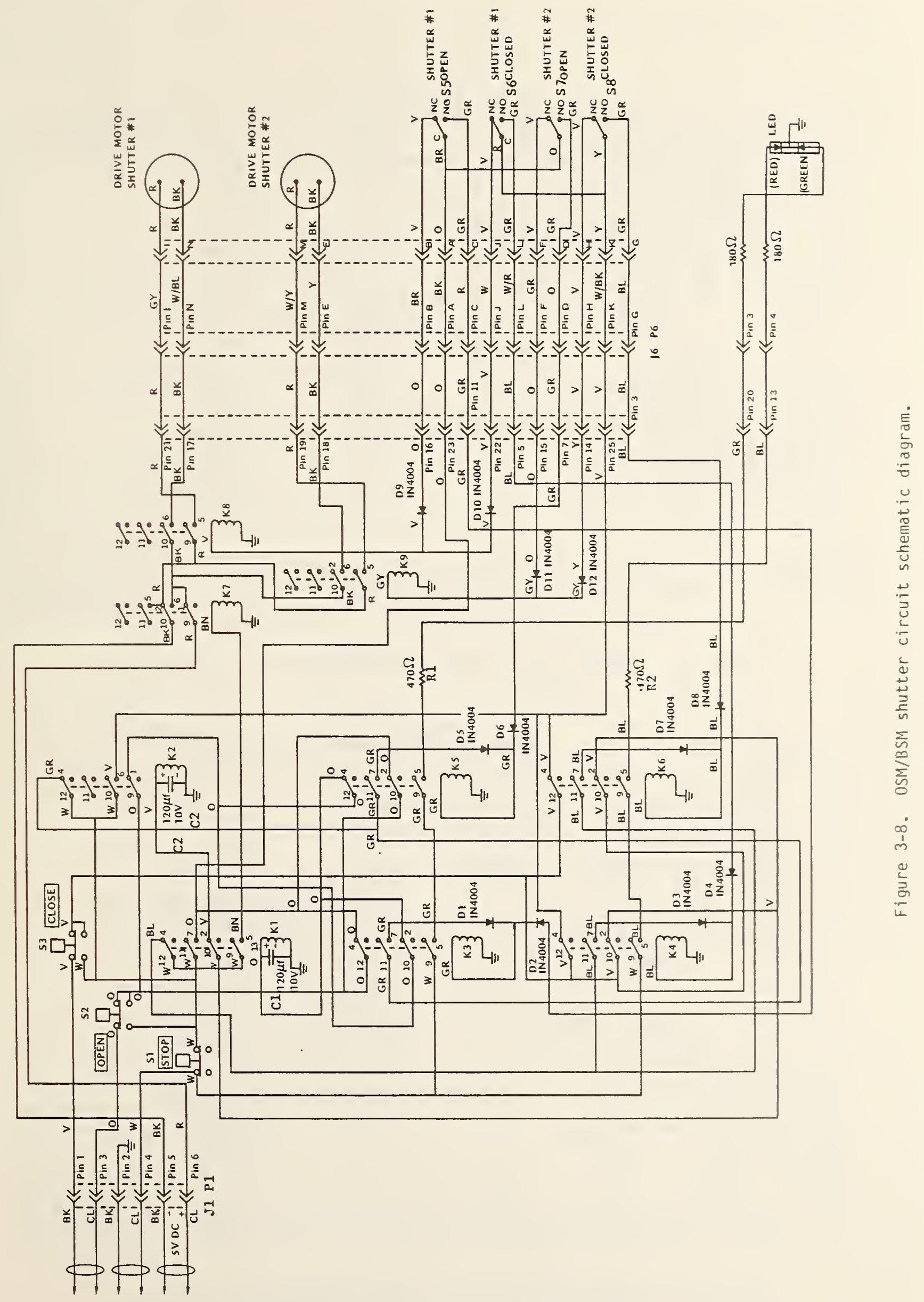




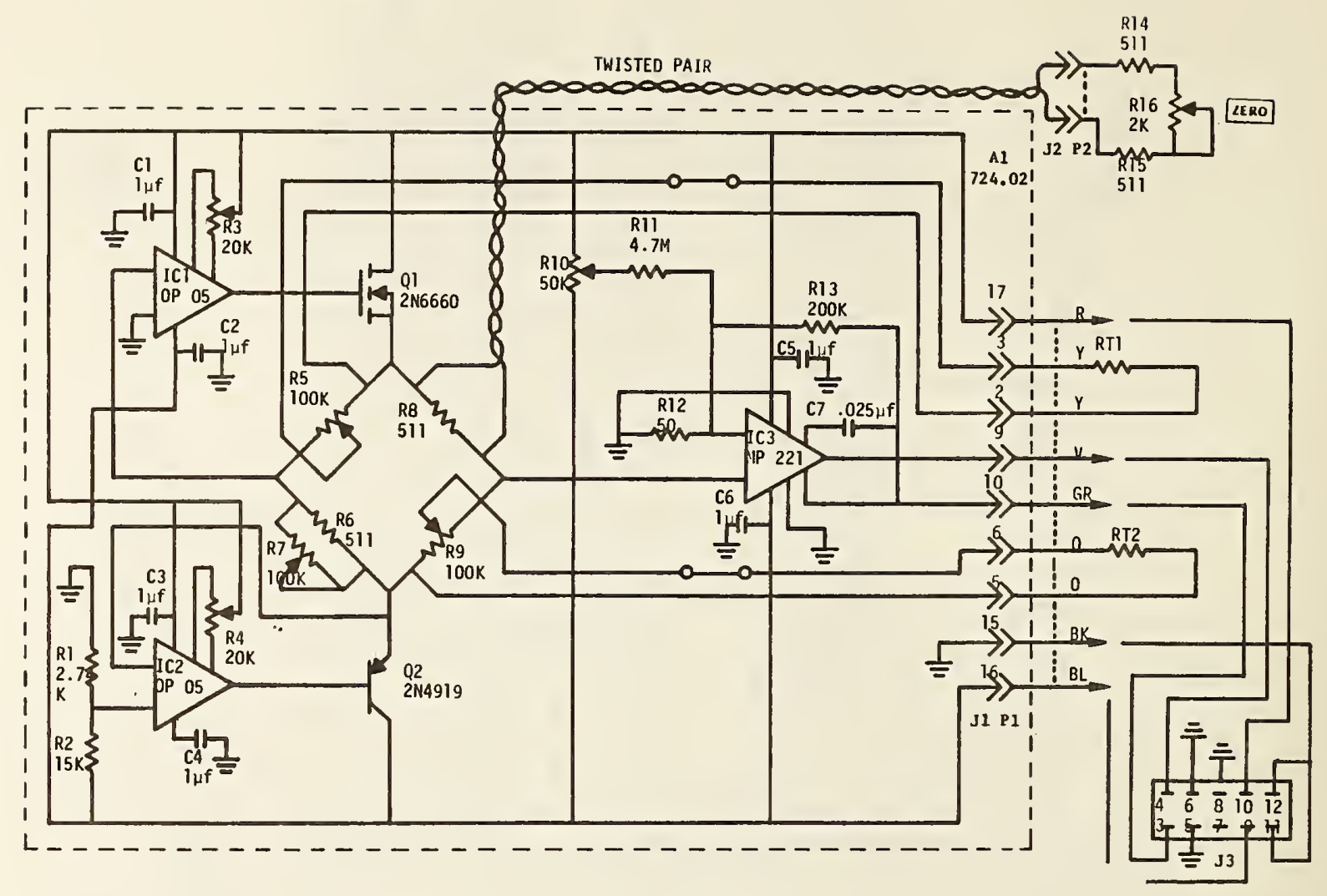

Figure 3-9. Separation tube bridge circuit schematic diagram (System H).

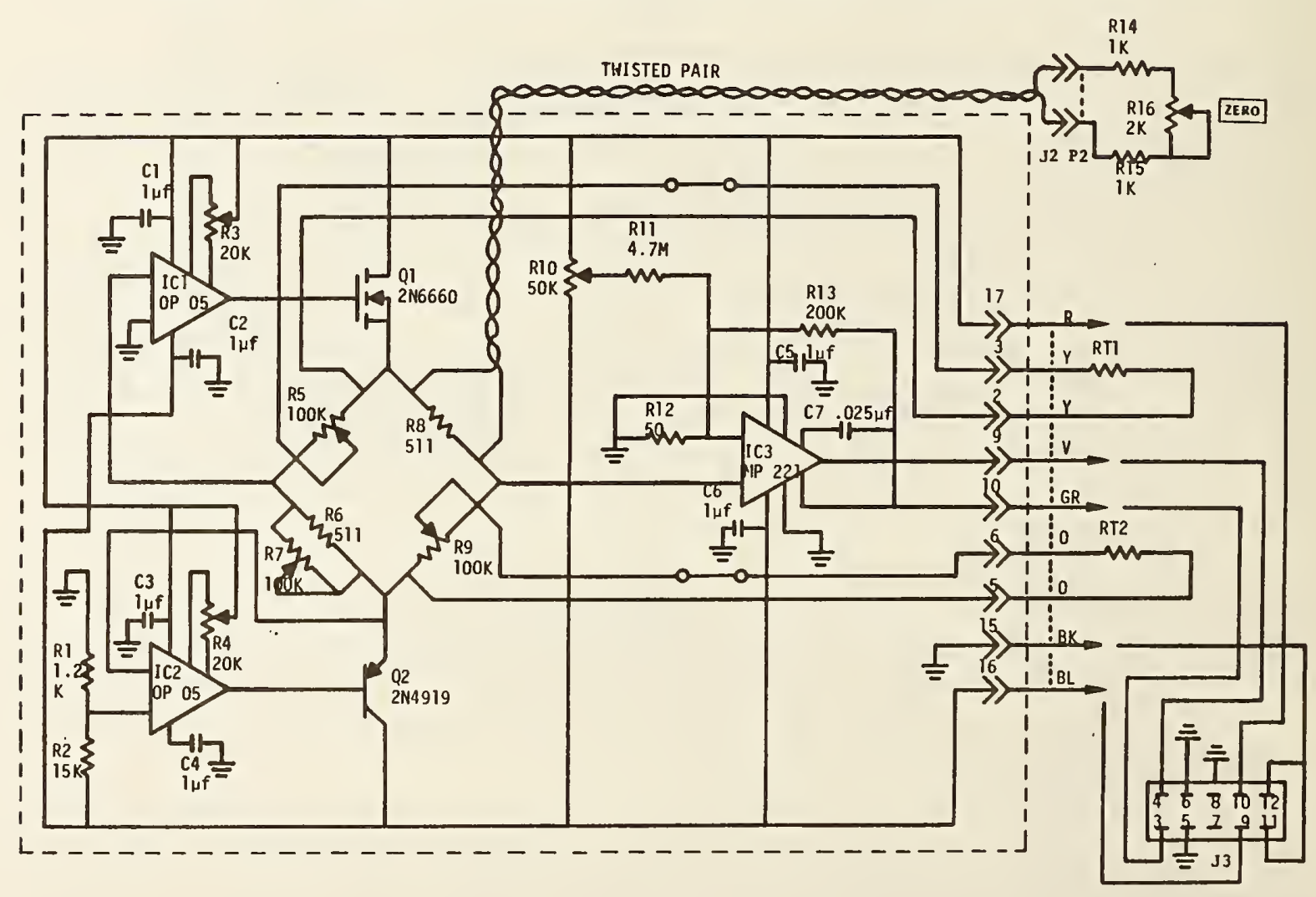

Figure 3-10. Separation tube bridge circuit schematic diagram (System T). 
necessitated by the fact that the volume absorber is often in a form that does not lend itself to a vertical orientation; e.g., small pellets, glass plates, etc.

The deflector unit consists of a frame of $1.6 \mathrm{~mm}$ aluminum which holds a reflecting surface at a $45^{\circ}$ angle to the incoming beam. The dimensions of the reflecting surface should be approximately $53 \mathrm{~cm}$ by $38 \mathrm{~cm}$ to best fit the frame. The front face of the frame, through which the laser beam enters, has a $43 \mathrm{~cm}$ diameter ring for connecting to the separation tube. The bottom surface of the frame, through which the laser beam exits, has a $43 \mathrm{~cm}$ diameter tube $19.5 \mathrm{~cm}$ long which projects down to the top surface of the main calorimeter. This tube plus the two triangular sides of the frame and the back of the reflecting surface are all instrumented for performing electrical calibrations and measuring temperature rise. The entire frame is enclosed in an aluminum box, lined on the inside with $2.54 \mathrm{~cm}$ foamed polystyrene, for isolation from the outside environment.

Each triangular side of the frame has a $10.16 \mathrm{~cm}$ diameter, $677 \Omega$ heater at its center. The $43 \mathrm{~cm}$ diameter tube has two $63.5 \mathrm{~cm}$ by $10 \mathrm{~cm}$ heaters, each $145 \Omega$, wrapped around the outside. These four heaters plus the one on the backplate are connected in parallel at a 10 contact terminal block from which leads are brought out to a six-pin connector on a circuit box (connections are as in fig. 3-2). Figure 3-11 is a schematic wiring diagram of the heaters. The resistance values of the various heaters are chosen to approximate relative heat distributions expected from laser shots.

The resistance thermometers (RTDs) are made from \#40 copper wire. All windings are placed on $89 \mu \mathrm{m}$ thick mylar tape with adhesive on both sides. This tape serves to insulate the windings from

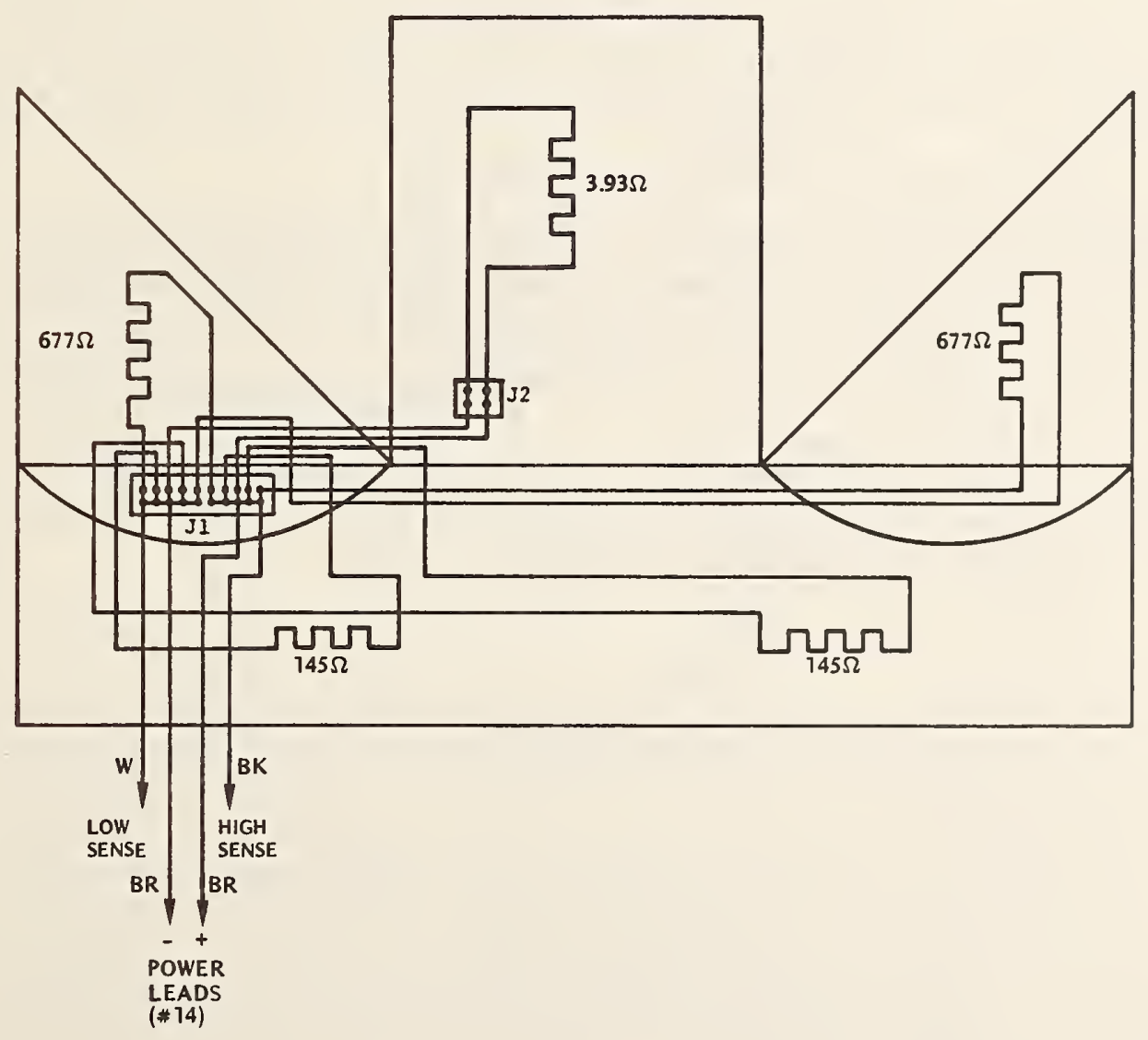

Figure 3-11. Schematic wiring diagram of deflector heater circuit. 
the metal and to hold them in place. They are covered with another piece of mylar and finally with 89 un copper foil tape.

On the frame the two triangular sides and the tubular bottom were wound with two bifilar windings. Both RTDs cover the three sections with continuous strands of the \#40 copper wire. These are brought out to an eight-contact terminal block which is attached to the frame with epoxy. Leads from the RTD on the mirror reflector are connected in series at the terminal block as shown in figure 3-12 and twisted pair leads brought out to the PC board in the circuit box on the outside of the unit.

On the triangular sides of the frame the pattern of the RTDs is a right isosceles trianyle with $25.4 \mathrm{~cm}$ legs. Each side has 3.8 turns. The tubular bottom has 5 turns. Resistance of the total thermometer is $300 \Omega$ (including the $200 \Omega$ of the mirror backplate).

The bridge circuit is shown in figure 3-13. Leads are brought out from the PC board to a 10-pin connector on the circuit box.

\subsubsection{Deflecting Plate}

The deflecting plate is a rectangular mirror approximately $2 \mathrm{~cm}$ thick. The mirror has a copper surface and therefore should not be used at uv wavelengths because of its reduced reflectivity. This surface will be useful in ir wavelengths and at longer visible ones.

The mirror itself does not contain the temperature sensors and electrical calibration heaters; these are mounted on a $1.6 \mathrm{~mm}$ thick aluminium backplate which is maintained in close thermal contact with the mirror by means of clamps and a layer of silicone grease. The central region of the backplate which holds the calibration heater is thermally isolated from the outer region by slots which are designed to force the electrical heat to flow into the mirror and back out again before reaching the sensors.

The sensor is two pairs of bifilar windings in the shape of a rectangular spiral. Thirty turns of \#40 copper wire are used, giving a resistance of $200 \Omega$. Leads to the RTD are connected via lugs to a four-contact terminal block attached to the backplate with epoxy. The RTD is mounted using mylar tape with adhesive on both faces to hold the \#40 wire in place and covered with copper foil tape.

The heater is a conmercially available model and has a resistance of $3.93 \Omega$. It is mounted in the central, isolated section of the backplate. Its leads go to a two-contact terminal block on the backplate before being connected in parallel with the other heaters.

\subsubsection{Foil Reflector}

The foil reflector was designed to furnish a "throw away" mirror surface. This was deemed prudent because of the high probability of damage from the intense laser pulses.

The support for the foil is an aluminum plate with a depression machined in the front side. A rectangular ring is attached with screws around the perimeter to hold the foil reflecting surface in place. The reflecting surface can be made from thin aluminum foil or from thin sheets of the metal. The critical elements are that it have a shiny surface and be made by a rolling process since this will reduce the number of potential damage sites. Also, the surface must be free of grease and fingerprints. 


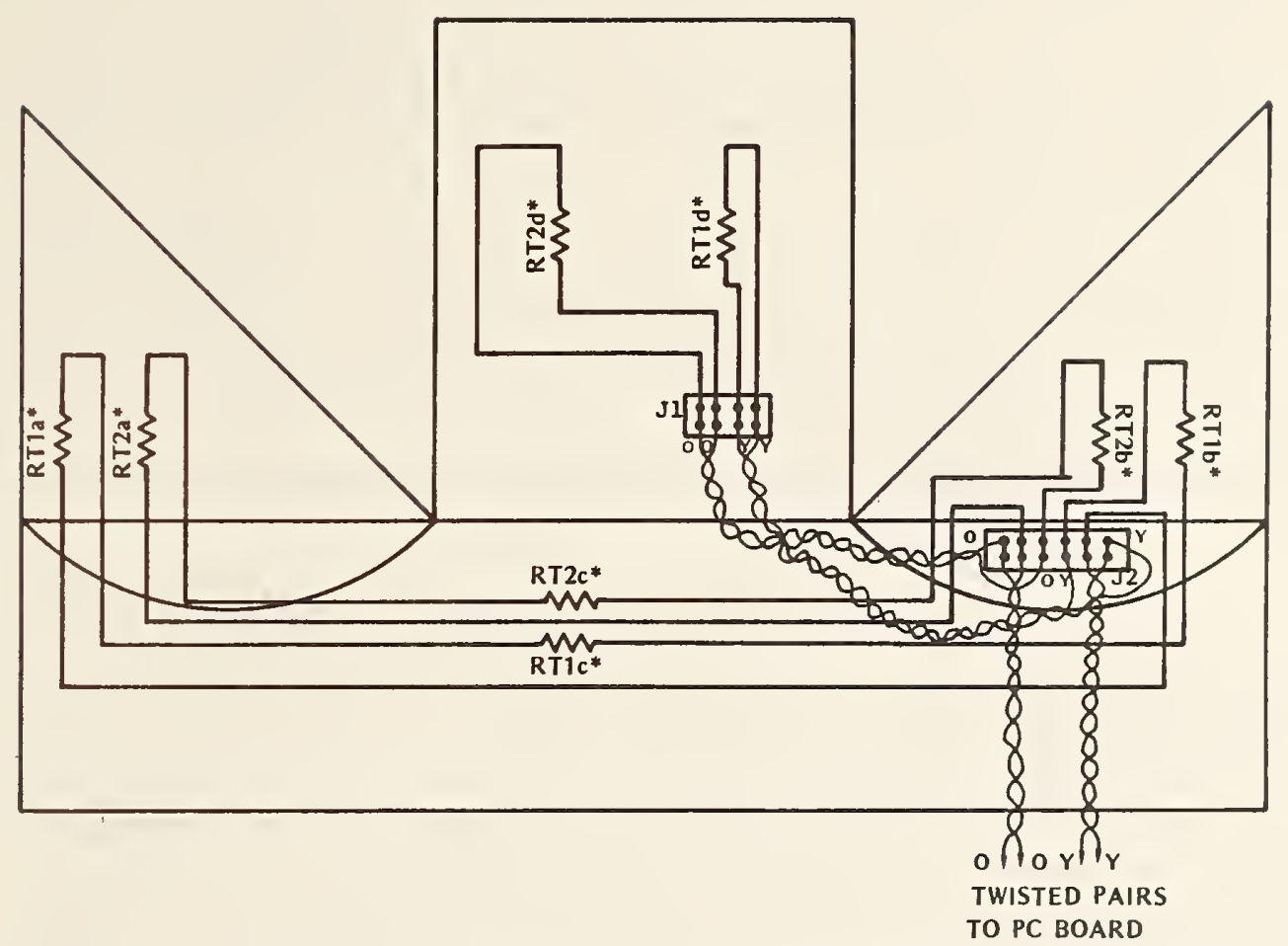

*RT1a, b, \& c and RT2a, b, \& c are shown as series-connected lumped elements but are actually one continuous length of \# 40 copper wire for each thermometer (RT1 \& RT2). The "d" elements are separate lengths of $\# \mathbf{4 0}$ copper wire connected as shown with twisted pairs of \#20 copper wire.

Figure 3-12. Schematic wiring diagram of deflector RTD circuit.

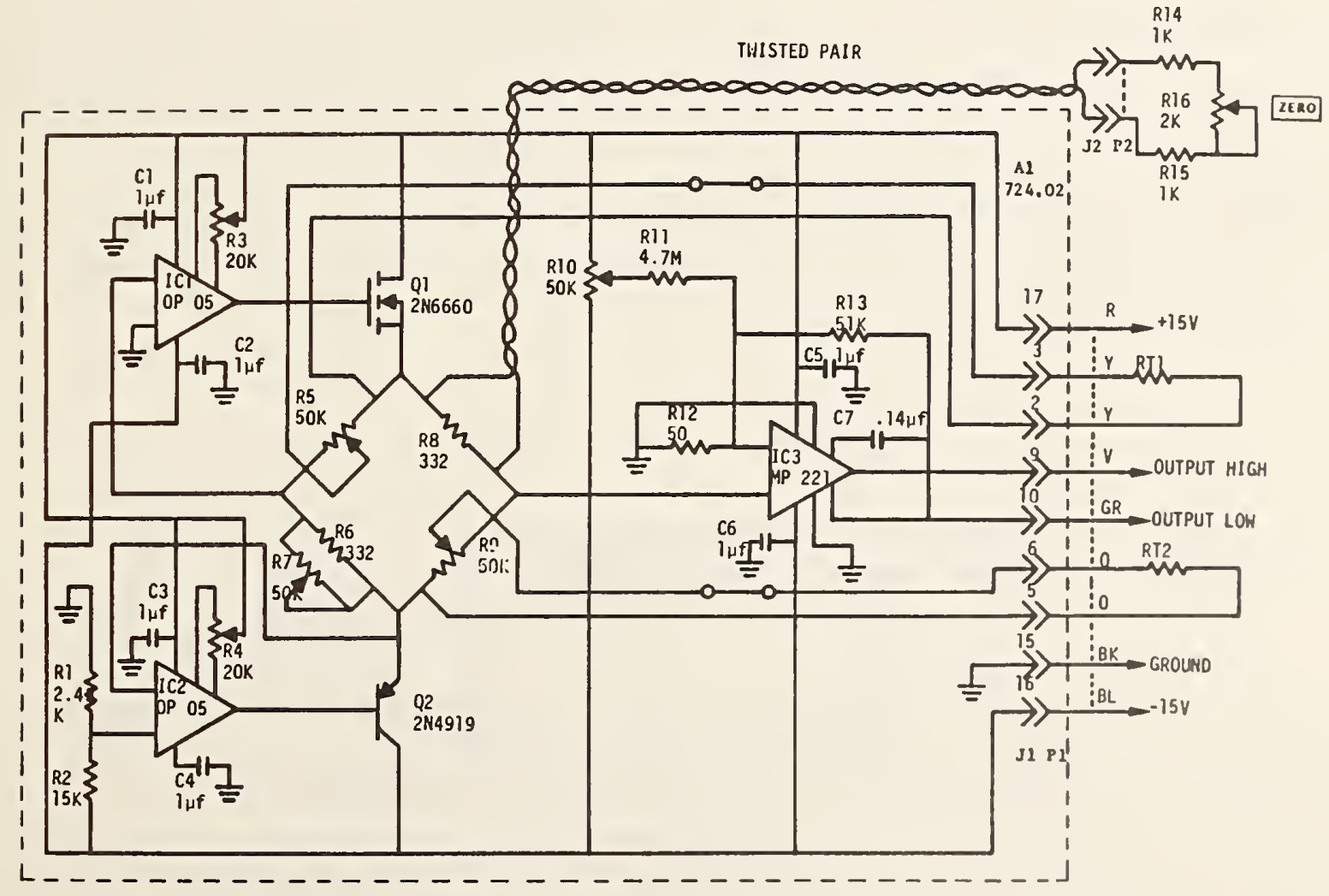

Figure 3-13. Schematic wiring diagram of deflector bridge circuit. 
While the surface does not have to be of high optical quality it should be reasonably snooth so that little or none of the laser radiation will miss the main calorimeter. Thin sheets will probably have enough rigidity to maintain the proper shape. Thin foil will more likely need careful stretching and a slight negative pressure applied through a fitting on the backside of the support place to achieve a satisfactory surface.

The electrical heater is mounted to one side of the fitting on the back. It is $12.5 \mathrm{~cm}$ by $17.5 \mathrm{~cm}$ and has a resistance of $44.5 \Omega$. The temperature sensor is two pair of bifilar windings of \#40 copper wire, each pair having a resistance of $200 \Omega$. These are wound in a " $\mathrm{C}$ " shape around three sides of the heater. Leads to the heater and the RTDs are connected to terminal blocks on the back side of the support plate so that the plate can be easily disconnected from the frame when it needs to be removed.

\subsection{Main Calorimeter \\ 3.6.1 General Features}

The main calorimeter is a copper vessel, $43 \mathrm{~cm}$ in diameter and $24 \mathrm{~cm}$ tall. It consists of a top section which hangs down into a lower section. Located centrally on the top piece is a $15 \mathrm{~cm}$ by $30 \mathrm{~cm}$ aperture through which the laser beam enters. A motor driven shutter seals this aperture for all phases of electrical and laser runs except for the time corresponding to laser energy injection. Below the aperture is a gold plated compartment for holding the volume absorbing material. The holder can be of various designs; e.g., basket for pellets, rack for stacked plates, etc. The lower section of the calorimeter contains a heater for performing electrical calibrations plus a copper RTD.

As discussed in section 1, dry nitrogen gas is used as a vehicle for transferring the heat of the absorbed energy from the volume absorber to a heat sensing thermistor. The gas flows in through a pipe on the side of the bottom section, up through the porous volume absorber, into the upper section, and out a pipe on the side of the upper section. Figure 3-14 is a cross sectional diagram of the calorimeter showing gas flow paths in the calorimeter and various sensor locations.

The whole calorimeter fits into an insulated box for isolation from ambient changes. The box sits on a shelf just behind the legs for the separation tube. The box with the calorimeter can rotate $90^{\circ}$ if it is desired to change the orientation of the input aperture. Also on the shelf are two circuit boxes for the associated electronics.

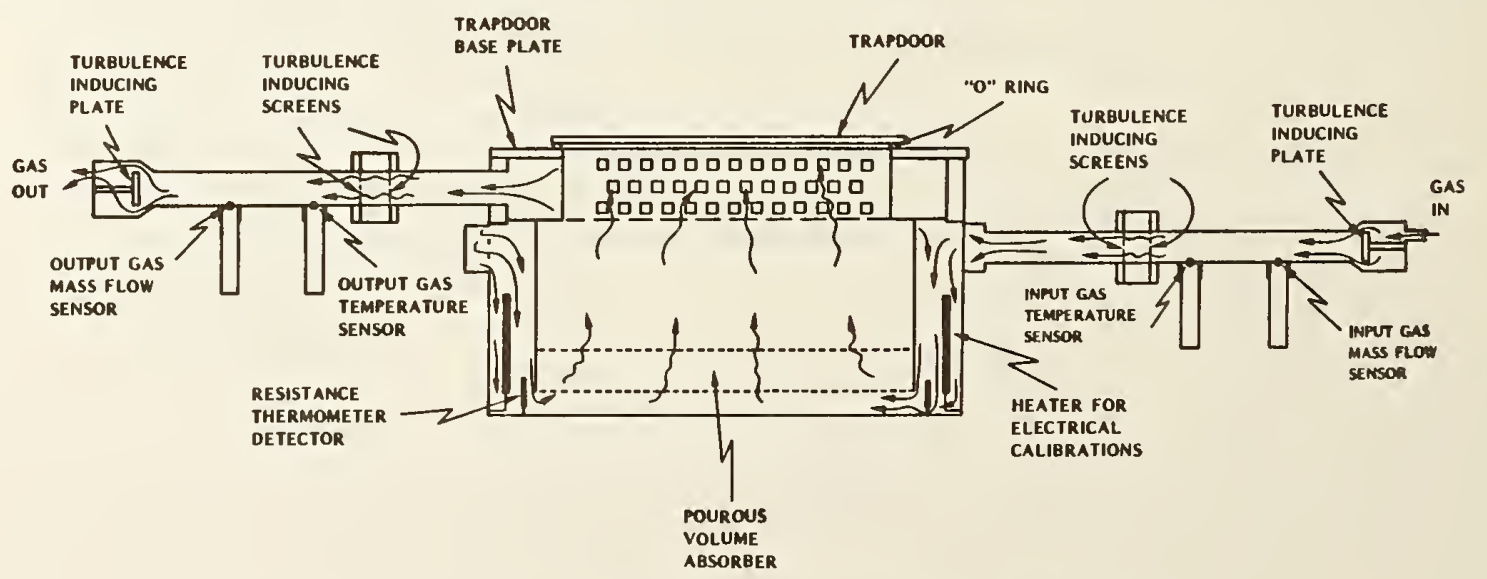

Figure 3-14. Cross sectional view of calorimeter unit. 


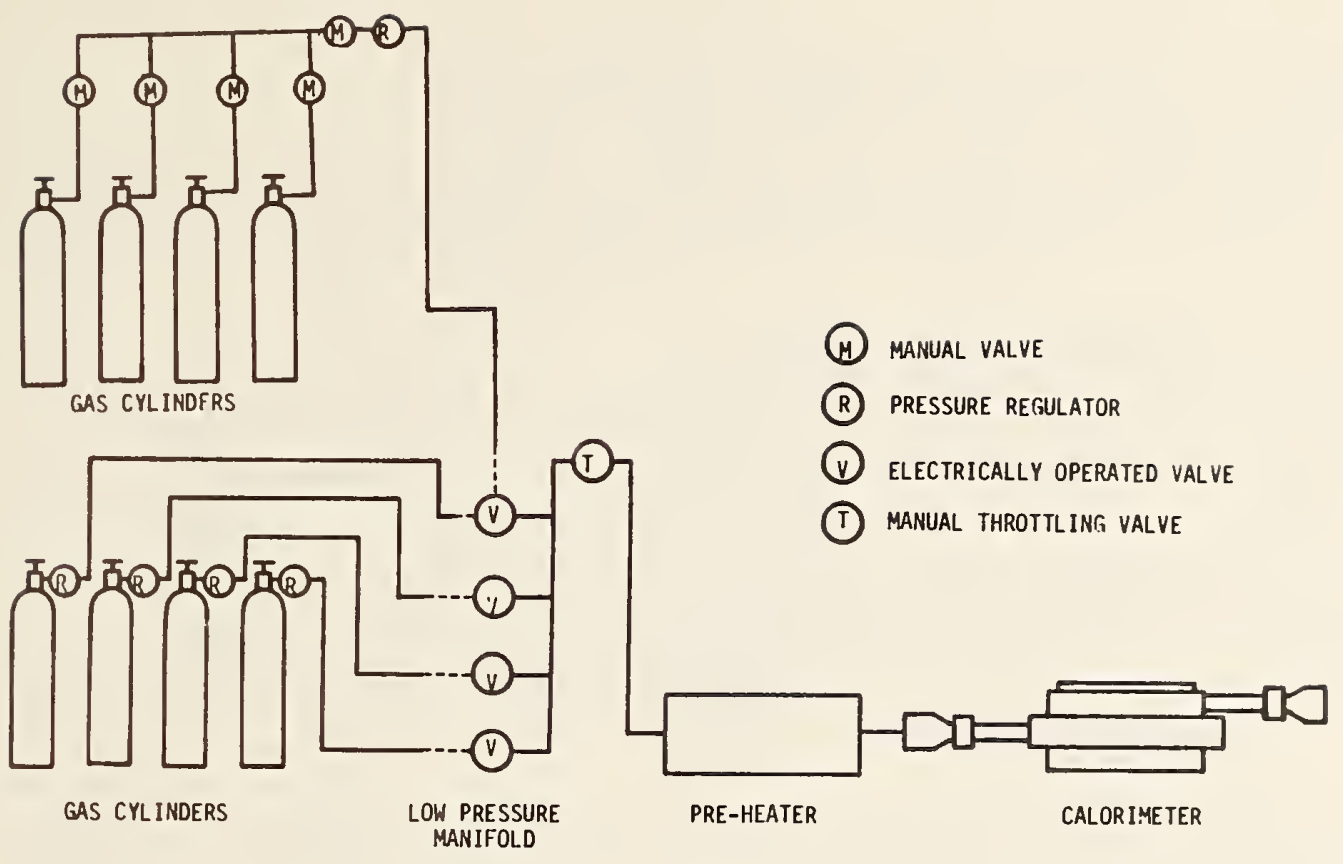

Figure 3-15. Total gas flow system for CLOP. Either the output from the high pressure manifold may be connected to an electrically operated valve on the low pressure manifold or individual cylinders with PRV's may be connected to the low pressure manifold.

\subsubsection{Gas Flow}

Figure 3-15 shows the total gas flow system. Gas flow is turned on and off with electrically controlled valves. Scanner contacts 34 through 37 actuate the four valves. Flow rate is controlled with PRVs and a throttling valve on the output of the low-pressure manifold. Dry nitrogen gas is supplied to the calorimeter by one of two methods. The preferred method uses three or more cylinders connected to a high-pressure manifold which has a PRV on its output, supplying gas at a constant reduced pressure to electrical valve $\# 1$ on the low-pressure manifold. All manifold valves to the cylinder are opened and two cylinders are opened up to the manifold while the rest are held in reserve. When the two cylinders begin to empty and the manifold pressure gets to the last graduation on the gauge, the manifold valve to one cylinder is shut off and the cylinder valve to the reserve cylinder opened. The empty cylinder can now be replaced with a full one. The operator should plan ahead of time to make this switch if the gas supply is in danger of running out during the data taking part of a run. When using this method of gas supply, manual valves on the output of unused electrical valves on the low-pressure manifold must be shut off to prevent back leakage through the electrical valves.

The second method uses two to four cylinders each with its own PRV and connected to separate electrical valves on the low-pressure manifold. This method is less desirable than the first because of the difficulty in setting two PRVs to the same pressure. The computer program (see section 4) leads the operator through the steps to adjust each regulator one at a time to get the same mass flow in reading for each PRV during the pre-run set up procedure. The operator presses a user-defined key during a run to turn off the empty cylinder and turn on the reserve cylinder. The empty cylinder can 
then be replaced. Thus there can be as low as one reserve cylinder or as many as three. The computer program is designed to handle any situation within this number. As with the preferred method, the operator should plan ahead to avoid running out of gas while he is out of the room during laser shots.

A preheater unit is installed after the low-pressure manifold to reduce temperature background drift caused by cooling due to adiabatic expansion of the gas. This preheater is rated at 680 wand with a resistance of $145 \Omega$ can supply up to a nominal $100 \mathrm{~W}$ when operated with a $120 \mathrm{~V}$ ac adjustable autotransformer.

As shown in figure 3-14, when the gas enters the input arm of the main calorimeter, it strikes a flat plate which induces turbulent flow. Turbulence is required to ensure good mixing of the gas and maximum flow past the sensors located near the wall of the pipe. The gas then passes throuyh a section in the input arm with a pair of screens which are used to break up laminar flow for cases where gas flow might be reversed. The yas then continues through the main chamber of the calorimeter and into the output arm. There it encounters another pair of screens which breaks up the laminar flow and induces turbulence. It then passes over the output sensors, comes to a final plate which (under reverse flow) corresponds to the initial plate, and flows out of the calorimeter.

In this section reference has been made to "reverse flow conditions." For some tests it may be advantageous to run the gas through the calorimeter opposite to what is normally done; e.g., in the top section, down through the volume absorber, and out the bottom section. Note that the calorimeter is designed symetrically with respect to input and output sensors and turbulence-inducing elements. Thus, the gas dynamics are roughly the same under both forward and reverse gas flow. However, no provision has been allowed for this in the computer program and the sensors will be labelled incorrectly. Also, input to the preheater control circuits will have to be changed.

\subsubsection{Electrical Instrumentation}

\subsubsection{Thermistor Sensors}

Thermistor sensors are used to measure the following gas parameters:

1. The mass of the gas flowing into the calorimeter,

2. The temperature of the gas flowing into the calorimeter,

3. The mass of the gas flowing out of the calorimeter, and

4. The temperature of the gas flowing out of the calorimeter.

The locations of these sensors are shown in figure 3-14.

Each sensor is actually a pair of thermistors in the opposite arms of the appropriate bridge circuits in figures 3-16 through 3-19. Figure 3-20 is a typical I-V curve for a thermistor. As explained in the figure, point $A$ indicates the $I-V$ point of the thermistor at $50^{\circ} \mathrm{C}$ while point $B$ is for $300^{\circ} \mathrm{C}$. The temperature sensors are operated in the linear portion of the curve well below point $A$ as shown in the figure for greatest sensitivity to temperature changes of the gas. Conversely, the mass flow sensors are operated at some high temperature as shown in the figure in order to minimize the effect of temperature changes in the gas. The exact point of operation is set by the bias current and is chosen to make the thermistor operate where the slope is maximum and slow changing. For the mass flow thermistors the bias current is approximately $10 \mathrm{ma}$. 


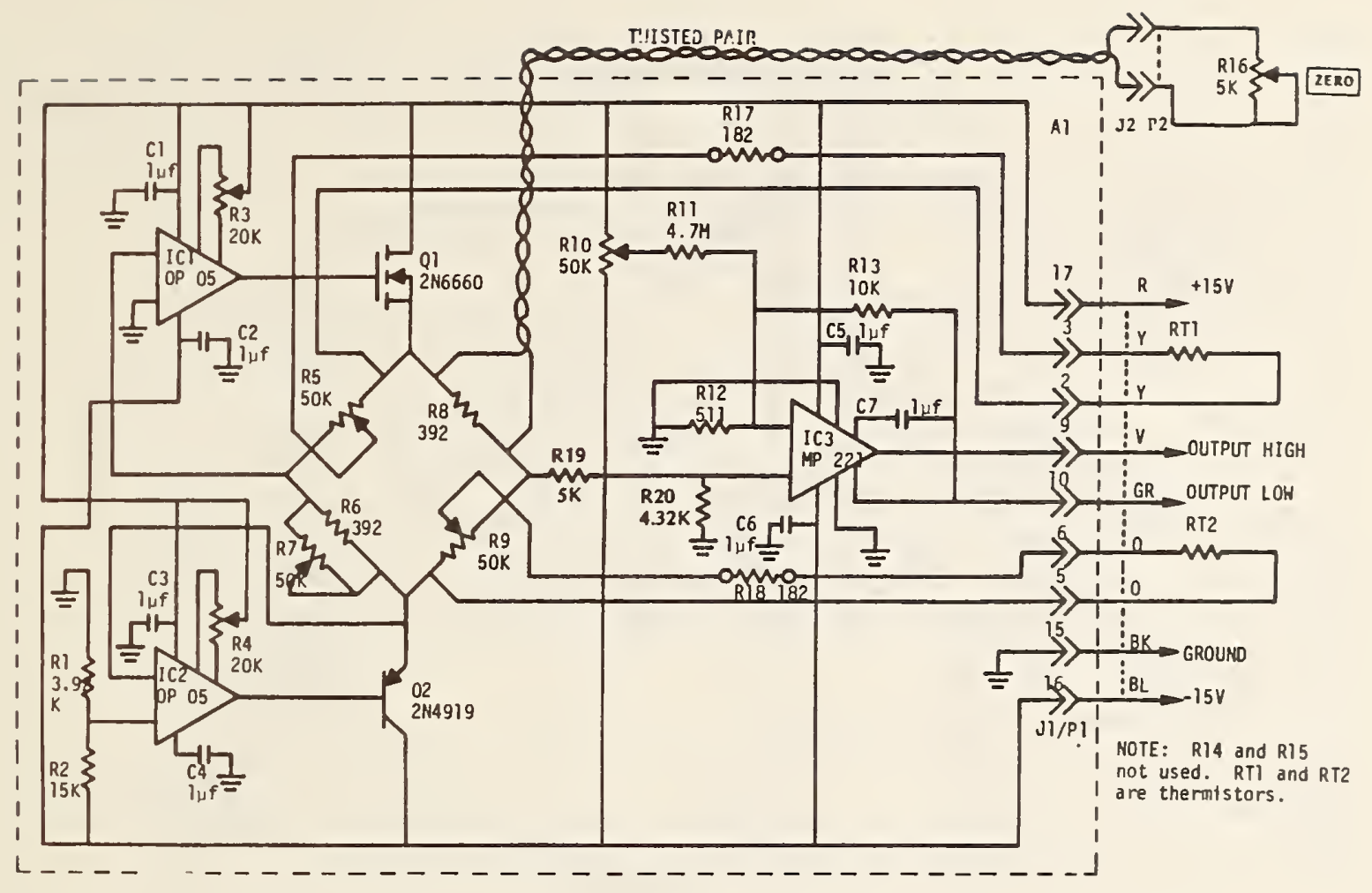

Figure 3-16. Schematic diagram of Mass Flow In bridge circuit.

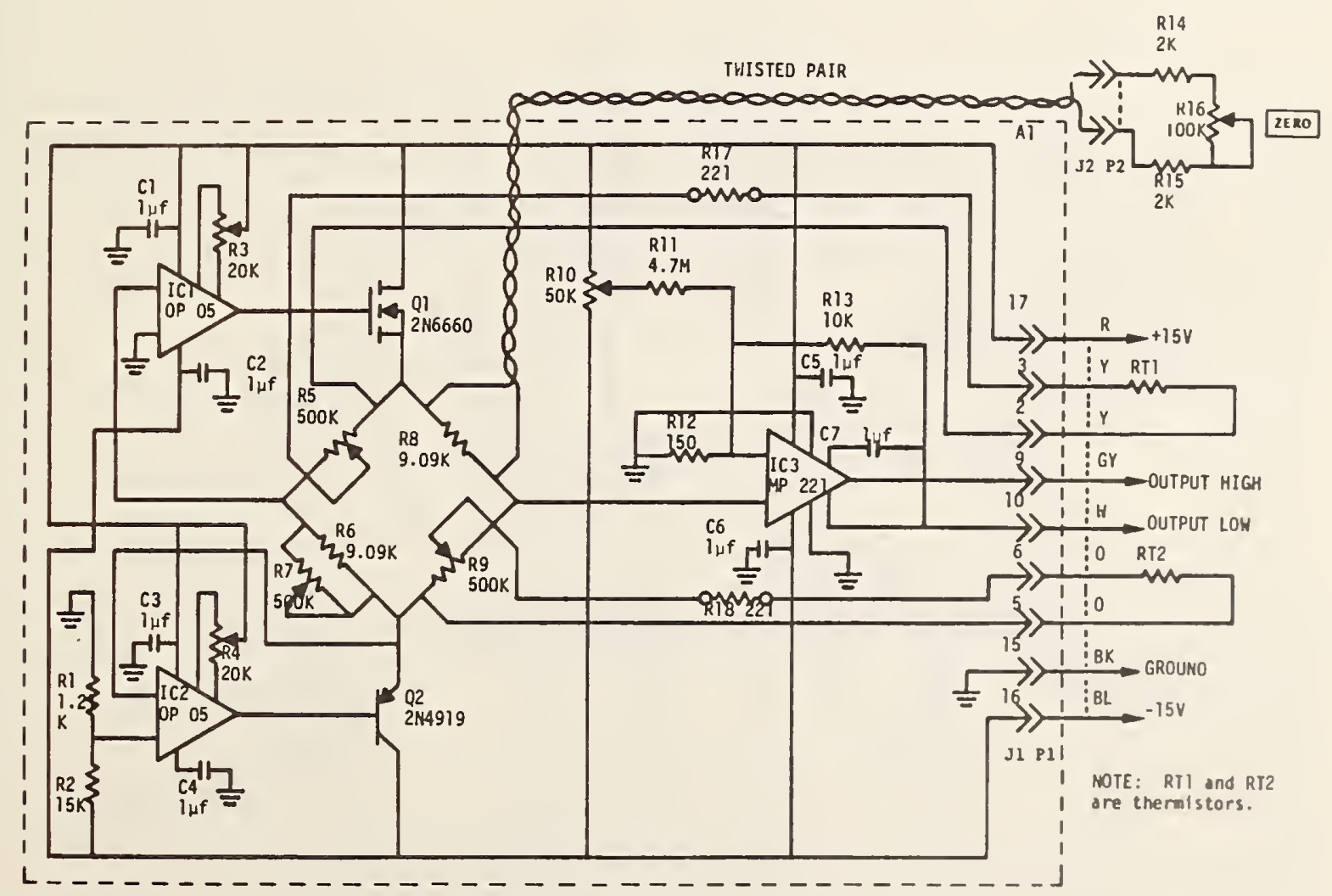

Figure 3-17. Schematic diagram of Temperature In bridge circuit. 


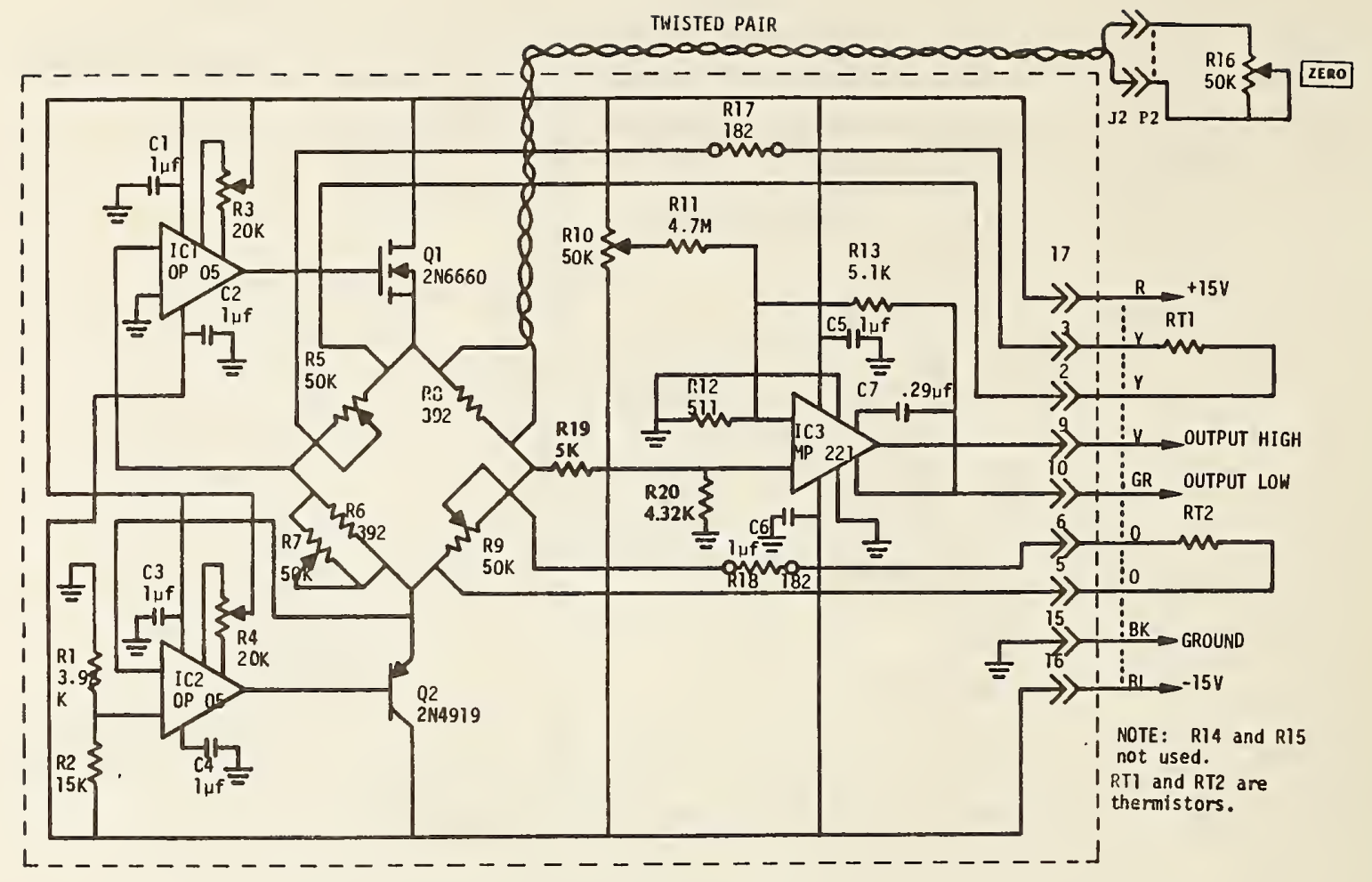

Figure 3-18. Schematic diagram of Mass Flow Out bridge circuit.

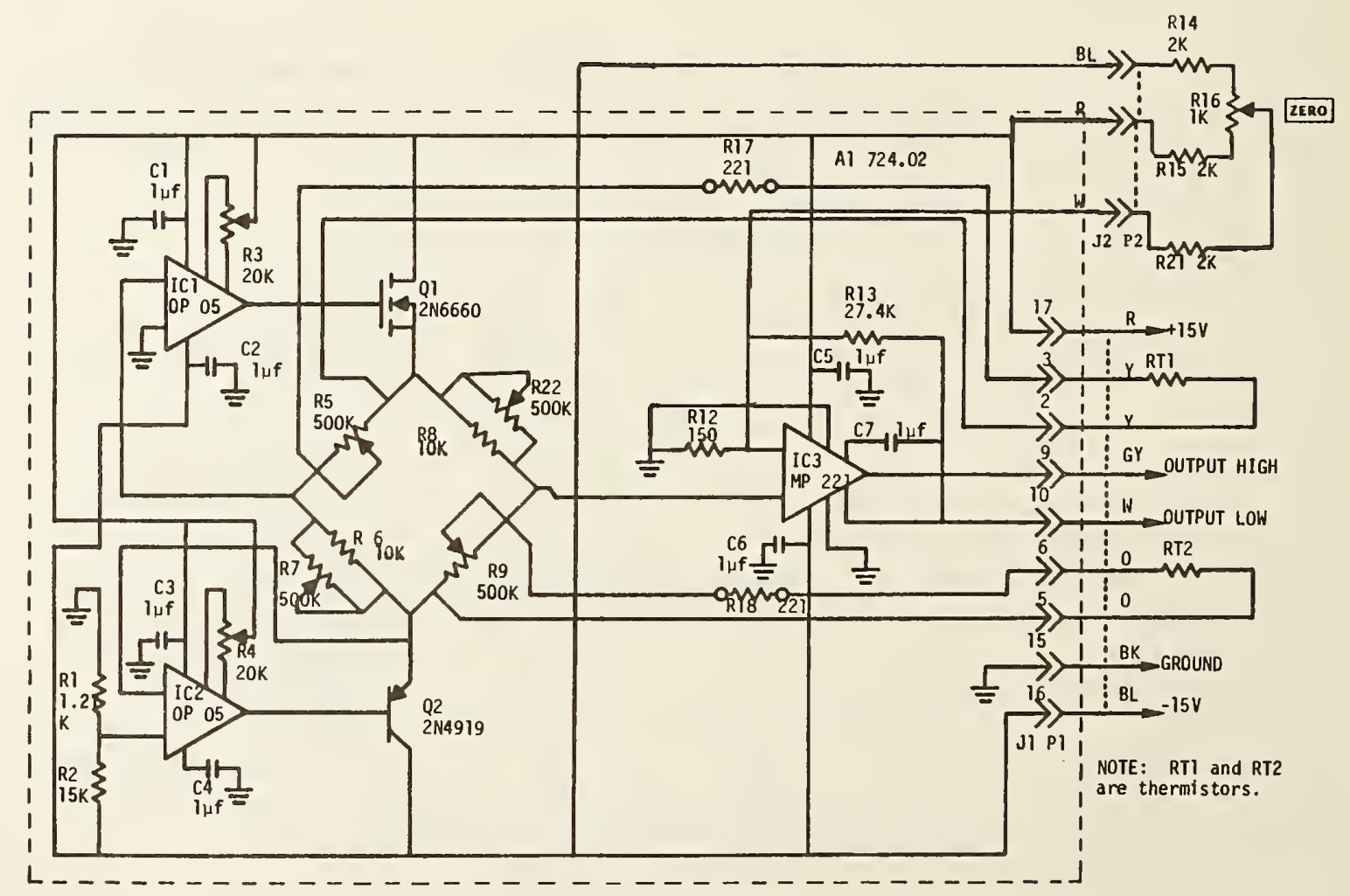

Figure 3-19. Schematic diagram of Temperature Out bridge circuit. 


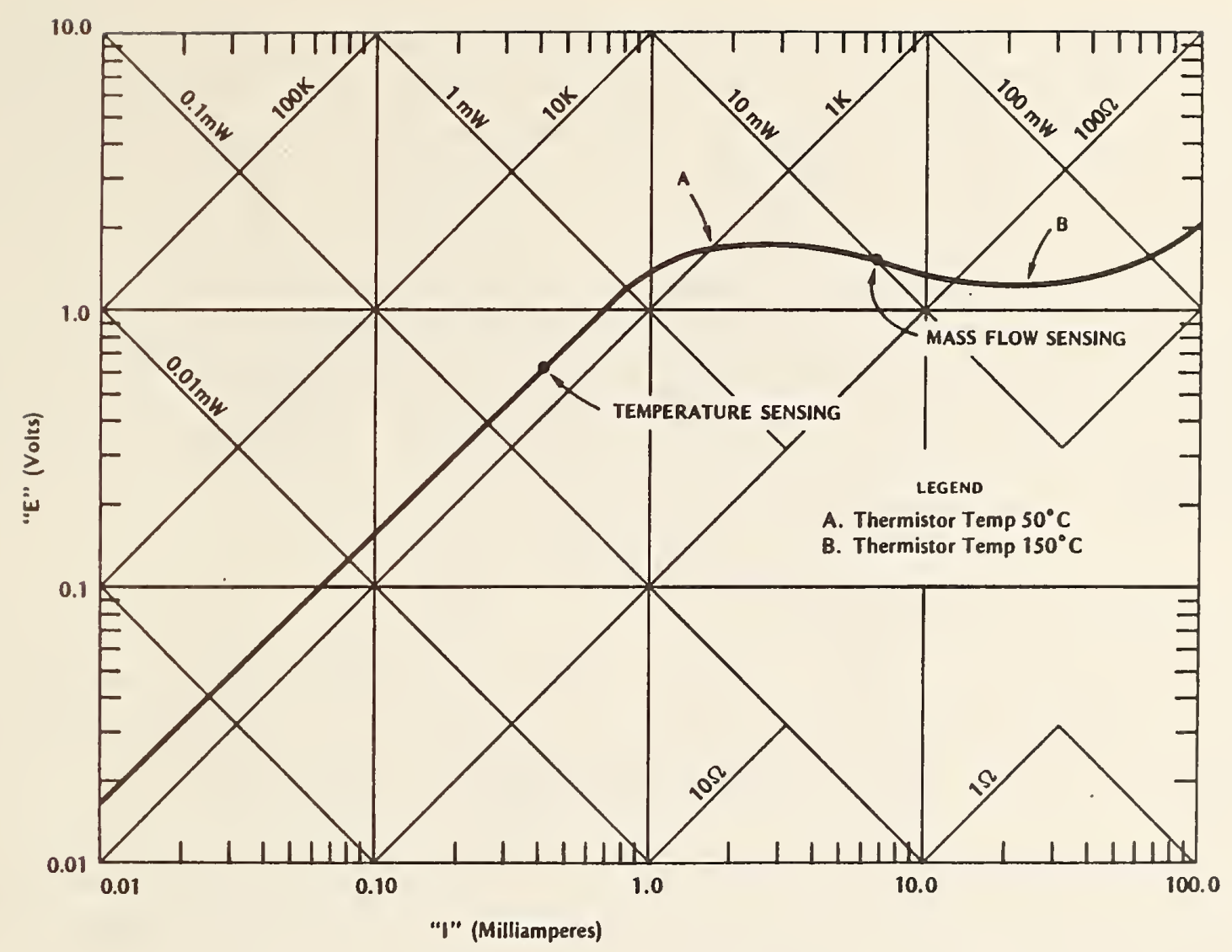

Figure 3-20. Typical I-V curve for thermistor sensors.

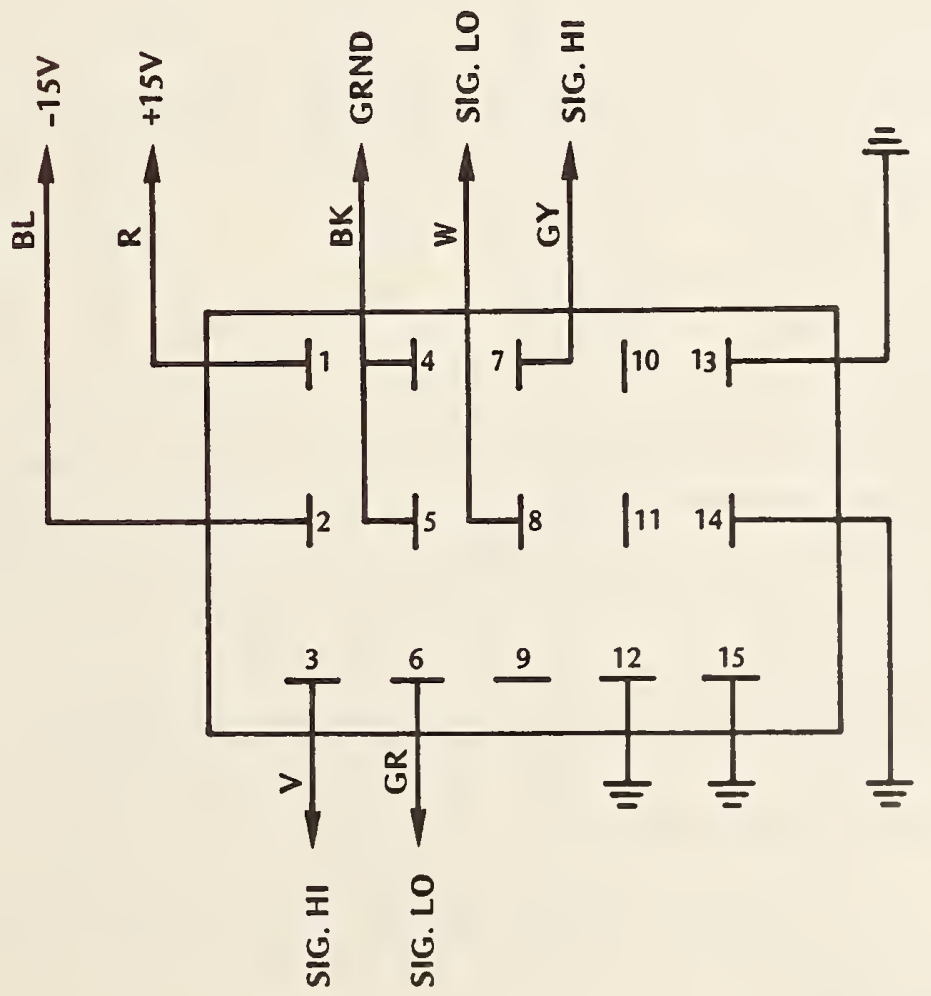

Figure 3-21. Wiring diagram for 15-pin connector on gas input circuits box. 
The electronic circuitry for measuring the input gas parameters is housed in a circuit box mounted on a bracket on the left side (as the observer faces the input of the extension tube) of the shelf on which the calorimeter rests. The two zero-adjustment pots are mounted on the box. Connections to the bridge circuits are made via a 15-pin connector. Figure 3-21 shows the diagram for this connector.

A circuit box for housing the electronics for the output temperature and mass flow circuits is mounted on the opposite side of the shelf. This box also contains the circuit board for the main calorimeter RTD (see section 3.6.3.2, below). All circuit zero adjustments are mounted on the box. This box can be moved to the back of the shelf if the calorimeter is rotated $90^{\circ}$. Connections for the output gas mass flow and temperature measuring circuits plus the RTD are via a 24-pin connector whose wiring diagram is given in figure $3-22$.

\subsubsection{Resistance Thermometer Detector}

A resistance thermometer detector (RTD) is installed in the lower section of the main calorimeter. It is located at the bottom just outside of the region where the lower part of the top section is suspended. The RTD is wound on a form of 16 equispaced posts made from $2.54 \mathrm{~cm} \mathrm{4-40} \mathrm{screws.} \mathrm{These}$ are arranged in a circular pattern having a $36.8 \mathrm{~cm}$ diameter.

The RTD is made from 2 bifilar windings of 48 turns of \#40 copper wire. The exact length was individually adjusted to equalize the two resistances to $219.5 \pm 0.1 \Omega$ at room temperature. The copper wires are enclosed between two pieces of $76 \mu \mathrm{m}$ thick Teflon tape which are in turn covered with 89 Im thick copper tape which serves as a radiation shield. Leads to the RTD are brought through the wall via hermetic seals. Pins 1 and 3 are for one pair of wires and pins 2 and 4 for the other pair. The leads then continue to the same circuit box that contains the mass flow out and temperature out circuit boards (see section 3.6.3.1).

Figure 3-23 shows the bridge circuit for the RTD. As mentioned in section 3.6.3.1, the zero adjustment is located on the outside of the circuit box. Power and signal connections are via pins 16 through 24 of the 24-pin connector shown in figure $3-22$.

\subsubsection{Calibration Heater}

A heater for performing electrical calibration is located in the lower section of the calorimeter. This heater is made of \#18 nickel chromium wire and is wound on a cylindrical wire frame. Its resistance is $15 \Omega$. The turns are insulated from the wire frame by a layer of glass fiber insulating tape. The ends of the heater are anchored to ceramic standoff insulators. Power leads to the heater are copper braid. Voltage sensing leads are bare stranded copper wire. The two current leads and the two voltage sensing leads are fed through the calorimeter wall via individual ceramic hermetic seals. The leads continue on to the circuit box containing the gas output bridge circuits and go through a six-pin connector to the data acquisition rack. Pin connections for this connector are as shown in figure 3.2 .

\subsubsection{Main Calorimeter Shutter}

As mentioned in section 3.6.1, a shutter is used to seal the input aperture of the main calorimeter for all phases of a run except for that time corresponding to laser energy injection. It is 


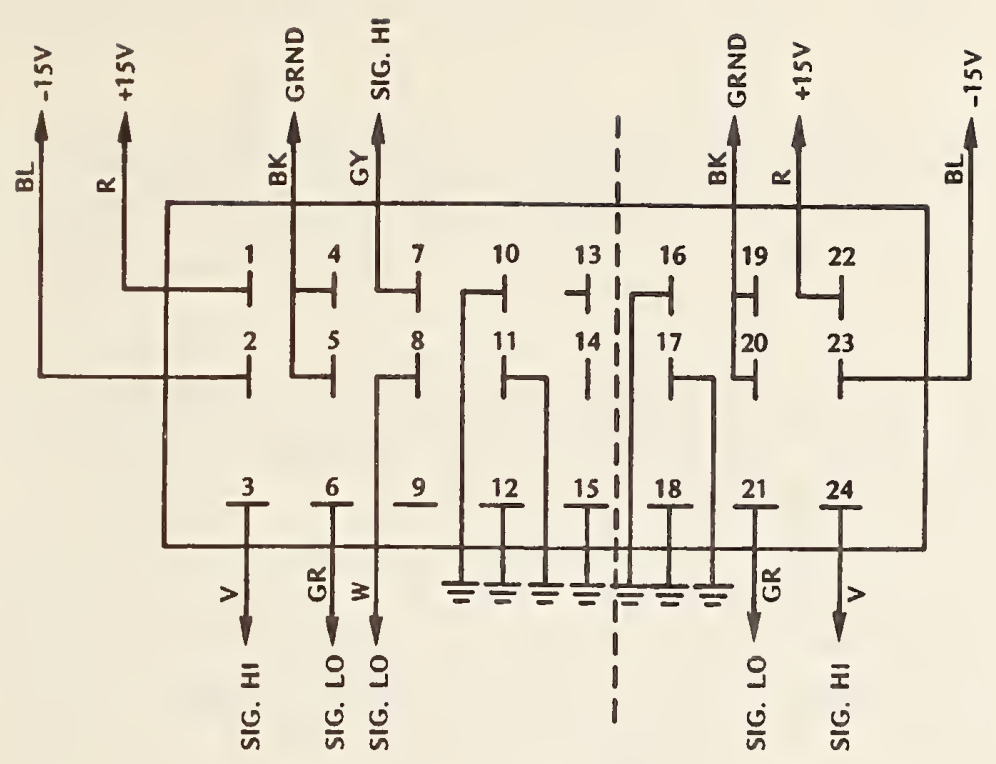

MASS FLOW/TEMP FLOW CONNECTIONS RTD CONNECTIONS

Figure 3-22. Wiring diagram for 24-pin connector on gas output circuits box.

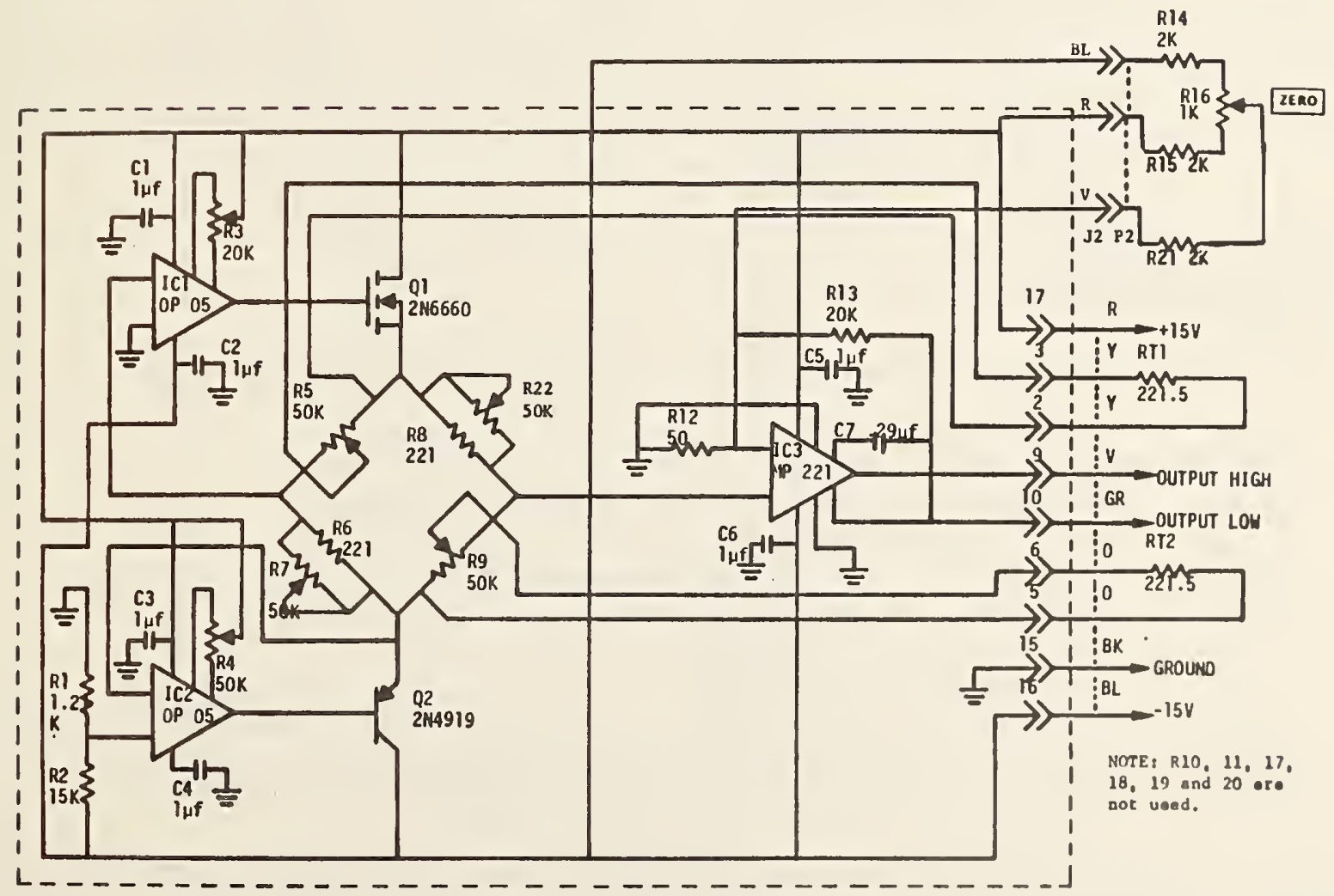

Figure 3-23. Schematic diagram for the bridge circuit for the main calorimeter RTD. 
essential that the seal be free from gas leaks as any loss of gas will ultimately result in an error in the measurement of injected energy. This is true for both electrical calibrations and laser measurements.

The shutter is in the form of a motor-driven trap door used in conjunction with a motor-driven latch for sealing purposes. The trap door is made of $6.25 \mathrm{~mm}$ aluminum and seals against a $6.25 \mathrm{~min}$ aluminum baseplate. An 0-ring is used to effect a gas tight seal. The 0-ring should be frequently checked for laser damage.

The latch consists of a rotating shaft with two arms which press down on the two corners opposite the hinged side of the trap door. A screw adjustment is provided on each arm to precisely set the amount of pressure needed for a gas-tight seal.

When closing, the trap door moves first and when its operation is completed the latch begins operation. This sequence is reversed when the shutter is opening. Miniature roller action switches sense when the trap door and latch reach the limits of their movement. Leads from the four switches and two motors all come out to a 25-pin connector which connects to a cable from the data acquisition rack where the controlling circuitry is located.

The shutter may be operated manually using pushbuttons labelled "OPEN," "CLOSE, " and "STOP" or it may be operated under computer control through scanner contacts. Momentary closure of scanner contact 30 opens the shutter while momentary closure of contact 31 closes the shutter.

Figure 3-24 is a schematic diagram of the control circuit for the calorimeter shutter. A six-pin connector, $\mathrm{Jl}$, on the chassis brings in $+10 \mathrm{~V} d \mathrm{dc}$ to operate the relays and a floating $5 \mathrm{~V} d c$ for powering the two motors. The polarity of this $5 \mathrm{~V} d c$ is reversible through the action of relay $K 5$ to control motor direction. The six-pin connector also brings in the OPEN and CLOSE signals from the scanner.

\subsection{Data Acquisition Rack}

\subsubsection{General Description}

The data acquisition rack contains equipment for performing the following tasks:

1. Controlling the sequence of events during electrical calibrations.

2. Controlling the sequence of events during laser energy measurements.

3. Accumulating, storing, and processing data from the various sensors in CLOP.

4. Measuring, recording, and processing the dc calibration voltage and current values.

5. Furnishing electrical power to all modules of CLOP.

6. Controlling electromechanical operations.

7. Maintaining the temperature of the input gas to the main calorimeter at a constant value.

8. Visually indicating the status of various critical elements of CLOP during runs.

The rack is $1.71 \mathrm{~m}(67.25 \mathrm{in}) \mathrm{high}$ by $0.61 \mathrm{~m}(24 \mathrm{in})$ deep. It has a front and rear opening, each $1.556 \mathrm{~m}$ (61.25 in) high in which may be mounted standard $48.2 \mathrm{~cm}$ (19 in) width panels. The rack is mounted on casters to permit easy movement. 


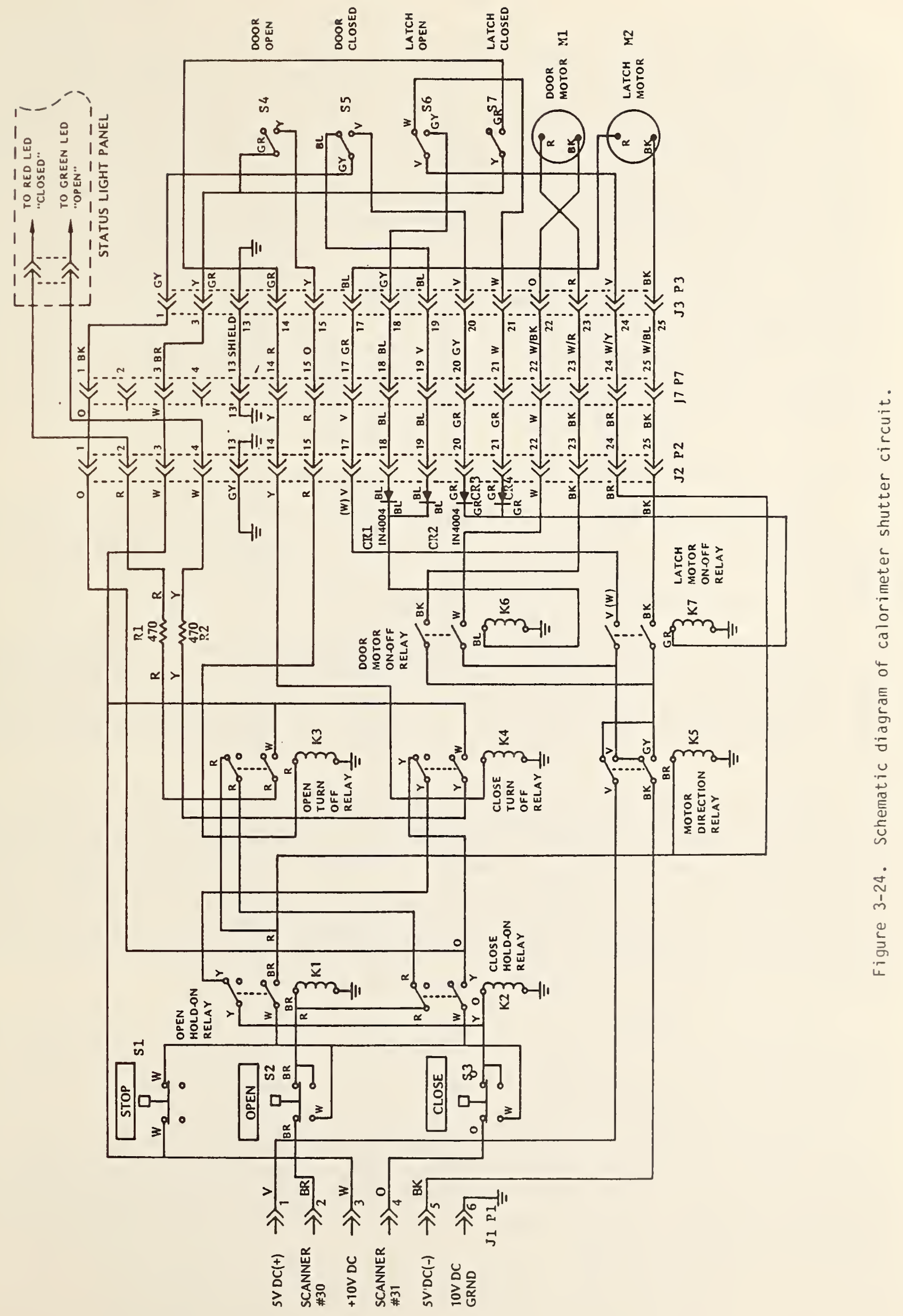


Figure $3-2 b$ is a front view drawing of the rack for System $H$ showing the positions of various pieces of equipment. The rack for System $T$, shown in figure 3-26, is quite similar except as noted below. Figure 3-27 is a rear view drawing showing the location of the outputs for the cables to CLOP and the ac power outlet locations. This section (3.7) will describe the various pieces of equipment in the data acquisition rack in the order of location in the rack, first the front from top to bottom and then the rear from top to bottom. There are two major differences in the computers which affect the data acquisition rack for each system. These are the large size of the System $T$ computer which prevents it from fitting into the rack and the fact that the System $H$ computer possesses an internal clock system for timing events while the System $T$ computer does not. The first difference means that System $T$ is located separately from the data acquisition rack. Its space is advantageously filled with the preheater control circuit which, in System $H$, is crowded onto the panel with the calibration power supply status circuit (see sections 3.7.10 and 3.7.13). The second difference requires a separate pacer (timing unit) for System $T$. This is a half-rack width instrument and is located next to the DVM, also a half-rack width instrument (see section 3.7.8).

\subsubsection{Main Power Switch Panel}

The main power switch panel is used to turn on and off the $115 \mathrm{~V}$ ac to the various units in the data acquisition rack. This is done with the white rocker switch on the front of the panel. Also mounted on the front of the panel is a neon pilot light and the RESET button of a $15 \mathrm{~A}$ circuit breaker. Figure 3-28 is a wiring diagram of the panel.

The panel uses a two wire (high and neutral) plus case ground system. Its input cord plugs into an outlet on the ac input panel (see section 3.7.11) and its output is a duplex outlet mounted on the back side of the panel. A seven-plug outlet strip which is mounted on the back of the rack is plugged into this duplex outlet. The various pieces of equipment in the rack plug into the outlet strip.

\subsubsection{Scanner}

The scanner is used to connect the output of the various sensors to the digital voltmeter (DVM) and to furnish signals for controlling various operations. This instrument has two plug-in units to perform these functions. A 20-contact duodecade unit is used to switch the sensor outputs. A 10contact actuator unit is used to control the operations. Full information on the contact arrangement of these plug ins is given the manufacturer's instruction book. Table 3.2 is a list of the instruments connected to the scanner channels. The sensors are connected to channels 00 through 14 and the operations are controlled by channels 30 through 37 as described in table 3.2.

The scanner is operated with the IEEE 488 bus. Its address is 9 . Since for the System $\mathrm{H}$ computer the general address of the bus is 700 , an example of the command to the scanner to turn on channels 7 and 32 and turn off all others is OUTPUT $7 \emptyset 9$ USING "K"; "3, 77,32 " for System H. For System T this command is PRINTO9: "3,07,32".

The expression USING " $K$ " is required in the System $H$ command to have the duodecade function correctly. The " 3 " in the command opens all contacts in the 30 decade. The " 07 " closes contacts 7 in the duodecade and by the nature of this plug-in all others are opened. Finally, the " 32 " closes these contacts. If contacts 32 had been al ready closed they would have remained closed continuously even though the " 3 " command was given. 


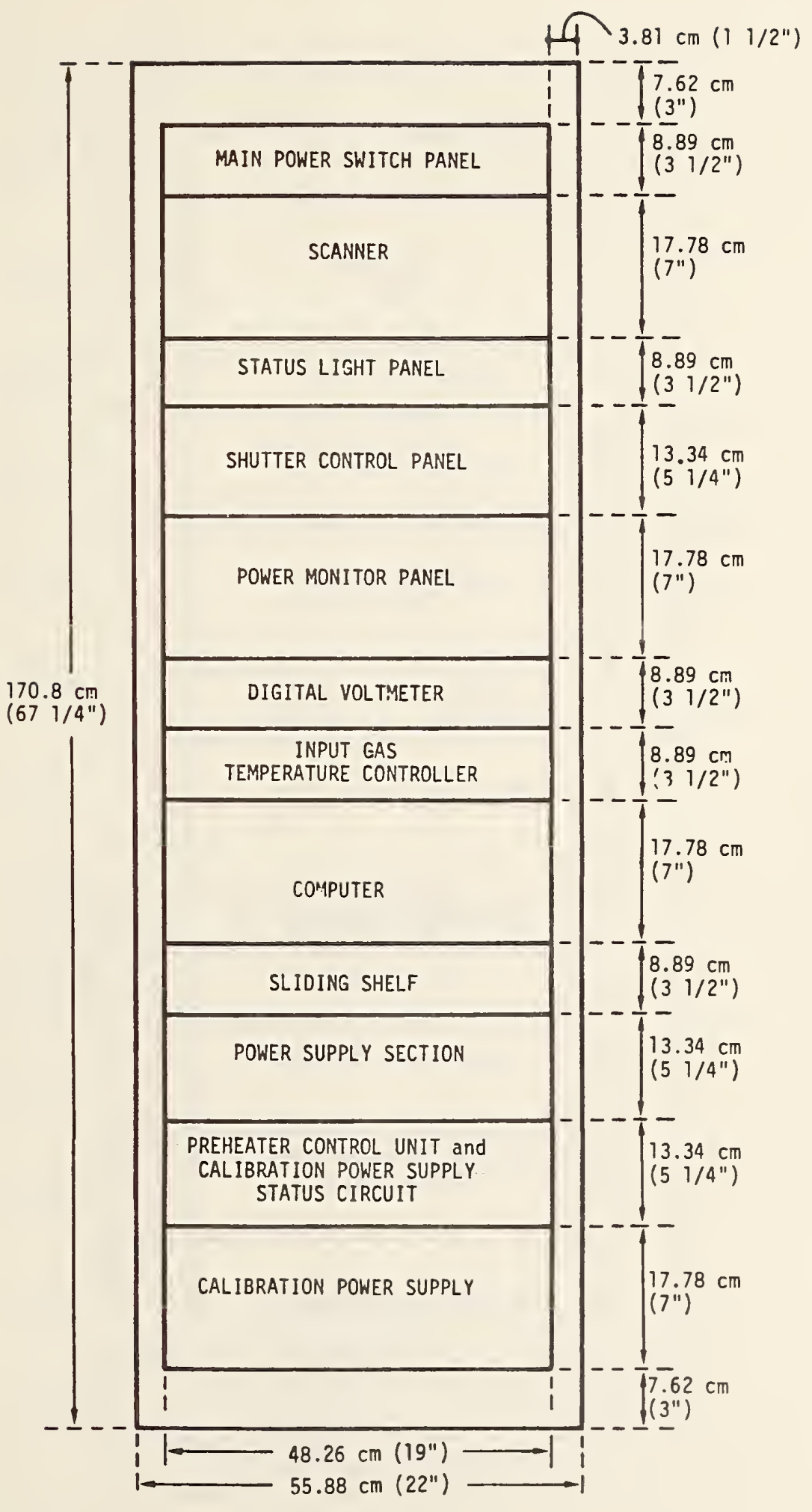

Figure 3-25. Front view of the data acquisition rack for System H. 


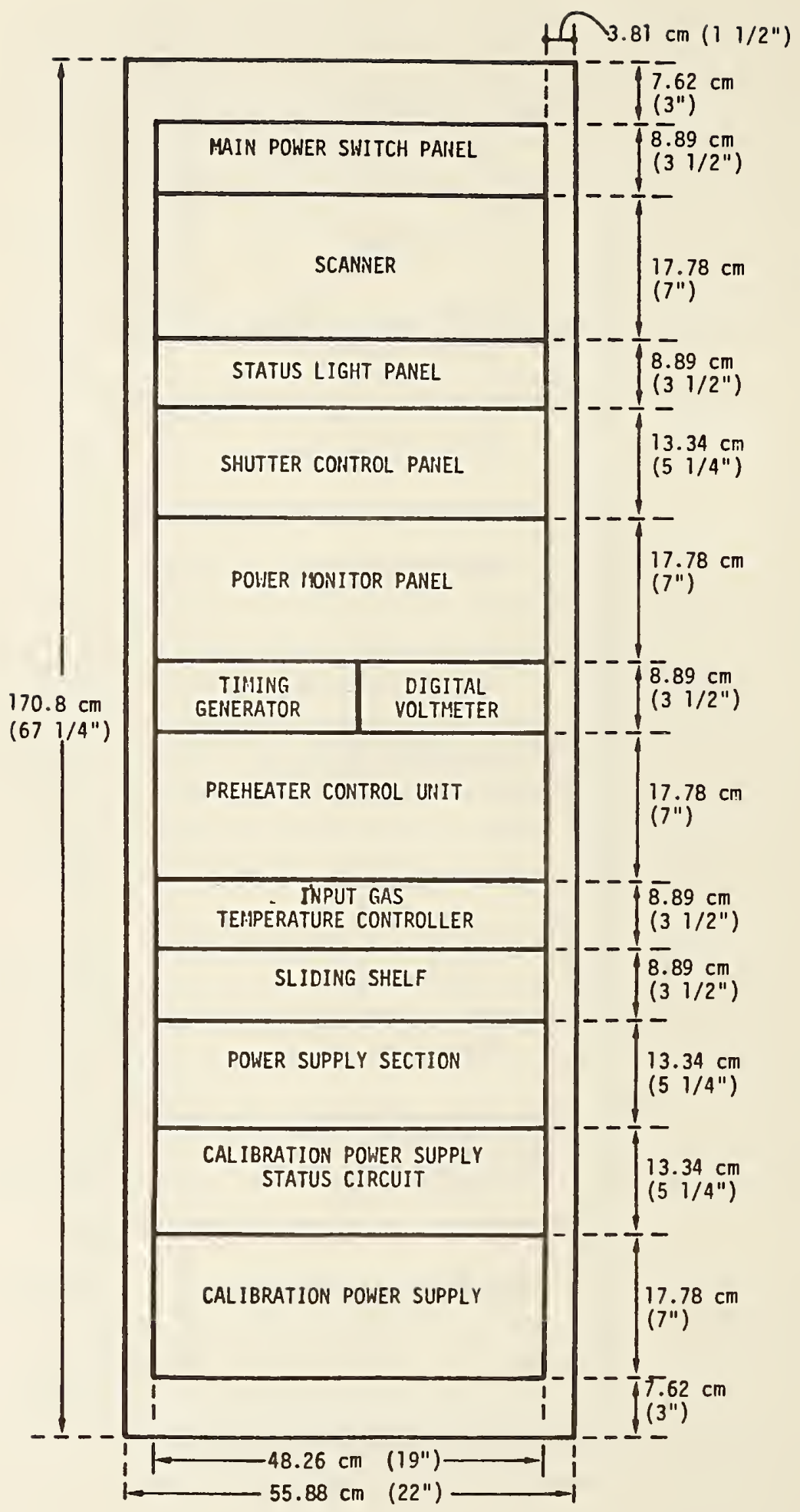

Figure 3-26. Front view of the data acquisition rack for System T. 


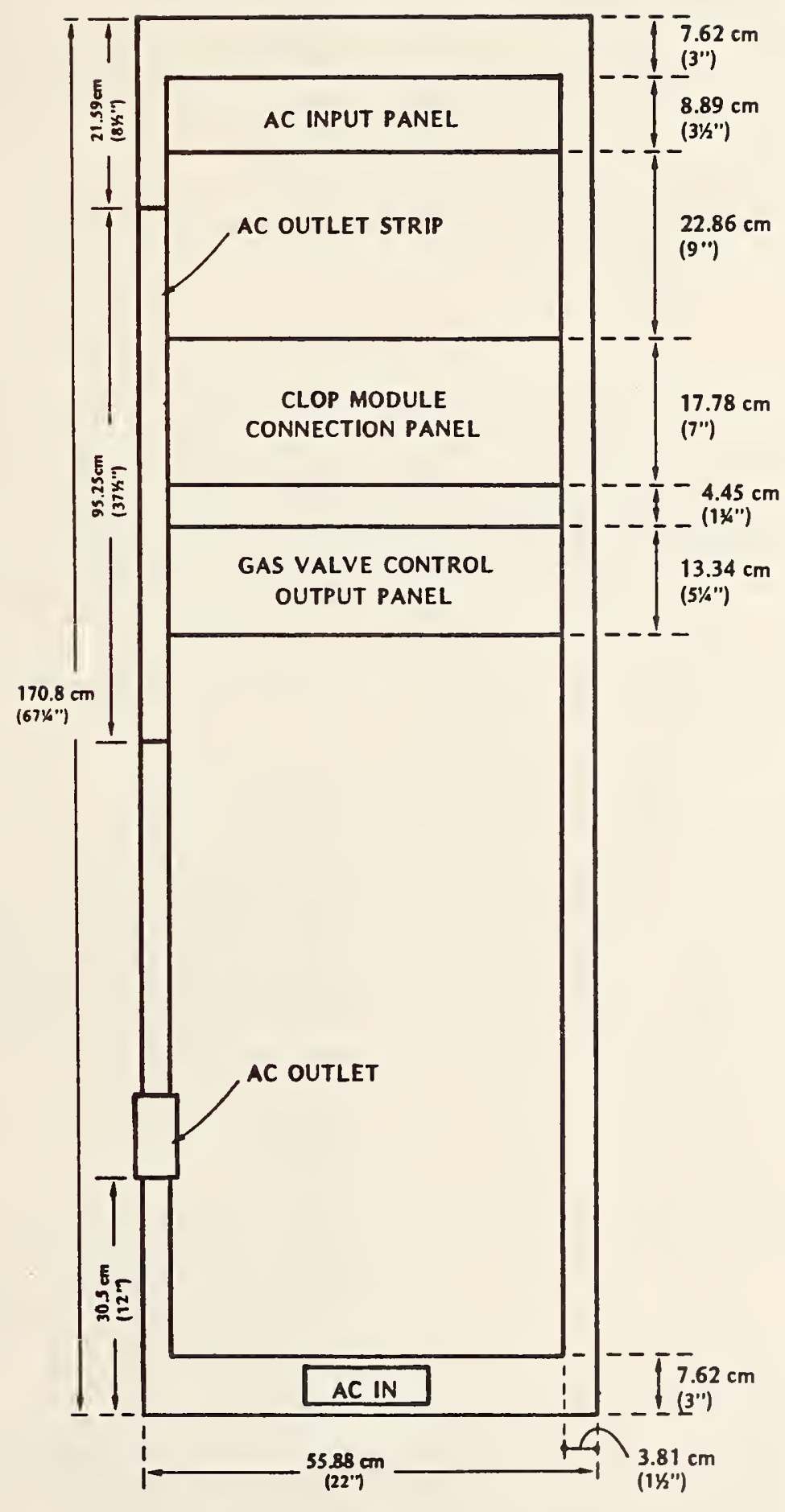

Figure 3-27. Rear view of the data acquisition racks for both systems. 


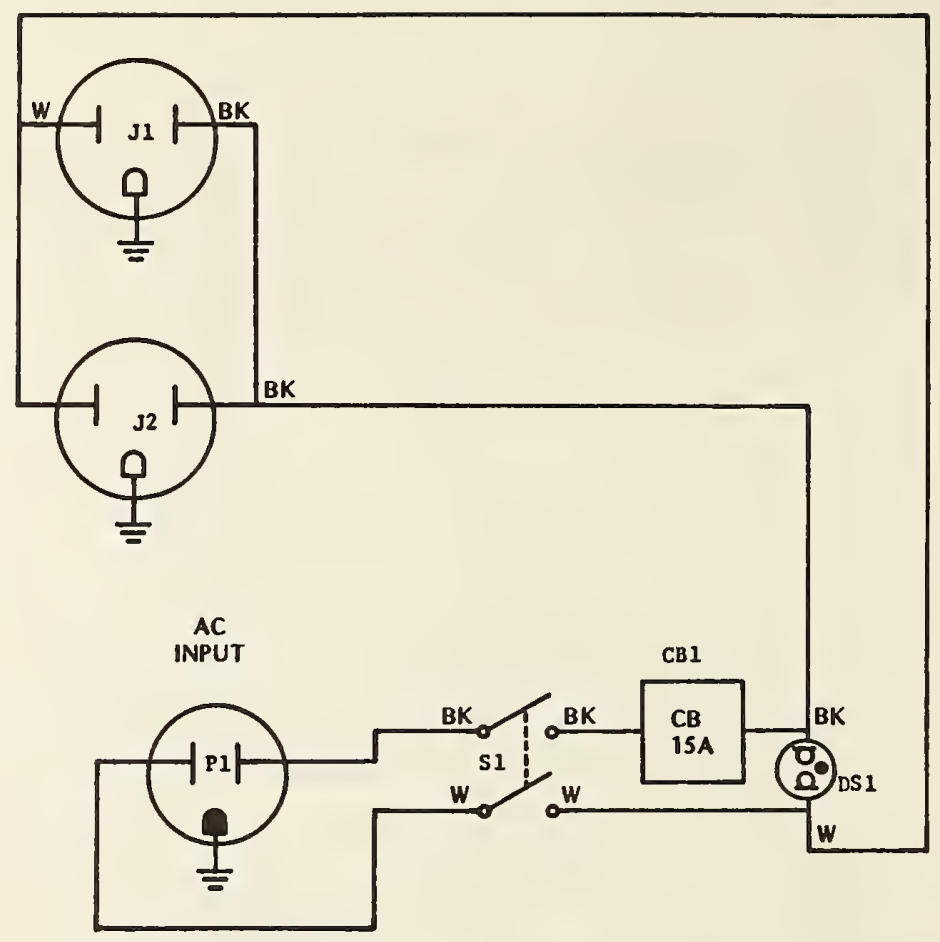

Figure 3-28. Wiring diagram of the main power switch panel.

Table 3.2. Scanner channel connection.

\begin{tabular}{ll}
\hline Channel & Sensor or Operation \\
\hline 00 & Main calorimeter RTD \\
01 & Main calorimeter output mass flow \\
02 & Main calorimeter output temperature \\
03 & Main calorimeter input mass flow \\
04 & Main calorimeter input temperature \\
05 & Mirror reflector \\
06 & Separation tube RTD \\
07 & BSM RTD \\
08 & OSM RTD \\
09 & Extension tube RTD \\
10 & Electrical calibration current \\
11 & Electrical calibration voltage \\
12 & Electrical calibration voltage $\div 10$ \\
13 & Electrical calibration voltage $\div 20$ \\
14 & Low voltage dc supplies \\
$15-19$ & Not used \\
30 & Main calorimeter shutter OPEN \\
31 & Main calorimeter shutter CLOSE \\
32 & OSM/BSM shutter OPEN \\
33 & OSM/BSM shutter CLOSE \\
34 & Gas valve \#1 OPEN \\
35 & Gas valve \#2 OPEN \\
36 & Gas valve \#3 OPEN \\
37 & Gas valve \#4 OPEN \\
$38-39$ & Not used \\
\hline
\end{tabular}


Table 3.3. Status light color indications.

\begin{tabular}{lll}
\hline \multicolumn{1}{c}{ Light } & \multicolumn{1}{c}{ Red } & Green \\
\hline Incandescents & no-go for laser shot & go for laser shot \\
Calorimeter & shutter closed & shutter open \\
BSM & shutter closed & shutter open \\
Calib. power supply units & ac off to one or both & ac on to both \\
Gas flow & gas not flowing & gas flowing \\
$+15 \mathrm{~V}$ & off & on \\
$-15 \mathrm{~V}$ & off & on \\
(spare) & not connected & not connected \\
\hline
\end{tabular}

\subsubsection{Status Light Panel}

The status light panel is an $8.89 \mathrm{~cm}$ ( $31 / 2$ in) high panel containing six dual-color LEDs plus one spare in System $H$ and seven red-green pairs in System $T$ that give a visual indication of the status of certain CLOP elements. Also on the front of the panel are red and green incandescent indicator lights that give the overall status of the run and a switch to set the proper logic for either a laser run or combination run. When the green incandescent light is on CLOP is ready for a laser shot. Figure 3-29 is a schematic wiring diagram of this panel for system $H$; figure 3-30 is for System $T$.

The LEDs enit red and green colors. Table 3.3 explains what the colors indicate for the different CLOP elements.

\subsubsection{Shutter Control Panel}

This panel is $13.3 \mathrm{~cm}$ (5.25 in) high and contains two chassis--one for the OSM/BSM shutter control circuit and the other for the main calorimeter shutter-control circuit. The front of the panel contains push buttons to OPEN, CLOSE, and STOP each shutter. A description of the OSM/BSM shutter circuit and operation is given in section 3.3.4. The description for the main calorimeter shutter circuit and operation is in section 3.6.4.

\subsubsection{Power Monitor Panel}

The power monitor panel is $17.8 \mathrm{~cm}$ (7 in) high. It serves two functions, which are (1) provide a means of measuring the low voltage dc supply voltages and (2) provide a means of measuring the dc voltage and current used in electrical calibrations.

On the front of the panel is the shaft of a five-position, double-pole rotary switch. The various low-voltage dc supply voltages are input to this switch via a nine-pin connector. The voltage selected is output through pins 1 and 2 of a four-pin connector, goes to contacts 14 on the scanner and is eventually measured by the digital voltmeter (DVM). Figure 3-31 is a schematic wiring diagram of the switching circuit. The position marked $-5 V$ measures the floating output supply that furnishes the reversible polarity power for the shutter motors. The other voltages are all referenced to ground potential.

The second module on this panel measures the dc voltage and current supplied during an electrical calibration. Figure 3-32 is a schematic diagram of the circuit. Input power from the calibration power supply (described in section 3.7.14) is furnished through pins $12(+)$ and 10 (ground) of 


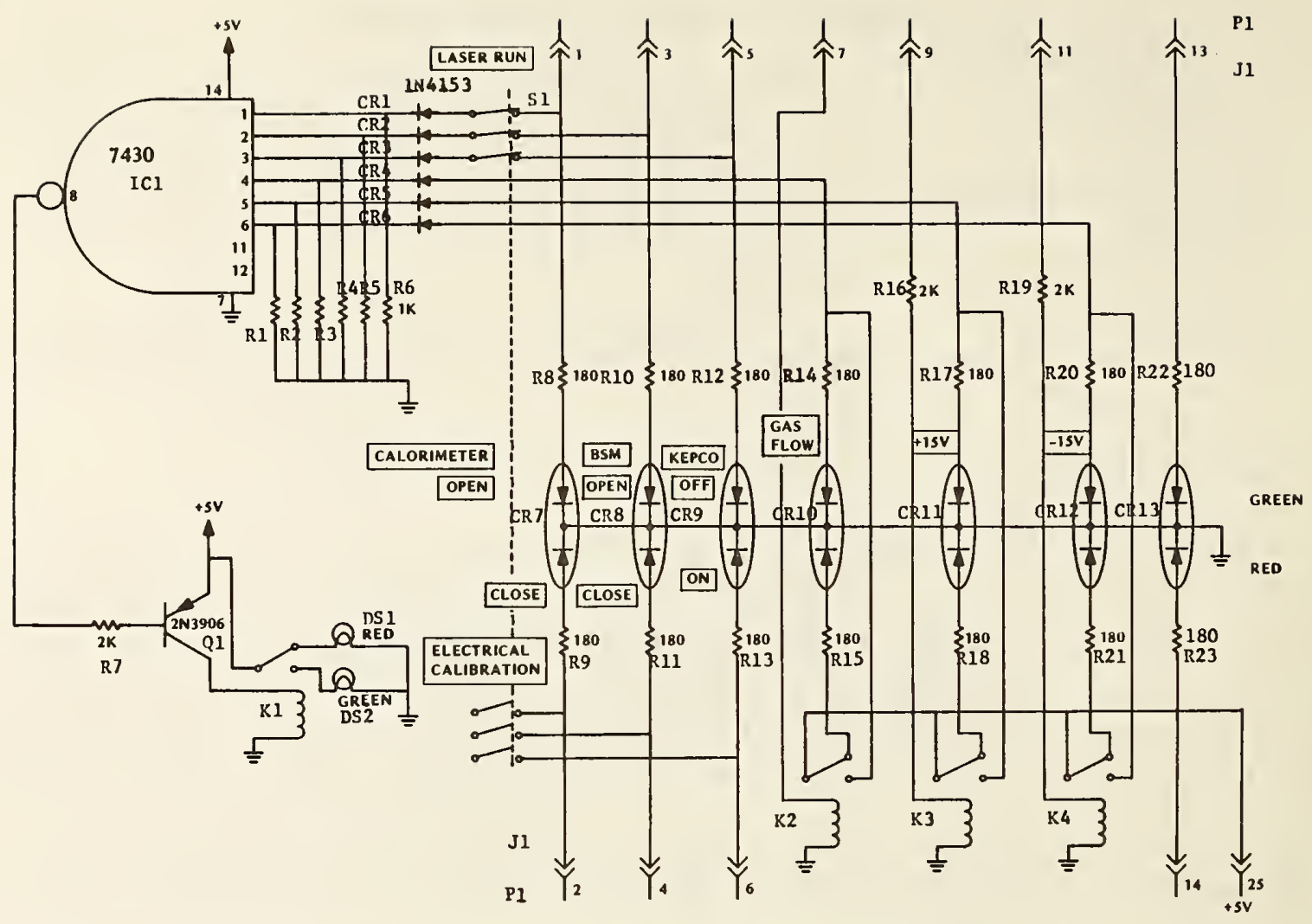

Figure 3-29. Schematic wiring diagram of the status light panel (System H).

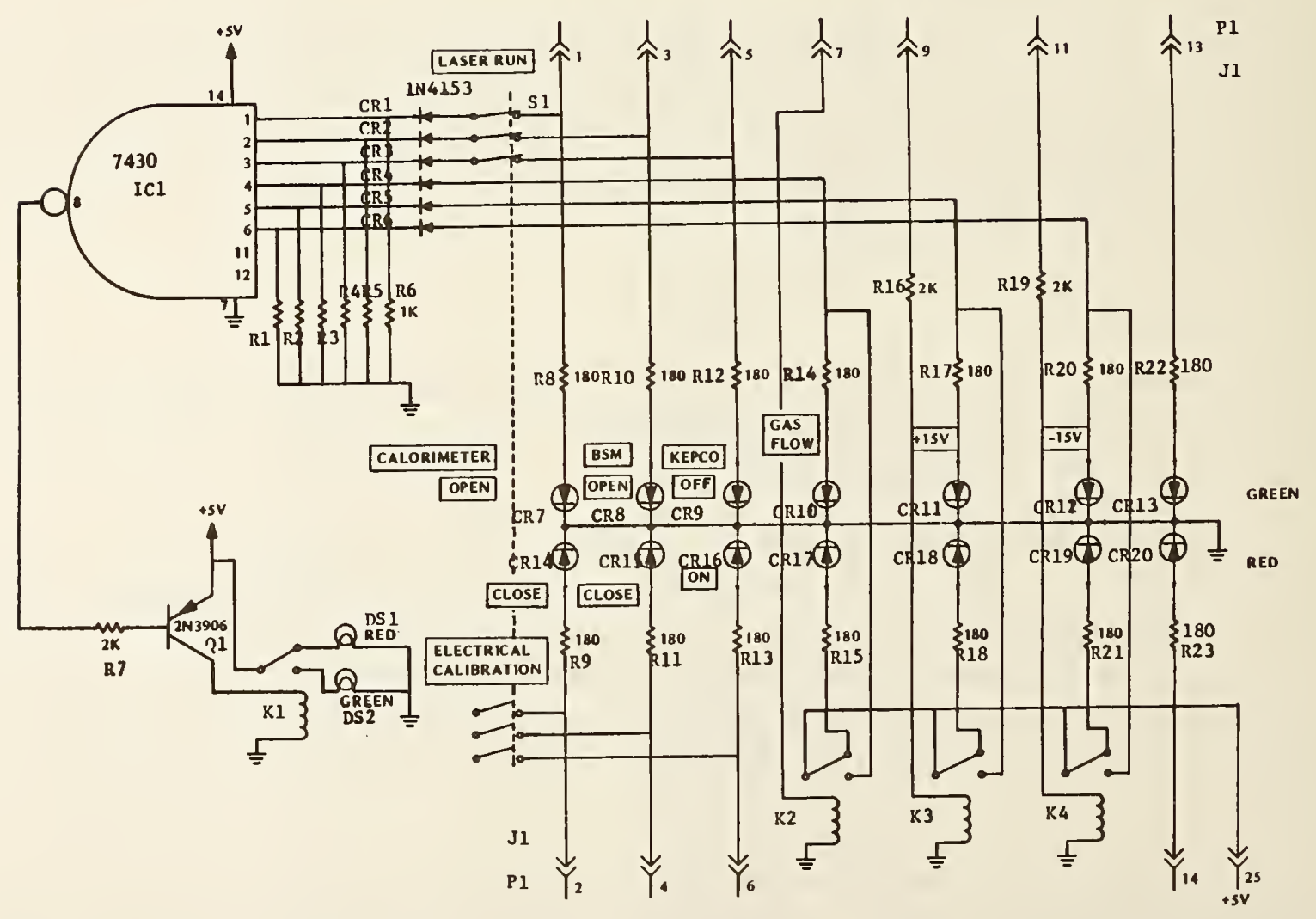

Figure 3-30. Schematic wiring diagram of the status light panel (System T). 


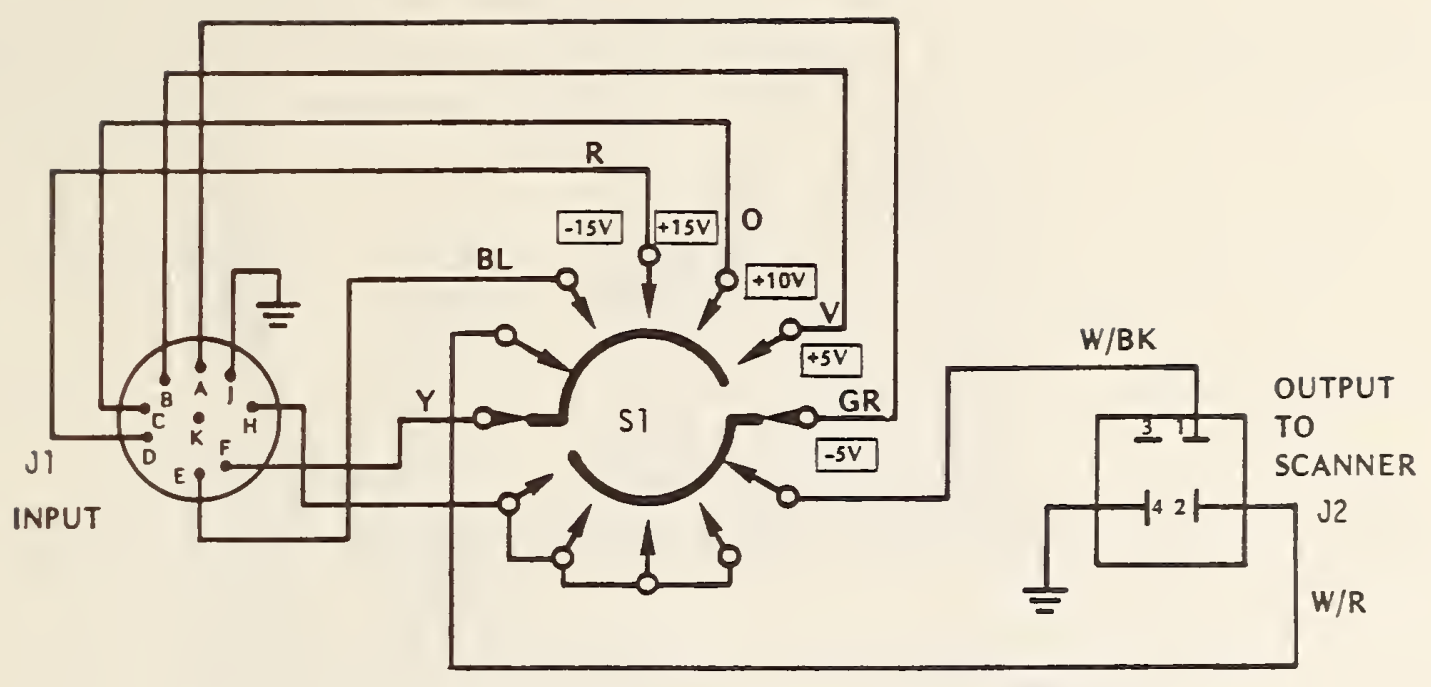

Figure 3-31. Schematic wiring diagram of the switching circuit for measuring low dc voltage.

connector P $406 \mathrm{DB}$. Voltage sensing leads from the power supply come in through pins 9 and 11 . Power output is through pins $12(+)$ and $10(10 \mathrm{w})$ of connector S $406 \mathrm{DB}$. Voltage across the load is brought in through pins $9(+)$ and $11(-)$ to the divider chain formed by $R 4$ and $R 5$.

The voltage across the total divider formed by $R 4$ and $R 5$ is equal to the voltage across the calibration heater. The wiper on $R 4$ is set to 0.1 times the voltage; the wiper on $R 5$ is set to 0.05 times the voltage. Output to the scanner (see table 3.2) and DVM is through the 25-pin connector.

If an adjustable precision voltage source is not available, the following can be used to set the divider chain, R4-R5.

1. Set the calibration power supply so the DVM reads approximately $+1.99 \mathrm{~V}$ on the $10 \mathrm{~V}$ range of the DVM when the scanner is on channel 11.

2. Switch the scanner to channel 12 and the DVM to the $1 \mathrm{~V}$ range.

3. Adjust R4 so the UVM reads the same as the previous reading; e.g., +1.990. Tighten the locking nut on the shaft of $R 4$.

4. Switch the scanner to channel 13 and adjust $R 5$ to read one half of the previous reading; e.g., +0.995. Tighten the locking nut on the shaft of R5.

Generally speaking, no measurements need be done on channel 13 as the calibration power supply does not ordinarily put out more than $100 \mathrm{~V}$.

\subsubsection{Digital Voltmeter}

The digital voltmeter (DVM) is described in the manufacturer's instruction book. It has five functions which are programmable through front panel pushbuttons and the IEEE 488 bus. These are:

1. Voltage range,

2. Trigger mode,

3. Trigger delay,

4. Number of readings taken per input trigger, and

5. SRQ enable/disable.

The operation of CLOP utilizes only the first three functions. The burst mode of operation and the SRQ are not used. 


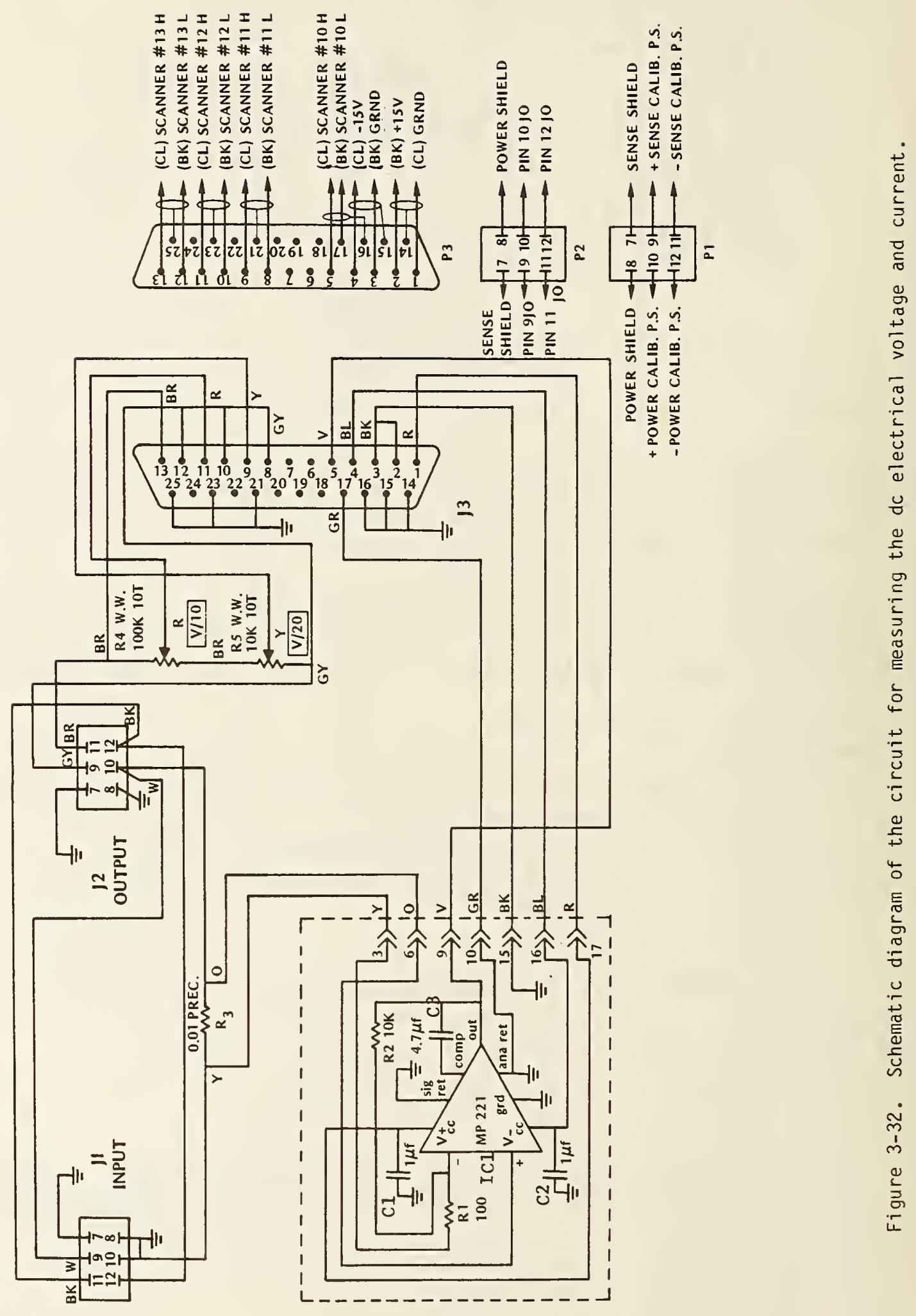


When using the pushbuttons, the voltage range and the trigger mode are set by merely pushing the desired button; e.g., $0.1 \mathrm{~V}, 1.0 \mathrm{~V}, 10 \mathrm{~V}$, INT, EXT, HOLD/MAN. To set a trigger delay; e.g., 50 ms, the following sequence of buttons are pushed:
1. DELAY
2. (decimal point)
3. 0
4. 5
5. SET

Note the decimal point is the first piece of data entered. This is required by the instrument to recognize the "DELAY" function. When the DVM is running in the internal trigger mode, the trigger delay function can be used to slow down the number of readings being taken. In the above case there would be 20 readings per second ( $50 \mathrm{~ms}$ period). In the external trigger and manual trigger modes, the trigger delay regulates the time lapse between the trigger command and when the reading is taken.

When using the IEEE 488 bus the DVM is addressed as device 24 . Table 3.4 is a list of the commands that the CLOP programs use.

Thus, a command on System $\mathrm{H}$ to tell the DVM to take a reading on the $1 \mathrm{~V}$ scale $5 \mathrm{~ms}$ after an external trigger signal is received is OUTPUT 724; "R2T2D. $095 \mathrm{~S} "$. On the System $T$ it is PRINTO24: "R2T20. $005 \mathrm{~S} "$.

Two methods may be used to take readings under computer control. The first method is used when readings are not to be taken very rapidly. The HOLD/MANUAL command, T3, is simply sent to the DVM each time a reading is to be taken. For taking 10 or 12 readings in less than $1 \mathrm{~s}$, the external trigger mode, T2, is used with a $5 \mathrm{~ms}$ delay. The external trigger is furnished by the scanner everytime it switches channels over a BNC cable from the scanner sync jack to the DVM external trigger input jack. The $5 \mathrm{~ms}$ delay is required to allow time for the scanner contacts to close and voltage transients to decay before making the DVM measurement.

Table 3.4.* IEEE 488 commands used by the DVM.

\begin{tabular}{|c|c|}
\hline ASCII Character & Description \\
\hline D & Delay \\
\hline$S$ & Store \\
\hline $\mathrm{R}$ & Range \\
\hline 1 & $0.1 \mathrm{~V}$ \\
\hline 2 & $1 \mathrm{~V}$ \\
\hline 3 & $10 \mathrm{~V}$ \\
\hline$T$ & Trigger \\
\hline 1 & Internal \\
\hline 2 & External \\
\hline 3 & Hold/Man \\
\hline
\end{tabular}

*Condensed from table 3.4, page 3-6, of manufacturer's operating manual. 
The rear-input, triaxial jack on the DVM is used since the instrument is mounted in a rack. This jack is connected via a triaxial cable to the common contacts of the duodecade plug-in of the scanner. The command to transfer the DVM reading to the memory in the System H computer is ENTER 724; V1. For System $T$ the command is INPUT 024:V1. In this example the reading is stored as the variable V1.

\subsubsection{Pacer Unit (System T Only)}

The pacer unit is located to the left of the DVM in System T. It is used to furnish a train of pulses at precisely equal time intervals to form a time base for CLOP to operate by. This unit tells the System $\mathrm{T}$ computer when to order certain operations be done. On the System $\mathrm{H}$ computer there are three internal programmable timers which obviate the need for a pacer in that system.

The pacer is programmable over the IEEE 488 bus and sends pulses to the $4052 \mathrm{~A}$ which counts them to keep track of the time that has elapsed since the run began. The pulses are first at $3 \mathrm{~s}$ intervals during the monitor period but change to a $1 \mathrm{~s}$ interval when data acquisition begins. The computer takes this into account when computing the time.

A typical command to the pacer is

PRINT O19: "P1פøE4SR"

where the $P$ signifies the pacer mode of operation (as opposed to the timer mode), 100E4 is the period in microseconds $\left(1 \times 10^{6}\right.$ or $\left.1 \mathrm{~s}\right)$, $S$ enables the SRQ on the unit, and $R$ either starts the pulse train or resets the internal pulse counter in the unit.

\subsubsection{Input Gas Temperature Controller}

The Input Gas Temperature Controller is used to supply a proportional signal that will maintain the temperature of the input gas to the main calorimeter at a constant value and cancel out the tendency of the gas to cool because of its expansion from the pressurized condition in the cylinder. The proportional correction signal is in the form of a variable duration pulse having a 1 pps repetition rate. This correction signal is furnished to the Preheater Control Unit (see section 3.7.13) to switch on and off the ac power to the preheater and thus control the temperature of the gas entering CLOP.

The correction signal is derived from the output voltage of the temperature bridge circuit. This voltage, after entering the data acquisition rack through jack $5 \mathrm{~B}$ of the CLOP Module Connection Panel (see section 3.7 .16 ) is routed to the input gas temperature controller chassis. A schematic diagram of the circuitry in this unit is shown in figure $3-33$.

In this unit the signal voltage is first sent to an isolation amplifier board with two outputs. One output leaves this chassis and goes to scanner contacts $\emptyset 4$ for measurement by the DVM. The other output goes to another PC board containing the proportional signal generator. On this board the temperature in voltage is connected to the inverting input of a differential amplifier. The non-inverting input of the differential amplifier is connected to an adjustable reference voltage. This reference voltage first is set so that the controller is just turned off while the gas is not flowing; i.e., the controller is not pulsing as indicated by the extinguished LED. When the gas starts flowing (and cooling) the balance is upset and the controller starts generating a correction signal. The 


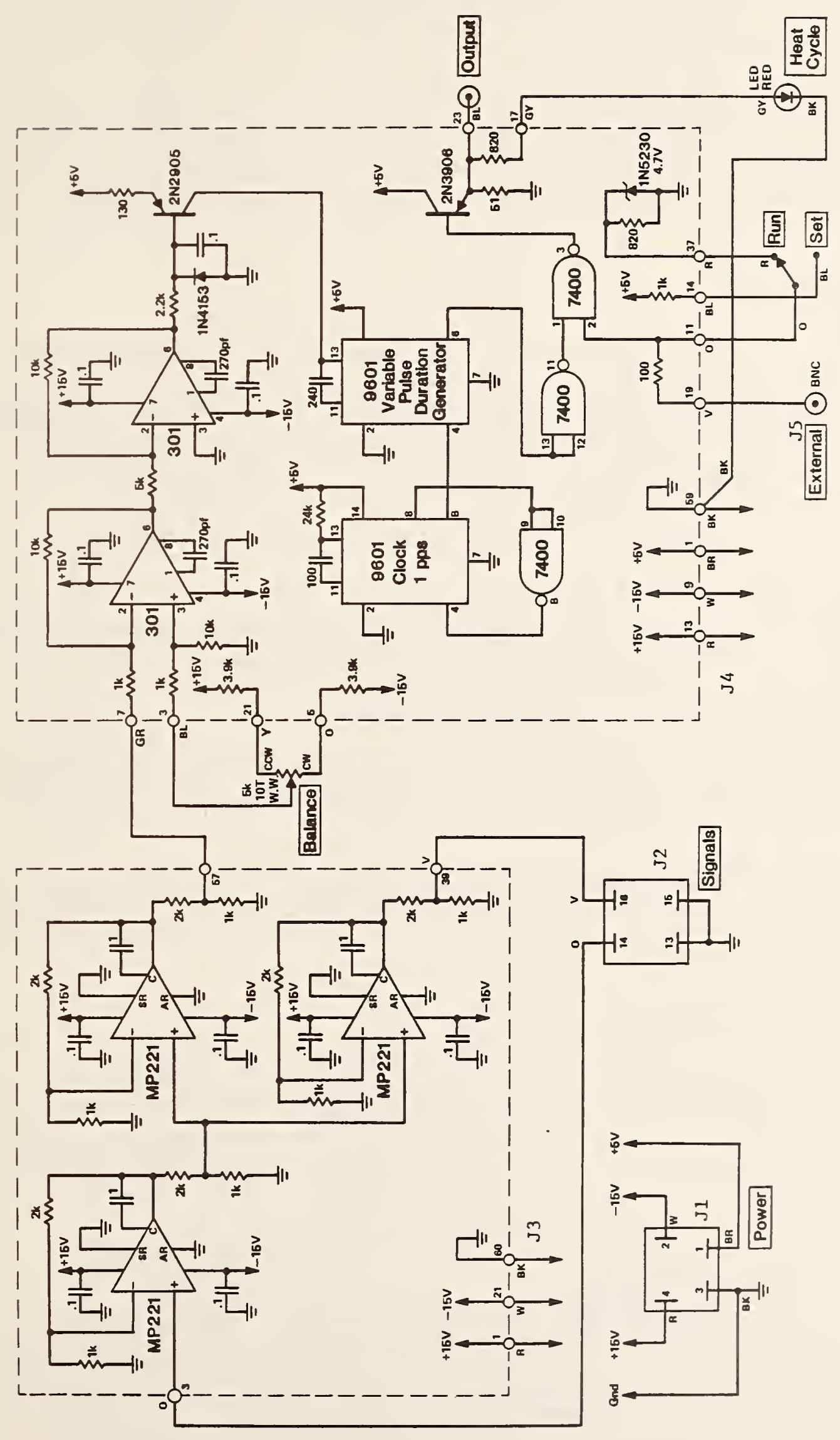

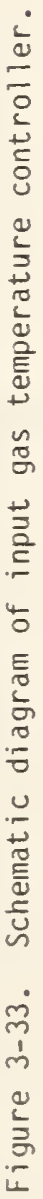


reference voltage is now reset to produce a temperature in reading called for in the program. If the gas becomes too warm the correction signal disappears until the natural cooling of the gas returns conditions to the balanced state.

When setting the balance conditions a RUN-SET switch is put in the SET position which turns on a gate and allows the correction signal to appear on the output. During a run the switch is put in the RUN position so that a gating signal from the Gas Valve Control Output panel (see section 3.7.17) turns on the correction signal only while gas is flowing. This gating signal enters via the BNC connector labelled EXTERNAL.

\subsubsection{Computer Section}

The next $26.5 \mathrm{~cm}$ (10.5 in) below the Input Gas Temperature Controller in System $\mathrm{H}$ only is used to nold the computer. The instrument is attached to a sliding shelf in the rack and may be pulled out for convenient use and pushed inside the rack for safe storage. The computer is described as to its specifications and programming in the manufacturer's instruction manual. No attempt will be made to go into great detail about its operation but certain useful facts are given below.

The computer is furnished with an IEEE 488 bus output and an RS232 output.

The computer has 32 kbytes of memory of which space for 30288 bytes is available. Programs requiring more space than this are split into smaller programs and stored on tape as separate files. When run, they are chained in the proper sequence to perform the complete program.

The programs are described in section 4 of this manual.

The System $T$ computer is too large to fit into the data acquisition rack. Hence, it is located externally to the rack and its space in the rack is filled by the preheater control circuit (see section 3.7 .13$)$.

This computer has available 54624 bytes of memory eliminating the need for chaining any of the programs described in section 4. It, too, has IEEE 488 and RS 232 interfaces and a four-slot ROM pack for external ROMs.

\subsubsection{Power Supply Section}

The power supply section is contained on a shelf behind a $13.3 \mathrm{~cm}(5.25 \mathrm{in}$ ) panel just below the computer. This section contains the power supplies that furnish the low voltage dc for powering the various sensor circuits and the shutter motors. It also contains an interfacing unit between the IEEE 488 bus and the calibration power supply (see section 3.7.13). These two parts are described in the following subsections.

\subsubsection{Low Voltage de Supplies}

One $\pm 15 \vee d c$ dual output power supply and three $5 \mathrm{Vdc}$ supplies are used to fill all the lowvoltage dc requirements of CLOP. Two of the $5 \mathrm{~V}$ supplies are connected in series to furnish $10 \mathrm{~V}$ dc as well as $5 \mathrm{~V} \mathrm{dc}$. Table 3.5 gives useful information about the power supply voltages. Figure 3-34 is a schematic wiring diagram of the low-voltage dc power supply section. 
Table 3.5. Low voltage dc supply summary.

\begin{tabular}{clcl}
\hline Designation* & Voltage & Current & Remarks \\
\hline A1 & $+5 \mathrm{~V}$ & $3 \mathrm{~A}$ & \\
$\mathrm{~A} 2$ & $+10 \mathrm{~V}$ & $3 \mathrm{~A}$ & $\begin{array}{l}\text { A second } 5 \mathrm{~V}, 3 \mathrm{~A} \text { power supply connected } \\
\text { in series with Al }\end{array}$ \\
A3 & + or $-5 \mathrm{~V}$ & $3 \mathrm{~A}$ & Output floating; polarity reversible \\
A4 & $\pm 15 \mathrm{~V}$ & $3 \mathrm{~A}$ & \\
\hline
\end{tabular}

* Refer to figure 3-34.

\subsubsection{Calibration Power Supply Interface Unit}

The calibration power supply interface unit is a commercially available unit made by the manufacturer of the calibration power supply. It is merely a $D$ to $A$ converter which receives a digital command on the IEEE 488 bus and puts out dc voltages specified by the command which are used to program the calibration power supply to the desired output voltage and current. Full particulars of the interface unit are given in the manufacturer's instruction book. Certain useful information is given in this section.

The unit has two output channels. Channel 1 is used to set the voltage limit and channel 2 sets the current limit. Only one channel need be set if the other needs no changing. For example, if the calibration power supply is running in the voltage limiting mode at $100 \mathrm{~V}$ and $6 \mathrm{~A}$ and the interface unit is set to $100 \mathrm{~V}$ limit and a $6 \mathrm{~A}$ limit, only a new voltage limit need be set on the interface unit to reduce the power supply output to a lower value, e.g., $50 \mathrm{~V}$.

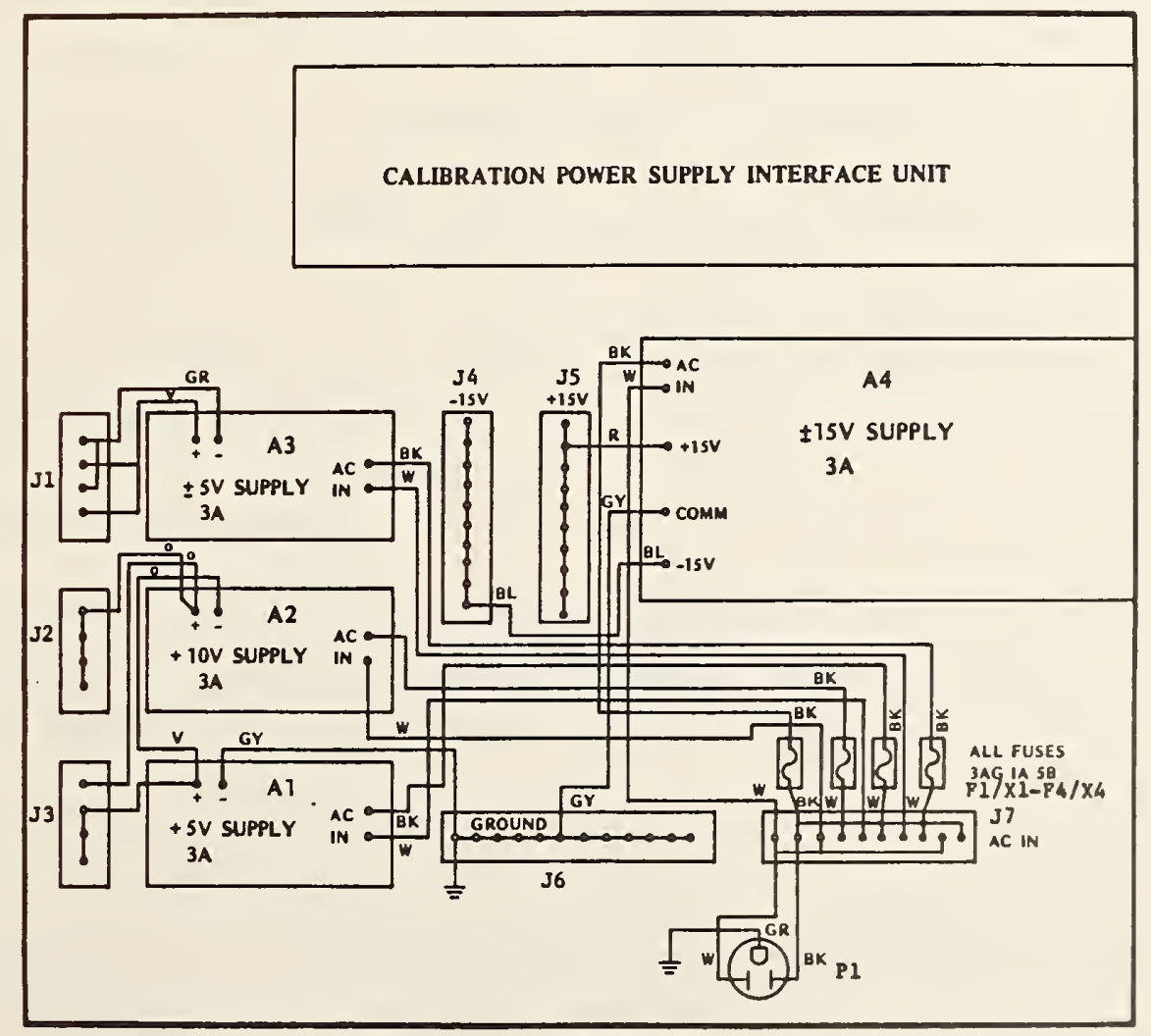

Figure 3-34. Wiring diagram of low voltage dc power supply section. 
Each channel has two output ranges, 0 to $+1 V$ and 0 to $+10 \vee$ which correspond to power supply output limits of $0 \mathrm{~V}$ to $10 \mathrm{~V}(0 \mathrm{~A}$ to $+10 \mathrm{~A})$ and $0 \mathrm{~V}$ to $+100 \mathrm{~V}$, respectively. In addition, the interface unit can set low and high negative voltage and current limits but these are not used with CLOP since the calibration power supply has a unipolar output with the negative side grounded.

The desired voltage and current limit are set with three-character hexadecimal words, $\emptyset \emptyset$ through FFF. Thus, the incremental steps of voltage and current are 1 part in 4096, or approximately 0.024 percent. In terms of calibration power supply output, this is $2.4 \mathrm{mV}$ resolution up to $10 \mathrm{~V}$ and $24 \mathrm{mV}$ from $10 \mathrm{~V}$ to $100 \mathrm{~V}$. Appendix $A$ is included for convenience as a review of the methods for converting back and forth between the decimal and hexadecimal based number systems.

The address of the interface unit on the IEEE 488 bus is device 6 . A five-character command is used to set the desired limit on the calibration power supply. The command is of the form (reading from top to bottom):

\author{
Channel 1 = voltage, 2 = current \\ Range $\quad 0=$ high positive, 2 = low positive \\ Magnitude $\emptyset \emptyset \emptyset$ through FFF
}

Thus the command to set a $50 \mathrm{~V}, 4$ A limit on the power supply is OUTPUT 7ø6; "1Ø7FF"; "22666" on the System H and PRINT@6:"1ø7FF";"22666" for the System T.

The unit has been modified to permit sampling of the ac input power as shown in figure 4-5 of the manufacturer's instruction book. This sampled ac goes to the calibration power supply status circuit (see section 3.7 .12 ) to sense whether the instrument is on or of.

\title{
3.7.12 Calibration Power Supply Status Circuit
}

This circuit is used to sense if both the calibration power supply and the calibration power supply interface unit are turned on or if either one is turned off. It then applies $5 \mathrm{~V}$ dc to either pin 5 or 6 of the status light panel which lights the color indicating the existing condition.

Figure 3-35 is a schematic wiring diagram of circuit. The two relays, K1 and K2, are activated by the $115 \mathrm{~V}$ ac from the interface unit and the power supply, respectively. These voltages are fed into the chassis through two recessed male receptacles. In the interface unit the ac is monitored on the input voltage selector board (see fig. 5-4 in the instruction book). In the calibration power supply the ac is sampled on terminals 1 and 5 of T201 (see fig. 6-3 in instruction book).

The $5 \mathrm{~V}$ dc for the status light panel comes in through pin $A$ of a five-pin connector and out on either pin $D$ or $E$ depending on the condition of $K 1$ and $K 2$. The contacts of $K 1$ and $K 2$ are wired such that they perform a logical AND function for the "ON" condition of the power supply and interface unit and a logical OR for the "OFF" condition.

\subsubsection{Preheater Control Circuit}

The preheater control circuit is contained on the same panel as the calibration power supply status circuit for System $H$ and is located separately for System $T$. It is used to apply ac power to 


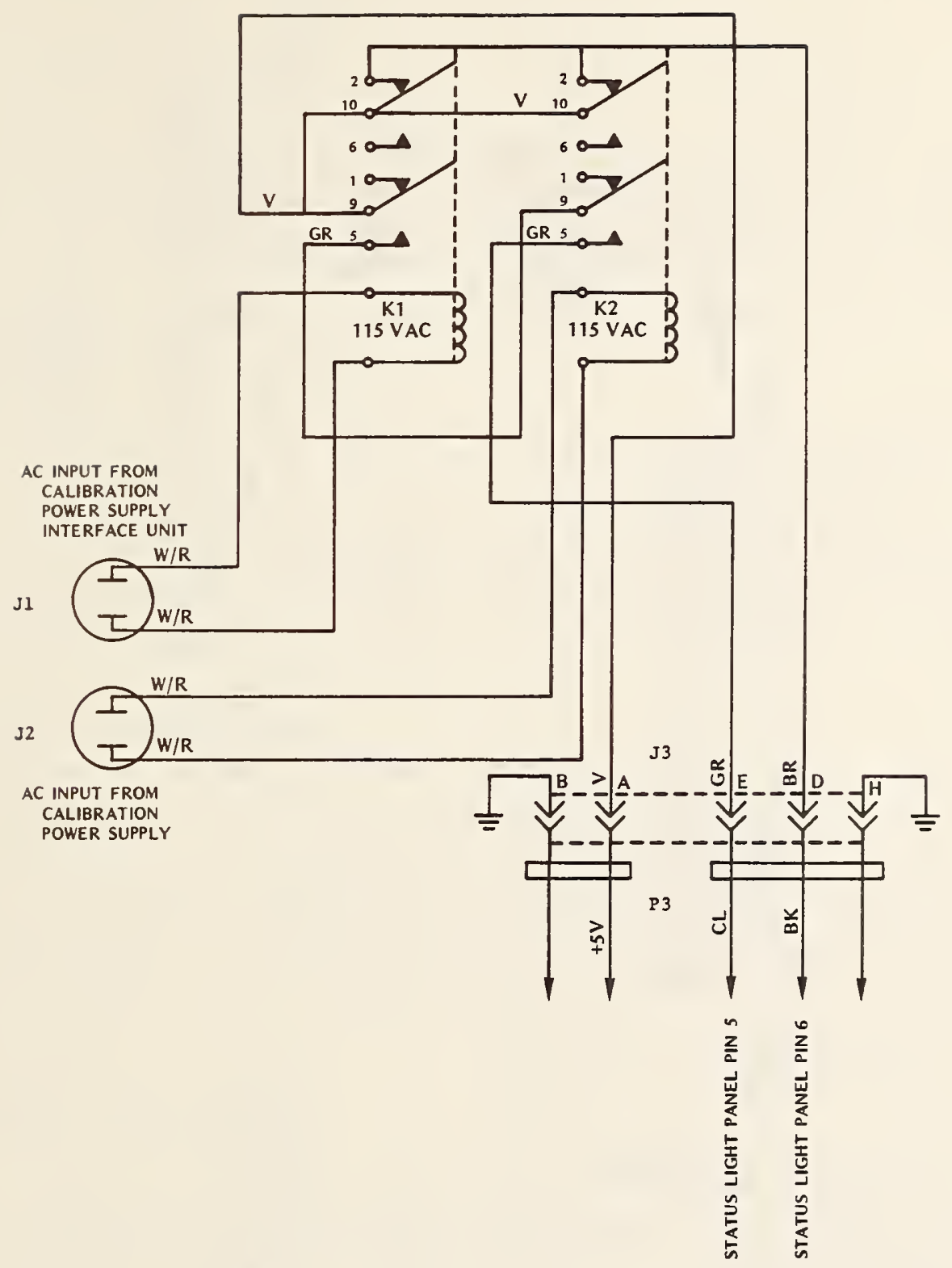

Figure 3-35. Schematic diagram of calibration power supply status circuit.

the preheater unit to heat the gas flowing into the calorimeter. The level of the ac power is adjustable by means of a variable auto transformer in the circuit. The output voltge of the autotransformer is converted to a proportional de voltage and displayed on a front panel DVM.

The unit may be operated either manually or under automatic control. When operated automatically, the output from the Input Gas Temperature Controller is fed into this chassis through the BNC connector labelled EXTERNAL. The signal goes to the control terminal on a solid state relay and turns on and off the ac power. If for some reason the Input Gas Temperature Controller is not used, the output from the gas valve control panel should go to this connector to turn off the ac power when the gas flow is off. 


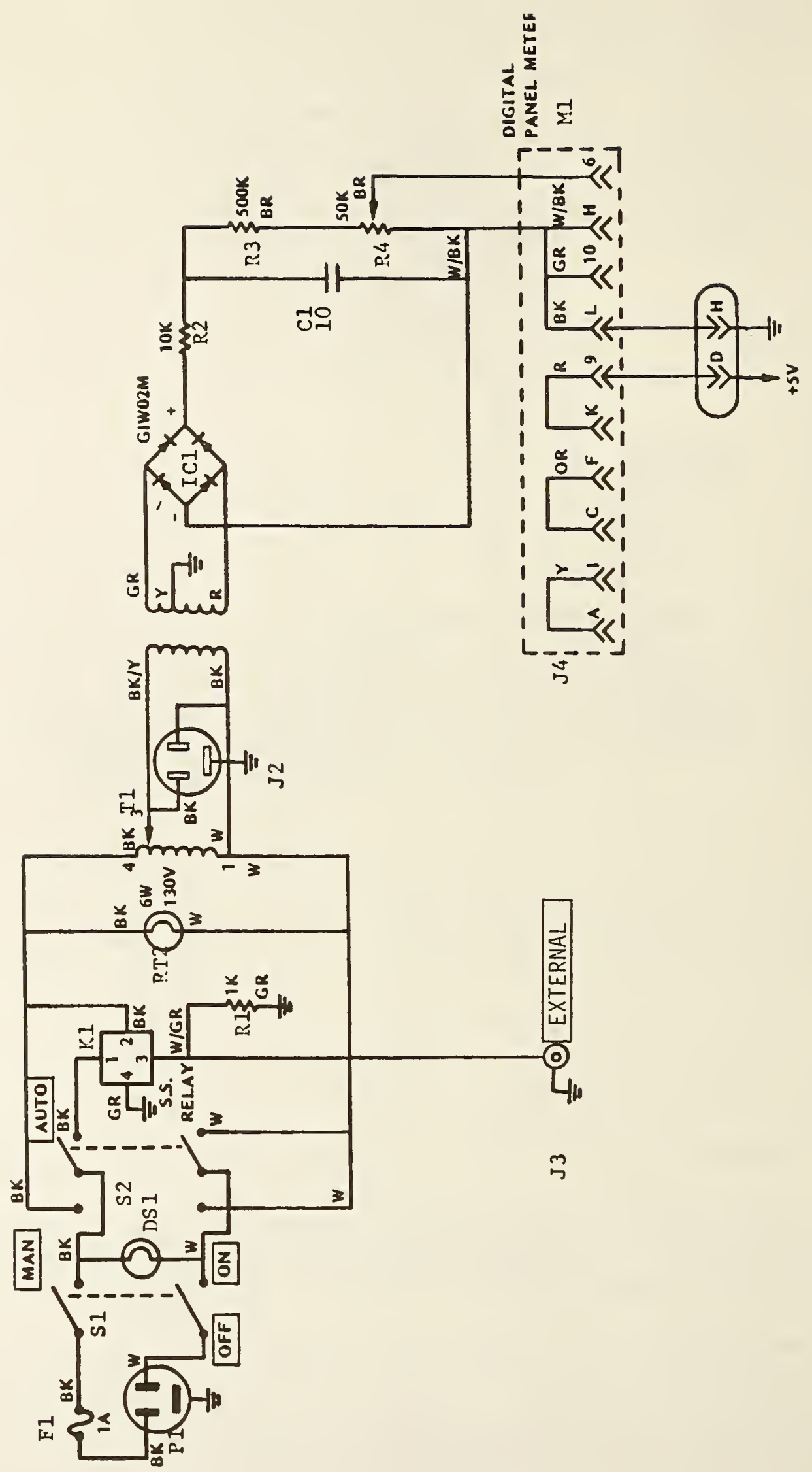

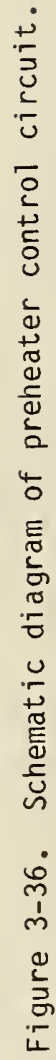


Figure 3-36 is a schematic diagram of the preheater control circuit. The output of this unit yoes to a duplex outlet on the lower left side of the rear of the data acquisition rack. The preheater plugs into this outlet.

\subsubsection{Calibration Power Supply}

The calibration power supply is located at the bottom of the front of the rack. Chassis supports are mounted in the rack to facilitate installing and removing the power supply. Alternating current power is supplied to this unit through a single special receptacle for $20 \mathrm{~A}$ which is mounted on the rack below the bottom of the rear opening. The receptacle has a $3.66 \mathrm{~m}$ (12 ft) power cord for connection to an ac power main. This power line should be connected to a separate ac main from the cord from the ac input panel to avoid overloading the mains.

The calibration power supply is rated at $100 \mathrm{~V} d c$ and $10 \mathrm{~A}$ output. Operation of the unit is as described in the manufacturer's instruction manual. Factory wiring has been modified as shown in figure 3-16 on page 3-17 of the instruction manual to permit remote programming by the interface unit (see section 3.7.11.2) and remote voltage sensing in the power monitor module (see section 3.7.6). Also, connections have been added to position 1 and 5 on 7201 in figure 6-3 of the instruction manual for monitoring the ac input power as discussed in section 3.7.12.

\subsubsection{Alternating Current Input Panel}

The ac input panel is located at the top of rear opening of the rack. It is $8.89 \mathrm{~cm}(3.5 \mathrm{in})$ high and contains one duplex receptacle unit. This receptacle has a $3.66 \mathrm{~m}$ (12 ft) power cord for connection to an ac power main. The duplex receptacle is powered whenever the power cord is connected to an ac source. The main power switch panel (see section 3.7.2) plugs into one outlet of the duplex receptacle; the other outlet is available for general utility. The power cord from this panel should be connected to a separate ac main from the cord from the calibration power supply to avoid overloading the main.

\subsubsection{CLOP Module Connection Panel}

This panel contains jacks into which plug all the cables coming into the data acquisition rack from the various components of CLOP. From the terminals on the jacks other cables go to the different units in the data acquisition rack such as the scanner, the low voltage dc power supplies, and the shutter control circuits. Table 3.6 lists the jacks on this panel and the CLOP module to which they connect.

Figures 3-37 through 3-47 are wiring diagrams of the nine output connectors on this panel in the two systems. The cables that go from these jacks to the CLOP modules are straight pin for pin connections; e.g., they have similar male and female connectors and pin 1 on the male connector is connected to pin 1 on the female connector, pin 2 to pin 2, etc.

\subsubsection{Gas Valve Control Output Panel}

The gas valve control panel has four output jacks into which plug power cables for the valves on the low pressure gas flow manifold (see section 3.6.2). These four jacks are labelled CHANNEL 34, CHANNEL 35, CHANNEL 36, and CHANNEL 37 which correspond to the scanner channel which controls their output. Cable 1, which comes from valve 1, plugs into channel 34, cable 2 into channel 35 , etc. 
Table 3.6. Jack panel connections to CLOP.

\begin{tabular}{lcl}
\hline Designator & No. of pins & \multicolumn{1}{c}{ Destination } \\
\hline $\mathrm{J} 0$ & 6 & Heater circuit on all modules (one at a time) \\
$\mathrm{J} 1$ & 10 & Extension tube bridge circuit \\
$\mathrm{J} 2$ & 24 & OSM/BSM bridge circuits \\
$\mathrm{J} 3$ & 10 & Separation tube bridge circuit \\
$\mathrm{J} 4$ & 10 & Mirror reflector bridge circuit \\
$\mathrm{J} 5 \mathrm{~A}$ & 24 & Main cal. temp and mass flow out and RTD bridge cir- \\
$\mathrm{J} 5 \mathrm{Cuits}$ & Main cal. temp and mass flow in bridge circuits \\
$\mathrm{J} 6$ & 15 & OSM/BSM shutter motors \\
$\mathrm{J} 7$ & 14 & Main cal. shutter motors \\
\hline
\end{tabular}

Figure 3-48 is a wiring diagram of the gas valve control output panel and the connecting cable plugs. The wiring of the cable plugs is included to show the interlock formed through pins 13 and 14 which allows the status light panel to give a more valid indication of the gas flow condition. Alternating current input to this unit is through a four-prong connector on the chassis. Direct current control signals from the scanner and connections to the status light panel and input gas temperature controller chassis are through a 25-pin connector.

\section{Computer Programs and Data Storage Files}

4.1 Introduction

This section gives a description of each program used with CLOP. There are two subgroups in the section, the first for System $T$ and the second for System $H$. A description of each program specifying what it is, what it does, etc. is given and the similar program in the other system is noted. Computer programs and variable maps for the System $T$ are given in appendix $B$ and for System $H$ in appendix c.

Data tape catalogs (indexes) are listed to show the schemes for data storage. These are somewhat different for the two systems since System $T$ has an external tape drive for the data tape cartridges while System $H$, with only the internal tape drive available, requires the plugging in and taking out of tape cartridges.

There are quite a few differences in the operation and basic languages of the two computers that require different methods to accomplish the same results in similar programs. Some of these are:

1. System $\mathrm{H}$ screen scrolls while System T pages.

2. System $H$ has a printer; System $T$ copies the screen.

3. System $T$ can FIND and OLD the next program under program control; System $H$ cannot perform a LOAD this way.

4. System $H$ has a programmabie PAUSE which CONT will terminate while System $T$ requires a software indefinite wait that is terminated by a user-defined key (UDK).

5. System $\mathrm{H}$ allows array index 0 ; System $\mathrm{T}$ does not. 


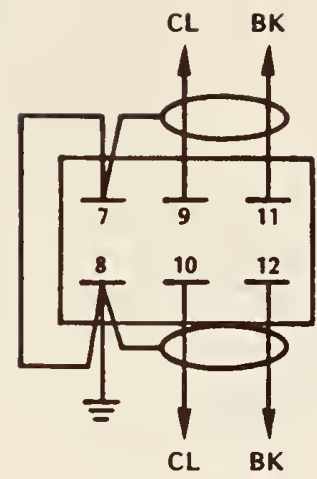

\begin{tabular}{|r|ll|}
\hline PIN & ACQUISITION RACK CONNECTION \\
\hline 7 & PIN 7 & V-I BOX OUTPUT \\
8 & PIN 8 & V-I BOX OUTPUT \\
9 & PIN 9 & V-I BOX OUTPUT \\
10 & PIN 10 & V-I BOX OUTPUT \\
11 & PIN 11 & V-I BOX OUTPUT \\
12 & PIN 12 & V-I BOX OUTPUT \\
\hline
\end{tabular}

Figure 3-37. Wiring diagram of connector J0 to heater circuits.

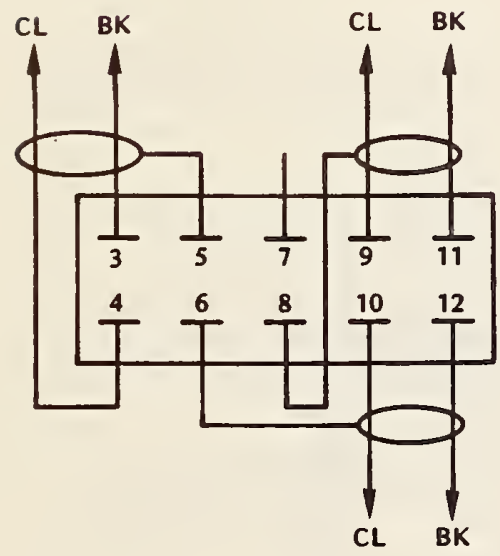

\begin{tabular}{|r|l|}
\hline PIN & ACQUISITION RACK CONNECTION \\
\hline 3 & SCANNER CONTACT O9 H \\
4 & SCANNER CONTACT O9 L \\
5 & SIGNAL SHIELD \\
6 & $+15 V$ SHIELD \\
7 & NC \\
8 & -15V SHIELD \\
9 & -15V DC POWER SUPPLY DECK \\
10 & $+15 V$ DC POWER SUPPLY DECK \\
11 & GROUND POWER SUPPLY DECK \\
12 & GROUND POWER SUPPLY DECK \\
\hline
\end{tabular}

Figure 3-38. Wiring diagram of connector Jl to extension tube bridge circuit (System $\mathrm{H}$ ).

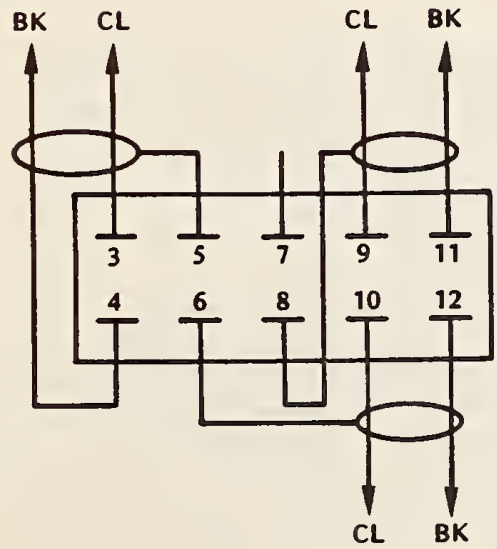

\begin{tabular}{|r|l|}
\hline PIN & ACQUISITION RACK CONNECTION \\
\hline 3 & SCANNER CONTACT O9 L \\
4 & SCANNER CONTACT 09 H \\
5 & SIGNAL SHIELD \\
6 & $+15 V$ SHIELD \\
7 & NC \\
8 & -15V SHIELD \\
9 & -15V DC POWER SUPPLY DECK \\
10 & +15V DC POWER SUPPLY DECK \\
11 & GROUND POWER SUPPLY DECK \\
12 & GROUND POWER SUPPLY DECK \\
\hline
\end{tabular}

Figure 3-39. Wiring diagram of connector J1 to extension tube bridge circuit (System T). 


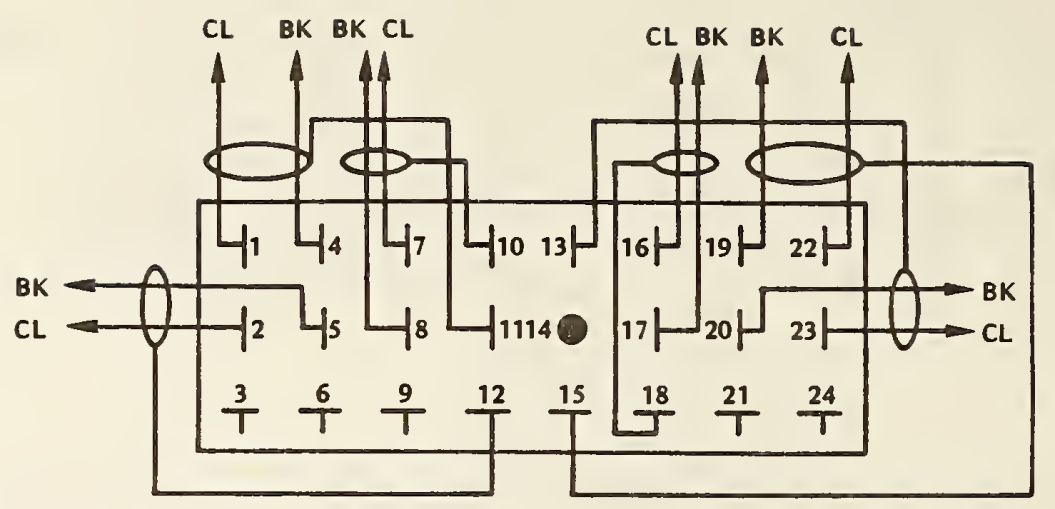

\begin{tabular}{|c|l|l|l|}
\hline PIN & ACQUISITION RACK CONNECTION & PIN & ACQUISITION RACK CONNECTION \\
\hline 1 & +15V DC POWER SUPPLY DECK & 13 & -15 V SHIELD \\
2 & -15V DC POWER SUPPLY DECK & 14 & NC \\
3 & NC & 15 & $+15 V$ SHIELD \\
4 & GROUND POWER SUPPLY DECK & 16 & SCANNER CONTACT 07 H \\
5 & GROUND POWER SUPPLY DECK & 17 & SCANNER CONTACT 07 L \\
6 & NC & 18 & SCANNER CONTACT 07 SHIELD \\
7 & SCANNER CONTACT 08 H & 19 & GROUND POWER SUPPLY DECK \\
8 & SCANNER CONTACT 08 L & 20 & GROUND POWER SUPPLY DECK \\
9 & NC & 21 & NC \\
10 & SCANNER CONTACT 08 SHIELD & 22 & $+15 V$ DC POWER SUPPLY DECK \\
11 & +15V SHIELD & 23 & -15V DC POWER SUPPLY DECK \\
12 & -1SV SHIELD & 24 & NC \\
\hline
\end{tabular}

Figure 3-40. Wiring diagram of connector J2 to OSM/BSM bridge circuits.

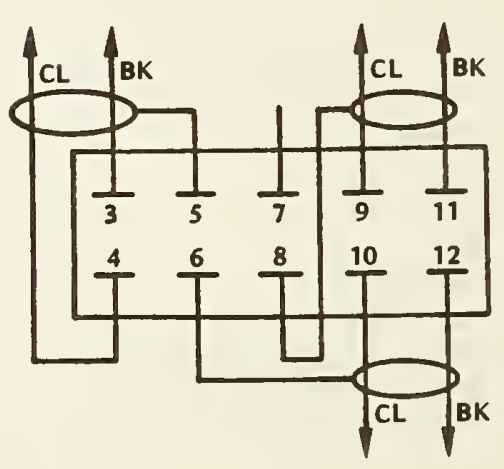

\begin{tabular}{|c|l|}
\hline PIN & ACQUISITION RACK CONNECTION \\
\hline 3 & SCANNER CONTACT O6 L \\
4 & SCANNER CONTACT O6 H \\
5 & SIGNAL SHIELD \\
6 & $+15 V$ SHIELD \\
7 & NC \\
8 & $-15 V$ SHIELD \\
9 & -15V DC POWER SUPPLY DECK \\
10 & +15V DC POWER SUPPLY DECK \\
11 & GROUND POWER SUPPLY DECK \\
12 & GROUND POWER SUPPLY DECK \\
\hline
\end{tabular}

Figure 3-41. Wiring diagram of connector 33 to separation tube bridge circuits. 


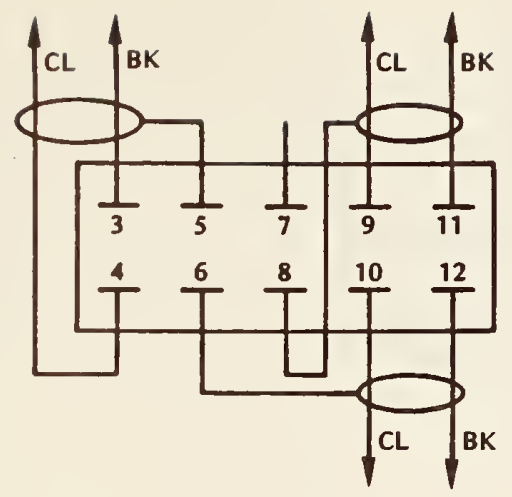

\begin{tabular}{|c|l|}
\hline PIN & ACQUISITION RACK CONNECTION \\
\hline 3 & SCANNER CONTACT 05 L \\
4 & SCANNER CONTACT O5 H \\
5 & SIGNAL SHIELD \\
6 & $+15 V$ SHIELD \\
7 & NC \\
8 & $-15 V$ SHIELD \\
9 & -15V DC POWER SUPPLY DECK \\
10 & +15 DC POWER SUPPLY DECK \\
11 & GROUND POWER SUPPLY DECK \\
12 & GROUND POWER SUPPLY DECK \\
\hline
\end{tabular}

Figure 3-42. Wiring diagram of connector 34 to deflector bridge circuit.

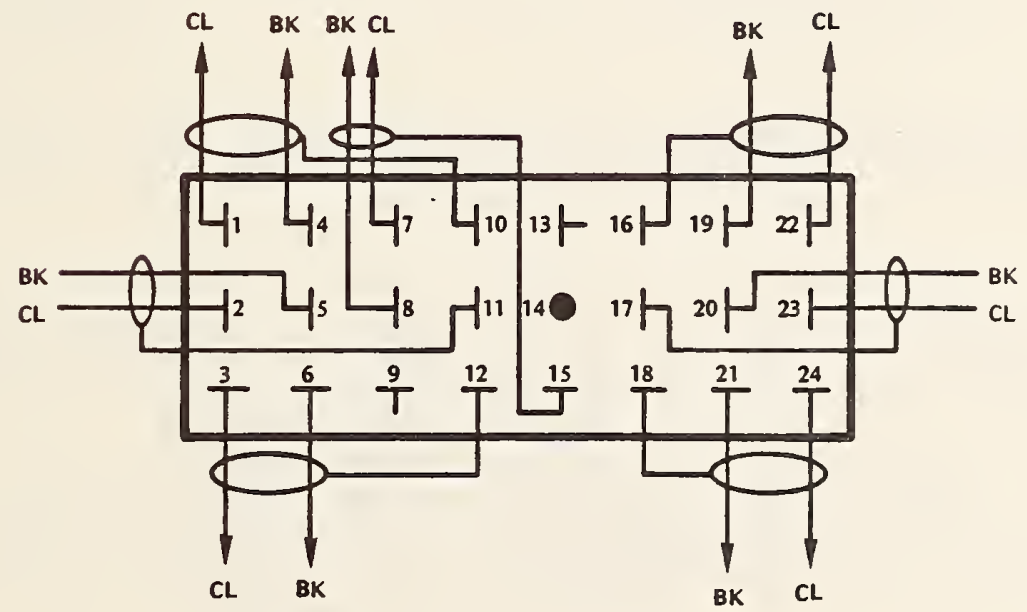

\begin{tabular}{|c|l|c|l|}
\hline PIN & ACQUISITION RACK CONNECTION & PIN & ACQUISITION RACK CONNECTION \\
\hline 1 & +15V DC POWER SUPPLY DECK & 13 & NC \\
2 & -15V DC POWER SUPPLY DECK & 14 & NC \\
3 & SCANNER CONTACT O1 H & 15 & SCANNER CONTACT 02 SHIELD \\
4 & GROUND POWER SUPPLY DECK & 16 & +15 DC SHIELD \\
5 & GROUND POWER SUPPLY DECK & 17 & -15V DC SHIELD \\
6 & SCANNER CONTACT O1 L & 18 & SCANNER CONTACT OO SHIELD \\
7 & SCANNER CONTACT O2 H & 19 & GROUND POWER SUPPLY DECK \\
8 & SCANNER CONTACT 02 L & 20 & GROUND POWER SUPPLY DECK \\
9 & NC & 21 & SCANNER CONTACT OO L \\
10 & +15V DC SHIELD & 22 & +15V DC POWER SUPPLY DECK \\
11 & -15V DC SHIELD & 23 & -15V DC POWER SUPPLY DECK \\
12 & SCANNER CONTACT 01 SHIELD & 24 & SCANNER CONTACT OOH \\
\hline
\end{tabular}

Figure 3-43. Wiring diagram of connector J5A to main calorimeter gas output circuits box. 


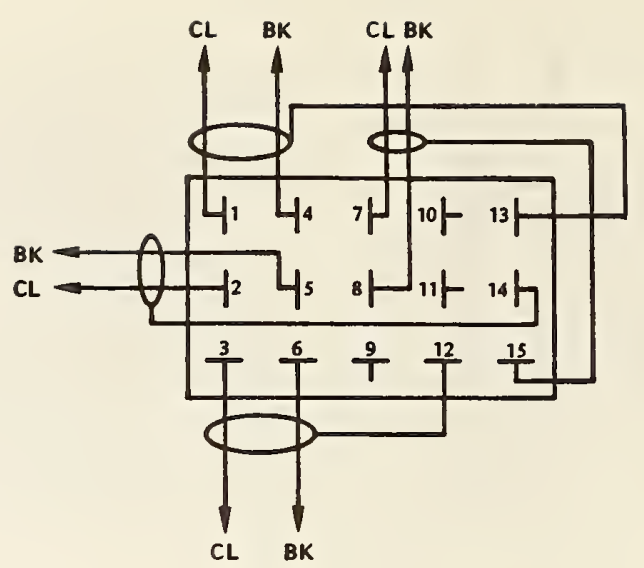

\begin{tabular}{|c|l|c|l|}
\hline PIN & ACQUISITION RACK CONNECTION & PIN & ACQUISITION RACK CONNECTION \\
\hline 1 & +15V DC POWER SUPPLY DECK & 9 & NC \\
2 & -15V DC POWER SUPPLY DECK & 10 & NC \\
3 & SCANNER CONTACT 03 H & 11 & NC \\
4 & GROUND POWER SUPPLY DECK & 12 & SCANNER CONTACT 03 SHIELD \\
5 & GROUND POWER SUPPLY DECK & 13 & $+15 V$ DC SHIELD \\
6 & SCANNER CONTACT 03 L & 14 & -15V DC SHIELD \\
7 & SCANNER CONTACT O4 H & 15 & SCANNER CONTACT O4 SHIELD \\
8 & SCANNER CONTACT O4 L & & \\
\hline
\end{tabular}

Figure 3-44. Wiring diagram of connector J5B to main calorimeter gas input circuits box (System $H$ ).

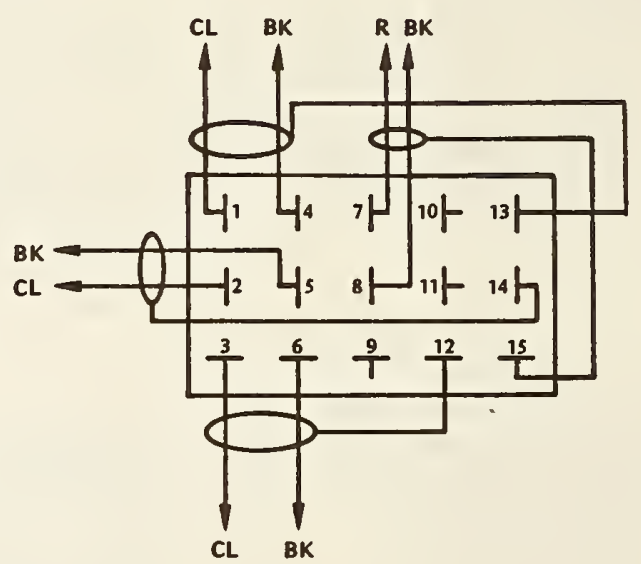

\begin{tabular}{|c|l|c|l|}
\hline PIN & ACQUISITION RACK CONNECTION & PIN & ACQUISITION RACK CONNECTION \\
\hline 1 & +1SV DC POWER SUPPLY DECK & 9 & NC \\
2 & -1SV DC POWER SUPPLY DECK & 10 & NC \\
3 & SCANNER CONTACT 03 H & 11 & NC \\
4 & GROUND POWER SUPPLY DECK & 12 & SCANNER CONTACT 03 SHIELD \\
5 & GROUND POWER SUPPLY DECK & 13 & +15 DC SHIELD \\
6 & SCANNER CONTACT 03 L & 14 & -15V DC SHIELD \\
7 & SCANNER CONTACT O4 H & 15 & SCANNER CONTACT O4 SHIELD \\
8 & SCANNER CONTACT O4 L & & \\
\hline
\end{tabular}

Figure 3-45. Wiring diagram of connector J5B to main calorimeter gas input circuits box (System T). 


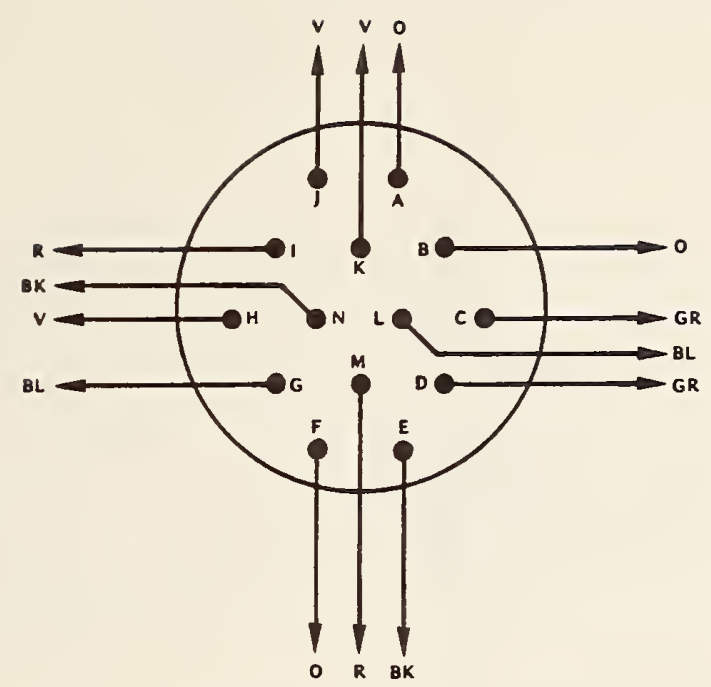

\begin{tabular}{|l|l|l|l|}
\hline PIN & CONTROL CHASSIS CONNECTION & PIN & CONTROL CHASSIS CONNECTION \\
\hline A & PIN 23 & H & PIN 14 \\
B & PIN 16 & I & PIN 21 \\
C & PIN 11 & J & PIN 22 \\
D & PIN 7 & K & PIN 25 \\
E & PIN 18 & L & PIN 5 \\
F & PIN 15 & M & PIN 19 \\
G & PIN 3 & N & PIN 17 \\
\hline
\end{tabular}

Figure 3-46. Wiring diagram of connector J6 to OSM/BSM shutter motors.

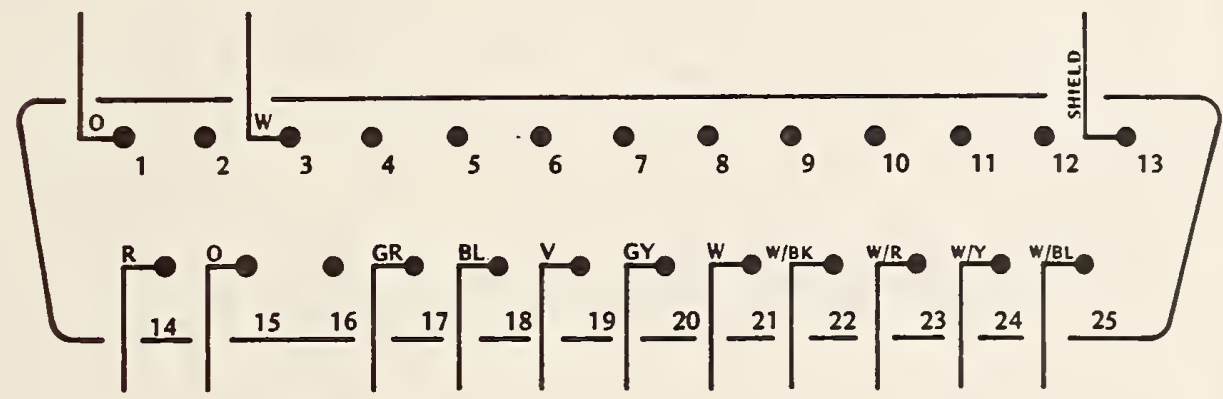

\begin{tabular}{|c|l|l|l|}
\hline PIN & CONTROL CHASSIS CONNECTION & PIN & CONTROL CHASSIS CONNECTION \\
\hline 1 & PIN 1 & 14 & PIN 14 \\
2 & NC & 15 & PIN 15 \\
3 & PIN 3 & 16 & NC \\
4 & NC & 17 & PIN 17 \\
5 & NC & 18 & PIN 18 \\
6 & NC & 19 & PIN 19 \\
7 & NC & 20 & PIN 20 \\
8 & NC & 21 & PIN 21 \\
9 & NC & 22 & PIN 22 \\
10 & NC & 23 & PIN 23 \\
11 & NC & 24 & PIN 24 \\
13 & PIN 13 & 25 & PIN 25 \\
\hline
\end{tabular}

Figure 3-47. Wiring diagram of connector 37 to main calorimeter shutter motors. 


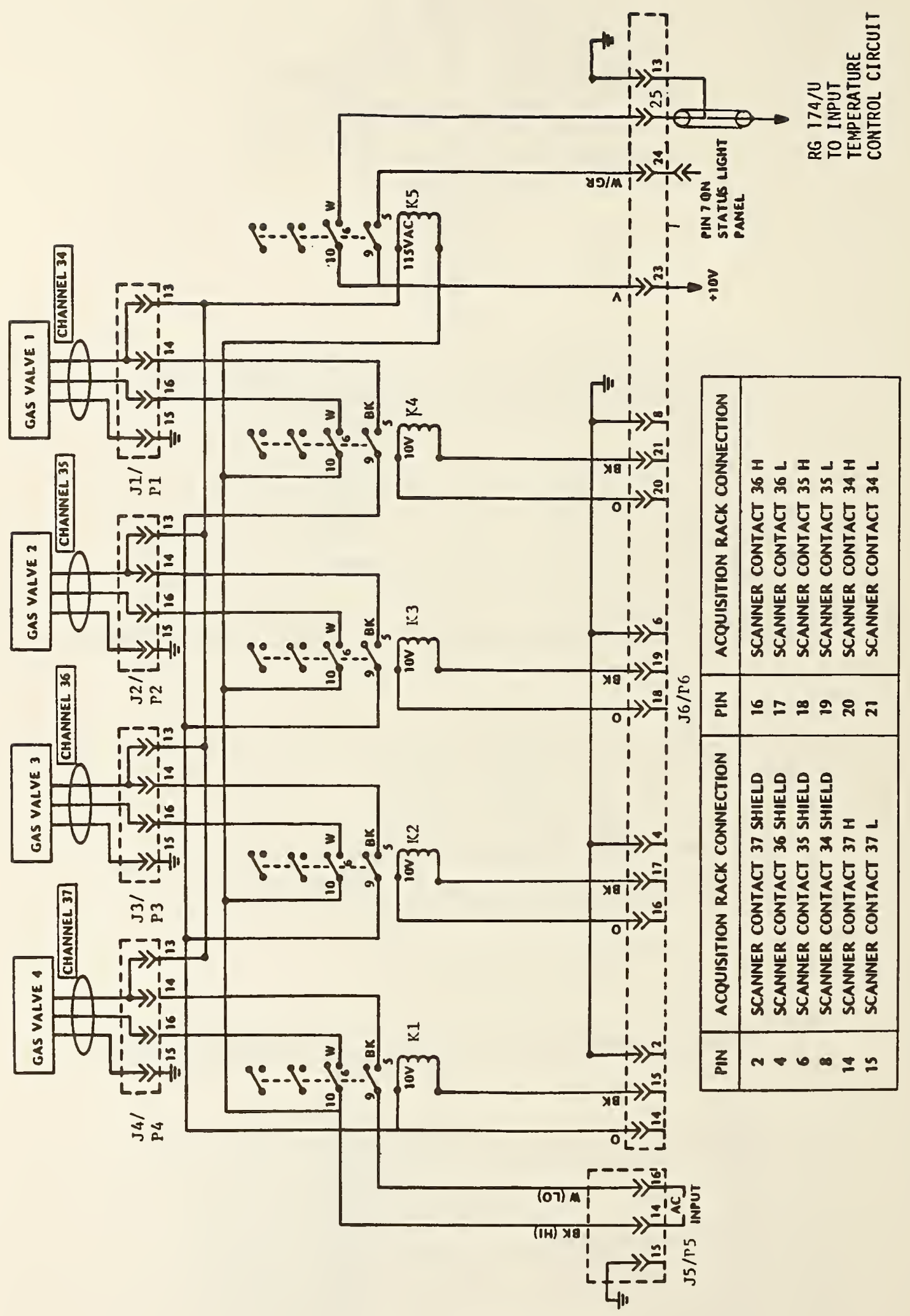

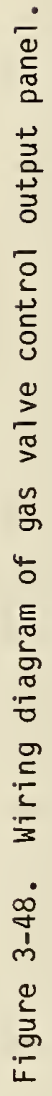


There are also some subtle differences in similar statements in the two basic languages. For instance, in the following sequence on System $T$

$$
\begin{aligned}
& J=1 \\
& J \$=\operatorname{STR}(J) .
\end{aligned}
$$

I\$ is a string two terms long having preserved the space for the implied plus sign. This space needs to be removed for concatenation and certain other operations. On System $H$ the space is dropped. Also, on System $\mathrm{H}$ in computed GOTO statements, arguments outside the range of accepted values (zero included) cause a fatal error. On System $T$ the computer goes to the next line, which allows software handling of mistakes such as wrong answers from keyboard input from the operator. Other differences will become apparent as the operator becomes better acquainted with the two systems.

\subsection{System $T$ Programs and Data Files \\ 4.2.1 Index (FILE 1)}

This index can most easily be run by pressing the AUTO LOAD button. The program lists the file number and name of each program on the tape and automatically loads and runs the program selected by the operator.

At the beginning of the program is a routine that tells the operator the other programs on the tape will not run if he is not using an "A" series 4050. See appendix B, section B.1, for a variable map and listing of this program.

The nearest thing on System $H$ is the command CAT which lists the programs only.

\subsubsection{CLOP (FILE 2)}

CLOP is the data acquisition program. It accepts run parameters input by the operator and then starts operating the calorimeter, performing such functions as reading and storing the output of all the sensors, operating shutters, turning on and off the electrical calibration power supply, and shutting off and turning on the gas flow. It also performs simple mathematical operations such as averaging data packets by dividing by 6 and scaling calibration voltages by multiplying by 10 .

After the run is completed results can be printed to the screen and copied, and then stored on the data tape in a temporary storage file. See appendix B, section B.2, for a variable map and listing of this program.

This program performs the same functions as "Autost" and "CLOP2" which are chained on System H.

\subsubsection{CHANNEL MONITOR (FILE 3)}

CHANNEL MONITOR is a general utility program. It is used to switch in various channels on the scanner to read the output from the sensor, or to perform certain operations such as switching open and closed gas valves and CLOP shutters. This program is extremely useful when setting up CLOP or repairing sensor and shutter circuits. See appendix B, section B.3, for a listing of this program. There is no variable map, since the program uses no variables.

This program is used for the same function as "CHMON" on System $H$ but is more elaborate because of the greater number of UDKs. 


\subsubsection{READ RUN DATA FILES (FILE 4)}

This program is used to read and list the contents of the temporary data storage files. If the operator has data stored that he does not wish to overwrite and lose, he can use this program to ascertain which file contains that data. This program also contains a graphing routine so the operator can use this program after he stores the data from CLOP to graph the sensor outputs. See appendix B, section B.4, for a variable map and listing of this program.

The equivalent program on System $H$ is "FILEXM". That program does not contain a graphing routine.

\subsubsection{CALCULATE RESULTS (FILE 5)}

This program retrieves the raw data from the temporary storage file and calculates the zeroth, first, and second moments for the zero rating, transition, and final rating periods. For electrical runs a calibration factor or stability factor, whichever is appropriate, is also calculated. Results from electrical runs are stored in electrical summary files. Results of laser and combination runs are stored in data files labelled LASER OR COMBINATION RUN RESULTS FILE \#1 through \#10. See appendix $B$, section B.5, for a variable map and listing of this program.

The corresponding program in System $H$ is "CALC".

\subsubsection{READ ELECTRICAL SUMMARY FILE (FILE 6)}

This program displays and lists the contents of the electrical summary file for any sensor of CLOP. For each electrical calibration run, the run parameters; zeroth, first, and second moments for the zero rating, transition period, and final rating period; and calibration factor (or stability factor) are printed. This program is useful when the operator wishes to obtain an over-all picture of how well CLOP is operating, environmental effects, etc. See appendix B, section B.6, for a variable map and listing of this program.

The corresponding program in System $H$ is "ELSCAN".

\subsubsection{CALCULATE CAL FACTORS (FILE 7)}

This program calculates the "best" values of calibration factor and drift as described in section 2. For the ancillary modules it calculates an average value; standard deviation; and 90 percent, 95 percent, and 99 percent confidence intervals. For the main calorimeter RTD and temperature out sensor, a least squares $f i t$ is performed. Standard deviations and confidence intervals are calculated for the $Y$-intercept and the slope.

An editing routine is included in the program to allow removal of bad or irrelevant runs. Also, provision is made to add a descriptive information note in which the operator can record comments pertinent to the data. The only character not permitted in the comments is an asterisk $(*)$ since this character is used as a delimiter between the individual information notes. Results are stored in file 23 in the form of an $8 \times 4$ array (see table 2.1) and a single alpha string containing the information notes for all sensors. See appendix B, section B.7, for a variable map and listing of this program.

The equivalent program in System $H$ is "FACTOR." 


\subsubsection{RUN KEPCU (FILE 8)}

This proyram is a general utility program. It allows the operator to set the electrical calibracion power supply to run at any desired voltage limit and current limit to the limits of the instrument ( $100 \mathrm{~V}$ and $10 \mathrm{~A}$ ). This is especially useful when one desires to set the divider ratios in the dc calibration voltage and current measuring circuits (see section 3.7.6). See appendix B, section B.8, for a variable map and listing of this program. In System H, program "KEPCO" performs the same functions.

\subsubsection{System $T$ Data Tapes}

All data tapes for System $T$ are formatted the same. Since this system has an external tape deck, this should require less changing of tape cartridges. The data tape index is given in table 4.1 .

File 1 is written in ASCII; all the rest are in binary. Since binary data takes less space than ASCII, this permits storing greater amounts of data. The binary data can also be accessed faster.

File 1 is marked to hold 5120 bytes. Files 2 through 11 hold 20224 bytes each. The electrical summary files, 12 through 22 hold 9216 bytes each. File 23, the electrical calibration summary file

Table 4.1. Index of System T data tapes.
CLOP Data Tape \#1 Index
FILE 1 : INDEX
FILE 2 : RUN DATA FILE \#1
FILE 3 : RUN DATA FILE \#2
FILE 4 : RUN DATA FILE \#3
FILE 5 : RUN DATE FILE \#4
FILE 6 : RUN DATA FILE \#5
FILE 7 : RUN DATA FILE \#6
FILE 8 : RUN DATA FILE \#7
FILE $9:$ RUN DATA FILE \#8
FILE 10 : RUN DATA FILE \#9
FILE 11 : RUN DATA FILE \#10
FILE 12 : MAIN CALORIMETER RTD ELECTRICAL SUMMARY
FILE 13 : MASS FLOW OUT ELECTRICAL SUMMARY
FILE 14 : TEMPERATURE OUT ELECTRICAL SUMMARY
FILE 15 : MASS FLOW IN ELECTRICAL SUMMARY
FILE 16 : TEMPERATURE IN ELECTRICAL SUMMARY
FILE 17 : FOIL REFLECTOR ELECTRICAL SUMMARY
FILE 18 : DEFLECTOR ELECTRICAL SUMMARY
FILE 19 : SEPARATION TUBE ELECTRICAL SUMMARY
FILE 20 : BACKSCATTER MONITOR ELECTRICAL SUMMARY
FILE 21 : OVERSPILL MONITOR ELECTRICAL SUMMARY
FILE 22 : EXTENSION TUBE ELECTRICAL SUMMARY
FILE 23 : ELECTRICAL CALIBRATION FACTOR SUMMARY FILE
FILE 24 : LASER OR COMBINATION RUN RESULTS FILE \#1
FILE 25 : LASER OR COMBINATION RUN RESULTS FILE \#2
FILE 26 : LASER OR COMBINATION RUN RESULTS FILE \#3
FILE 27 : LASER OR COMBINATION RUN RESULTS FILE \#4
FILE 28 : LASER OR COMBINATION RUN RESULTS FILE \#5
FILE 29 : LASER OR COMBINATION RUN RESULTS FILE \#6
FILE 30 : LASER OR COMBINATION RUN RESULTS FILE \#7
FILE 31 : LASER OR COMBINATION RUN RESULTS FILE \#8
FILE 32 : LASER OR COMBINATION RUN RESULTS FILE \#9
FILE 33 : LASER OR COMBINATION RUN RESULTS FILE \#10 
is 1536 bytes. The last 10 files, 24 through 33, are 14848 bytes each. Thus, there is space in the electrical summary files for the results of 55 electrical calibrations. Files 24 through 33 can each hold the results of 13 laser runs.

The total space on the tape used is 458 kbytes. The tape deck has trouble marking this much space so it is recommended that marking of new data tapes be done with the internal drive of the System $T$ computer. When making a new file 23 (or after a KILL 23:), a dummy array and information note must be put in the new file. The following program will perform this operation.

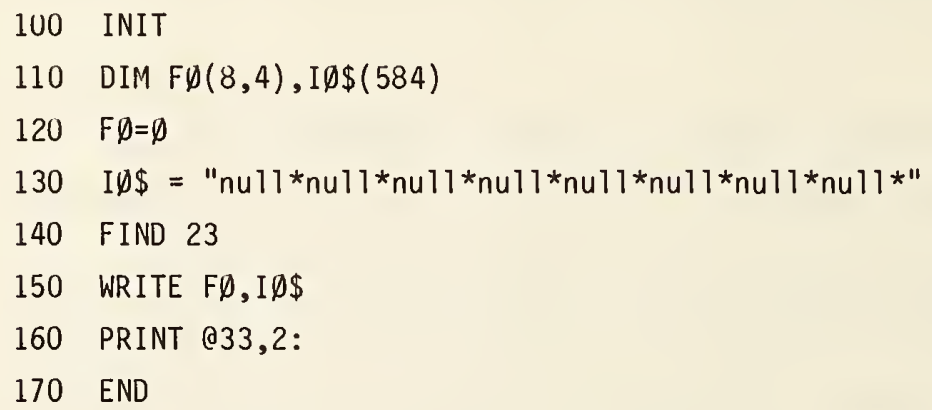

\subsection{System H Programs and Data Files}

4.3.1 "Autost"

This program, along with CLOP2 (see section 4.3.2) which is chained to it, performs the same function as CLOP on System $T$ (see section 4.2.2). Autost performs all the operations up to the start of the data-taking process. This program is named Autost so that it will load and run automatically when System $\mathrm{H}$ is first turned on. It may also be loaded the normal way by typing LOAD "Autost" followed by RUN. See section 4.2 .2 for a more complete description of the operations performed by this program.

This program, since it is chained with CLOP2, requires that some variables be stored in COMMON. Those variables so stored are preserved for use in CLOP2; all others are discarded during the chaining operation. In the program map variables in COMMON are marked $(C)$. See appendix $C$, section C.1, for a variable map and listing of this program.

\subsection{2 "CLOP2"}

This is the second half of the main data-acquisition program and is chained to Autost. Together these two programs perform the same function as CLOP does for System $T$ (see section 4.2.2). This program begins with the data-taking routines and completes all phases of the run thereafter. This program cannot be run alone as many of the variables need to be defined in Autost.

Variables stored in COMMON are marked $(C)$ in the variable map. See appendix $C$, section C.2, for a variable map and listing of this program.

\subsection{3 "CALC"}

This program performs the same functions as program CALCULATE RESULTS (FILE5) in System T (see 4.2.5). The program retrieves the raw run data from a temporary storage file on tape RUN DATAD or RUN 
DATAl and does the required mathematical calculations. For electrical calibration runs the results are stored in the appropriate electrical summary file on the tape marked ELEC. SUMMARY. Results of laser and combination runs are stored in files on the tape marked LASER RUNS 1 . See appendix C, Section C.3, for a variable map and listing of this program.

\subsection{4 "ELSCAN"}

"ELSCAN" is similar to the program READ ELECTRICAL SUMMARY FILES (FILE6) on System T (see section 4.2.6). See appendix C, section C.4 for a variable map and listing of this program.

\subsection{5 "FACTOR"}

This program is the System $H$ equivalent of CALCULATE CAL FACTORS (FILE 7) on System $T$ (see section 4.2.7). The same statistical methods are used for the various sensors and editing of the electrical summary file data is possible.

The information note utilizes certain infrequently used characters unique to the System $H$ computer as delimiters. These characters are listed below with their associated keystrokes.

Table 4.2 Delimiter characters used with the HP85 information notes.

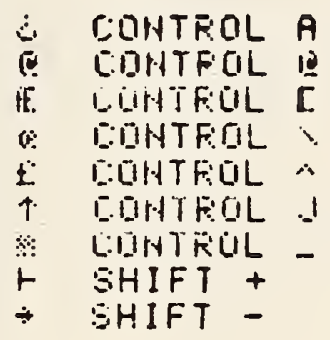

These delimiters are listed in the order they appear in the long alpha string, except for the control A. This character is not in the alpha string and hence, when its position is searched for, a zero is returned indicating the beginning of the alpha string. Thus, on System $H$ the asterisk is permitted in the information notes.

A variable map and listing for this program are given in appendix C, section C.5.

\subsection{6 "FILEXM"}

"FILEXM" is the System H equivalent of READ RUN DATA FILES (FILE 4) on System $T$ (see section 4.2.4). This program performs the same functions as its system $T$ counterpart except there is no routine included for graphing sensor output. See appendix C, section C.6, for the variable map and a listing of this program. 


\subsection{7 "CHMON"}

This program is similar to program CHANNEL MONITOR (FILE 3) on System T (see section 4.2.3). Since there are only eight UDKs on System $H$, only six of the sensor outputs are available with a single keystroke. However, UDK\#7 allows the operator to input via the keyboard any channel command he desires. UDK\#8 terminates the program. A variable map and listing for this program are given in appendix $C$, section $C .7$.

\subsection{8 "KEPCO"}

This program performs the same function as its System $T$ equivalent RUN KEPCO (FILE 8) (see section 4.2.8). Appendix $C$, section $C .8$, has the variable map and program listing.

\subsubsection{System H Data Files}

Data files are maintained on separate tape cartridges according to the type of data stored. Since the internal tape drive of System $H$ is the only drive available for tape use, the data and program tapes must be plugged in and removed at various times during program operation. Usually this will be done according to prompting messages displayed on the screen.

Temporary files for storing the raw data acquired by "Autost" and "CLOP2" are available on tapes RUN DATA $\emptyset$ and RUN DATA 1. Each of these two tapes has 10 files, RUN DATA $\emptyset$ through RUN DATA 9 and RUN DATA 10 through RUN DATA 19, respectively. Each file holds data from one run.

The data tape marked ELEC. SUMMARY contains the electrical summary files for all the sensors. Each file can hold the results of 69 electrical calibrations. Also on this tape is the file "CALFAX" which contains the statistical summary for each of the temperature sensors.

The tape labelled LASER RUNS 1 is used to store the results of L- and C-type runs. The tape has 9 files, each capable of holding the results of 28 runs. Tables 4.3 through 4.6 list catalogs of the four data tapes for System $H$.

Table 4.3. Catalog for data tape RUN DATA $\emptyset$.

\begin{tabular}{llccc}
\hline Name & Type & Bytes & Recs & File \\
\hline DATA $\varnothing$ & DATA & 256 & 70 & 1 \\
DATA1 & DATA & 256 & 70 & 2 \\
DATA2 & DATA & 256 & 70 & 3 \\
DATA3 & DATA & 256 & 70 & 4 \\
DATA4 & DATA & 256 & 70 & 5 \\
DATA5 & DATA & 256 & 70 & 6 \\
DATA6 & DATA & 256 & 70 & 7 \\
DATA7 & DATA & 256 & 70 & 8 \\
DATA8 & DATA & 256 & 70 & 9 \\
DATA9 & DATA & 256 & 70 & 10 \\
\hline
\end{tabular}


Table 4.4. Catalog for data tape RUN DATA 10.

\begin{tabular}{llclc}
\hline Name & Type & Bytes & Recs & File \\
\hline DATA10 & DATA & 256 & 70 & 1 \\
DATA11 & DATA & 256 & 70 & 2 \\
DATA12 & DATA & 256 & 70 & 3 \\
DATA13 & DATA & 256 & 70 & 4 \\
DATA14 & DATA & 256 & 70 & 5 \\
DATA15 & DATA & 256 & 70 & 6 \\
DATA16 & DATA & 256 & 70 & 7 \\
DATA17 & DATA & 256 & 70 & 8 \\
DATA18 & DATA & 256 & 70 & 9 \\
DATA19 & DATA & 256 & 70 & 10 \\
\hline
\end{tabular}

Table 4.5. Catalog for data tape ELEC. SUMMARY.

\begin{tabular}{|c|c|c|c|c|}
\hline Name & Type & Bytes & Recs & File \\
\hline MCRTD* & DATA & 150 & 69 & 1 \\
\hline MAOUT* & DATA & 150 & 69 & 2 \\
\hline TEOUT* & DATA & 150 & 69 & 3 \\
\hline MASIN* & DATA & 150 & 69 & 4 \\
\hline TEMI N* & DATA & 150 & 69 & 5 \\
\hline DEFLC* & DATA & 150 & 69 & 6 \\
\hline FOREF* & DATA & 150 & 69 & 7 \\
\hline SPTUB* & DATA & 150 & 69 & 8 \\
\hline BSMON* & DATA & 150 & 69 & 9 \\
\hline OSMON* & DATA & 150 & 69 & 10 \\
\hline EXTUB* & DATA & 150 & 69 & 11 \\
\hline CALFAX & DATA & 256 & 4 & 12 \\
\hline
\end{tabular}

Table 4.6. Catalog for data tape LASER RUNS 1.

\begin{tabular}{lllll}
\hline Name & Type & Bytes & Recs & File \\
\hline LAS100 & DATA & 822 & 28 & 1 \\
LAS1 1 & DATA & 822 & 28 & 2 \\
LAS102 & DATA & 822 & 28 & 3 \\
LAS1 10 & DATA & 822 & 28 & 4 \\
LAS104 & DATA & 822 & 28 & 5 \\
LAS105 & DATA & 822 & 28 & 6 \\
LAS106 & DATA & 822 & 28 & 7 \\
LAS107 & DATA & 822 & 28 & 8 \\
LAS108 & DATA & 822 & 28 & 9
\end{tabular}


5. References

[1] Hoya Glass Works Std., Hoya color filter glass, p. 6, Catalog No. 7109E.

[2] Laser Focus, Buyers' Guide, p. 444 (1983).

[3] Johnson, Jr., E. G. Evaluating the inequivalence and a computational simplification for the NBS laser energy standards. App. Opt. 16: 2315-2331; 1977 August.

[4] Natrella, M. Experimental statistics, Nat. Bur. Stand. (U.S.) Handb. 91; 1963 August. pp.5-10.

[5] Bennett, H. E., et. al. Infrared reflectance of aluminum evaporated films in high vacuum. J. Opt. Soc. of Am. 53(9): 1089-1095; 1963 September. 
Appendix A. Conversion Routines Between Decimal and Hexadecimal Based Number Systems

The electrical calibration power supply utilizes commands containing hexadecimal numbers to set voltage and current limits. The routines used in the CLOP computer programs employ the conventional hexadecimal digits 0 through 9 and continuing $A$ through $F$, where $F_{16}=15_{10}$ and $10_{16}=16_{10}$. The algorithm used to convert from the decimal to hexadecimal base involves dividing the decimal number by 16 and recording the remainder, $R$, of each step as illustrated in the following.

Convert $(1240)_{10}+(?)_{16}$

$$
\begin{aligned}
16 \mid \frac{77}{1240} & R=8 \\
16 \mid \frac{4}{77} & r=13_{10}=D \\
\left.16\right|^{\frac{0}{4}} & R=4
\end{aligned}
$$

Therefore, $1240_{10}+408_{16}$.

The inverse operation involves multiplying each hexadecimal digit, starting with the most significant, by 16 and adding in the next digit before again multiplying by 16 . An example is given below.

Convert $(4 D 5)_{16} \rightarrow(?)_{10}$.

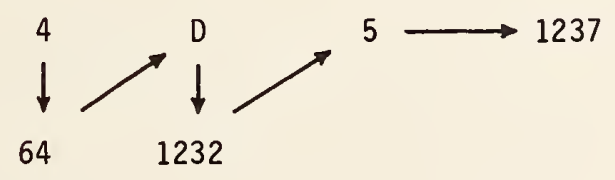

Therefore, $4 D 5_{16}=1_{123}$. 
Appendix B. System T Program Listings and Variable Maps

B1. Index (FILE 1)

Program Listing

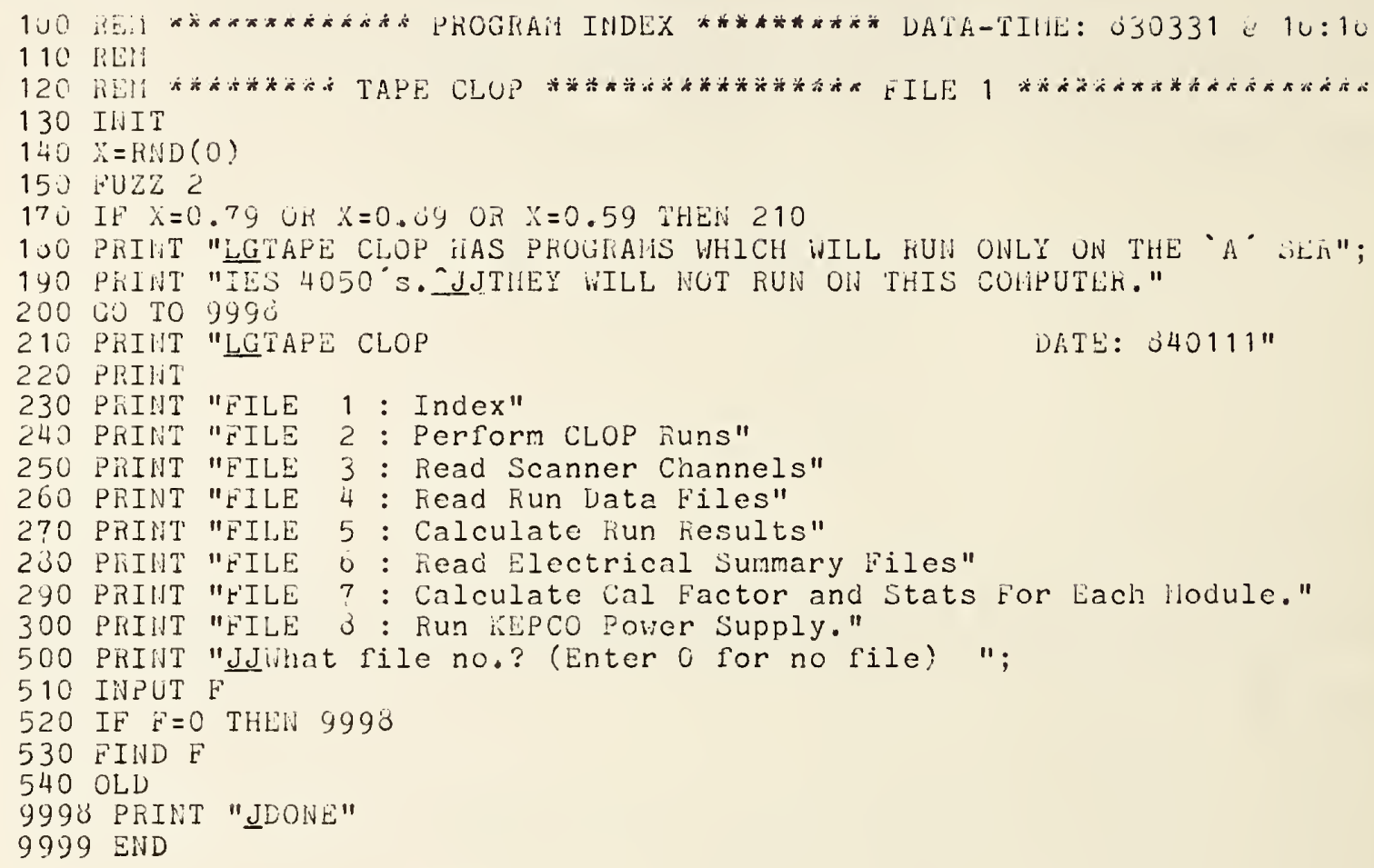

Variable Map

F-file number of proyram to run

$X$-number indicating type of System $T$ computer beiny used 
B2. CLUP (FILE 2)

Proyram Listing

1 INIT

2 SET KEY

3 SO TO 100

4 REH READ HASS IN

5 IF $F 3\langle 1$ AIND F3 32 THEN ?

Ó GOSUB 9000

7 RETURN

8 HEM KEAD TEHP IH

9 IF $F 3<>1$ AND F $3<>2$ THEN 11

10 LUSUB 9900

11 RETURII

16 REM PAUSE ROUTINE

$17 \mathrm{~F} \dot{\partial}=1$

18 RETURN

44 REH GAS ON

45 IF $F 3<>1$ AIND F3 32 THEN 4 ?

46 GOSUB 9600

47 RETURN

48 REM GAS OFF

49 IF $F 3<1$ AND $\& 3<>2$ THEN 51

50 GOSUB 9700

51 KETURI

52 REM CHANGE GAS CYLINDER

53 IF F $3 \longleftrightarrow 1$ THEN 55

54 GOSUB 10100

55 RETURN

80 REI ABOKT RUN ROUTINE

81 IF $F 2=0$ THEN 96

82 PHINT e 19:"D"

$33-3=0$

$84 F 2=0$

85 IF J>120 THEN 92

86 GOSUB 9700

87 PRINT "JJGProgram aborted! $\underline{G}$ CLOP is on HOLD before 2 min adj period."

88 WBYTE $256,4,1$ :

89 CALL "IFC"

90 GOSUB 10000

91 GO TO 3740

92 PRINT "JJGGJGAbort activated! We are retreating to the $2 \mathrm{~min}$ adjus";

93 PRINT "tment period."

94 CALL "WAIT",?

95 GO TO 3740

96 FETURN

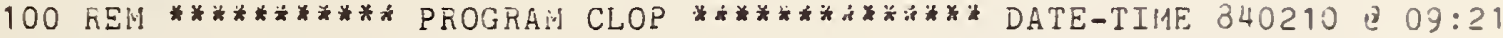

$110 \mathrm{REM}$

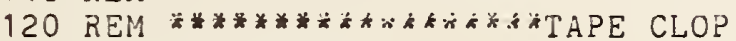

130 REM INIT EQUIP.

140 OIf SRQ THEN 10300

150 PRINT 26:"12000"; "2200F"

10 O VIBYTE $255,4,1$ : 


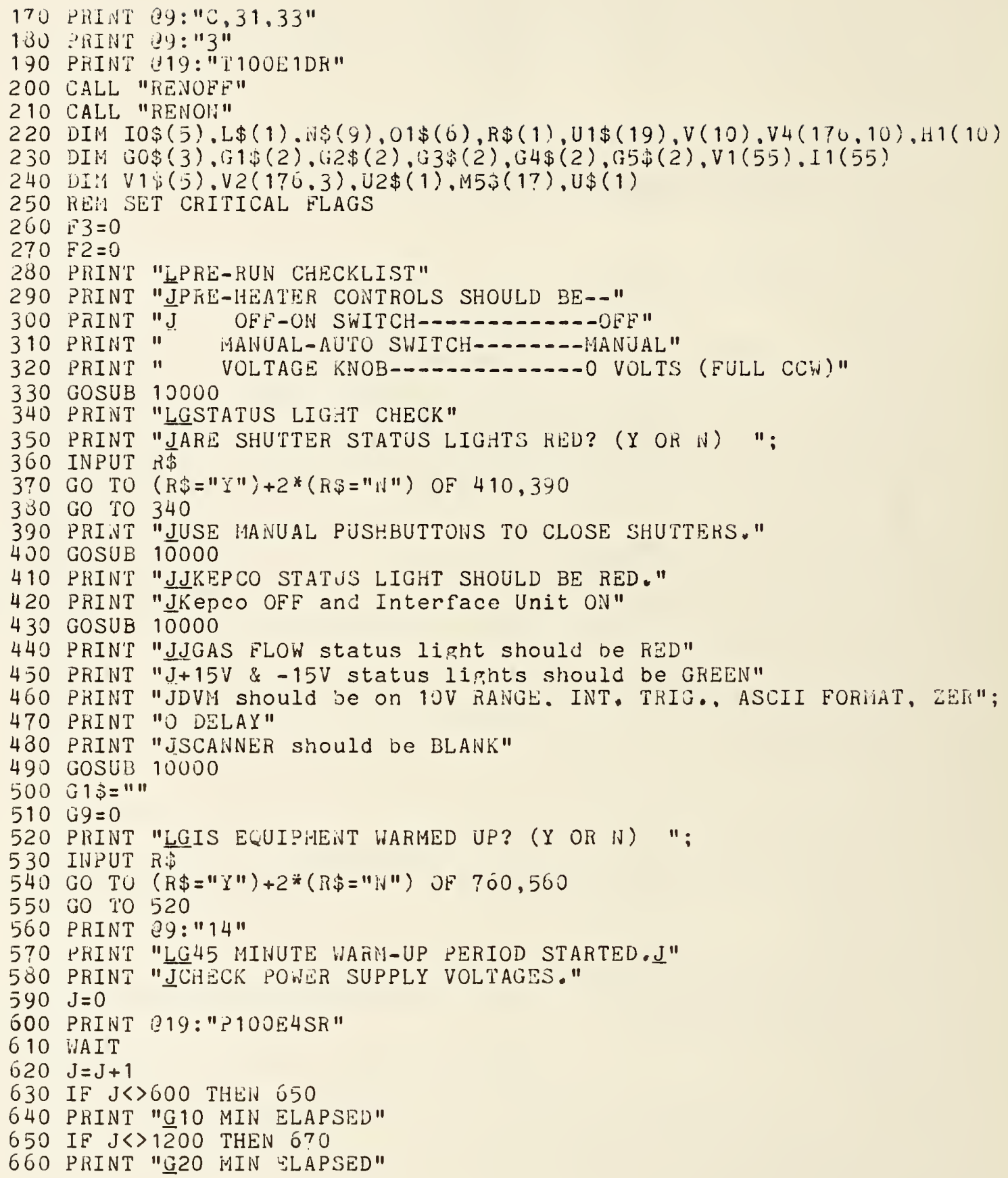




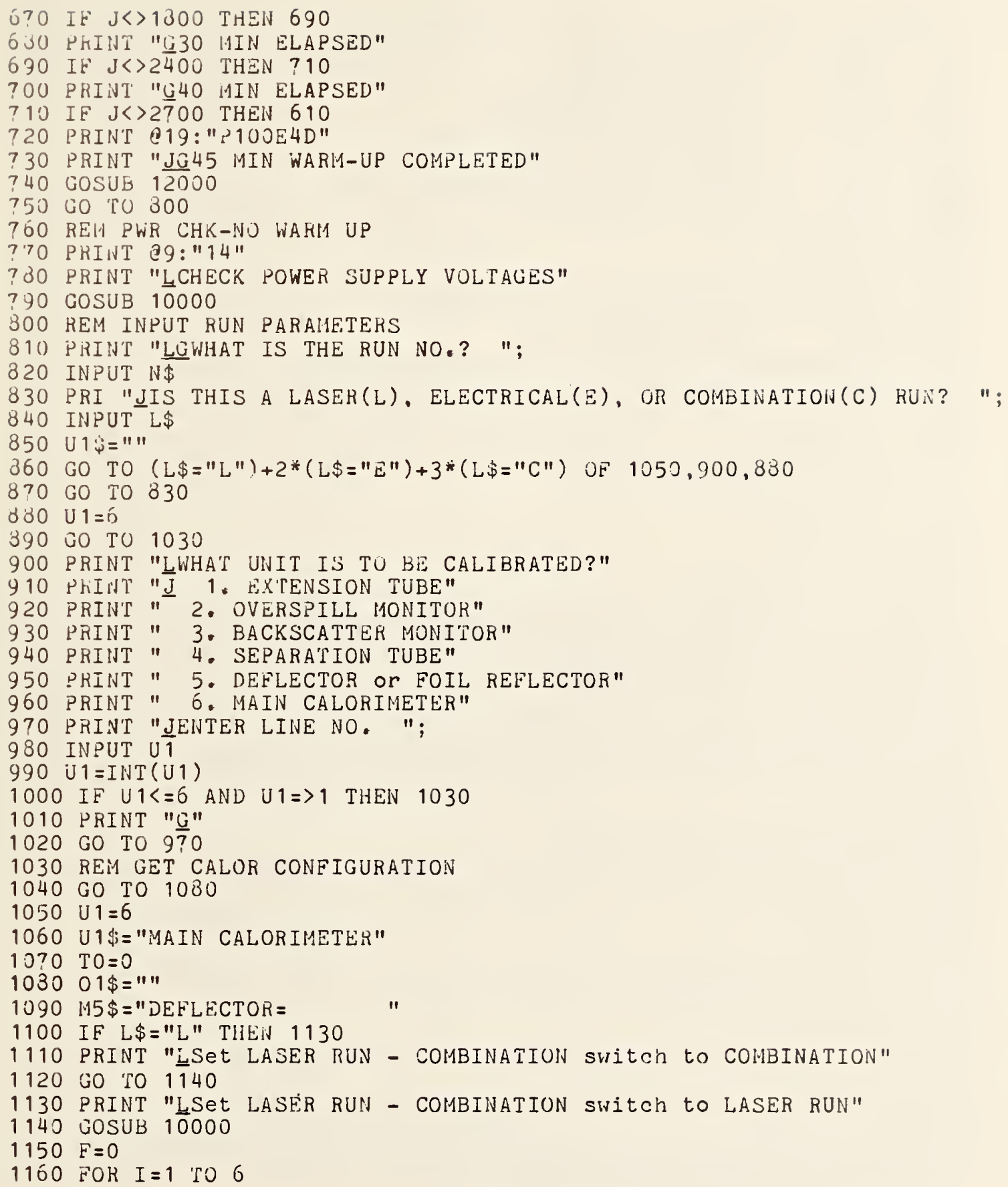




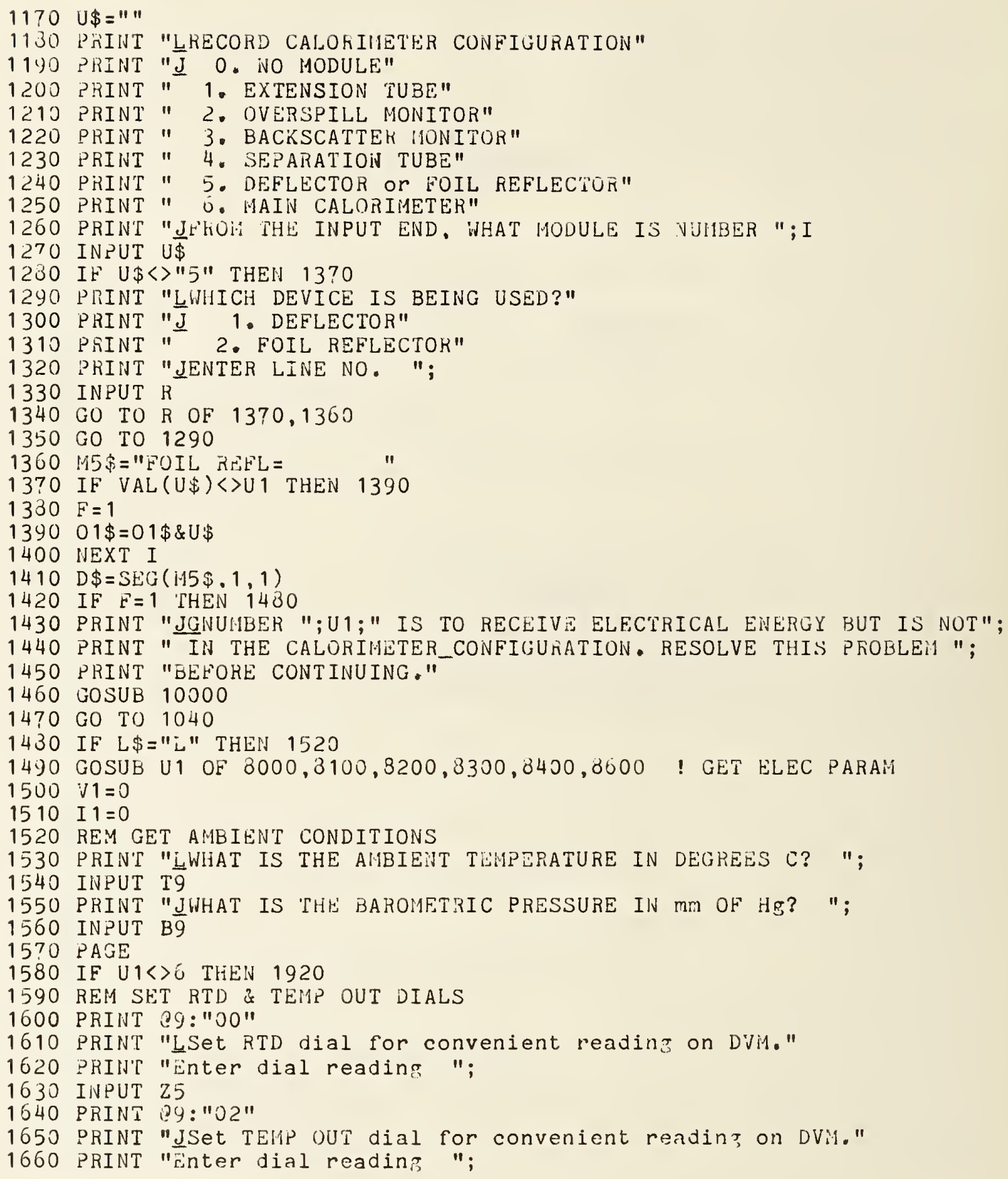




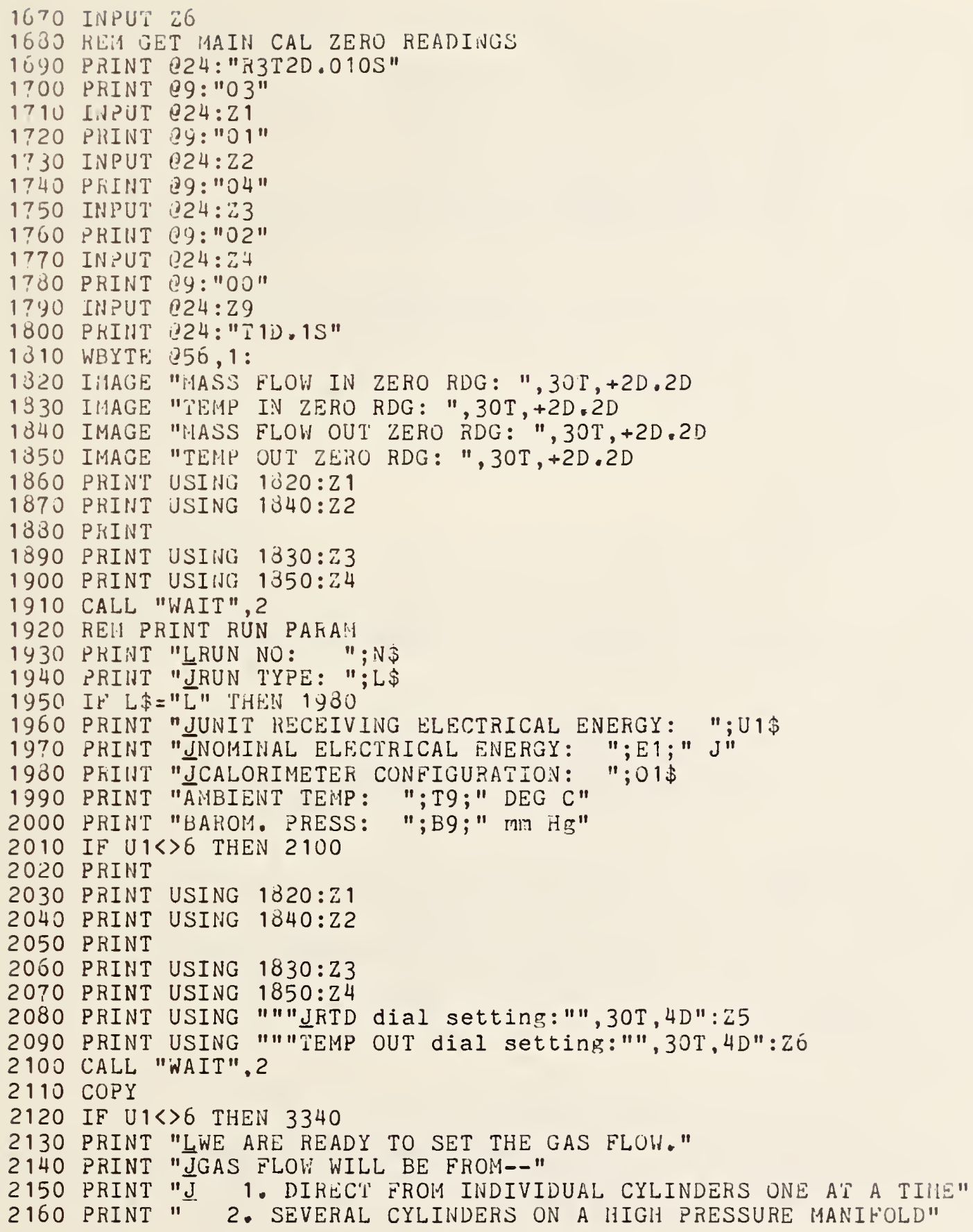




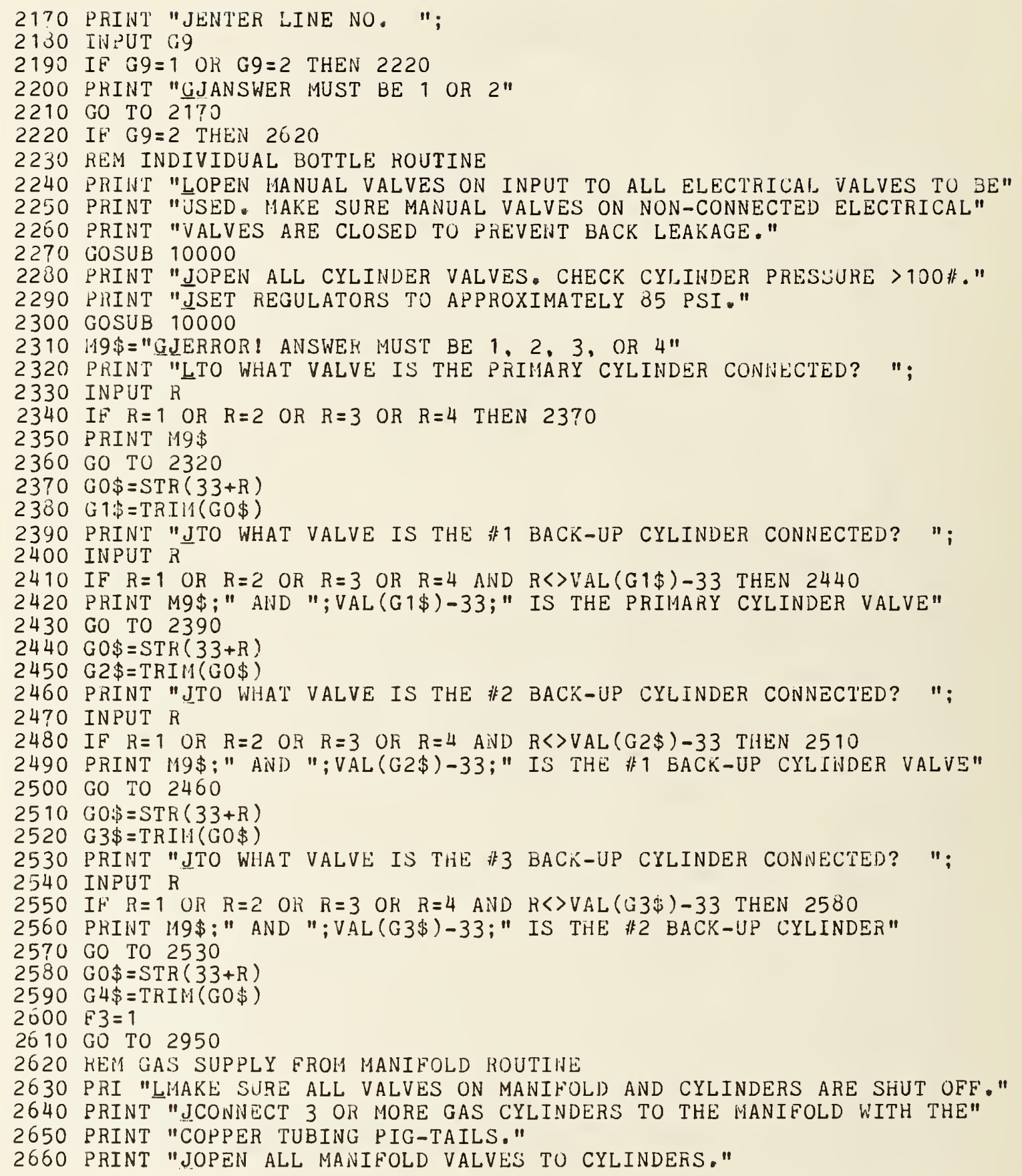




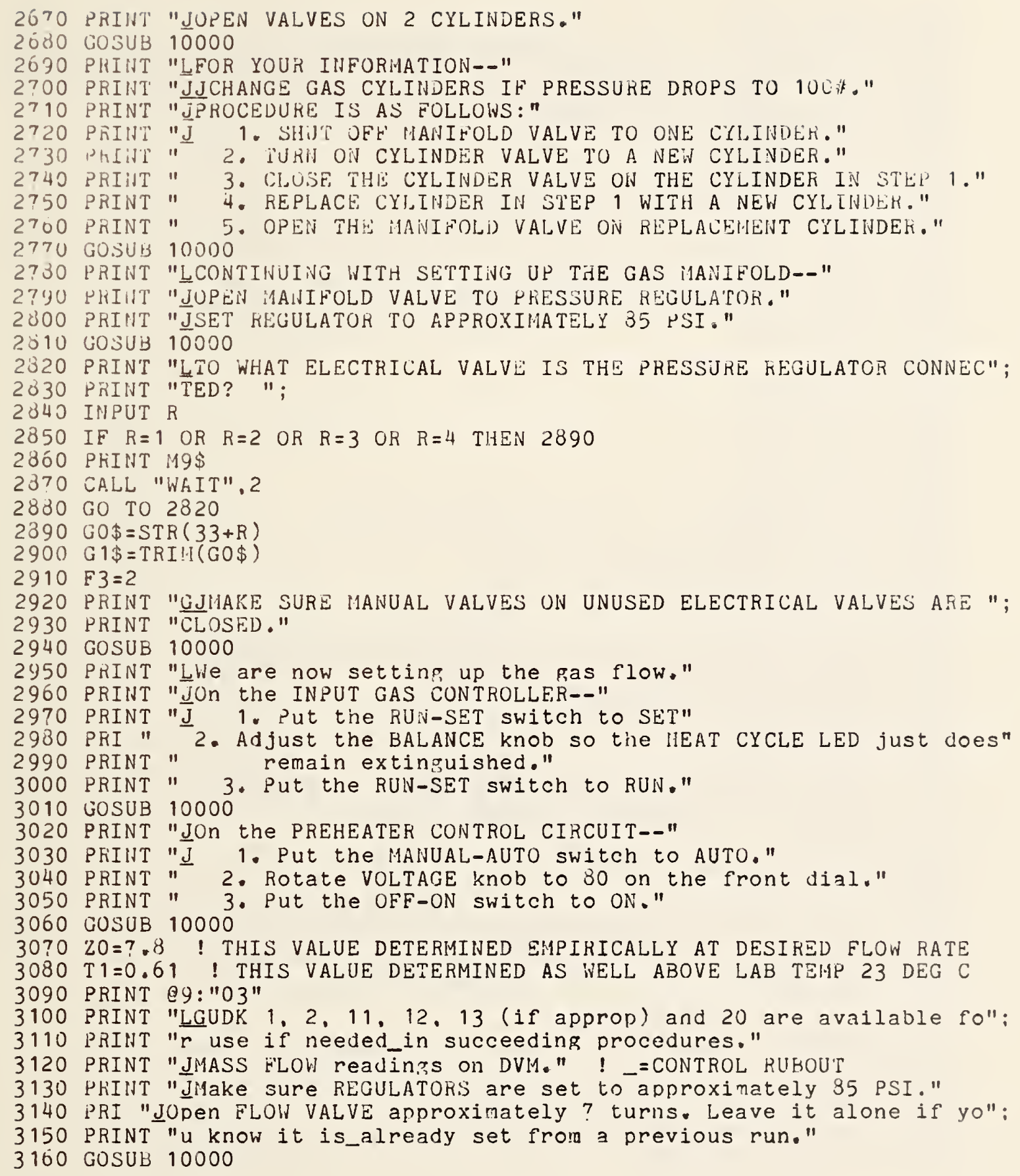




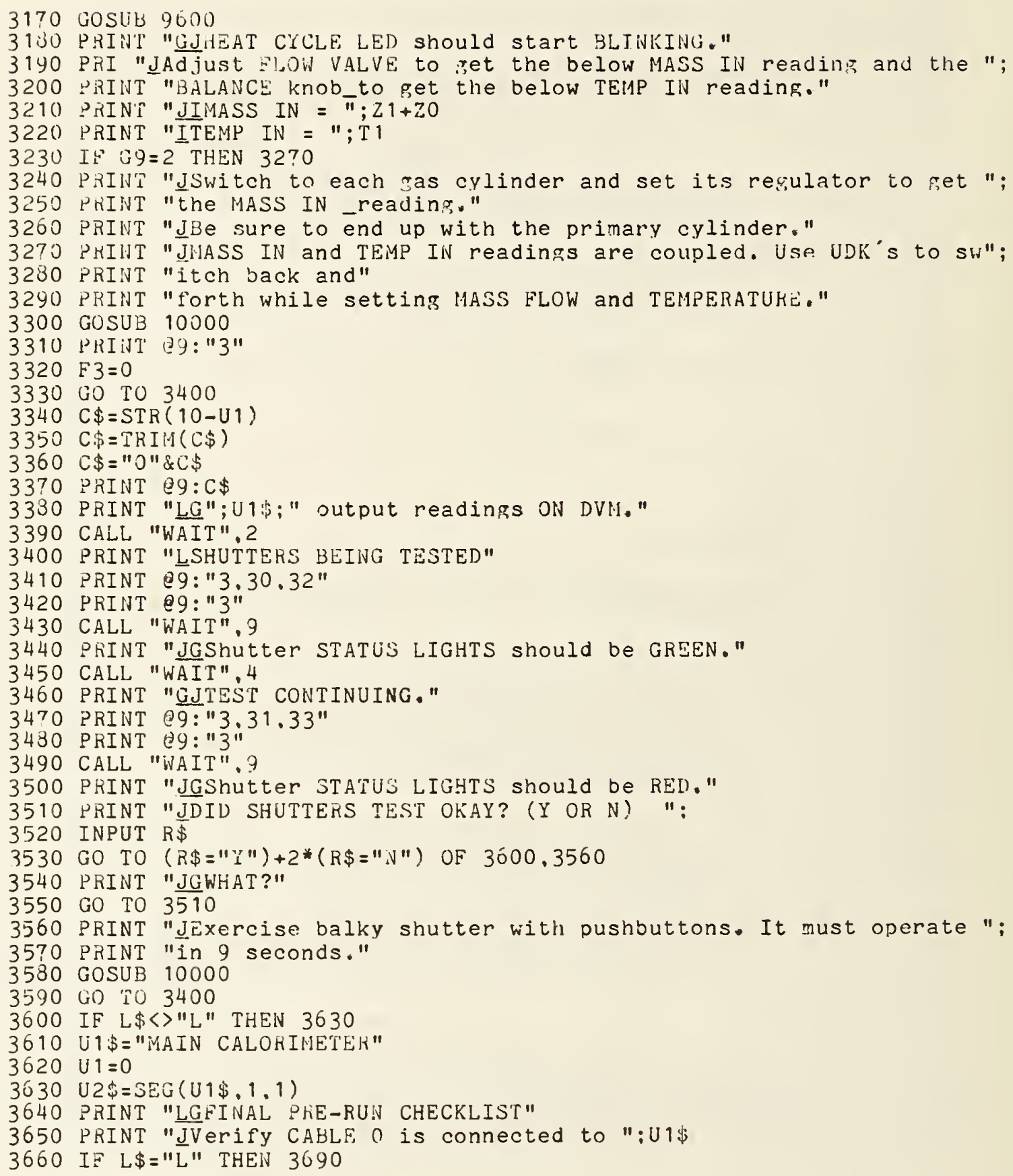




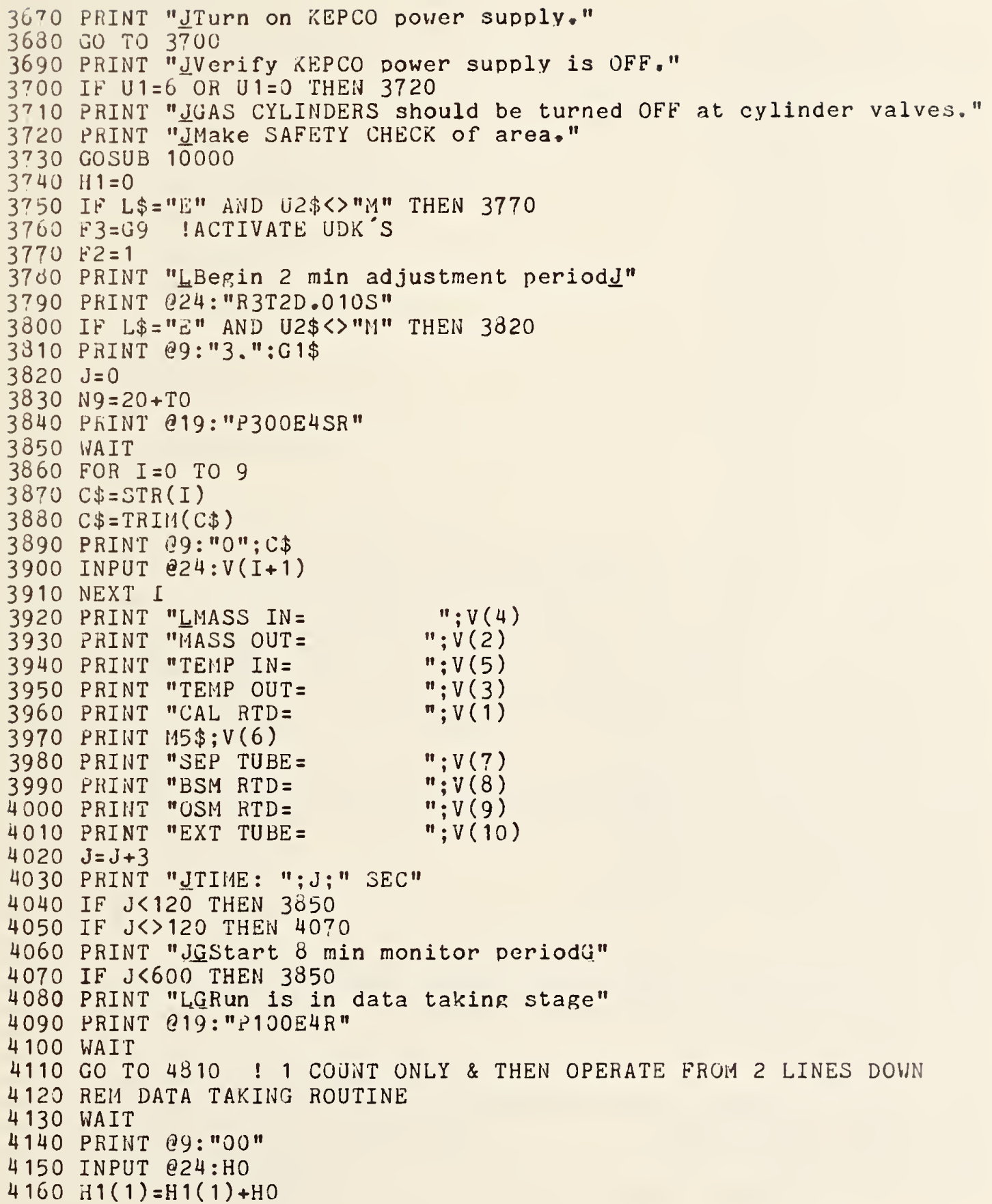




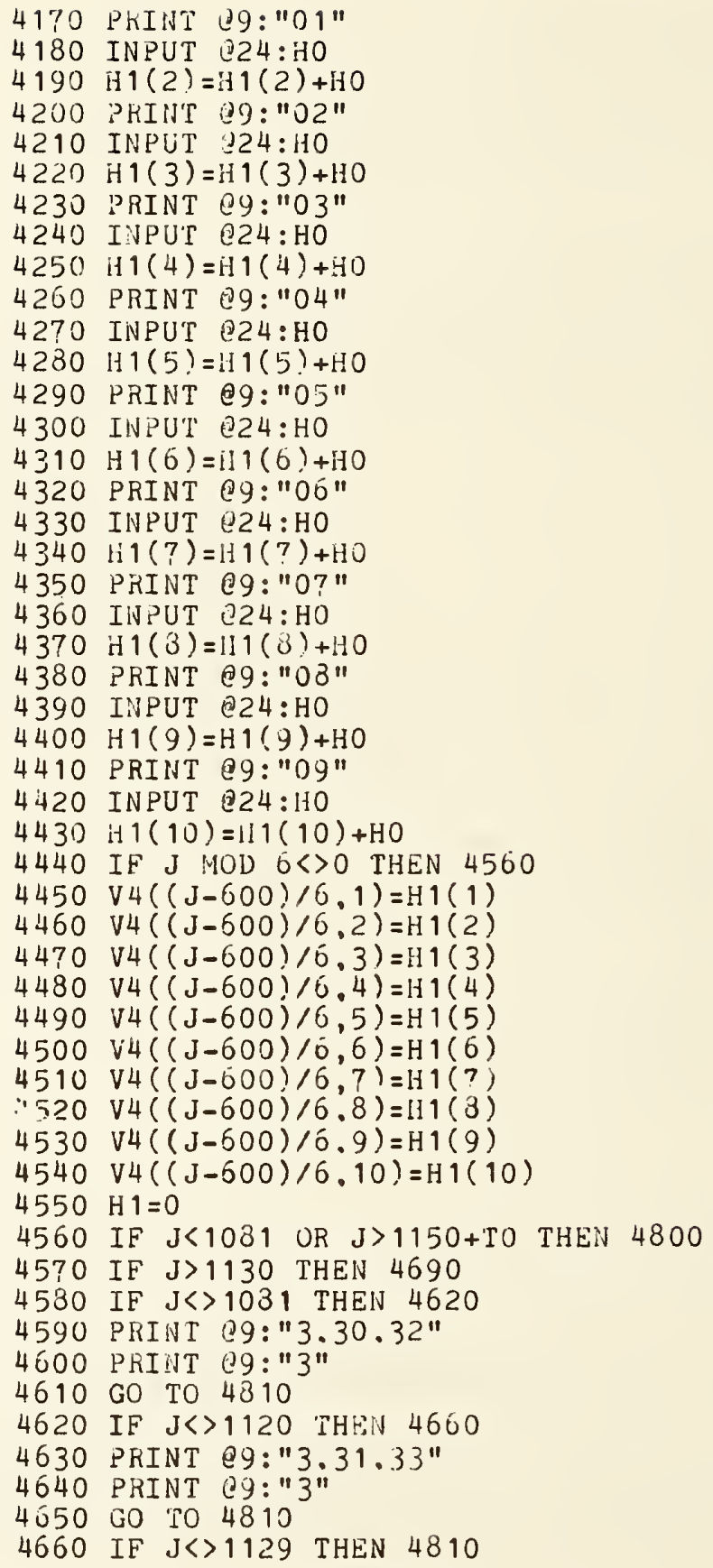




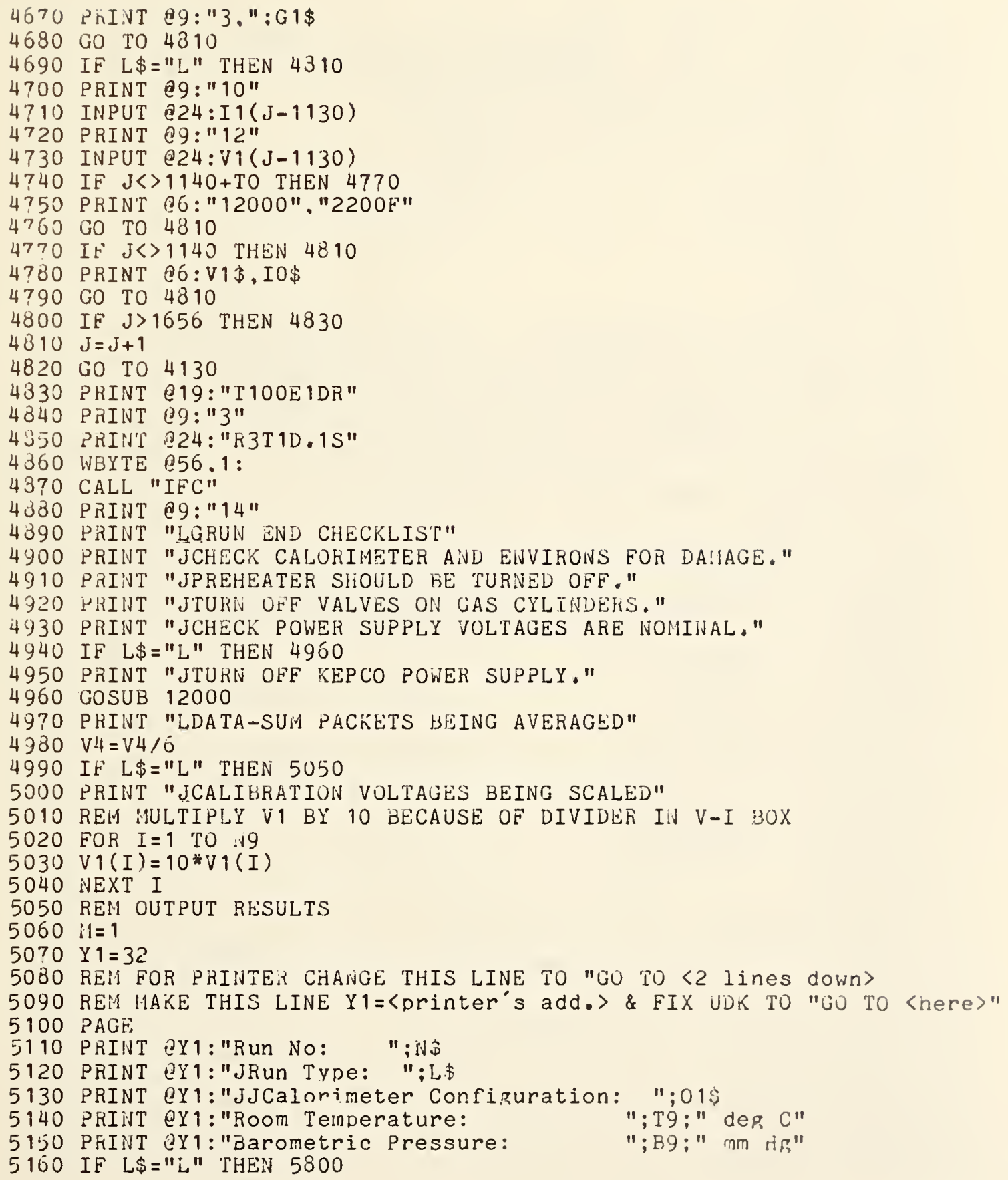




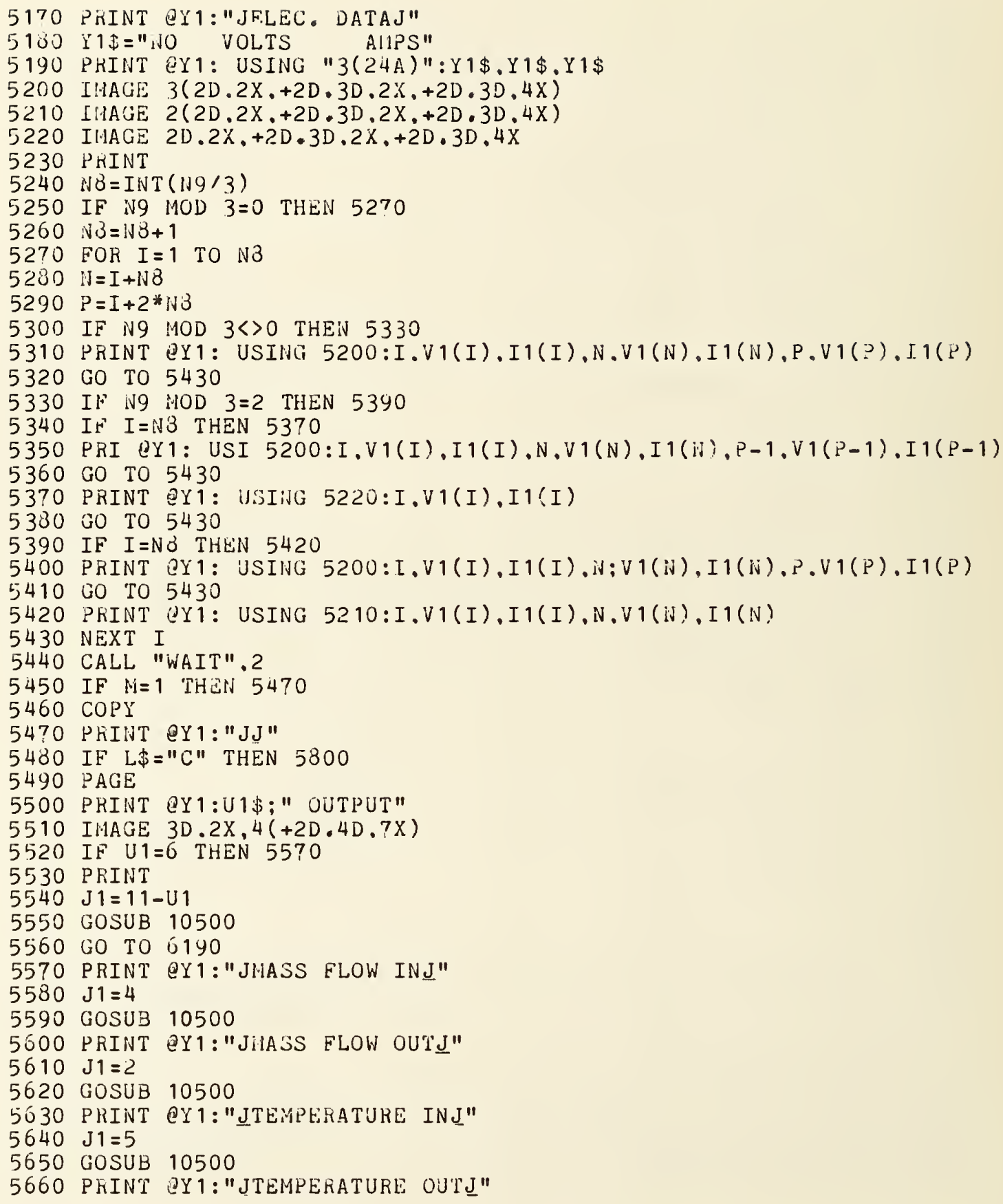




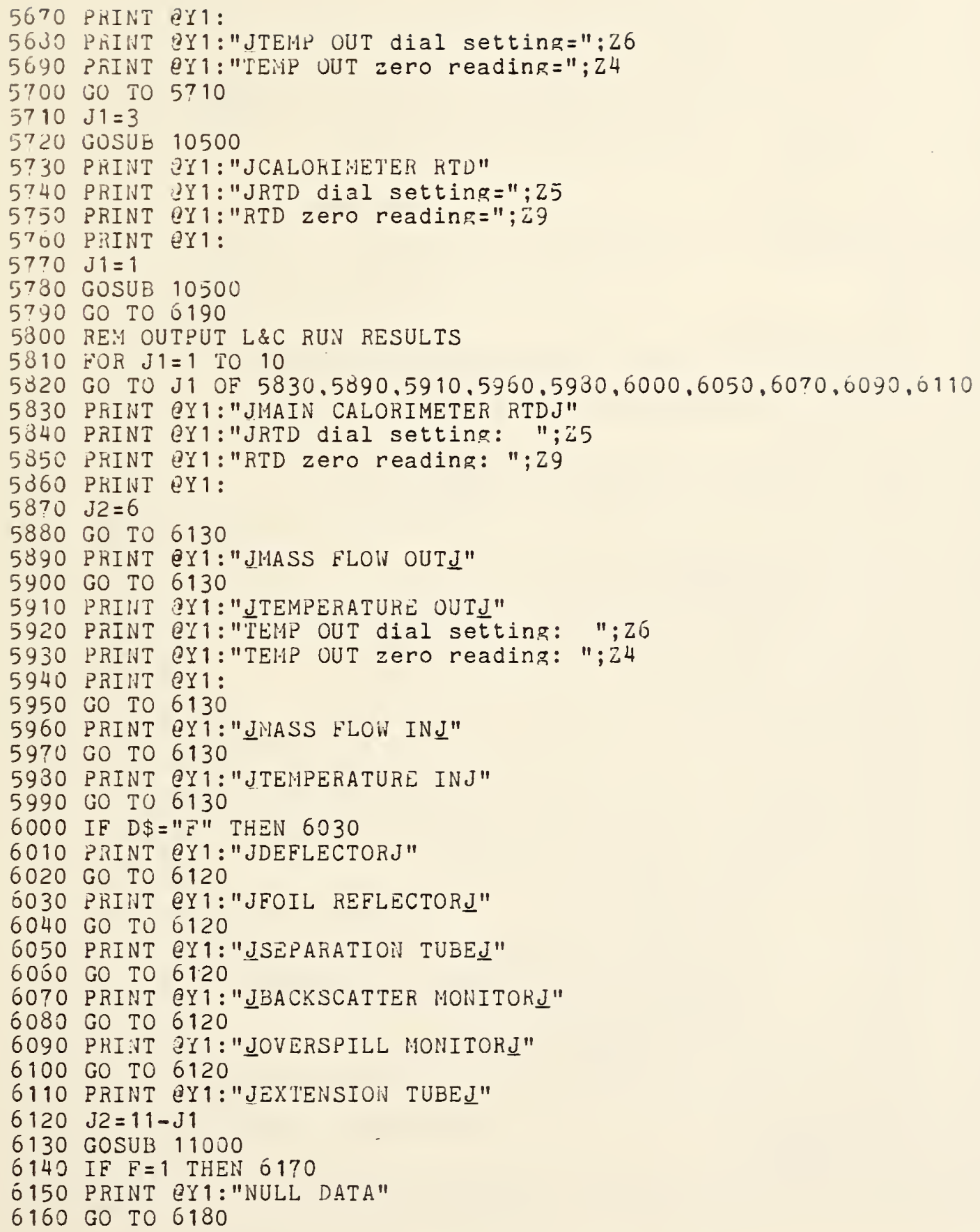




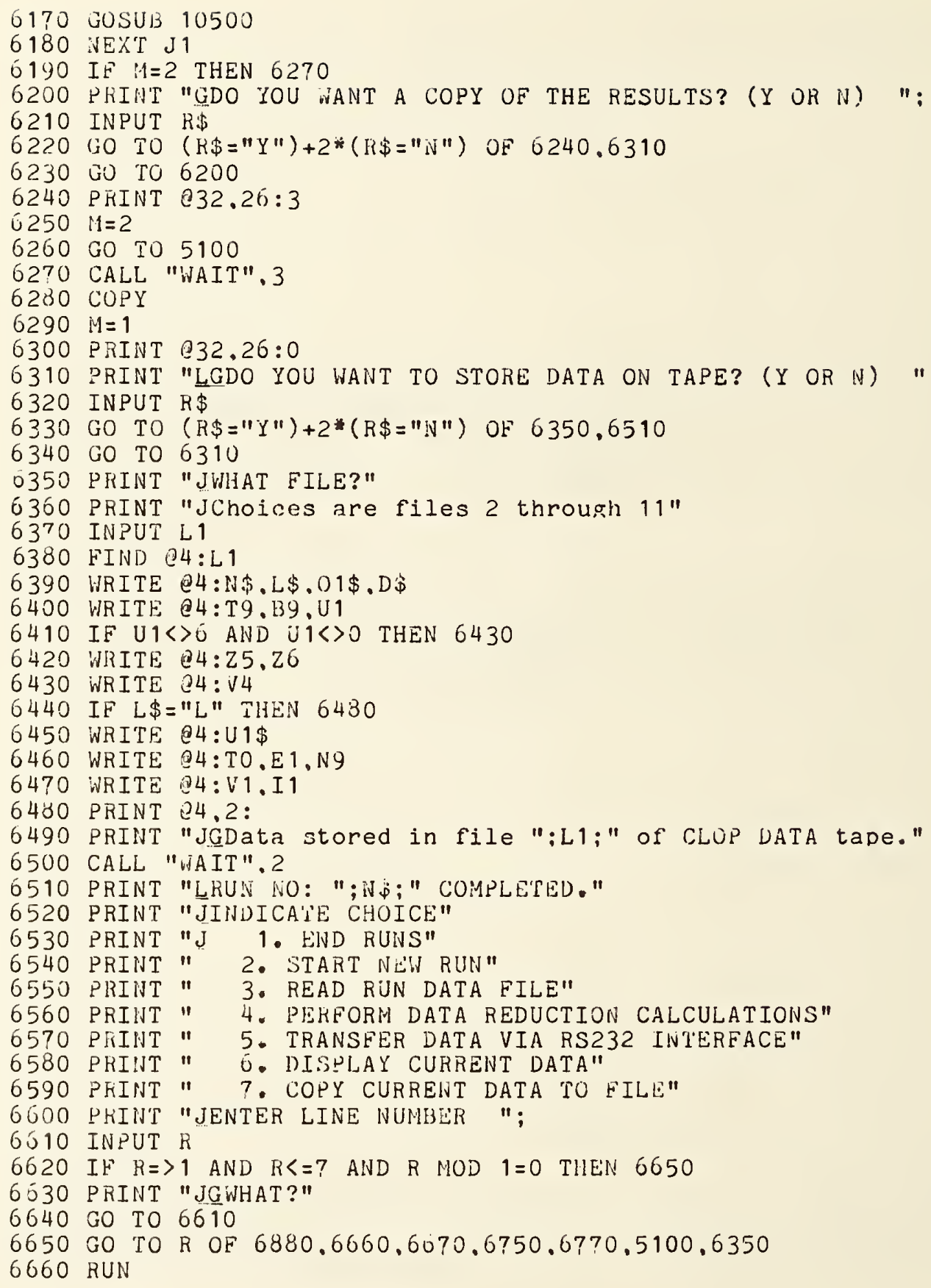




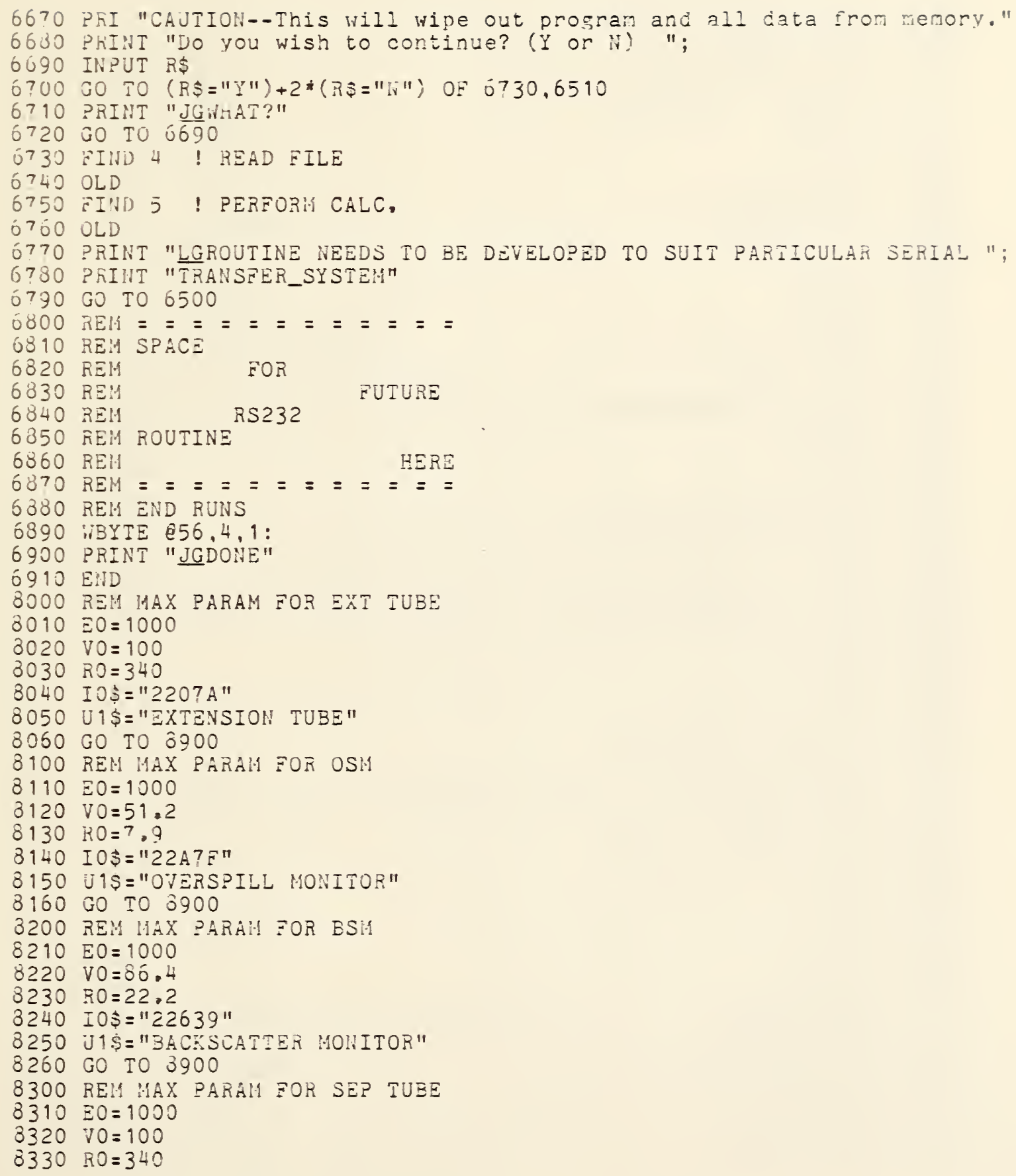




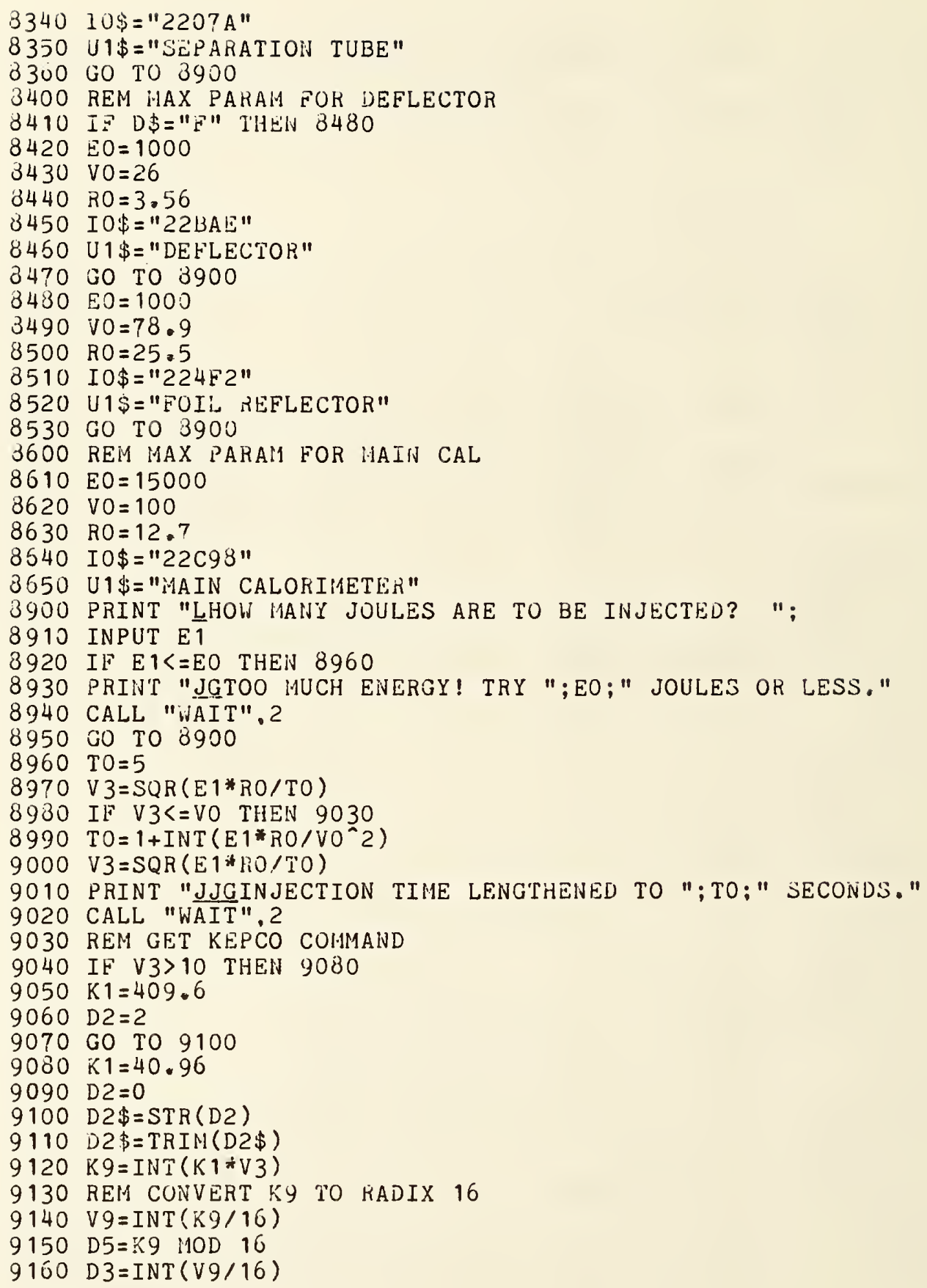




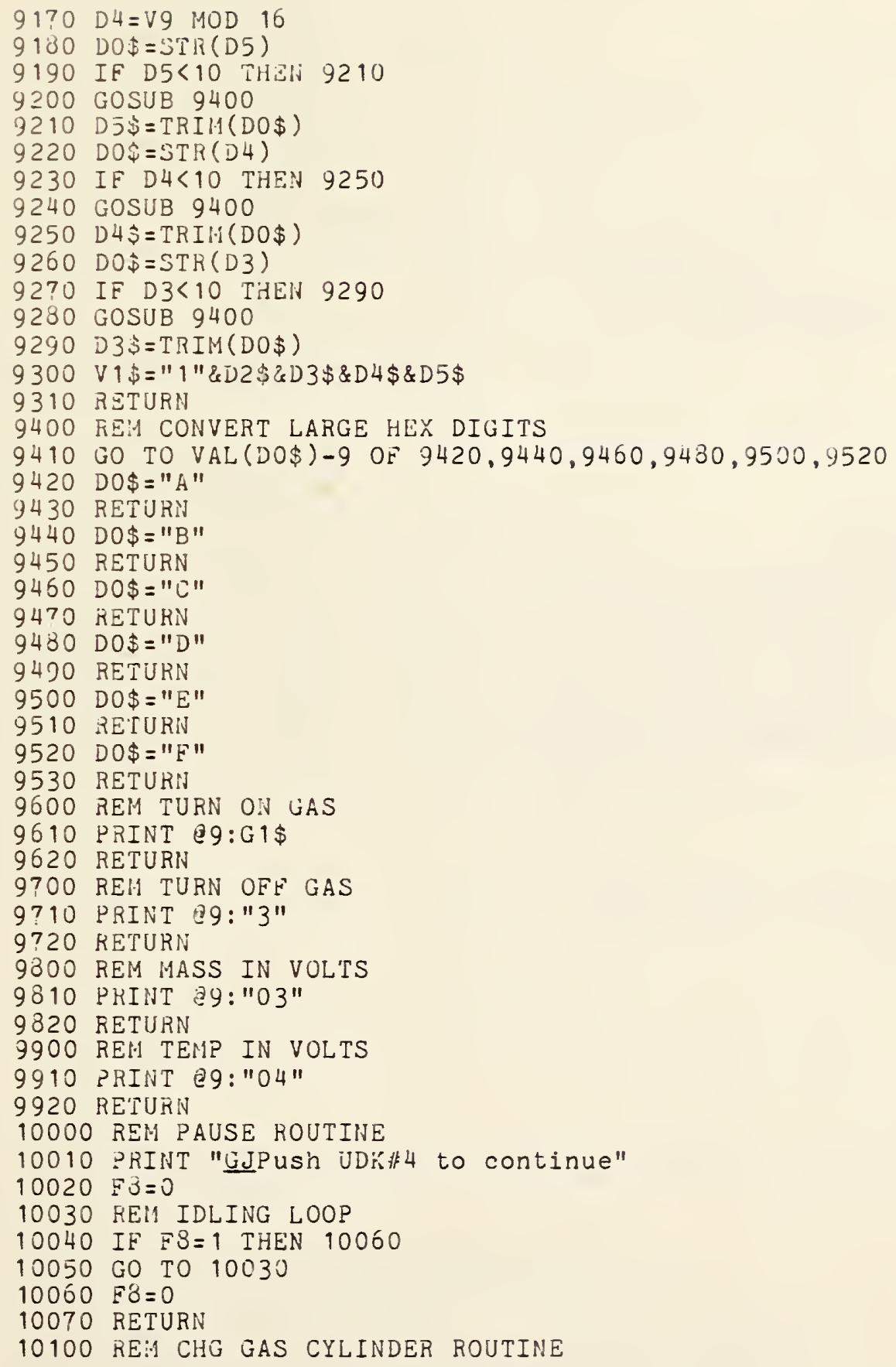




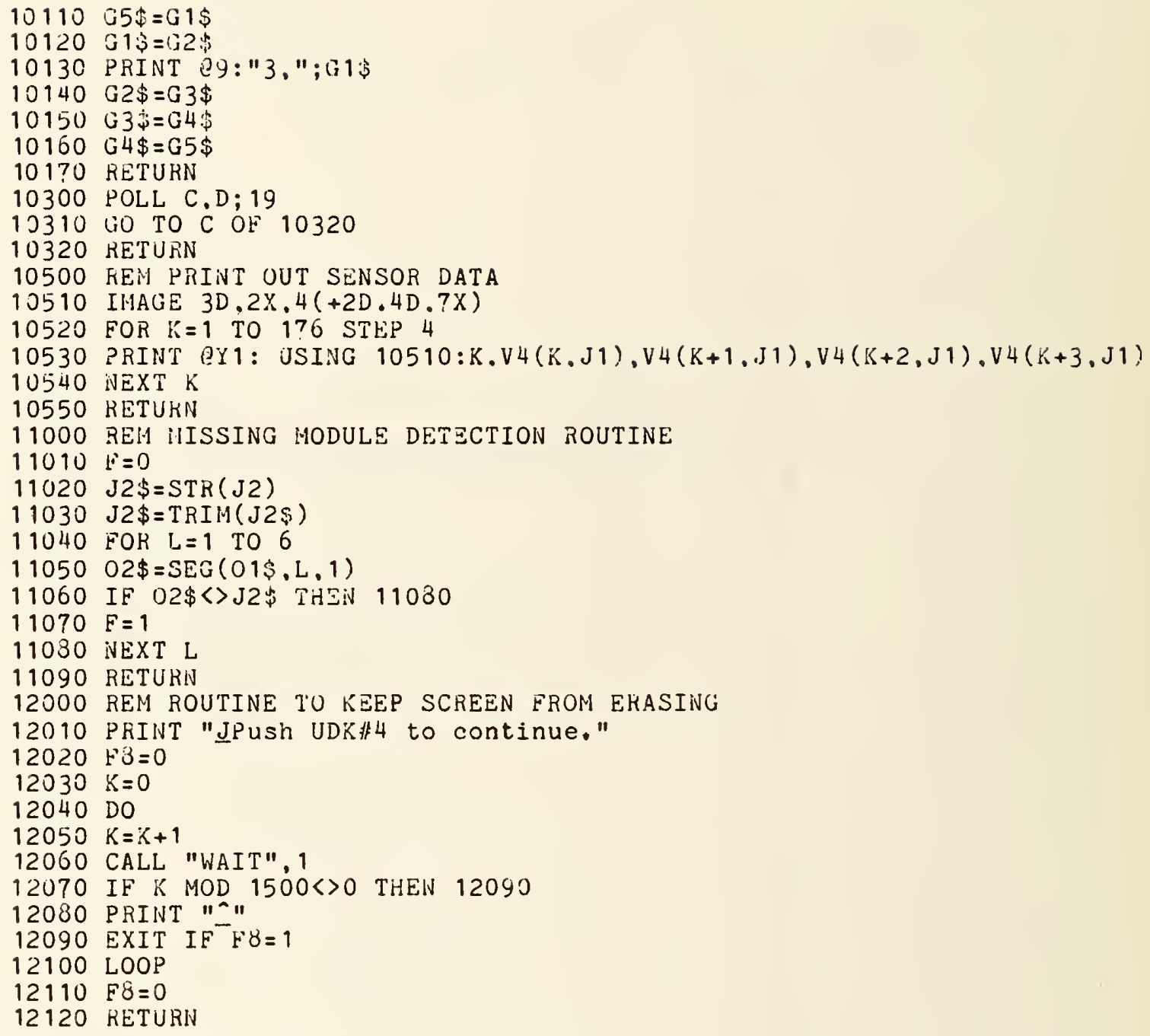


By - barometric pressure in $\mathrm{mm}$ of $\mathrm{Hg}$

C - polling variable indicating unit activating SRQ

cs - scanner channel command for switching sensor channels

D - polling variable indicating SRQ message

U2 - number indicating power supply voltage range

U3 - first hexadec. digit (MSD) of voltage part of power supply command

04 - second hexadec. digit of voltage part of power supply command

D5 - third hexadec. digit (LSD) of voltage part of power supply command

US - deflector-type descriptor ( $F=$ foil reflector, $D=$ mirror deflector)

U2\$ - second digit in power supply command (string version of D2)

U3\$ - third digit in power supply command (string version of D3)

U4\$ - fourth digit in power supply command (string version of D4)

US\$ - fifth digit in power supply command (string version of U5)

UY\$ - temporary string variable for converting hexadec. digits to string variables

El - nominal electrical energy input

EO - maximum allowable electrical energy

F - flay to look for unit missing from calorimeter configuration

F.2 - flay to lock out UDK $\# 20$

F3 - flay to lock out UDKs $\# 1$, \#2, $\# 11$, \#12, and $\# 13$

F8 - flag to leave indefinite wait subroutine

Gy - method of yas supply ( 1 = low press. manifold, 2 = high press. manifold)

G1\$ - electrical valve channel for primary gas cylinder (LP and HP supply)

G2\$ -

G3\$ -

G4\$ -

65\$ -

GUS -

electrical valve channel for \#l back-up gas cylinder (LP supply)

electrical valve channel for \#2 back-up gas cylinder (LP supply)

electrical valve channel for \#3 back-up gas cylinder (LP supply)

temporary string variable for changing order of gas cylinders in LP supply

temporary string variable for setting up gas flow valve priorities

H1 - array for acquiring by summing sensor output data packets

$\mathrm{HD}$ - measured sensor output voltage to be summed to $\mathrm{HI}$

I - counter

$11-$

array containing electrical calibration current readings

IUS -

current limit command to calibration power supply

$J$ - counter

J1 - index indicating sensor data being handled

J2 - index indicating unit being searched for missing module routine

$\mathrm{J} 2 \$$ - string version of $\mathrm{J} 2$

K - counter

Kl - sealing constant for calculating power supply command

$\mathrm{KY}$ - decimal equivalent of hexadecimal voltage part of power supply command

L - counter

L1 - no. of file in which data is to be stored

$L \$$ - run type ( $L=$ laser, $C=$ combination, $E=$ electrical)

$M$ - results output-type descriptor (1 = display, 2 = hardcopy)

M5\$ - deflector-type name display messaye during monitor period

M9\$ - error message in gas set-up routine

$\mathrm{N}$ - line number of second column of VI - II data

N8 - number of lines of VI and II readings to be displayed

N9 - number of $V 1$ (and I1) readings

N\$ - run number

01\$ - calorimeter configuration description

P - index of third column of VI - Il data being displayed 


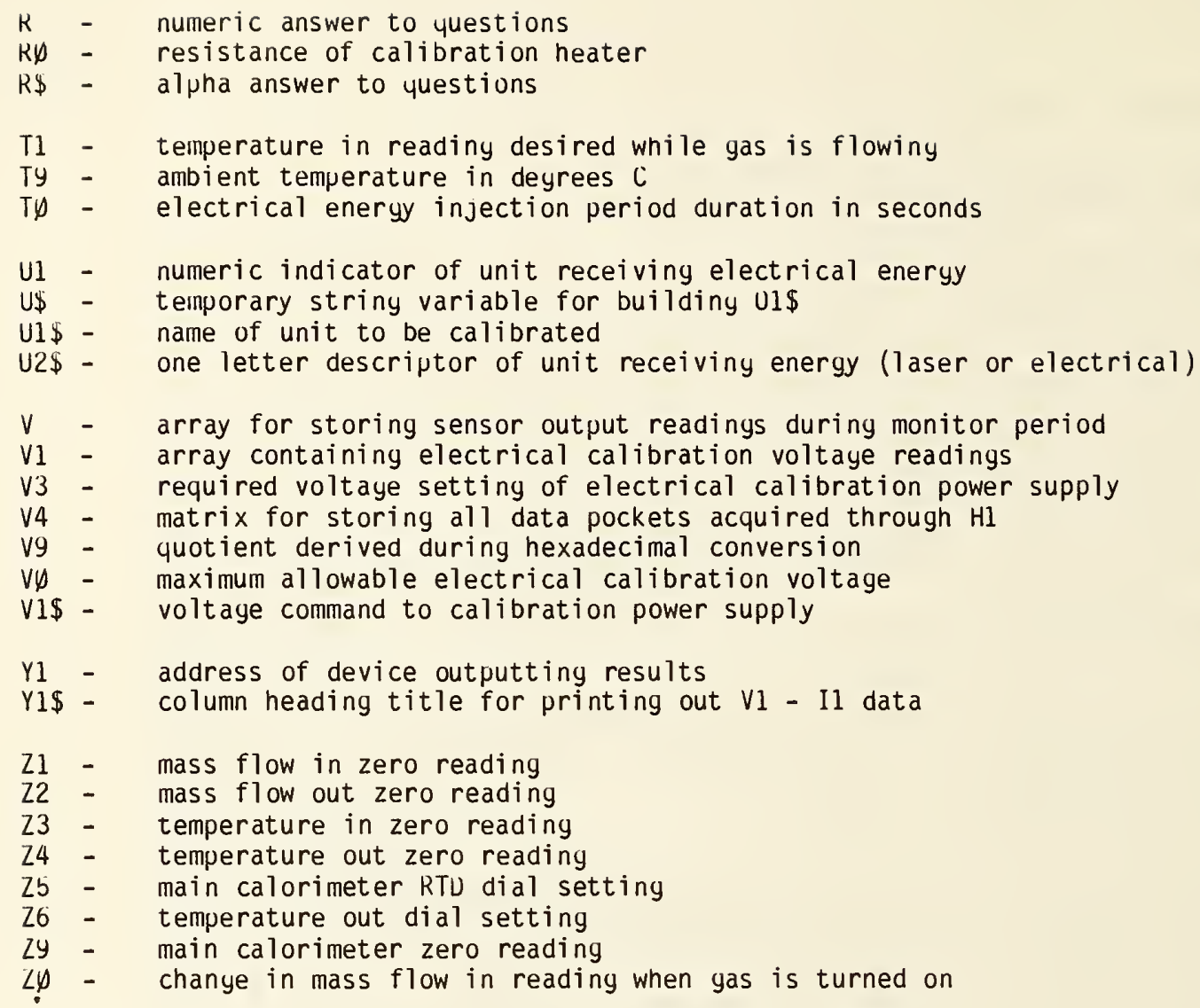


B3. CHANNEL MUNITUR (FILE 3)

Proyram Listiny

1 IIIIT

2 SET KEY

3 GO TO 100

4 KEII KEAD HAIII CAL RTD

5 PRIHT $99:$ "OO"

6 PRIHT "LJJJJHAIU CAL RTD READIINGS ON DVH"

7 KITURA

O RELH READ IIASS FLOW OUT

9 PRIITT C9: "O

10 PRINT "LJJJJIIASS FLOW OUT READIHGS ON DVH"

11 RETURN

12 REM READ TEMP OUT

13 PRINT $29:$ :02"

14 PRINT "LJJJJTEMPERATURE OU'T READINGS ON DVH"

15 RETURN

16 REM READ HASS FLOW IN

17 PRINT $29:$ :03"

18 PRINT "LJJJJHASS ELOW IN READINGS ON DVM"

19 RETURN

20 REH READ TEHP IN

21 PRINT 89:"04"

22 PRINT "LJJJJTEHPERATURE IN READINGS OH DVM"

23 RETURIN

24 REH READ DEFLECTOK

25 PRINT C9: "05"

26 PRINT "LJJJJDEFLECTOR READINGS ON DVII"

27 RETURIN

23 REN READ SEP TUBE

29 PRINT Q9: "06"

30 PRINT "LJJJJSEPARATION TUBE READIINGS ON DVM"

31 RETURN

32 REM READ BSH

33 PRINT Q9: "0?"

34 PRINT "LJJJJBACḰSCATTER MONITOR READINGS ON DVM"

35 RETURN

36 REM READ OSH

37 PRINT $29:$ :08"

38 PRINT "LJJJJOVERSPILL MONITOR READINGS OIN DVI1"

39 RETURN

40 REM READ EXT TUBE

41 PRINT $29:$ :O9"

42 PRINT "LJJJJEXTEHSION TUBE READINGS ON DVH"

43 RETUKN

44 REV GAS VALVE 非 1

45 PRINT E9:"34"

46 RETURN

48 REM GAS VALVE 非 2

49 PRINT C9: "35"

50 RETURN

52 REM GAS VALVE \#3 


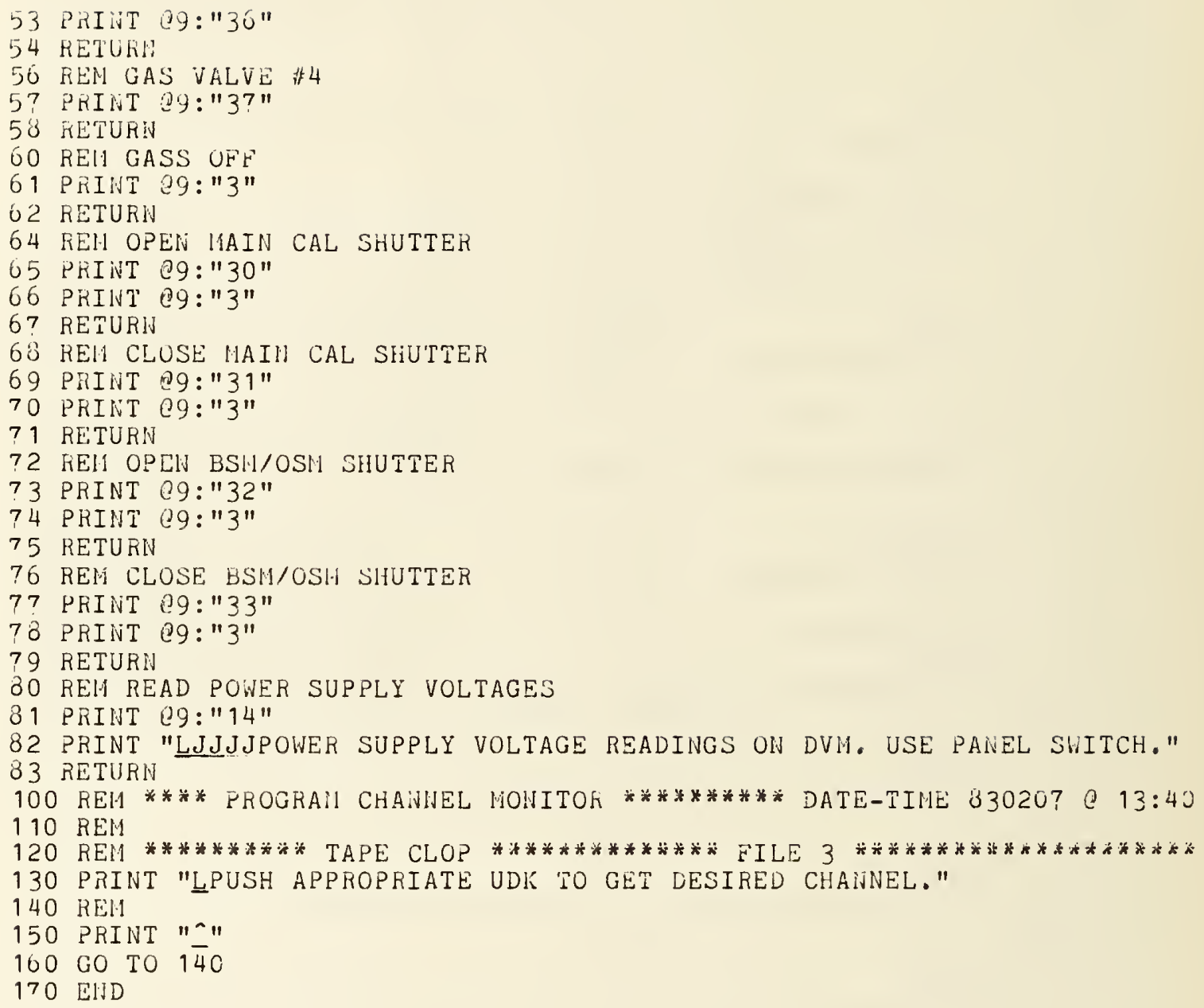

Variable Map, no variables used 


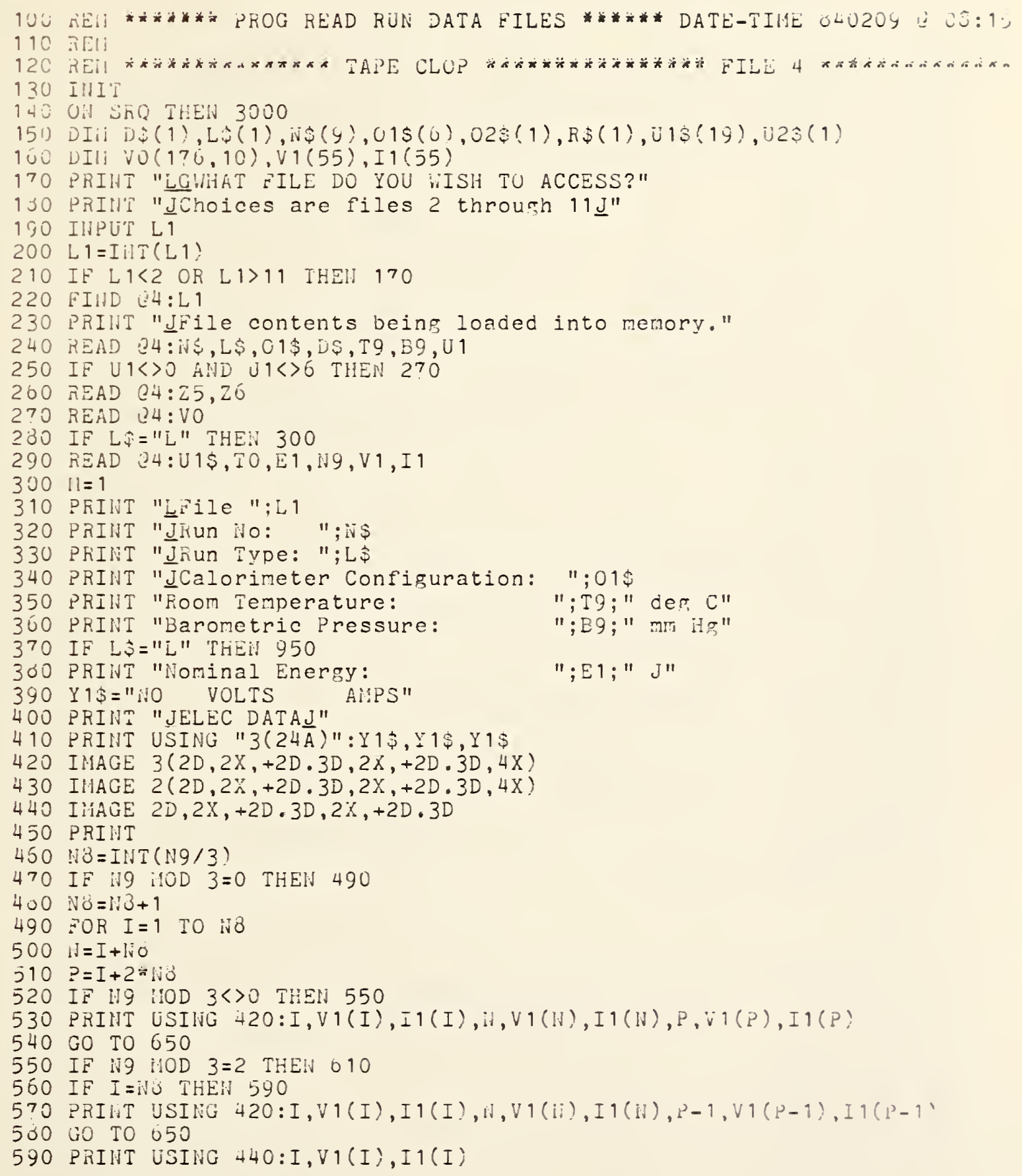




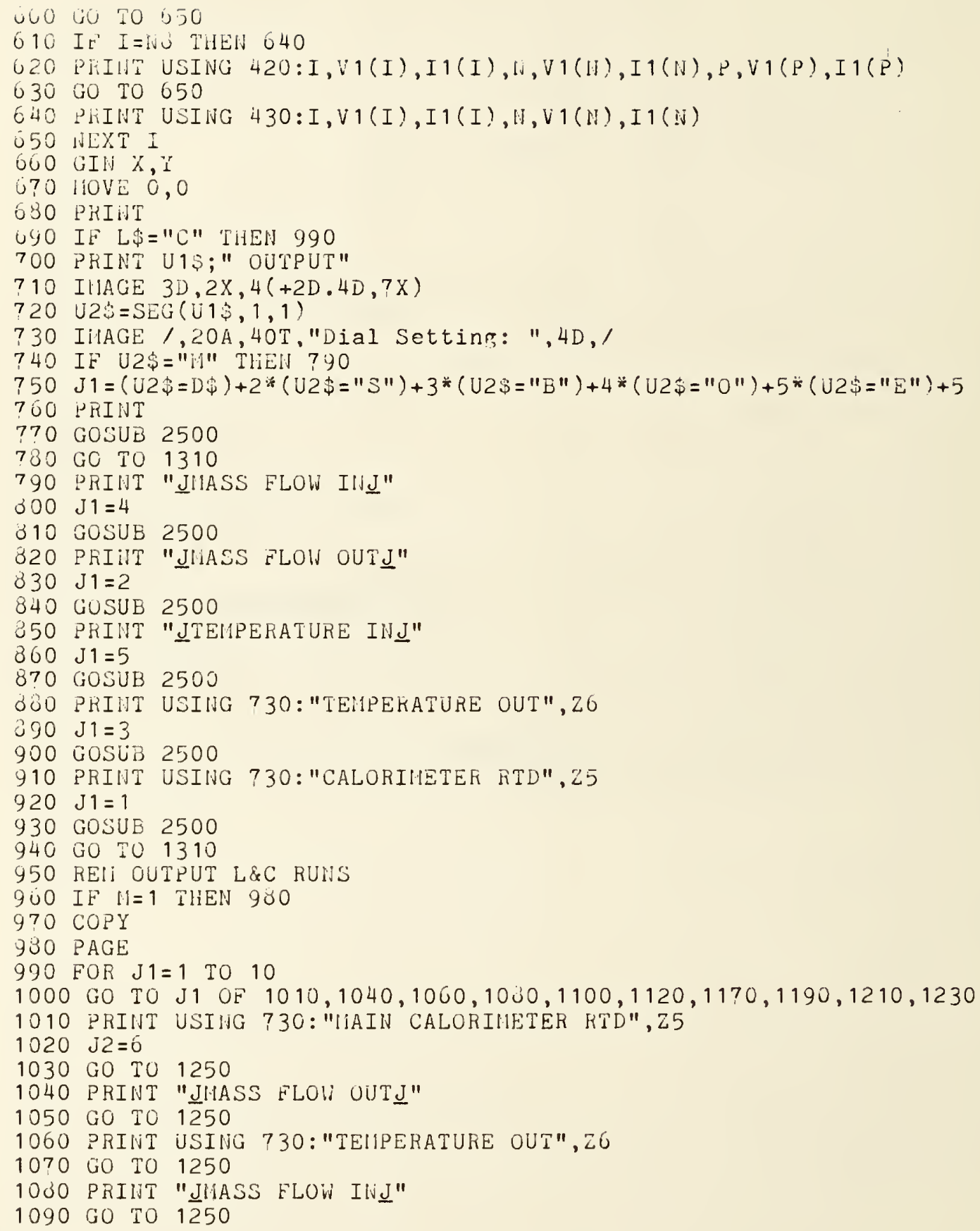




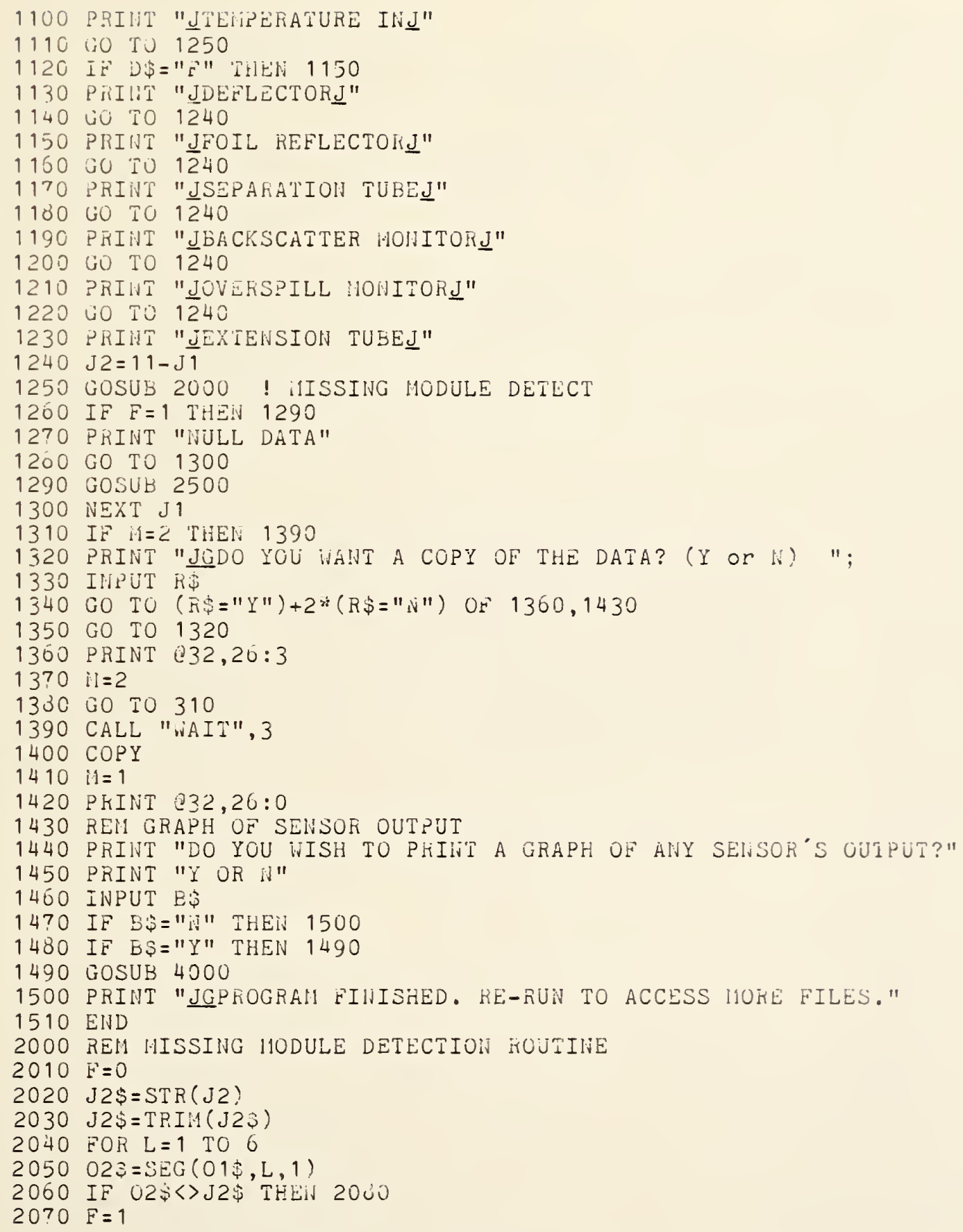




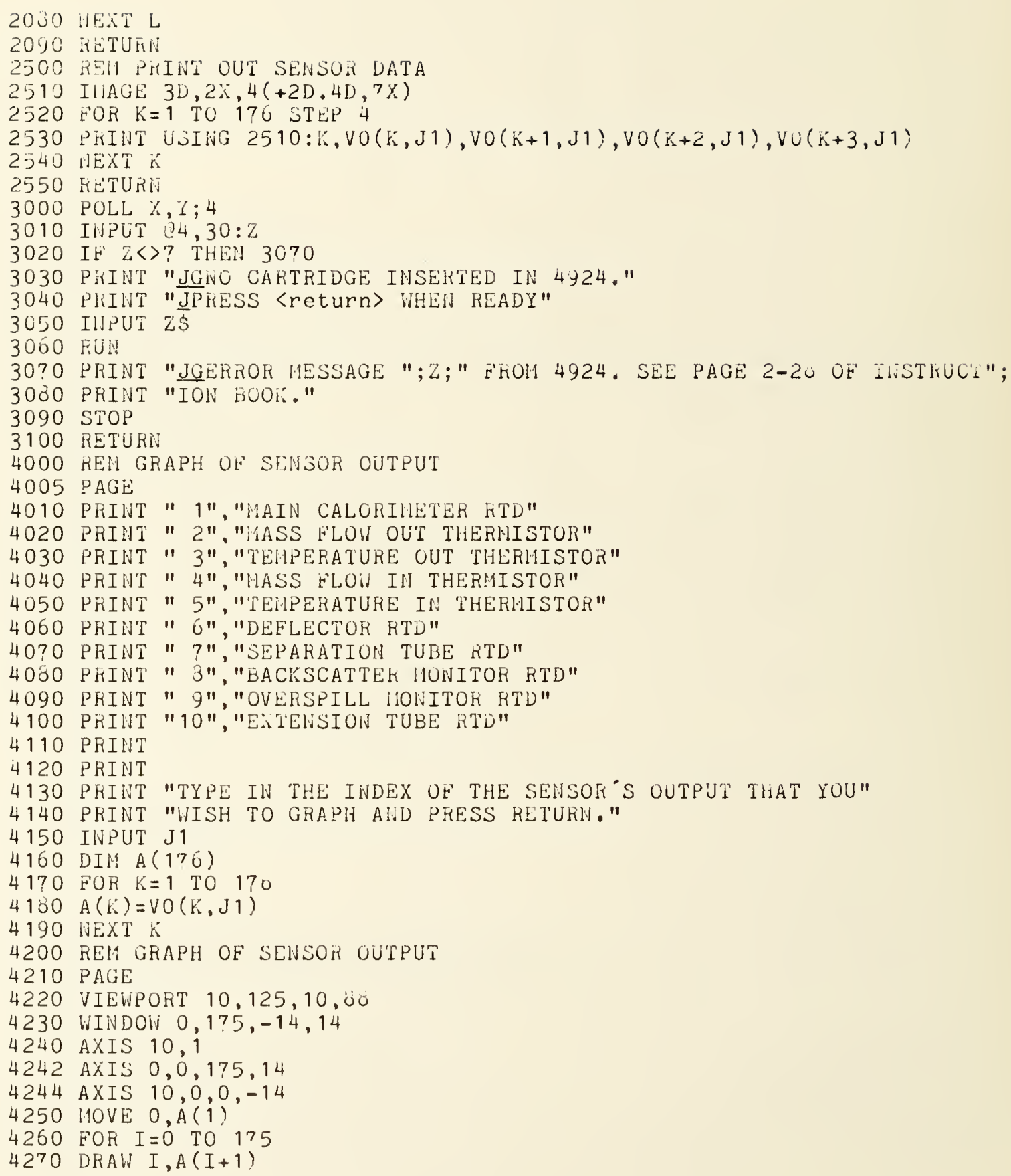




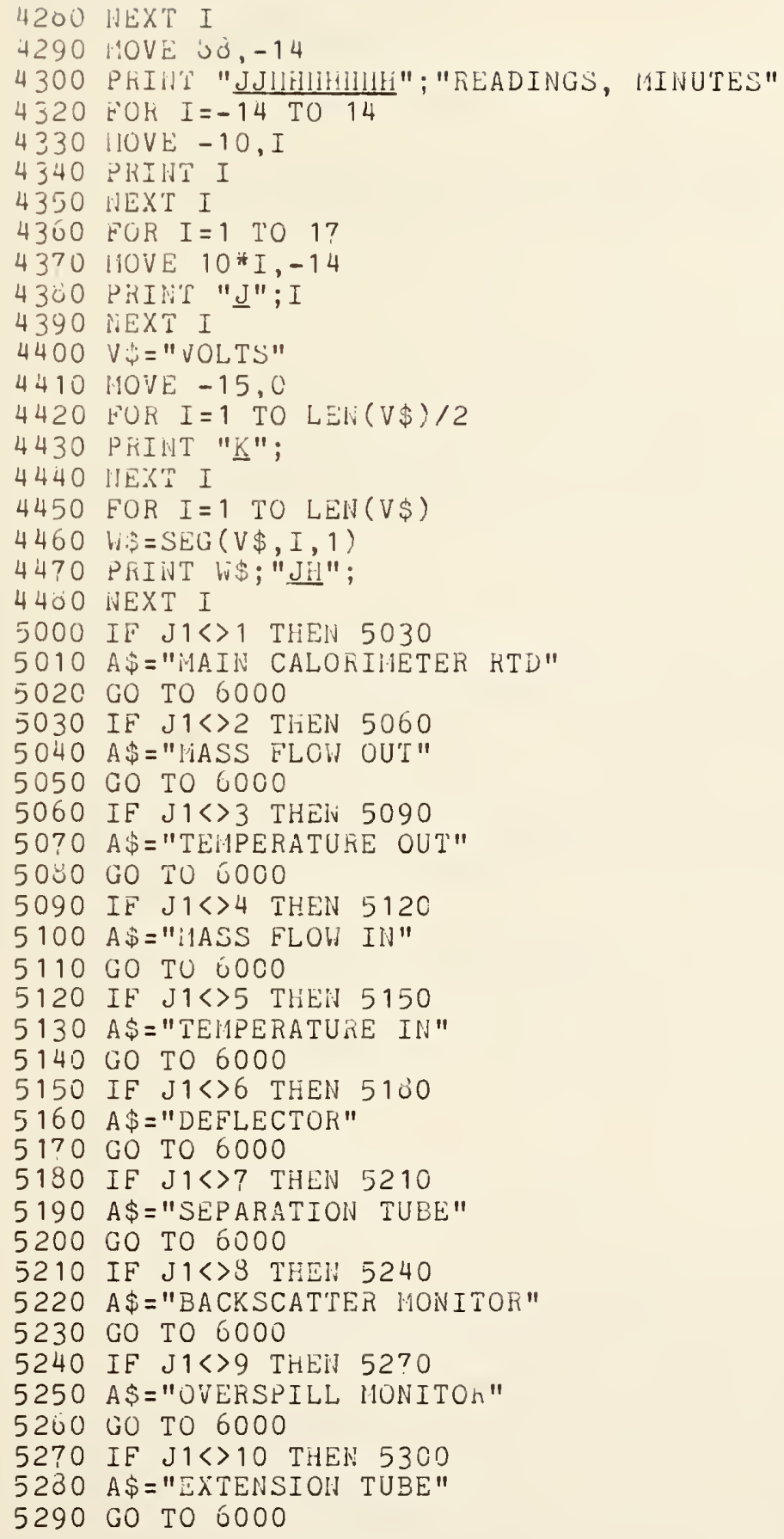




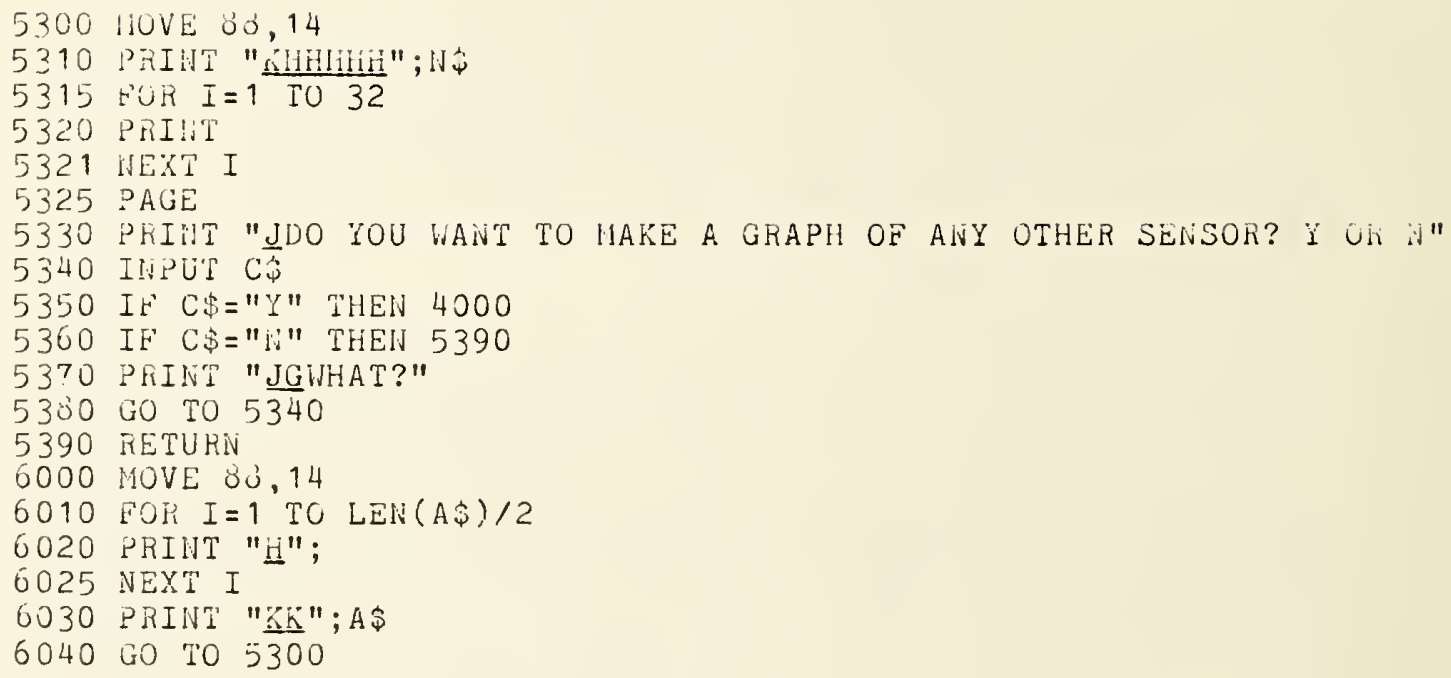


A - array containing sensor output values to be graphed

A\$ - name of sensor output being graphed-graph label

$B 9$ - barometric pressure in $\mathrm{mm}$ of $\mathrm{Hg}$

$B \$$ - answer to yraphing question

C\$ - answer to "yraph ayain" question

U\$ - deflector-type descriptor $(D=$ mirror deflector, $F=$ foil reflector $)$

El - nominal electrical energy injected

F - flay in missiny module routine $(0=$ missing, $1=$ present $)$

$1 \quad$ - counter

11 - array containing electrical calibration current readings

Jl - column index in VD indicating particular sensor

$\mathrm{J} 2$ - numeric indicator of module

J2\$ - string equivalent of J2 for comparing in missing module routine

$k \quad$ - counter

L - counter

L1 - number of data storage file to be read

$L \$$ - run type ( $L=$ laser, $C=$ combination, $E=$ electrical $)$

$M$ - results output-type descriptor $(1=$ display, 2 = hardcopy $)$

$N$ - line number of second column of VI - Il data

NY - number of lines of $V 1$ and $I 1$ readings to be displayed

NG - number of V1 (and II) data points

N\$ - run numbers

$01 \$$ - calorimeter configuration description

U2\$ - seyment of U1\$ in missing module routine

$P \quad$ - index of third column of VI - Il data being displayed

R\$ - alpha answer to questions

Ty - ambient temperature in deyrees $C$

To - duration of injection period in seconds

U1 - number of module receiviny eneryy (laser or electrical)

UI\$ - name of module receiving electrical eneryy

U2\$ - one letter descriptor of unit receiving electrical eneryy

V1 - array containing electrical calibration voltaye readinys

VW - matrix $(176 \times 10)$ containing output values for all sensors

V\$ - yraph ordinate label

$W \$$ - segment of $V \$$ for printing ordinate label vertically

$x$ - GIN variable in routine to create PAGE FULL

$Y \quad$ - GIN variable in routine to create PAGE FULL

Y1\$ - column heading title for printing out VI - Il data, also POLLing variable

$Z$ - error message number from tape deck

Z5 - main calorimeter RTD dial setting

Z6 - temperature out dial setting 
B5. CALCULATE KESULTS (FILE b)

Proyram Listiny

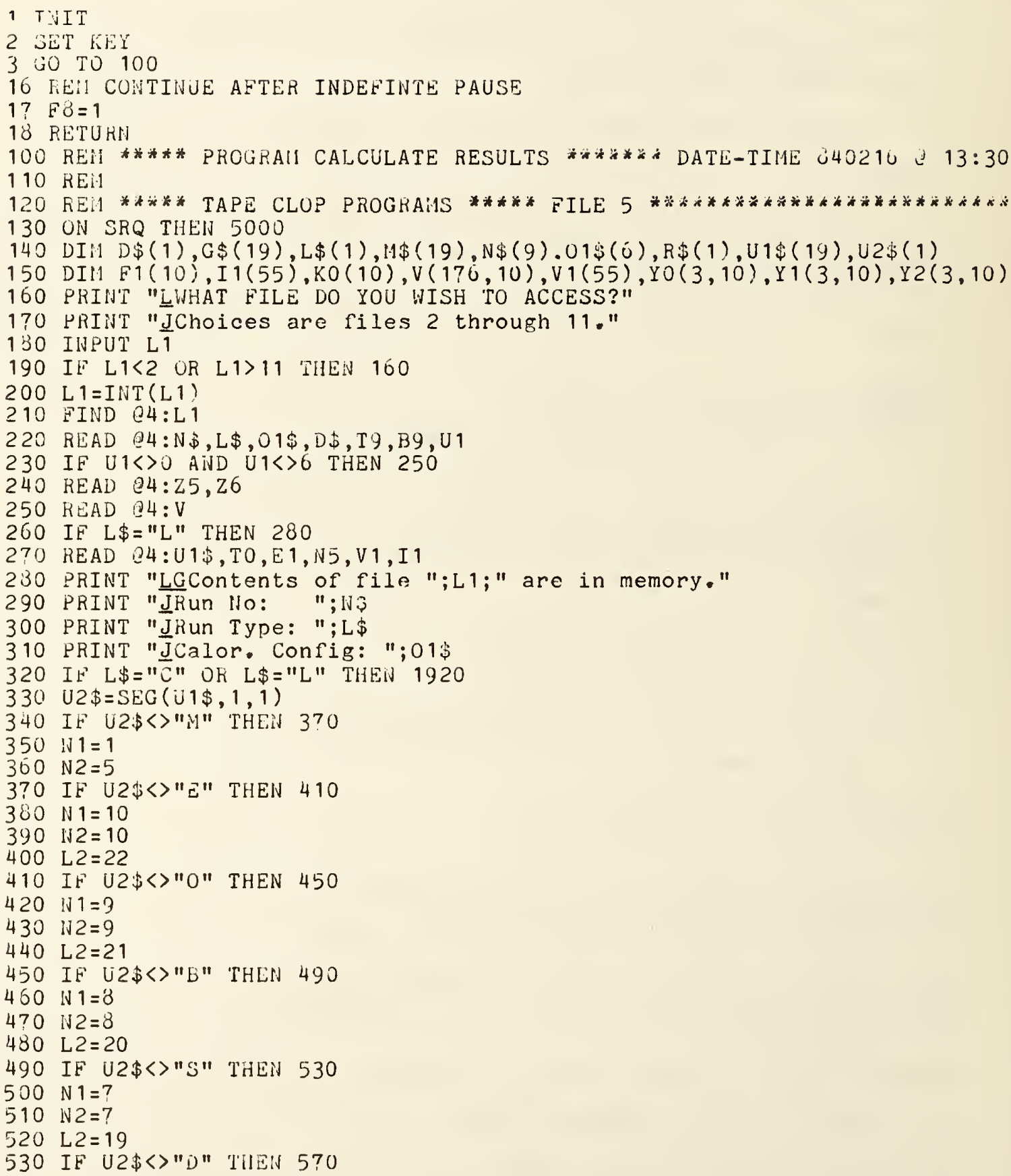




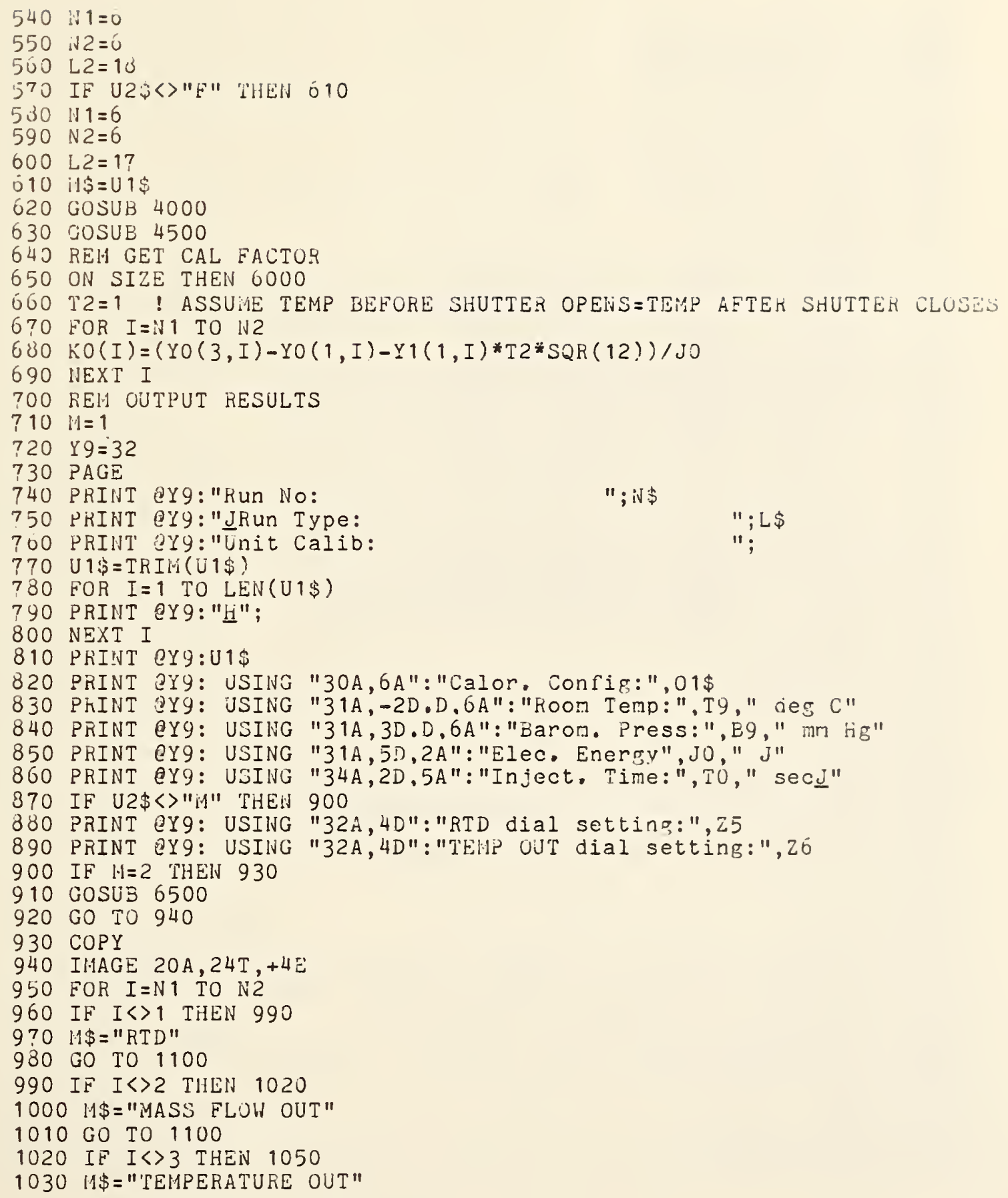




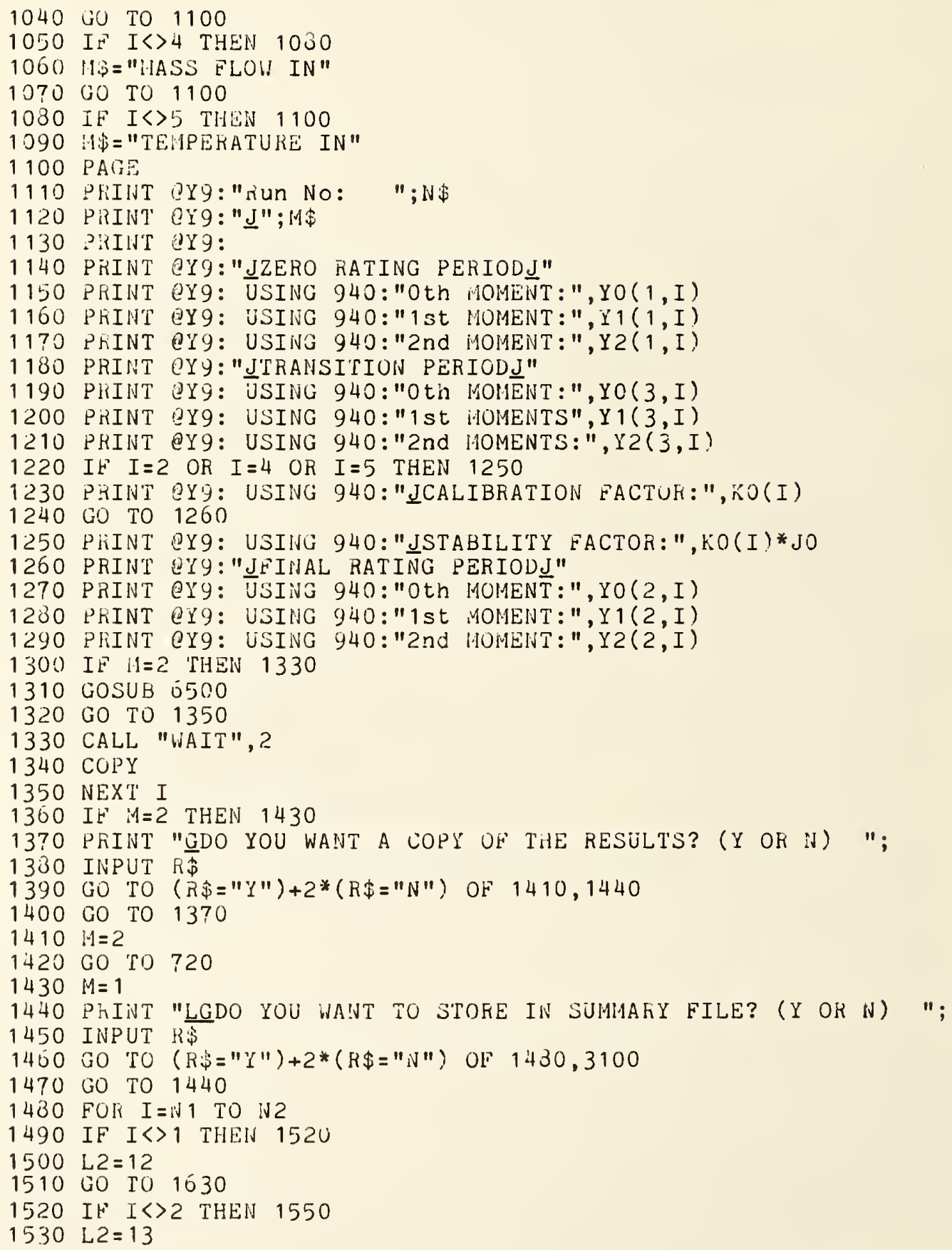




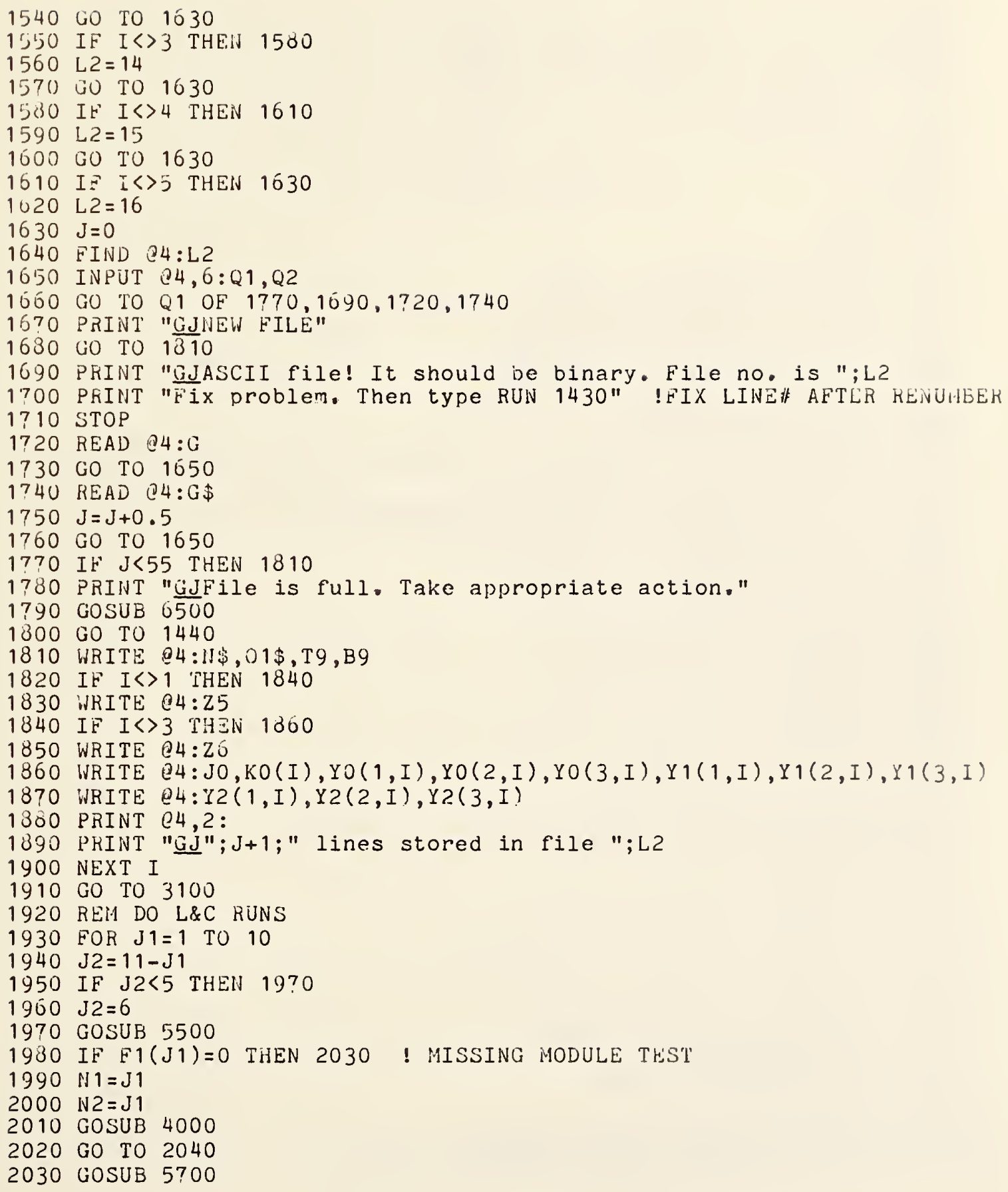




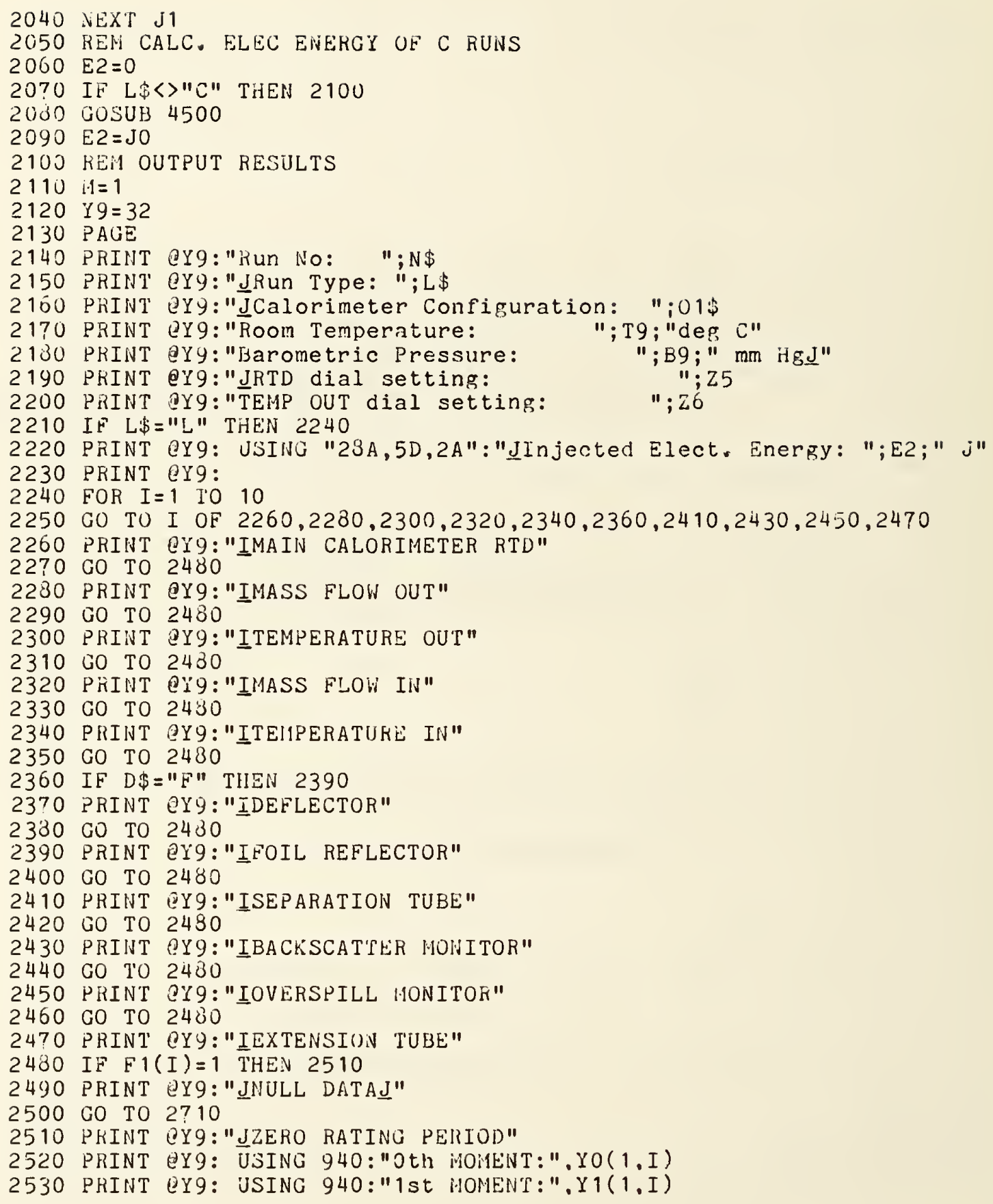


2540 PRIHT 2Y9: USING 940:"2nd HOMENT:",Y2(1,I)

2550 PRINT $2 Y 9:$ "JIRANSITION PERIOD"

2500 PRINT EY9: USING 940: "Oth HOHENT:",YO(3.I)

2570 PRINT EYY: USING 940:"1st HOMENT:",Y1(3,I)

2580 PKINT UY): USING 940:"2nd MOlIENT:",Y2(3.I)

2590 PRINT QYY9: "JFINAL KATIING PERIOD"

2000 PHIIT QY9: USING 940:"Oth WONENT:",YO(2,I)

2610 PRINT EYG: USING 940:"1st HOMENT:",Y1(2,I)

2020 PRINT QY9: USING 940:"2nd MOMENT:",12(2,I)

2630 PRINT PY9:

2640 IF $I=10$ THEN 2660

2650 IF I-1:10D $2<>0$ THEN 2710

2660 GIN $X, Y$

2670 HOVE 0,0

2680 PRINT

2690 IF $H=1$ THEN 2710

2700 CALL "WAIT". 3

2710 NEXT I

2720 IF $H=2$ THEN 2800

2730 PRINT "JDO YOU WANT A COPY OF THE RESULTS? ( $Y$ OR N) ";

2740 INPUT R\$

2750 GO TO ( $R \$=" i ")+2 *(R \$=" N ")$ OF 2770,2840

2760 GO TO 2730

$2770 \quad 11=2$

2730 PHINT $932,26: 3$

2790 GO TO 2120

2800 IH SUM(F1) MOD $2=0$ THEN 2320

2810 COPY

$2820 \quad M=1$

2030 PhINT $232,26: 0$

2340 PRINT "GJDO YOU WANT TO SAVE RESULTS ON TAPE? ( $Y$ OR $\mathrm{N}$ ) ";

2350 INPUT R\$

2860 GO TO (R\$="Y") $+2 *(R \$=" H ")$ OF 2330,3100

2870 GO TO 2840

2380 PFINT "JWHAT FILE NUMBER? (Choices are 24 through 33) ";

2890 PRINT "WOTE--each file can hold results of 13 runs"

2900 INPUT L2

2910 IF L2<23 OR L2>32 THEN 2830

2920 L2 $=\operatorname{INT}(\mathrm{L} 2)$

2930 FIND $04:$ L2

2940 INPUT $04,6: 21, Q 2$

2950 GO TO Q1 OF $3040,2930,3000,3020$

2960 PRINT "JG iJew File"

2970 GO TO 3040

2980 PRINT "JGASCII FILE! It should be binary. File number is ";L2

2990 STOP

3000 READ $94: G$

3010 GO TO 2940

3020 READ $84: G \$$

3030 GO TO 2940 


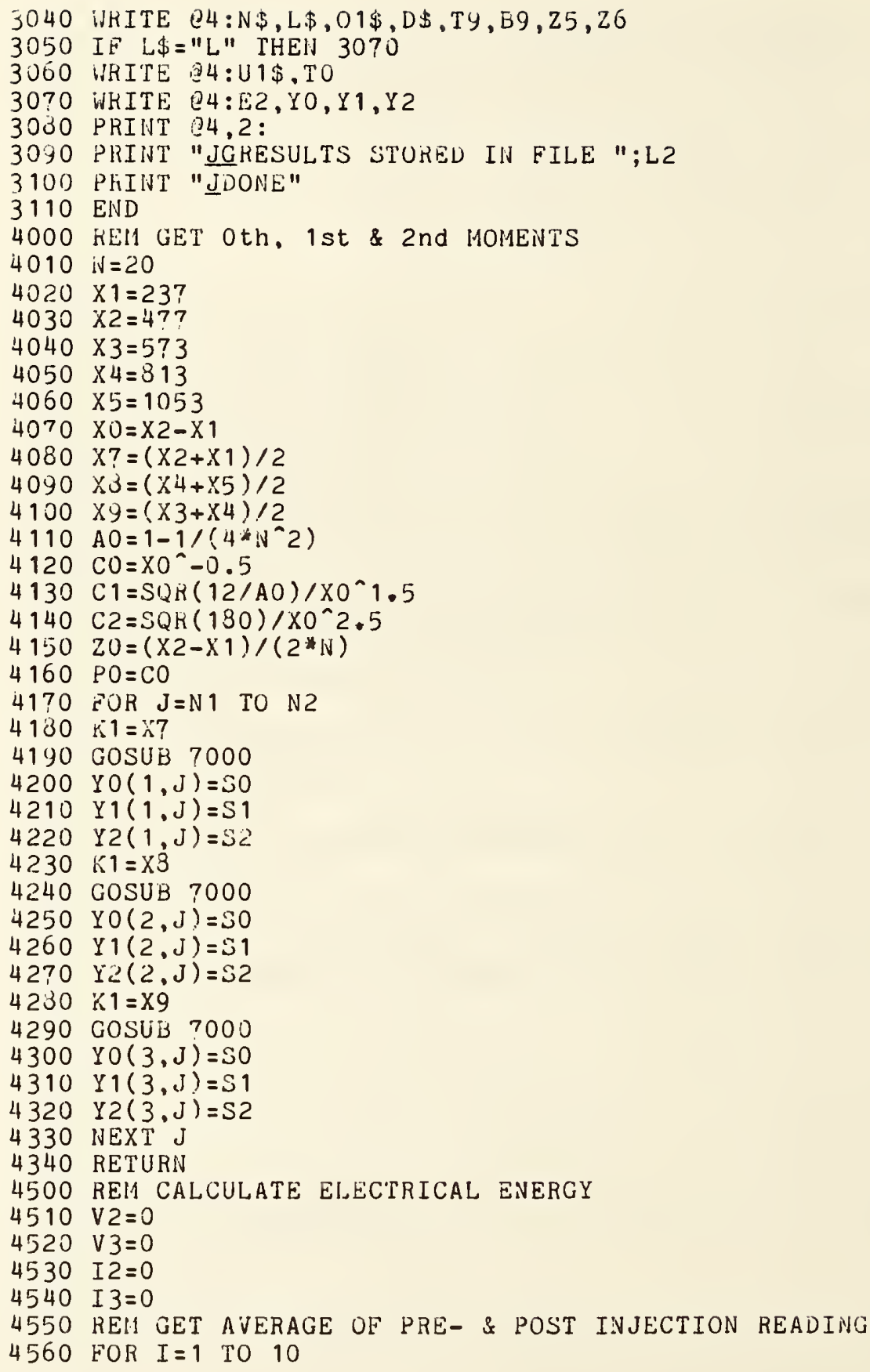




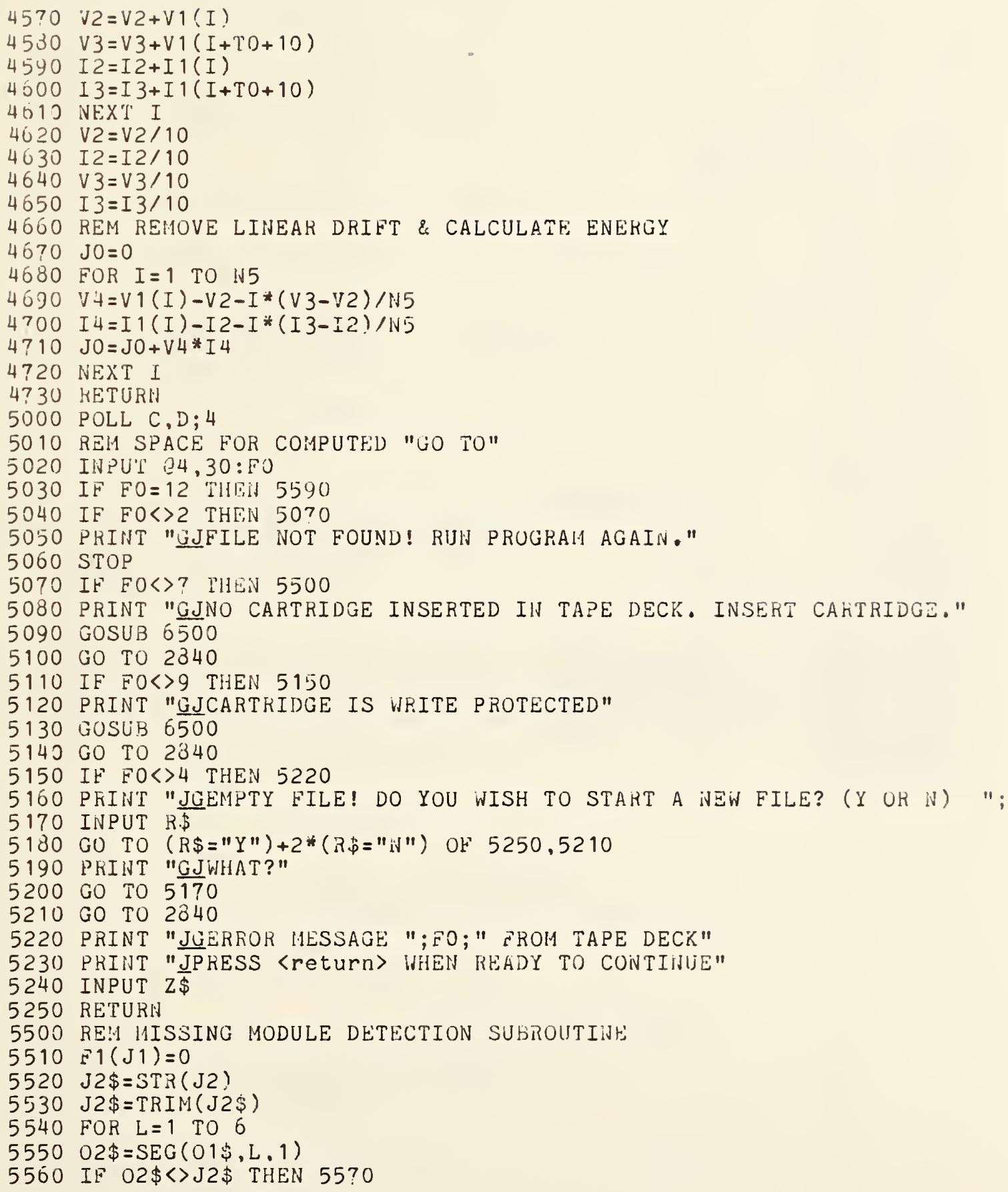




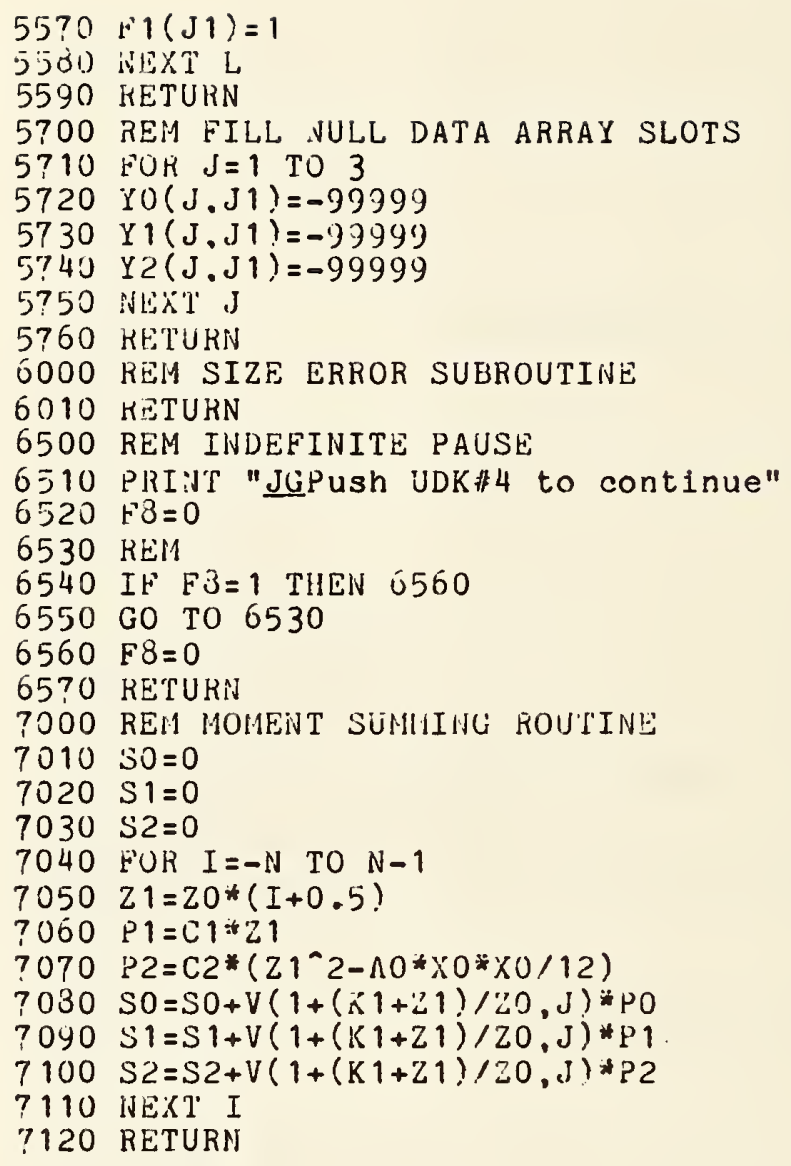


Al - first-order correction factor to get orthogonality between moments

B9 - barometric pressure in $\mathrm{mm}$ of $\mathrm{Hg}$

C - PULL variable

C1 - normalization factor for first moment

C'2 - normalization factor for second moment

CU - normalization factor for zeroth moment

U - PULL variable

U\$ - deflector-type descriptor $(D=$ mirror deflector, $F=$ foil reflector $)$

El - nominal electrical energy injected

E'2 - energy injected during $C$ run

Fl - array containing flays indicating missing modules

F8 - flay in indefinite wait routine

Fy - error message number from tape deck

G - tnrowaway variable while finding EOF

G\$ - throwaway string variable while finding EOF

I - counter

I1 - array containing electrical calibration current readings

I2 - averaye zero reading of Il before injection

I3 - average zero reading of Il after injection

I4 - I1 readings corrected for drift

$J$ - counter

$\mathrm{Jl}$ - counter while calculating moments of $L$ and $C$ runs

$J^{\prime 2}$ - number indicating unit being searched for in missing mod test

$J \emptyset$ - electrical energy injected during calibration run

$\mathrm{J} 2 \$$ - string equivalent of $\mathrm{J} 2$ used in missing module routine

K1 - midpoint of period being calculated

Ky - calibration factor

L - counter

L1 - number of file containing data to be processed

L2 - number of file in which results are to be stored

$L \$$ - run type $(L=$ laser, $C=$ combination, $E=$ electrical $)$

M - results output-type descriptor $(1=$ display, 2 = nardcopy $)$

$M \$$ - temporary label for printing name of unit

$\mathrm{N}$ - number of data packets in half duration of any time period

N1 - lower sensor index of data to be processed

N2 - upper sensor index of data to be processed

N5 - number of V1 (and I1) readings

$N \$$ - run number

$01 \$$ - calorimeter configuration description

$02 \$$ - segment of $01 \$$ being searched for in missing module routine

P1 - first moment function

P2 - second moment function

$P y$ - zeroth moment function

Q1 - $\operatorname{TYP}(\varphi)$ command variable indicating type of data read

Q2 - TYP $(\varphi)$ command variable indicating length of data read

$K \$$ - alpha answer to yuestions

Sl - first moment summiny variable

S2 - second moment summing variable 
T2 - factor representing ratio of temp. after shutter closes to temp. before shutter opens

Ty - ambient temperature in deyrees $C$

Ty - duration in seconds of electrical eneryy injection period

U1 - numeric indicator of unit receiving energy (laser or electrical)

U1\$ - name of module receiving electrical eneryy

U2\$ - sinyle letter descriptor of unit receiving electrical energy

$V \quad$ - array $(176 \times 10)$ containing voltage output readinys for the 10 sensors

V1 - array containing electrical calibration voltage readings

$V 2$ - averaye zero reading of $V 1$ before injection

V3 - average zero reading of V1 after injection

V4 - V1 readings corrected for drift

$X \quad$ - GIN variable used in creating PAGE FULL

$X 1$ - time in seconds of startiny point of zero rating period

$x_{2}$ - time in seconds of ending point of zero rating period

$x_{3}$ - time in seconds of starting point of transition period

$X_{4}$ - time in seconds of ending point of transition period

$x_{b}$ - time in seconds of ending point of final rating period

$X 7$ - miduoint of zero rating period in seconds

$x 8$ - midpoint of transition period in seconds

$x y$ - midpoint of final rating period in seconds

$x y$ - period duration in seconds

$Y$ - GIN variable used in creating PAGE FULL

$Y 1$ - array containiny first moments of three time periods for all sensors

$\gamma 2$ - array containing second moments of three time periods for all sensors

$Y y$ - address of device outputting results

$Y y$ - array containing zeroth moments of three time periods for all sensors

21 - time coordinate of the point under question

Zb - main calorimeter RTD dial setting

26 - ternperature out dial setting

$Z \emptyset$ - number of readings averaged to get one data packet

$Z \$$ - throwaway answer to wait routine 


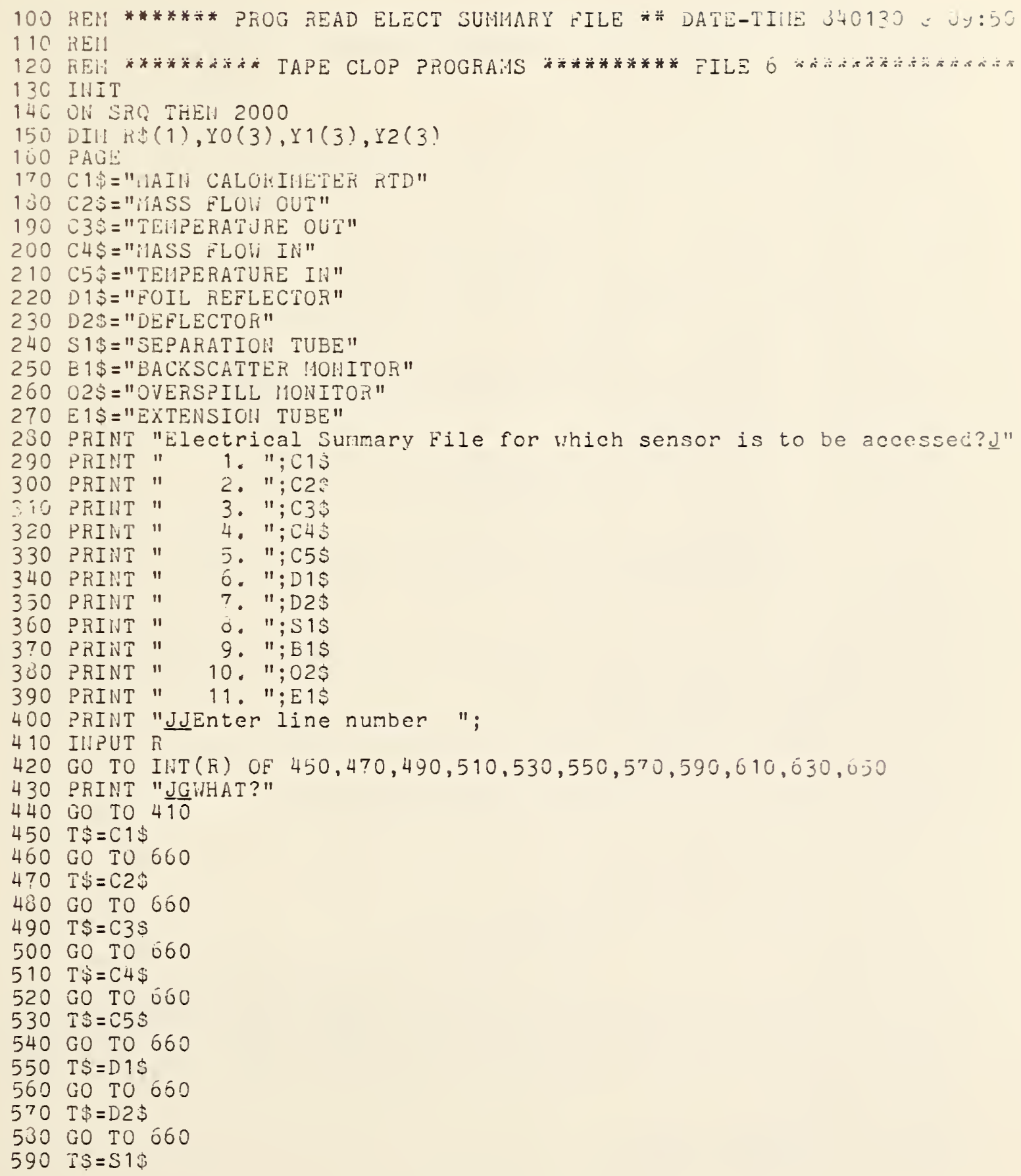




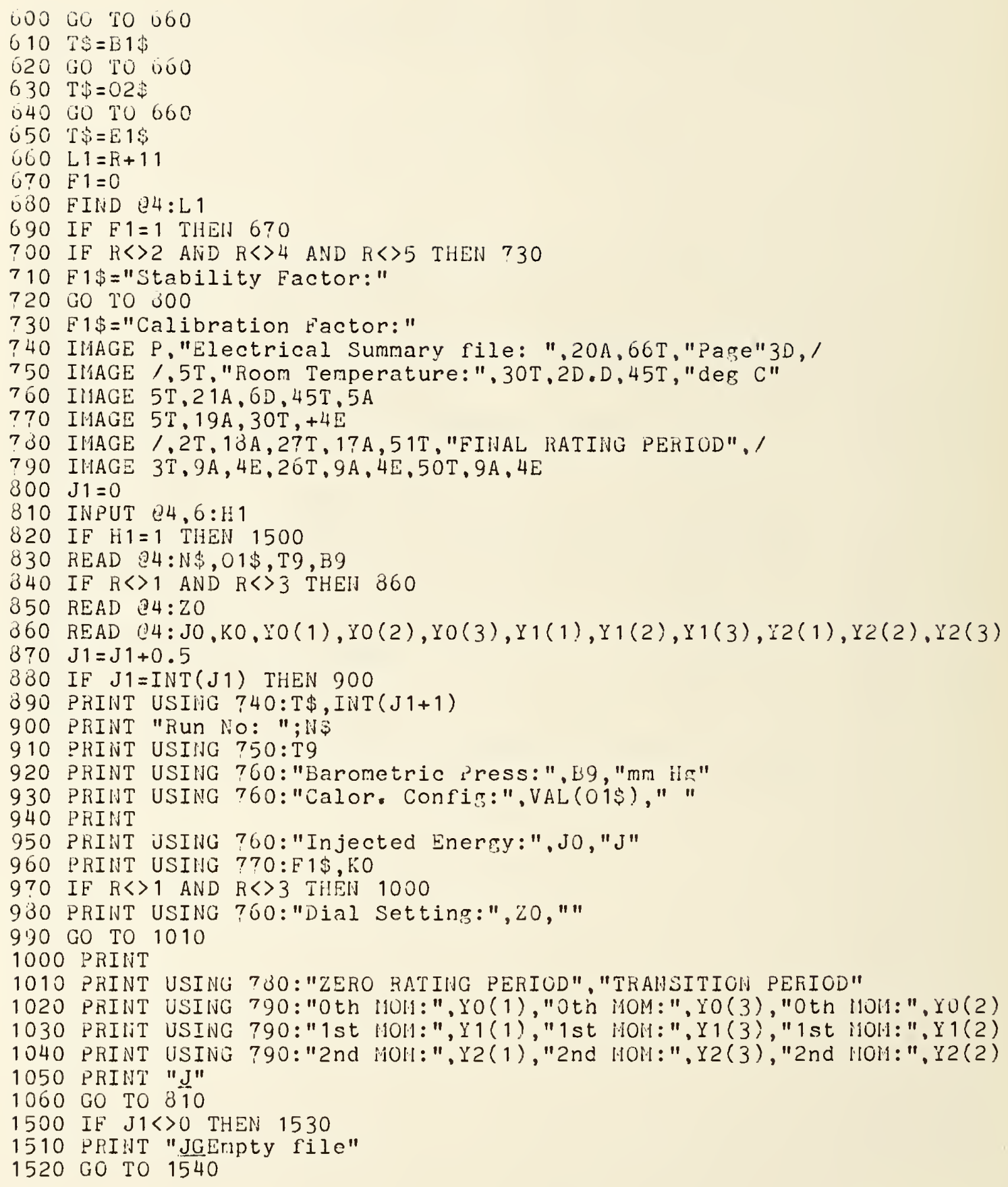


1530 PIIn "Jkead out of file "; 1 ; " for "; T\$;" conpleted"

1540 PRINT "JGke-run propram to access other files"

1550 EllD

2000 ?OLL Q1.02;4

2010 IHPUT $34,30: \mathrm{H}$

2020 GO TO H UF' $2040,2060,2000,2100,2020,2100,2200,2250,2270,2320$

2030 GO TO H-10 OF 2340,2360

2040 PFIHT "JGDomain error or invalid argument--Error messare 1"

2050 SIUP

2060 PRIUT "JGGFile not found--Error message 2 "

2070 STOP

2080 PliNT "JGilar tape format error--Error message 3"

2090 STOP

2100 PRIM "JGIllegal access--Error message 4"

2110 FIND Q4:L1

2120 PRINT "JHeaderJ"

2130 IHPUT Q $4,9: 110 \$$

2140 PRIHT HO\$

2150 STOP

$2160 \quad F 1=1$

2170 RETURN

2180 PRIIIT "JGRead error (10 re-reads)--Error message 6"

2190 STOP

2200 PRIIIT "JGNo cartridge inserted--Error message7"

2210 PRINT "JPush 〈ret> when ready to continue"

2220 INPUT $Z \$$

$2230 \mathrm{~F} 1=1$

2240 RETUKN

2250 PRINT "JGover-read (illegal tape record length)--Error messarc u"

2260 STOP

2270 PRINT "JGCartridge write-protected--Error messafe 9 "

2280 PRINT "JPush 〈ret> when ready to continue"

2290 INTU'T $Z \$$

2300 FIND L 1

2310 KETURN

2320 PRINT "JGRead after write error--Ẽrror message 10 "

2330 STOP

2340 PRINT "JGEnd of medium--Error message 11"

2350 STOP

2360 PRIINT "JGEEnd of rile--Error message 12"

2370 PRINT "JHit BREAK twice to abort run"

2300 PRINT "JPush 〈ret> to continue"

2390 INPUT $Z \$$

2400 RETURN 
Variable Map

Proyram: REAU ELECTRICAL SUMMARY FILE

Vate: 840210

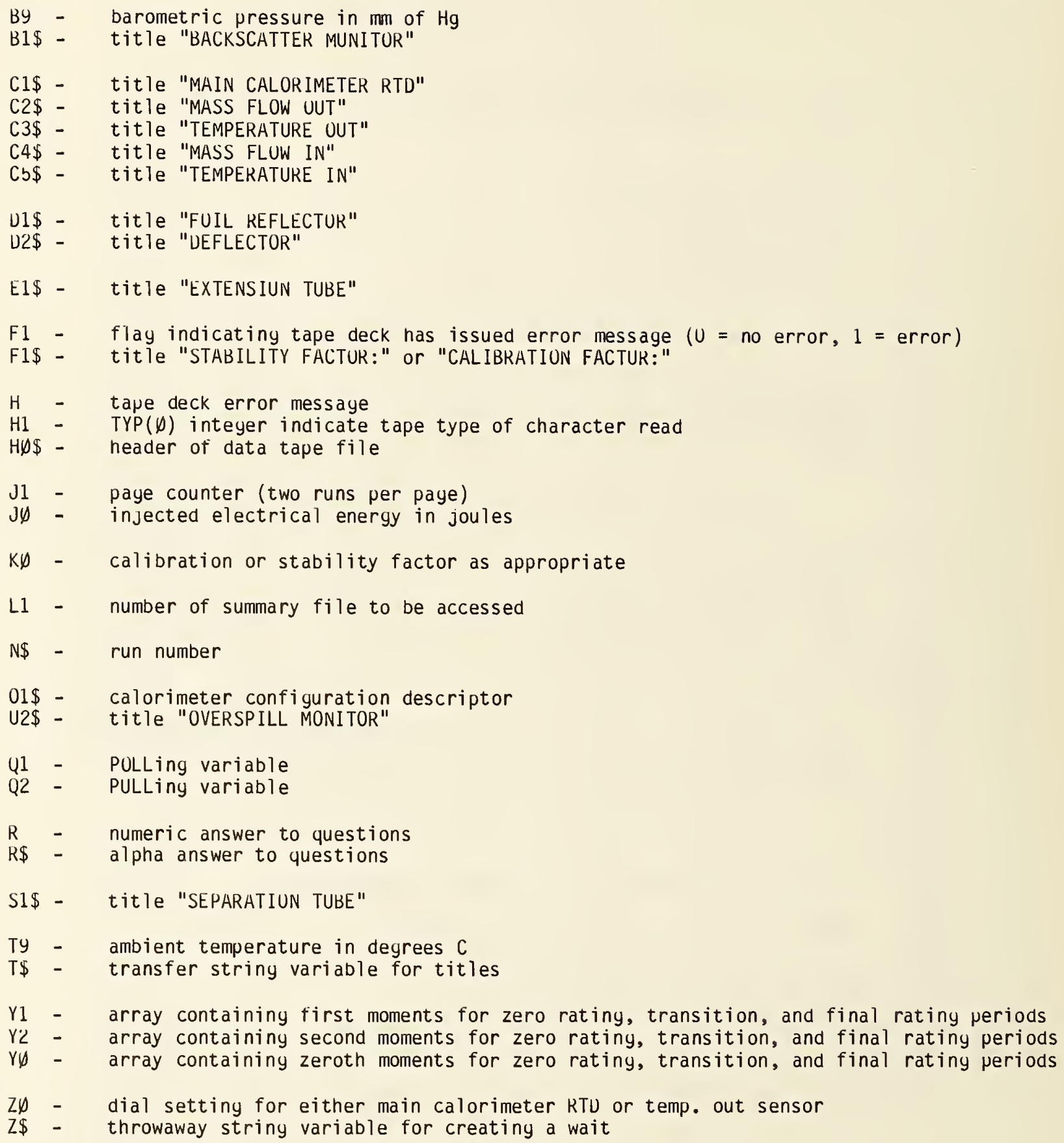


87. Calculate cal facturs (file 7)

Proyram Listiny

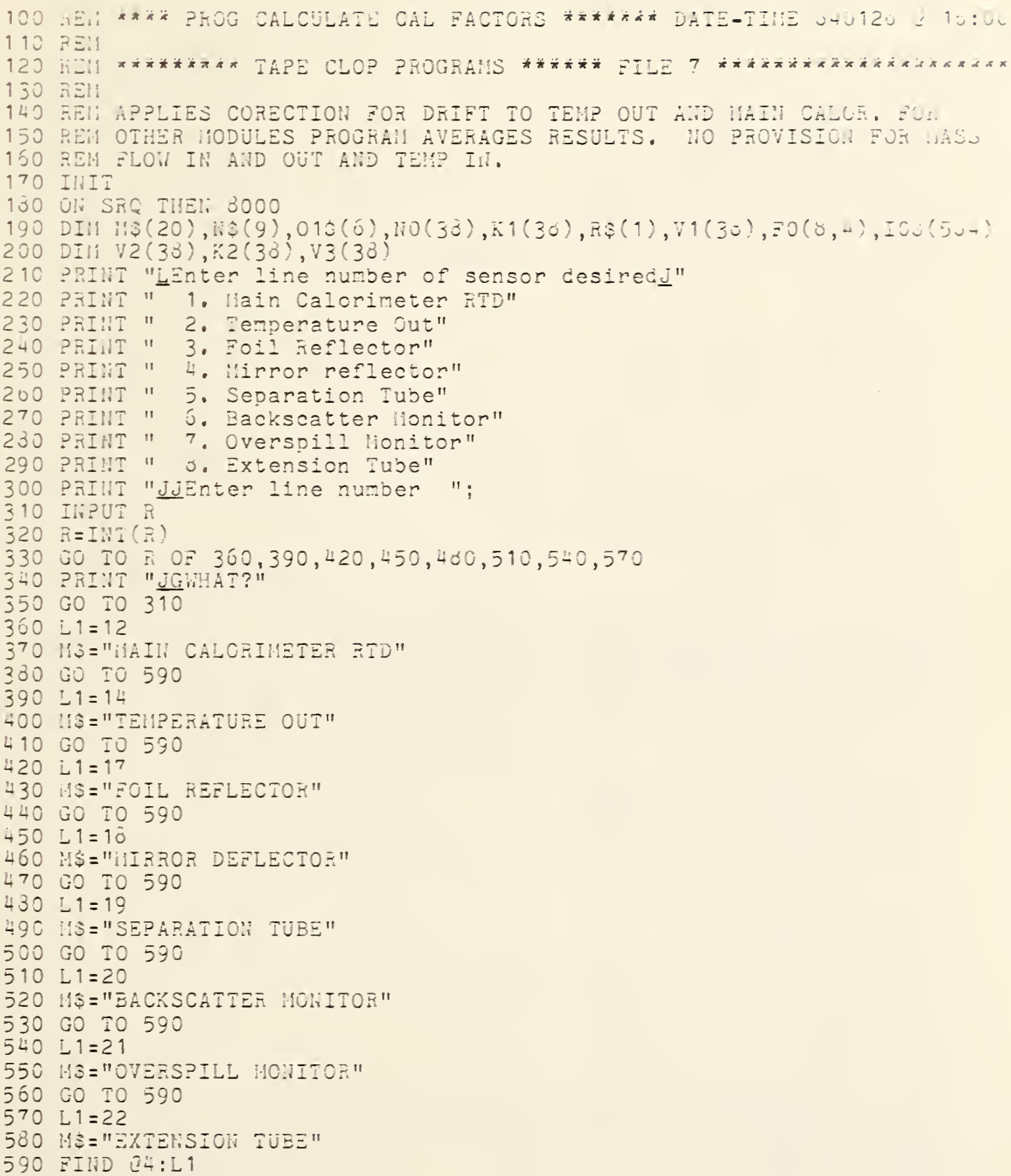




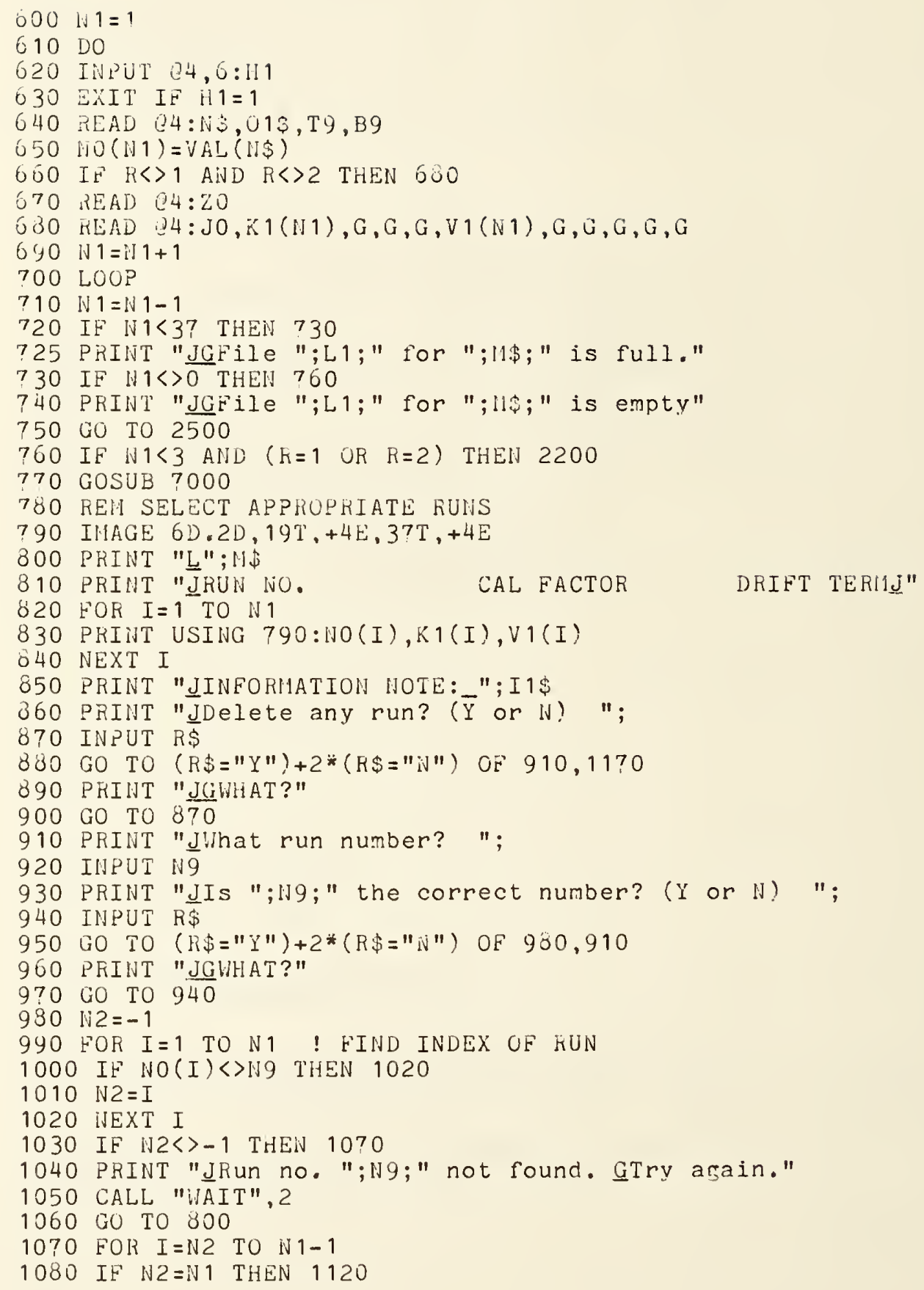




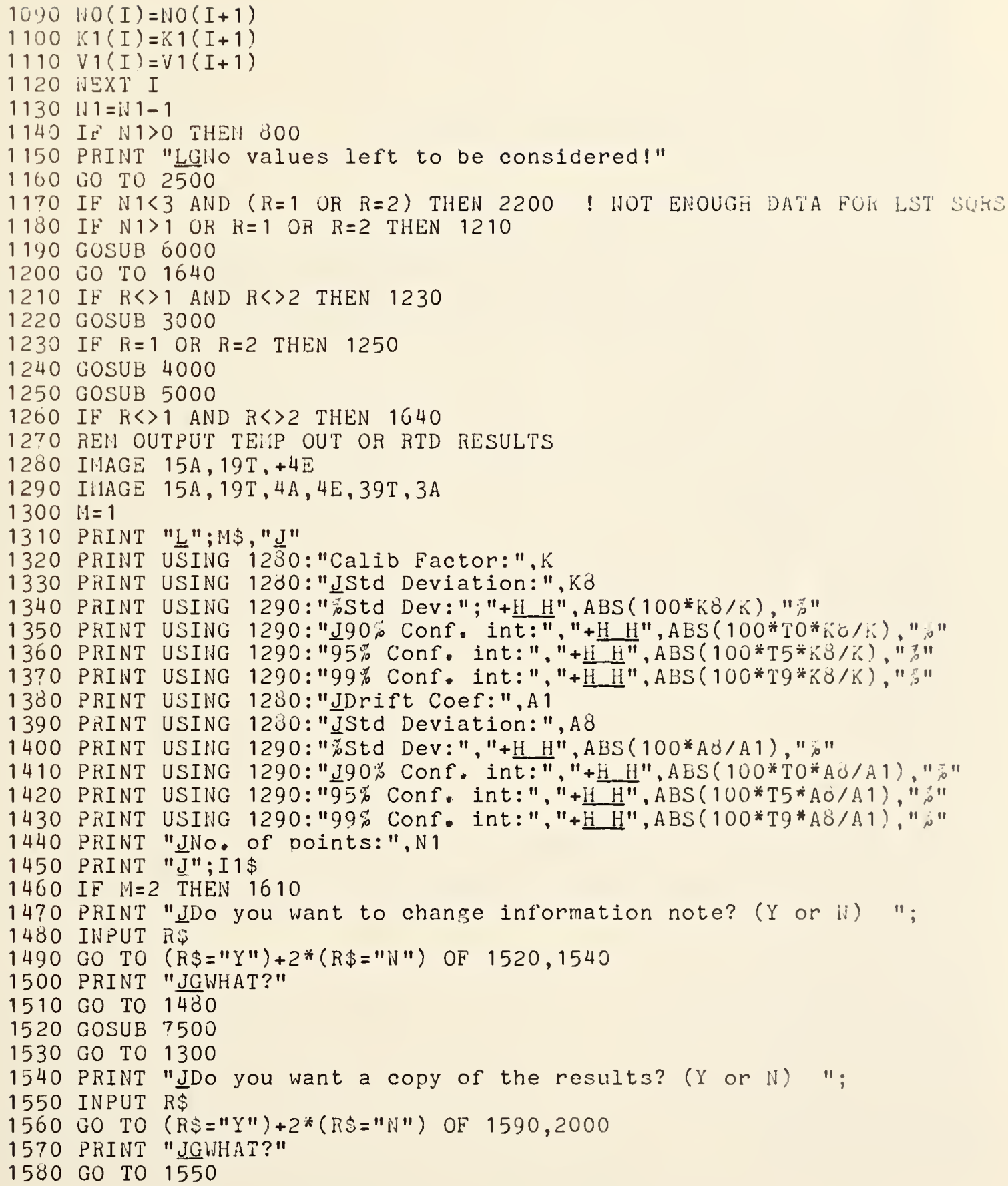




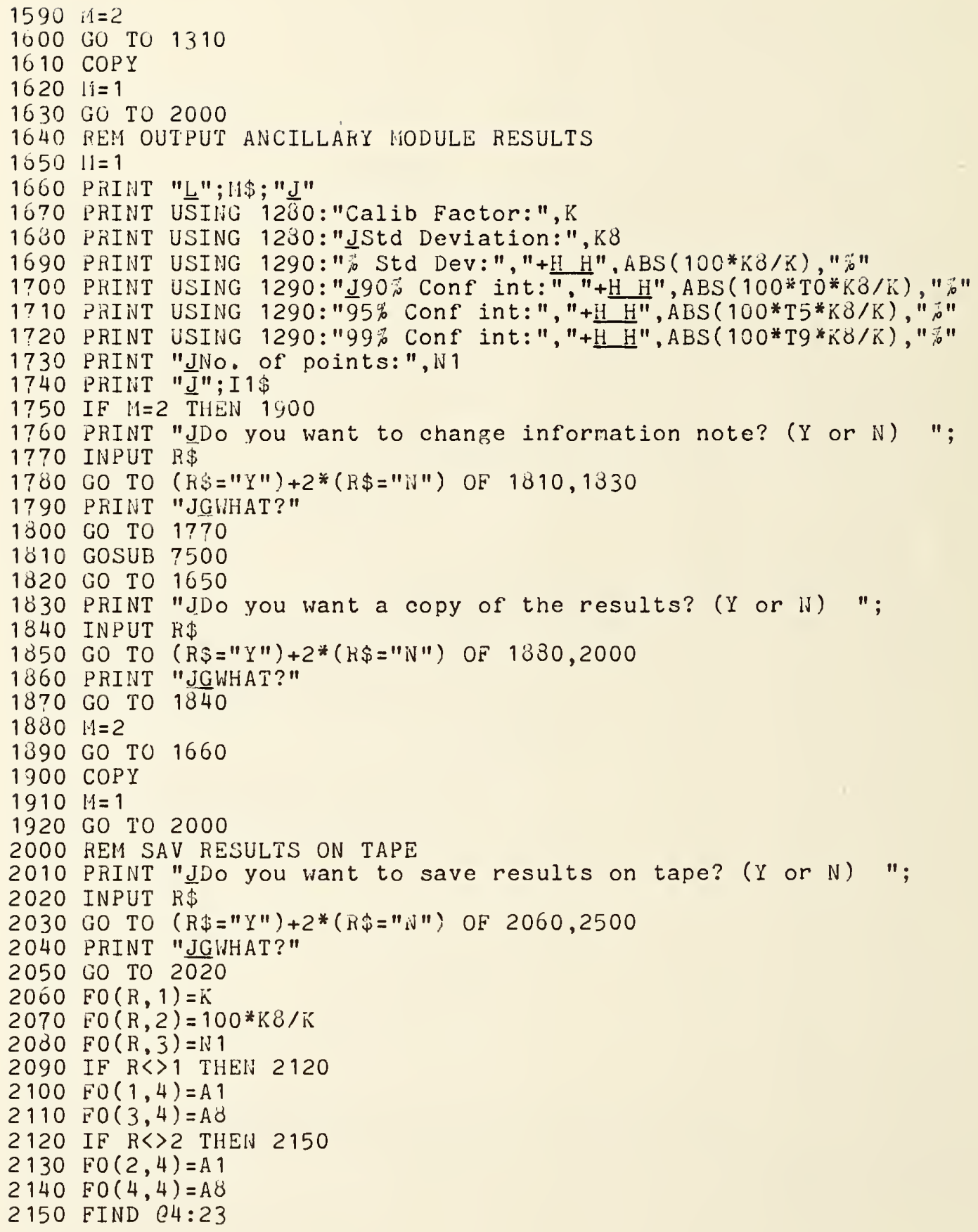




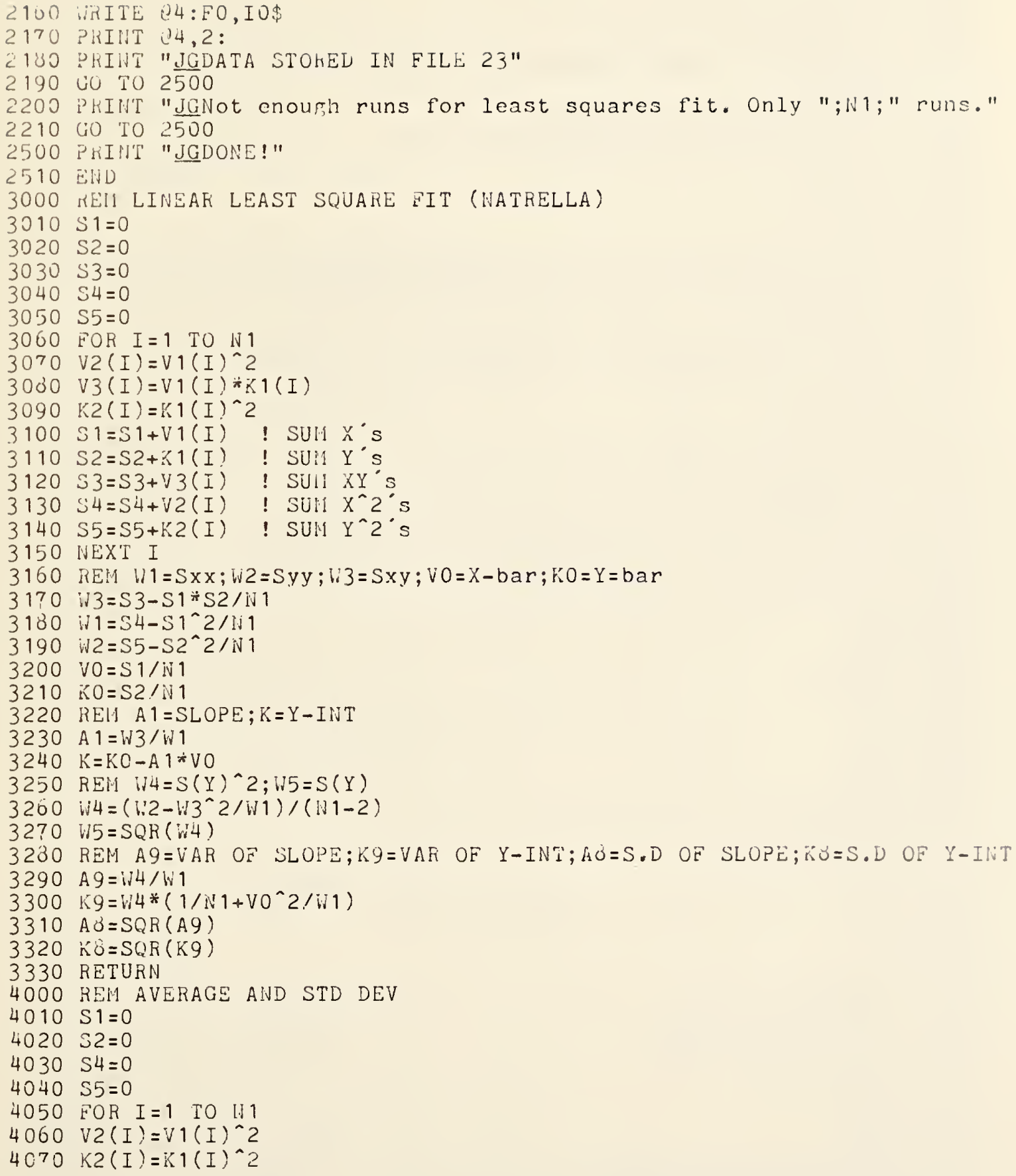




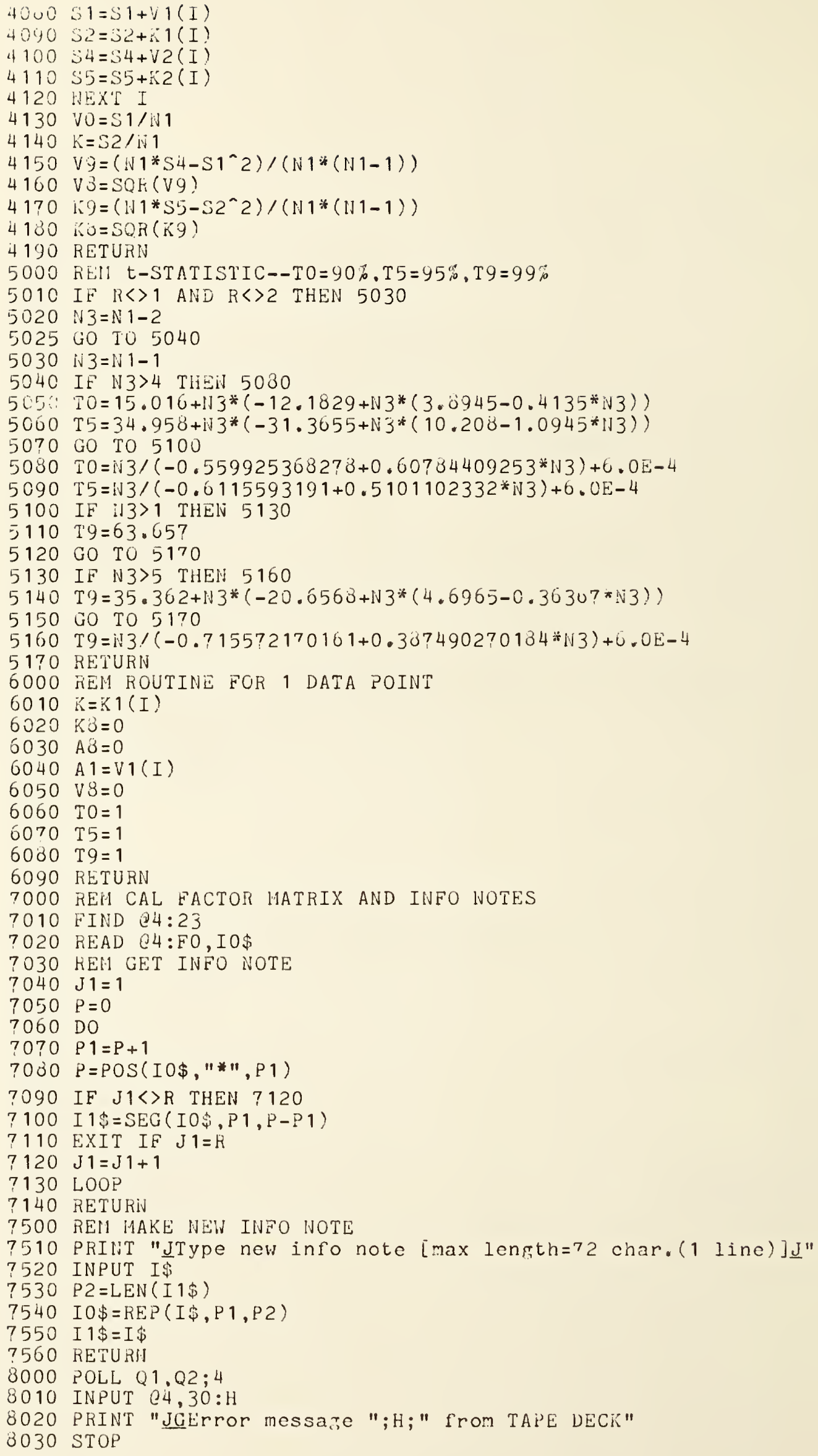


Al - drift coefficient (slope from least squares fit)

A8 - standard deviation of Al

A9 - variance of the slope

By - barometric pressure in $\mathrm{mm}$ of $\mathrm{Hg}$

Fy - $\quad 8 \times 4$ array containing "best" values of temperature sensors

li - tnrowaway variable

H - error inessaye from tape deck

$H I$ - $\operatorname{TYP}(\phi)$ inteyer

1 - counter

I\$ - new information note to replace II\$

II\$ - information note for data being considered

IU\$ - alpha striny containiny info note and delimiters for all eight sensors

J1 - steppiny index to find info note of sensor

$J \forall$ - electrical energy injected

$K$ - "best" value of calibration factor

$\mathrm{Kl}$ - array containing cal factors read from elec. summary file

K8 - standard deviation of $K$

Kg - variance of $K$

$K \emptyset \quad$ - average value of $K I$

Ll - file number of electrical summary file to be accessed

$M$ - results output type descriptor $(1=$ display, $2=$ copy $)$

$M \$$ - name of sensor for electrical summary file

$\mathrm{Nl}$ - counter of lines of data

N2 - index of run data to be edited out

N3 - deyrees of freedom in t-statistic subroutine

NY - run number for data to be edited out

No - array containiny numeric equivalents of N\$

$N \$$ - run number

U1\$ - calorimeter confiyuration descriptor

P - position of next delimiter in Iழ\$

Pl - starting point in I $\$ \$$ to look for next delimiter

Q1 - PULLing variable

Q2 - POLLing variable

$R \quad$ - numeric answer to questions

$R \$$ - alpha answer to questions

S1 - summation of $\mathrm{Vl}$ terms

$\mathrm{S} 2$ - summation of $\mathrm{KI}$ terms

$\mathrm{S3}$ - summation of $\mathrm{Vl}_{2} \times \mathrm{Kl}$ terms

S4 - summation of $\mathrm{VI}^{2}$ terms

$\mathrm{S5}$ - summation of $\mathrm{Kl}^{2}$ terms

T5 - 95 percent t-stat

T9 - ambient temperature in deyrees $\mathrm{C}$; after line $2 b \mathrm{U}$, 99 percent $t$-stat

Ty - $9 u$ percent t-stat

V1 - array containing first moments for zero ratiny from elec. sum. file

$V \emptyset$ - ave value of VI

Wl - sum of the squares of the $V 1$ residuals

W2 - sum of the squares of the $K I$ residuals 
W3 - sum of the squares of the $V 1 \times K 1$ residuals

W4 - $\left(W^{2} 3^{2} / W^{2}\right) *(N 1-2)$

Wb - square root of $w^{4}$

ZV - dial setting for either main calorimeter KTU or temp. out (as appropriate) 
B8. KUN KEPCU (FILE 8)

Proyram Listing

1 IIJIT

2 SET KEY

3 Gi) TO 100

4 hEII TURI OFF KEPCO

5 P RIIIT 0 : "12000","22000"

6 PRINT "JGñEPCO TURNED OFF."

24 KEH READ KEPCO VOLTAGE

25 PRINT $\mathrm{U} 9: " 12 "$

26 RETURN

20 REII READ KEPCO CURRENT

29 PRIVT U6: "10"

30 KETURE:

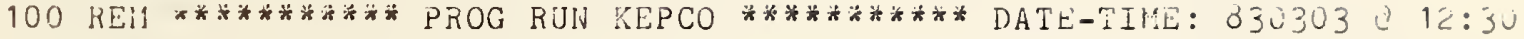
110 REII

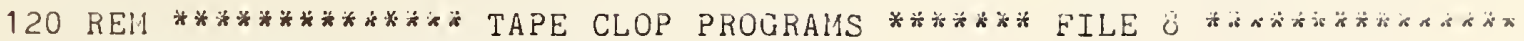

130 PRINT "LWHAT VOLTAGE LIHIT? ";

140 INPUT V1

150 IF $V 1>10$ THEN 180

$160 \mathrm{~K} 1=409.6$

170 GO TO 190

$180 \mathrm{~K} 1=40.96$

$190 \mathrm{VO}=\mathrm{INT}(\mathrm{K} 1 * \mathrm{~V} 1)$

200 D $1 \$=" 1 "$

210 IF $V 1>10$ THEN 250

220 D $2 \$=" 2 "$

230 GOSUB 1000

240 GO TO 270

$250 \mathrm{D} 2 \$=" 0 "$

260 GOSUB 1000

$270 \quad A \$=X \$$

200 REM SET CURREHT LIHIT

290 PRINT "JWHAT CURRENT LIHIT? ";

300 INPUT V2

310 D $1 \$=" 2 "$

$320 \mathrm{D} 2 \$=" 2 "$

$330 \mathrm{VO}=\operatorname{INT}(409.6 * \mathrm{~V} 2)$

340 GOSUB 1000

350 B $\$=X \$$

360 PRINT $06: A \$ ; B \$$

370 PRINT "LGKEPCO SET TO "; 1 ; "VOLTS AND ";V2;" AIPS."

380 PRINT "JJJPRESS UDK \#1 TO TURN OFF KEPCO."

390 PRI HT "JPRESS UDK \#6 TO READ VOLTAGE."

400 PRINT "PRESS UDK 非? TO HEAD CURREINT."

410 END

1000 REII CONVERT VO TO RADIX 16

$1010 \mathrm{E} 1=\operatorname{INT}(\mathrm{V} 0 / 16)$

$1020 \quad D 5=V 0-16 * E 1$

$1030 E 2=\operatorname{INT}(E 1 / 16)$

$1040 \mathrm{D} 4=\mathrm{E} 1-16 * \mathrm{E} 2$

$1050 \mathrm{D} 3=\mathrm{E} 2$ 


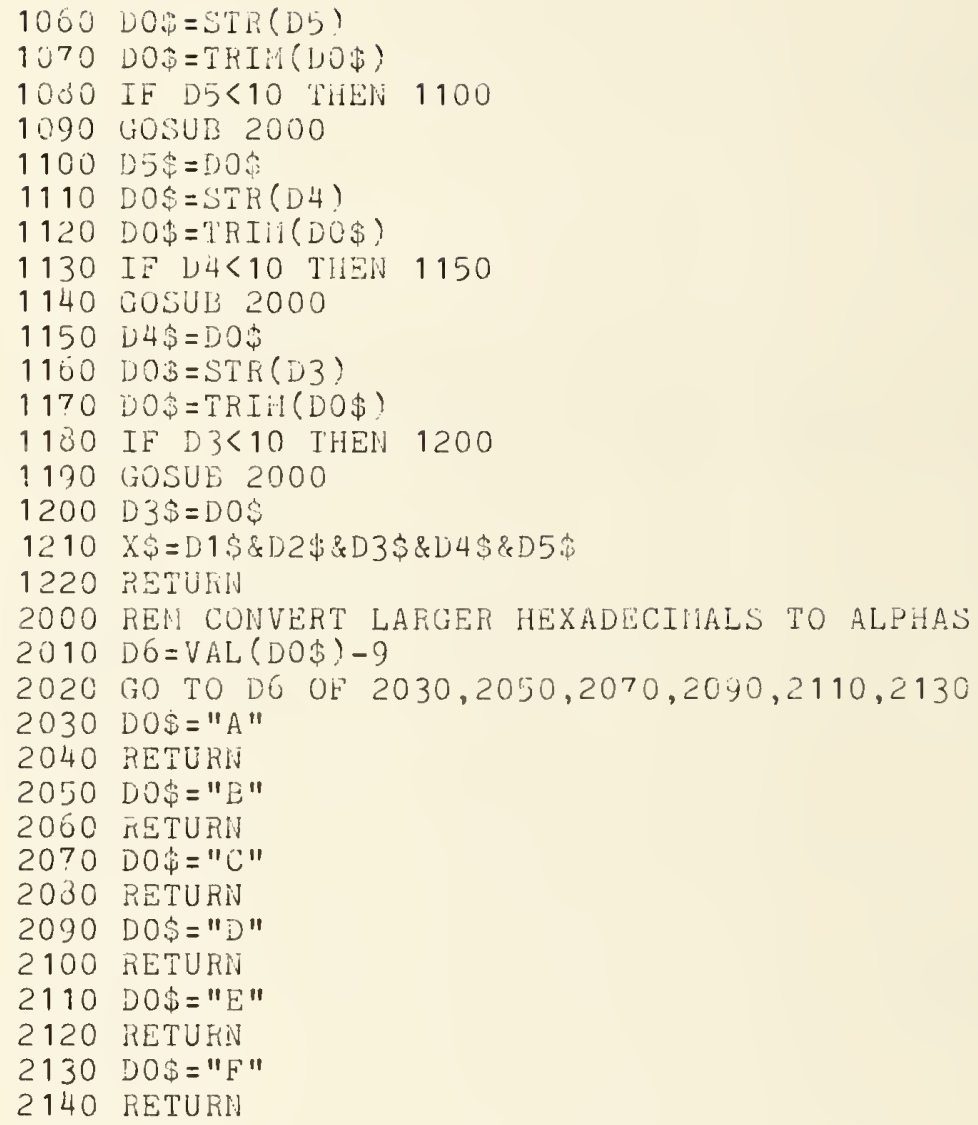


Variable Map

Proyran: RUN KEPCO

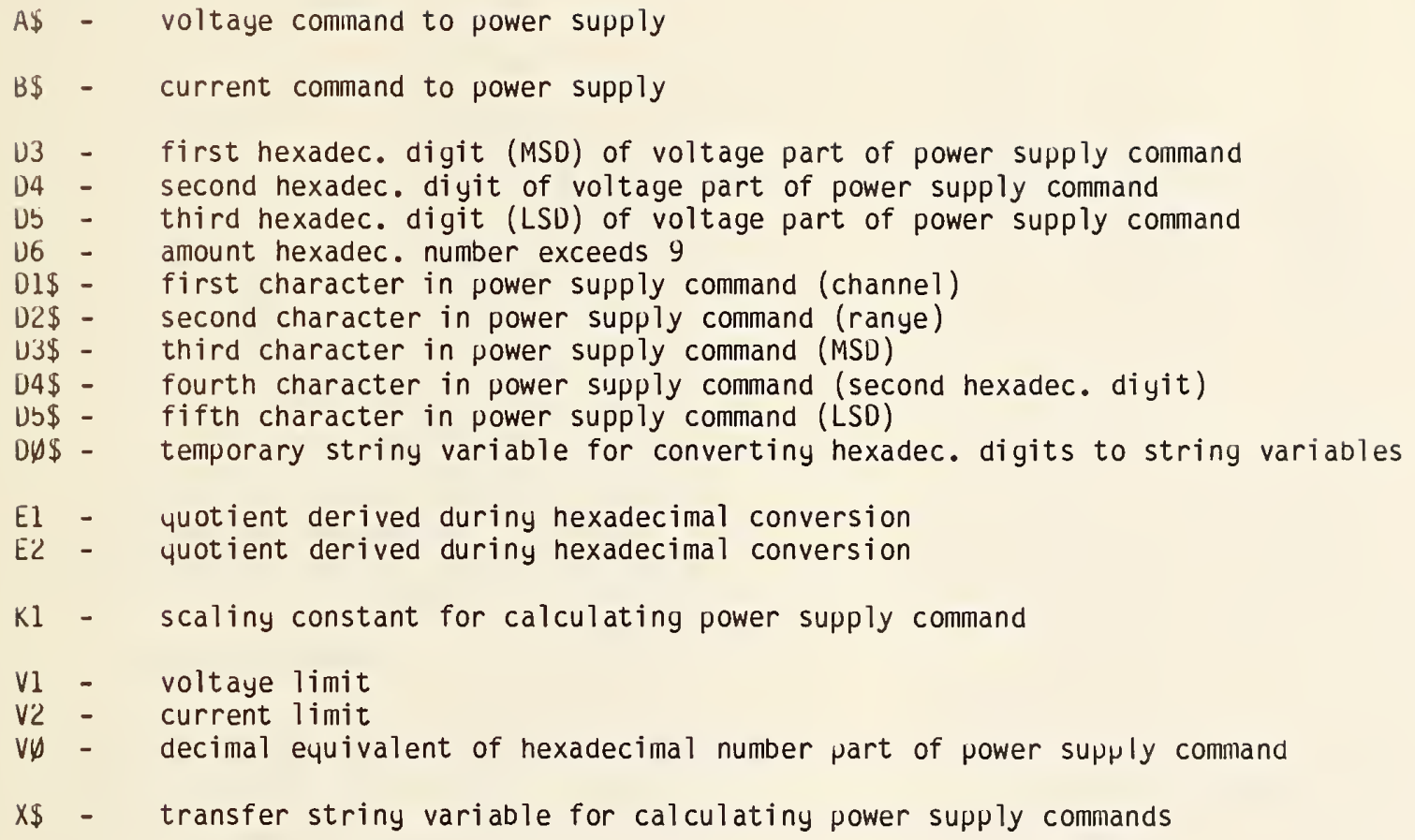


Appendix C. System H Program Listings and Variable Maps

C1. "AUTOST"

Program Listing

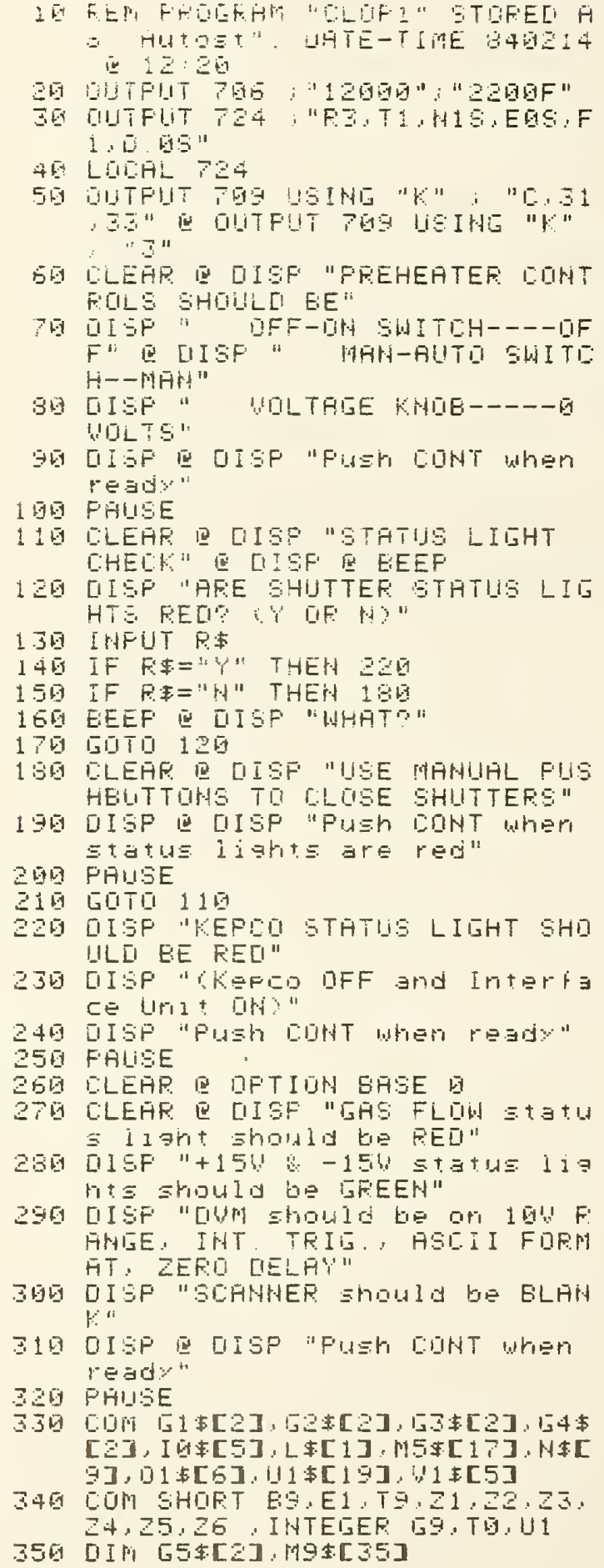

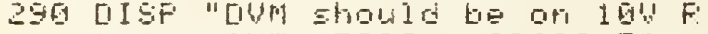
FHLE. IHT. TRIG. ASLII FOPM FT: ZEFO [IELF'"

JWD DISF "SCHAHER Should be BLHA $\because "$

J18 OISP E UISP "FUER EUHT When ready"

320 PHISE

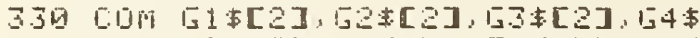
$[2], I 6+[5], L \$[1], M 5 \$[17], N \$[$ $9], 01 \neq[6], 111+[19], 11 \neq[5]$

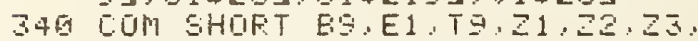

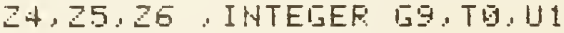

350 [IM G5.[2], M99[55]

35U IHTEGEF: F:I A. ?

马YG UITFUT 709 USING "K" "14"

380 [:LEHF

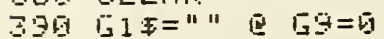

460 LISF "IS EQUIFIAENT WHFMEL LFF

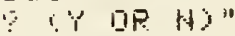

41 I IFFUT FOT

42G IF QD=" $Y$ " THEH EBD

430 IF FIT= "H" THEH $46 \mathrm{~B}$

445 DISF W EEEF

45E [I]EF "WHAT?" GQTO 4 GE

46日 FEM WARM UF PEF:IDO

$47 G$ LLEAF \& IISF "45 MIH WARM LIF PERIDO STARTED' Q DISF

480 DISF "CHECK PUWEF SIIFPL' WOL TAGES" छ EEEP

$496 \quad 1=6$

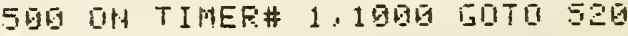

516 GOTO

$520 \quad j=.1+1$

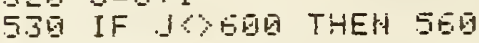

S4D EEEF Q UISF "10 MIN ELRFSEQ"

55日 GUTO 510

56 IF JO12GE THEH 530

579 EEEF E DISP "ZV MIN ELAPSEU"

566 GUTि 510

591 IF J $18 G 0$ THEN E2Q

GEG EEEF 世 [ISF "Zू MIN ELAFSE["

E19 GUTO 510

Q20 IF $1<2400$ THEN ESE

E.J日 BEEF E UISP " 4 G MIN ELAPSED"

54

E5R IF ISPTBQ THEH 510

EEब UFF TIMER\# 1 E EEEF Q [ISF" WHFA ISP FEFIOD CUMFLETEO" E WFIT 2 BEE

6.7日 10TI 7.

BGG FEM PWR CHK-NI WARM UIF

GOG LLEAR E EEEF

FOG UISP "GHECK PDWEF SUPFLY UDL TALES" \& UISF

719 [ISF "PuSh EONT when EheEk i S IOMF] J TE"

PUN PALISE

T.JG REA INPUT RUNH FARAMETERSS

74 CLEAF

759 OISP "WHAT IS THE FUN NO.":

GE IHFUT HE

PPB LISF E UISP "IS THIS H LASER (LI: ELEETRICAL CE) CIF COMBE INATIOH SE RUN":

780 INFUT L\$Q U1\$=1:"

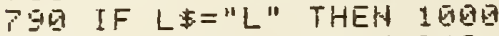

SË IF L\$="C" THEH 840

810 IF L\$="E" THEN 850

BEG EEEF E UISF E LISF "WHAT?"

B.3日 Б口TO

840 U1=0 EOTC 950

850 ELEAR "WHAT UNIT IS TO EE EAL IEFATED" EISF 
S79 [ISF " 1. EYTEHSIOH TUBE"

GSG पISF" " 2 DUEFSFILL MONITDF

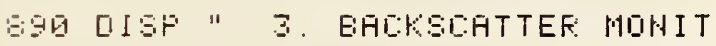
DF"

GGE UISF" 4. SEFHFHTIOHA TUEE"

प1日 [ISP " 5. DEFLELTEF:FIL F:E FLEI:TDF"

GE ПISF " E. MHIN EALDFIMETEF"

GIE UIS Q [ISF "EHTEF LIHE HÜ."

94 IHFUT U1

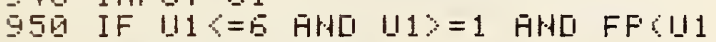
$Y=6$ THEN 980

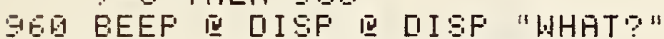

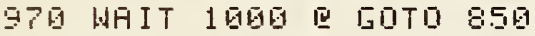

GEG REM GET CALOF. CDHF I GURAT IDH 99日 БОTO 1 G1E

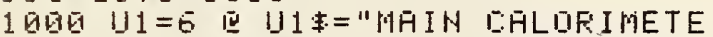
F " I

1010 101:=" "CIEFLEI:TDF:=

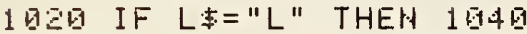

1日SE DISF "SET LASER FUUN - DOMEI HAT I DH $\equiv$ i tah to LOHE IHAT I H" E GTO 1 G5

1 G4 NHT I DHA sw i tar" to LASEF"

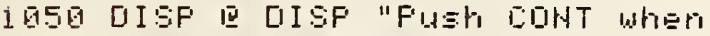
ready" E FUUSE

1 GE FUF: $I=1$ TO

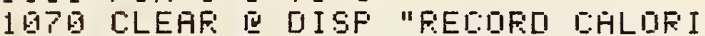
METER LOHF IDUFATIDH" E [IISF

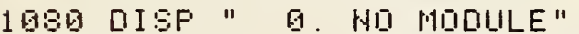

1096 IISF " 1. EXTENSIDH TUEE"

$110 \mathrm{G}$ [ISF" $" 2$. WWERSFILL MOHITI $\mathrm{F} "$

111 DISF" 3. EACEKSEATTER MOHI $T$ TOF"

112 UISF " 4. SEFHFETIOH TUEE"

1130 [ISF" EFLEL:T DF"

1140 [ISF" "E. MHIH ËHLDFIMETEF

1150 IISF "FFOM THE IHFUT EHO, W HAT MOLULE IS MUMEER ": I

1160 IHFUT FE

1170 IF Fit "5" THEH 1250

11 B日 DLEFF: E OISF "WHICH DEUIIE IS EE IHE USEL?"

1190 [ISF UISF" 1. [IEFLELTDF " $Q I S F " ~ 2$. FIIL FEFLEIT IIF:"

12 [ISISF Q "i

1210 IFAFUT R

1220 IF $R=1$ DF $R=2$ THEH 1230 ELS E 12 回日

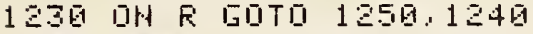

1240 M5\%="FDIL REFLECTOF:

1250 IF VHL
$12 \operatorname{Fo}=1$

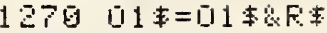

$12 B E$ HERT I

1290 IF $F=1$ THEH 1340

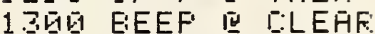

1310 UISF USIHL "K"; H1F,"IST I RELEIUE EHERE'Y EIIT IS HIT

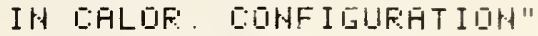

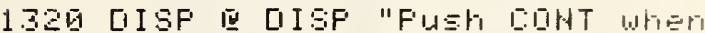

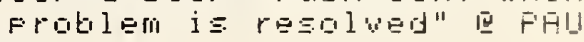
SE

133 G0TO 986

134 IF L走="L" THEH 1370

I SGE FEM GET ELELTFIIAL FHRAMETE Fi:

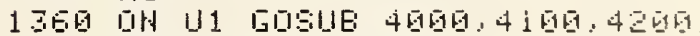

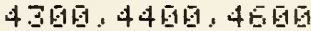

1370 FEM GET HMEIEHT DODHLITIOHS

135 ELEHF MEIEHT TEMFEFATUEE IH DES E?"

1396 INFUT TS

14日E I:LEHF: W [ISF "WHAT IS THE E ARDMETFII: FFESSUFE IN rim"

1.41E IHFUT BGE I:LEAF

1420 IF U1 26 THEH 1710

I 43 REN SET RTO \& TEMF DUT [IIFL

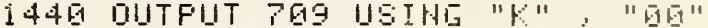

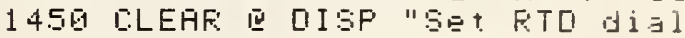
for convenient reaslia ar [ Wh"

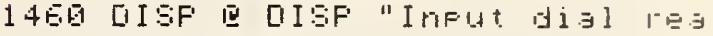
d 1 1

1476 IHFUT 25

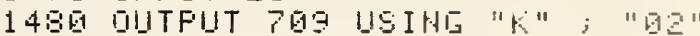

1436 LLEHF Q

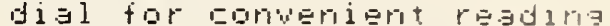
Dri [uा"

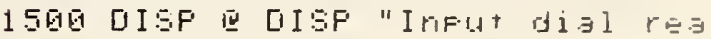
ding ":

1510 IHFiIT ZF

152 REN GET MAIH EAL ZEFO F[IS

15.3 DUTFUT P24; "R

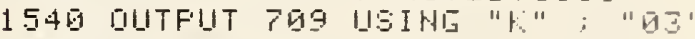

15.51 EHTEF: $724 ; 21$

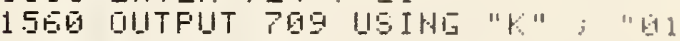

1570 EHTEF $724 ; 22$

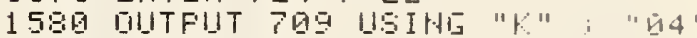

159 EHTER $724 ; 23$

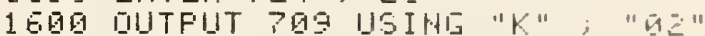

1610 EHTEF $724 ; 24$

1620 OUTFUT P24; "T1D.15" Е LIOH L 724

1E.3E IMHEE "MASS FLOM IH ZEFO FO Б: ", $2 \%, 5[2,2 \mathrm{C}$

1E4G INAE "TEMF IH ZEFID FEII", $\%, 5 \square 2.2[1$

1 E.5日 IMAEE "MHSS FLOW DUT ZERD F

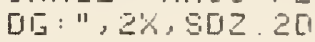

1.EБ日 IMHLE "TEMP UUT ZEFD FOG $2 \%, 5 T_{1} 20$ 


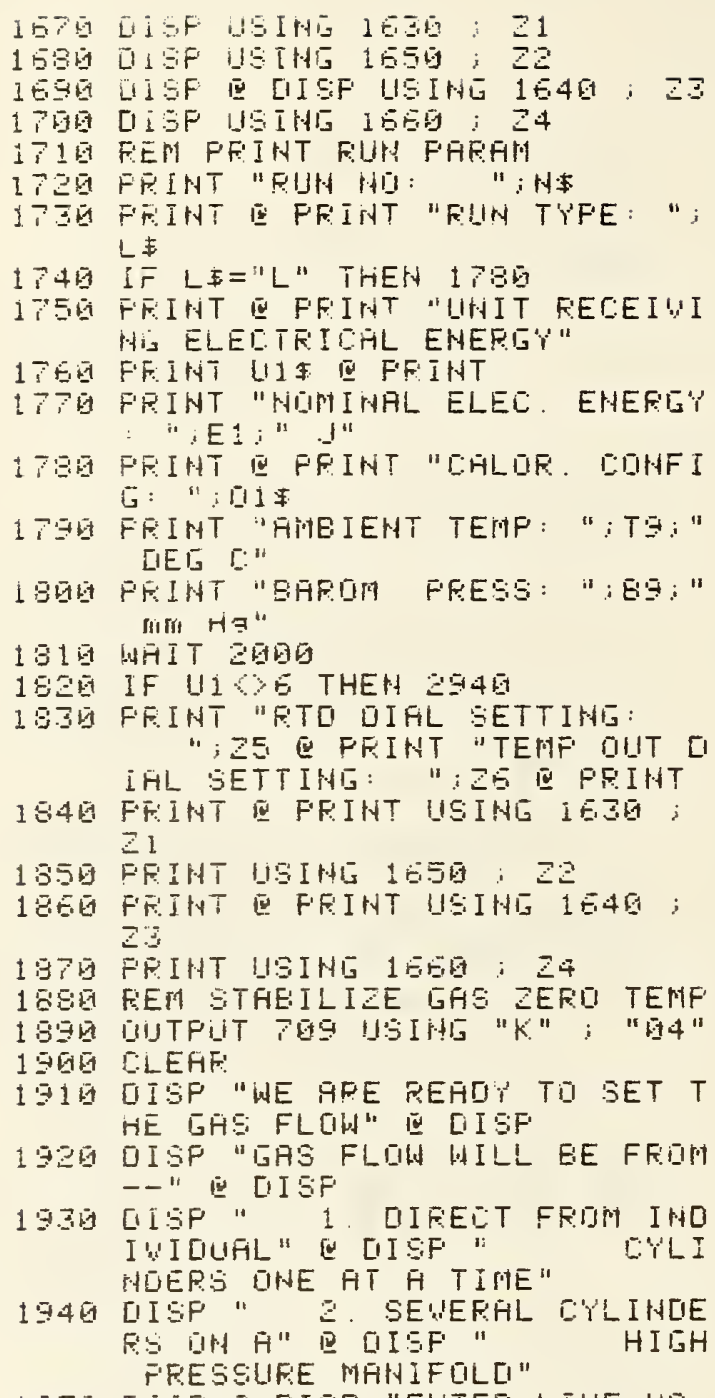

1959 UISP E DISP "EHTEP LINE HO

1960 INFUT 69

1979 IF $\square=1$ UP $\square 9=2$ THEH 1996

ISEG BEEF E LISP "AHSWEF MUET EE 1 DR $2 "$ Q

1990 IF $G 9=2$ THEH 2270

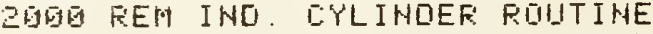

2E10 LLEAF: $Q$ DISP "OFEN MAHHUAL U ALUES DN IHPUT TO FLL ELECT F.ICAL UALUES LISEL."

2029 DISP "NAKE SUFE MAHHLAL UALU ES an HOH-COHNECTEL ELECTFI CHL WALUES ARE LLOSED TO FR EUENT":

2039 DISF " BACK LEAKAIGE."
2040 GUEUE 5E2

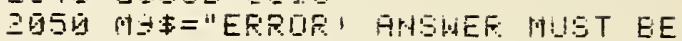
1. 2.3 GF $4 "$

20BG LLEAR O DISF" "TO WHAT "ALUE IE THE FFIMAF' CYLIHUER CO MANELTELI?"

207 INFUT F:

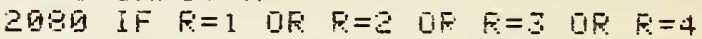
THEH 2106

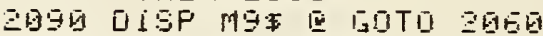

21日G GI =UAL $33+F)$

211日 UISP Q OISF "TO HHAT UALUE IS THE \#I EACK-LIF CULIHEEF CDHAECTEUT"

2120 IMPUT $P$

2130 iF $R=1$ OR $R=2$ DR $R=3$ DR $R=4$ HNL POUALEI Y-SZ THEH 21 50

2140 OISF MGE: FNO ":R:" IS TH E FFIMAEY CYLINEEF UALUE" E EEEF Q IOTO 2110

2156 G2\$=VAL $33+F$

216日 DISP Q IISF "TE WHAT VALUE IS THE \#Z EACK-LIF CYLINLER DONHECTED?"

2170 INFIIT $F$

2180 IF $R=1$ DR $R=2$ QR $R=3$ GR $R=4$ FHU FO G日.

219日 GISP MED:" AHL ";F:" IS THE \# 1 EACF-UIF CYLIHEIEF "HLWE" E EEEF Q GOTO $216 \overline{0}$

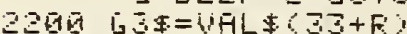

2219 UISF I DISP "TO WHAT URLVE IE THE \#3 EACK-UF CYLINDEF CONHECTEG?

$223 \bar{A}$ INFIIT F

2230 IF $R=1$ QR $R=2$ UR $R=3$ iR $R=4$ FHE ROUFLUES-33 THEN 23 56

2240 OISF MOS;" HHO "R;" TS THE \#2 ERCK-LF CYLIHLIEF WALUE" E BEEF [O GDT 2310

$225 \bar{G}$ G4\$=UAL $\$ 33+F)$

2200 G0T0 252日

2270 REN GAS FROM MANIFGLO

228G LLEAR Q IISF "MAKE SUIEE FLL WALUES DN MAMIFDLO AHO CYL INDEFE AFE SHUT OFF." E IIS $F$

229G DISF "CONAECT 3 DR MURE GAS C.YLIMLIEFE TO MANIFOLE WITH THE EQFPER TUEIHI FIITAILS

23日G UISP Q DISF "OFEH ALL MANIF ULEI UALUES TU CYLINEEFE" E IISP

כ319 UISF "OFEN UALUES TO 2 LYLI HLIERS."

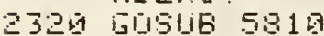


233 LLEHF E IISF "FOF YULE INFO FIMTIIIN-D" II CISP

234D LISF "LHAHLE CYLIHDEFS IF $F$ FEESIJPE GROPS TO IDE\#"

235E DISF "FROCELUIRE TO FOLLOW I 5: " E [IISP :" 1. SHIIT UFF MNHIFOLO WHLVE TO OHE C'YLIMCEE:"

236 OISF" 2 . TUEN OH DYLIHDE F. WHLUE TO A NEW EYLI HIER

2375 UISF" 3. CLISE THE CYLIH DIEF UALUE DH THE C'IL IHIIER IH STEP 1 "

3380 LISF" 4 FEFLACE CYLIHCE F IN STEF 1 WITH H HEW CYLIHCIEF" "

$239 \overline{9}$ OISP " 5 . DPEN MANIFDLO U HLWE DIN THE FEPLACEMEN T C'TLIHCIER."

240 TISUE 5810

2419 CLEAF E IISP "DONTINUIHT WI TH SETTING UIF THE GAS MAHIF DLD-D" D DISF

2420 [IISF "OPEN MAHIFOLD VALVE T o PRESURE REGIILATUR." I IIS $F$

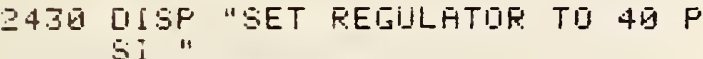

244日 GUSUE 581日

2450 OLEHR OU DISP "TO WHAT ELECT F.ICHL WALUE IS THE REGULATI Fe CONNECTEO?"

24EE INFIIT F

2479 IF $R=1$ or $R=2$ or $R=3$ oR $R=4$ IHEN 2490

24B日 UISP Q UISF M9 Q BEEF E WA

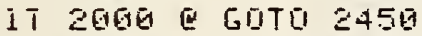

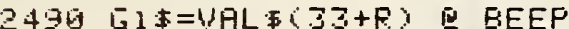

2590 $015 \mathrm{~F}$ Q DISF "MAKE SURE MANU FL UHLUE ON UNUUSEO ELECTRID FL "ALWES ARE CLOSED.

251 G $5050 \mathrm{~B} 5919$

2320 CLEAR Q UISP "We are now $=0$ t ting UF the $\exists a s$ flow." [E ISP

25.3日 OISP "DN the INPUT GAS TENP COHT-C" EIISF

2540 UISP" 1. Fut the RUUH-SET SwI TEh ta

2550 0ISP " 2 . Hijus the EALA NCE knob $\equiv 0$ the HEAT I VILLE LEO JUEt"

2560 015F" daes renain ext I riguished."

25T0 UISF" ? Fut the RULH-SET switeh to Plot the Run

258 GUSUE 5810

2505 UISP Q OISP "On the PREHEAT EF: COHTFOL UNIT" E IISF zega [iSF" \&

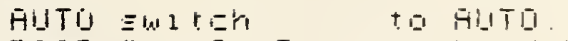

2610 DIEF" 2 " ROT HIJE knob to FliLL ELGCK WI $\mathrm{SE} "$

2620 DISF " I. Fit? the JFF-DH $\equiv$ wit i t

26.30 G0SUE 5810

2640 ZU日ด ! THIS JALUE DETERMIHE [I EMFIFICALL"

$2645 T 4=.55$ ! REITRAR'I UALIJE AEI WE FUIIM TEMF

265日 ON KE'\# 1, "LAS DH" GOSUE SZ Dis

265日 DH KEY\# 2. "GHS DFF" GUEUE 4 两舟

2570 IF $\mathrm{G}=2$ THEN $259 \mathrm{G}$

2680 OH KE"\# Z "CHE LUL" GQSUE 7⿹丁口

2690 DH KEY\# 5. "MASS IH" GOSUE S 560

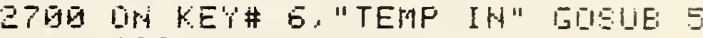
E.06

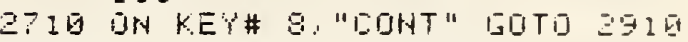

272G OLTFUT TOS DEINT "R" : "GI

2730 CLEAR Q KE' $r$ LABEL

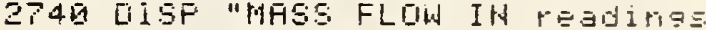
on [unt"

275G UISP "HIKE SURE RELULATEPS are Set to 4 G FSI

27BG UISP "GFER FLIW "WLUE 2 thr nis."

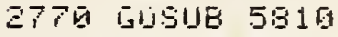

2780 GISUE 5309

2790 EEEP Q CLEAR IQ KE'Y LABEL

2309 LISP "EhECR HEAT CYCLE LELI $1 \Xi$ ELIHKIHI"

2E1G [ISF "USE FLOW WHLUE and EAF LFHCE kriab regPECTIVEl\% to Get $b=i$ aw RAS:

282Q UISP "IH and TEMP IN readin 3E."

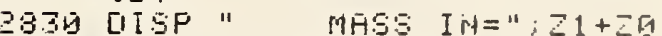

284G [ISF " TEMF IH="; T4

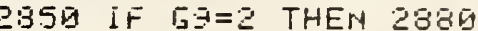

2BEG UISF "SWIten to each FEGULF TOF and setit to get these roadiries HT End"

237日 UISP "EMItCh to primary Eirider."

28B⿹ DISP "MASS IH and TEMP IN $r e$ coufled. Switch back and torth to moritorboth resdin gE. "

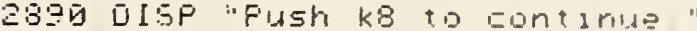

2906 GLTU 2909

2919 DLTPUT Tด马 USIHG "K" ; "3"

2920 OFF KEY\# 1 E OFF KEYA 2 is 0 FF KE'Y 3 \& DFF KE' $F$ KEY\# \& E LLEFE: 
293060702970

2940 DiTPUT 7Q9 USIHI "K"; "G"G UHL $1016-12$ )

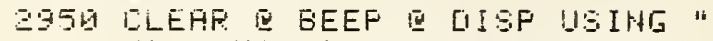
1." : UI\$: "DUTFUT REALINGS Dry [1WM"

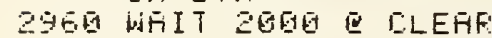

2970 DISP "SHUTTEFS EEIHI TESTED

29GG DUTPUT 709 USIHE "K" ; "3, Z B. 32

29GE DUTFUT TEG USIHI "K"；"Z"

3 GEG WFIT 1600

3010 EEEF G DISF "SHUTTEP LEO' SHIULU EE GREEH" Q WHIT ZQGG b

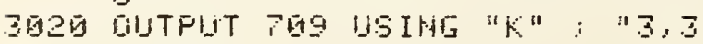
1.:3"

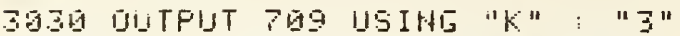

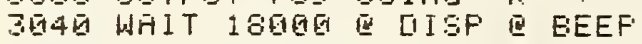

3G5G DISP "SHUTTER LED' E SHOULO EE FELI" W LISF

3050 DISP "UIO SHUTTERS TEST OK? (T) $\mathrm{CH}$ "

BOTG INFUT RE

3080 IF FE= " $"$ "THEN 3170

3990 IF P\$= "N" THEN 3120

3106 EEEF E DISF "WHAT"?

3110 100TO 3060

3120 CLEAF:

3130 UISP "EXERCISE BALK' SHITTE F: WITH PUSHEUTTOHE. IT MUST DFERATE IN 19 SEI" E DISF

3140 UIEP "FuEh cord unen ready"

3150 FHISE

3160 LLEAR E GITT 2970

3170 CLEHF:

3180 IF L C "L" THEH 3220

3190 UI\$="MHIH CFLOFIMETER"

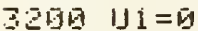

3210 UISF "FIHAL FRE-RUH LHECK L IST" ए IISF

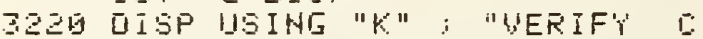
HELE IS IS DHHECTEG TO ":U I五

3230 IF $L=" L "$ THEM 3256

324日 DISP "TUEH ION KEPCO PIJUER S UFPL' $Y$ " E GOTO 3200

3250 DISF "UERIFY KEFIO FOUER SU F'F'Y IS UFF"

3269 IF $U 1=5$ OF $1 J 1=0$ THEN 328 Q

3270 DISF $Q$ LISF "GHS EOTTLES SH DULI EE TURHED DFF AT CYLIH [IEFS:

32B日 UISP Q QISP "NAKE SAFETY DH ELE UIF AFEA"

I29日 GISP Q DISF "PUSh DUHT when ready"

33 GI FHUSE

3319 CMAIH "CLOFE"
4QEGE FEM MHY FHEAH FUF: EYT TUEE

4010 E

$4620 \quad V 6=160$

4030 R

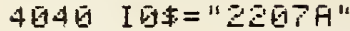

4DSG HIT= "EXTEHSIOH TUEE"

4EE

41 旦

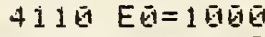

4120 ,

$4136 \quad F \bar{G}=7.8$

414 I I

4156 UI\$="OUEFEFILL MOHITOF:"

4156 GITO 47 G日

42 GE REM HAY FGEAM FUIF ESH

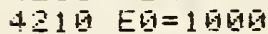

$4226 \quad$ W $=80.4$

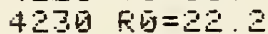

4246 I $65=" 22639$ "

4250 U1:= "EACKSCATTER MONITOR"

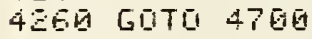

430 FE MAX FAFAM FOE SEF TUEE

$4310 \mathrm{E}=1 \mathrm{G}$

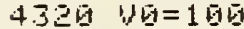

4330 FE $=340$

434 I

4356 UI:="EEFFFATIUH TUEE"

4.36 15TO 4 \%

449日 FEM MHK FHRAM FOR DEFLEITIOF

441 IF IF $M 511,1]=" F "$ THEN 4480

$442 \bar{G} \quad E=1960$

$443 \mathrm{~B} \quad 4 \mathrm{~B}=20$

$444 \overline{\mathrm{C}} \mathrm{K} \overline{\mathrm{U}}=3.5 \mathrm{~S}$

4450 IE末 "ZEEAE"

$446 \overline{1}$ UL: $=$ "DEFLECTOR"

4476 GOTO 4780

$4486 \quad E G=1060$

$4490 \quad$ VG $=78$

4500 F $F^{\prime}=2.5$

4516 16和="Z24FZ"

4530 UI: $=$ "FIIL REFLECTIR"

4536 GOTO 4706

$45 E \bar{Q}$ REM MAX FARAM FUE MAIN C:AL

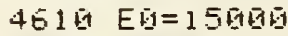

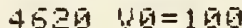

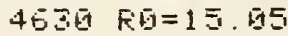

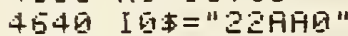

4 E.5 U1 = "MAIN CHLGRIMIETER"

47 GQ CLEAR E DISF "HOW MAHY JOUL ES HFE TO BE IN IELTEL?"

471 INAPUT EI

4726 IF E 1 $=E E$ THEH 4750

4730 EEEP \& OISF USIME "K": "TO I MIITH ENERIY. TRY ": EQ:" I UIILES OR LESS." Q WHIT 1 QEE

474 GOTO 4706

$4750 \quad T E=5$

4760 UI SNR (E1末RO

4778 IF V1 $=$ U THEN 4810

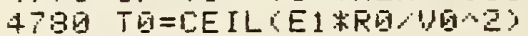




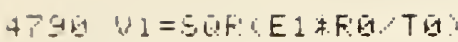

4\$GG BEEF Q DIGF "IHJECTION TIME LENGTHEHEO TO "T TU: "SEQOH

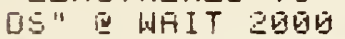

4 :1 FEM EET KEFCO EOMMAHLI

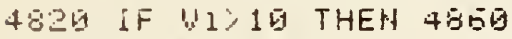

$453121=4195$

$454 \overline{0} \quad 0=2$

485 口田可 4886

$4356 k i=41.95$

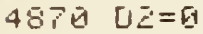

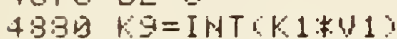

489G FEM CQHUERT KG TO RALI\% 1 E

430 WG=INT KO 10

$4916 \quad[5=K 9-15 * 19$

$492 \overline{0} \mathrm{D}=\mathrm{INT}(\mathrm{V} 9 / 1 \mathrm{~B})$

$4535 \quad[14=69-16 * 113$

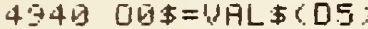

4956 IF $05>9$ THEN GOSUE 5190

4960 ○.5

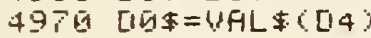

4338 IF $04 \% 9$ THEN GOSUR 5100

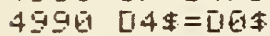

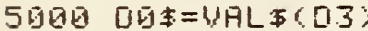

501 IF $43>9$ THEN G0SUE 5169

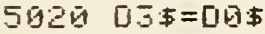

56.30 W1 \$

5D4G RETUPN

51 BQ REM LONUERT LAFEE HEX DIT.

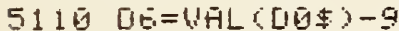

5129 DN DO GOTO 5130.5150 .5170 .5 $140.5210,5230$

5130 D国="月"

514 KEETUR:H

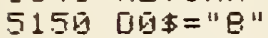

516 FETUF:N

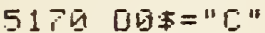

51 SE RETIIRN

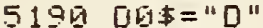

52 GI RETUF:N

$521 \overline{1} \quad[\overline{5} \%=" E "$

$52 Z B$ FETUFIN

52.39 पBD $\$=" F "$

5240 RETUFN

53 GB FEM TURN DN THS

5310 DUTPUT 769 USINT "K": GLF 5.220 FETUF:N

5400 FEII TUFN DFF GAS

5419 DUTPUT 799 USING "K": "马"

5429 FETUF'N

55 BS REM MASS IN WILTS

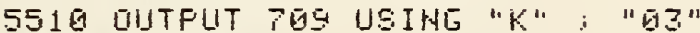
552 RETUFN

56GE FEM TEMF IH WOLTS

5619 DUTPUT 709 USIHL "K" : "Q4"

5EZE FETUFN

570 RE RM EHG GAS EITTLE FIUUTIHE

$571 \bar{A}$ F'EM

$5725 \quad 155=51 \%$
$57 \Xi 515=\square 25$

5749 DUTFUT 7G9 USING "R"

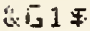

$5759 \quad 52=15.3$

$576 E$ GET=64:

$5776 \quad 547=15.57$

5780 RETUF:H

55BG REM FAUSE SUERLIITIHE

$581 \bar{G}$ EEEF ¿ UISF

5520 DISP "Fush CDHT when rog:"

БВ亏̈ FHUSE

5840 FETURN 
Variable Map

Proyram: AUTUST

Uate: 840214

B9 - barometric pressure in min of $\mathrm{Hg}$

D2 - number indicating power supply voltage range

U3 - first hexadec. digit (MSD) of voltage part of power supply command

U4 - second hexadec. digit of voltage part of power supply command

Ub - third hexadec. digit (LSU) of voltage part of power supply command

U6 - amount hexadec. number exceeds 9

U3\$ - third character in power supply command (string version of D3)

U4\$ - fourth character in power supply command (string version of $\mathrm{U} 4$ )

Ub\$ - fifth character in power supply command (string version of U5)

UИ\$ - temporary string variable for converting hexadec. digits to string variables

El - nominal electrical eneryy input

$E y$ - maximum allowable electrical eneryy

F - flag to look for unit missing from calorimeter configuration descriptor

G9 - method of gas supply (1=10w pressure manifold, 2=high pressure manifold)

G1\$ - electrical valve channel for primary gas cylinder (L.P. and H.P. supply)

G2\$ - electrical valve channel for \#1 back up yas cylinder (L.P. supply)

G3\$ - electrical valve channel for \#2 back up gas cylinder (L.P. supply)

G4\$ - electrical valve channel for \#3 back up gas cylinder (L.P. supply)

Gb\$ - temporary string variable for changing order of yas cylinders in L.P. supply

$J$ - counter

$L \$$ - run type ( $L=l$ aser, $C=$ combination, $E=$ electrical)

M9\$ - error message in gas set-up routine

N\$ - run number

$01 \$$ - calorimeter configuration descriptor

$R \phi$ - resistance of calibration heater

$K \$$ - alpha answer to questions

T4 - temperature in reading desired while gas is flowing

Ty - ambient temperature in degrees $C$

Ty - electrical energy injection period duration in seconds

U1 - numeric indicator of unit receiving electrical 
eneryy

(c)

UI\$ - name of unit to be calibrated

VI - reyuired voltage setting of electrical calibration power supply

vy - yuotient derived during hexadecimal conversion

vo - inaximum allowable electrical calibration voltage

VI\$ - voltaye command to calibration power supply

(c)

$\angle 1$ - mass flow in zero readiny

(c)

inass flow out zero reading

(c)

temperature in zero reading

(c)

temperature out zero reading

(c)

main calorimeter RTD dial setting

(c)

temperature out dial setting

(c)

change in mass flow in reading when gas is

turned on

(c) 
C2. "CLUP2"

Proyram Listiny

16 FEN" "LLFE" LATE-TIME GB11

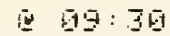

2Q OFTIOH EASE G

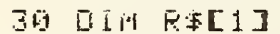

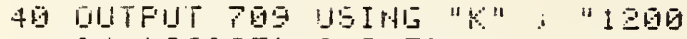
G" "220日F" GLEAF"

5 的

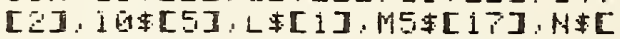

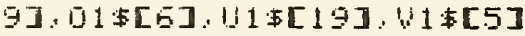

6日 COM SHOET EG.E1,TG,Z1,Z2.Z3

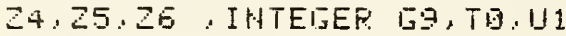

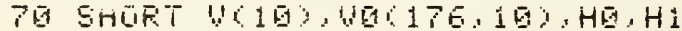
(16), 1655), I1 55 )

5 IHTEGEF I, I, I1, IE, K.L,HG,F

96 FDR I = TO TO

160 HISI? $=9$

110 HEXT I

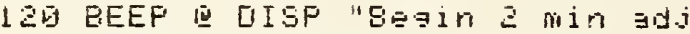
UEt mert FEF I Id "

139 IF LD="E" FHD U1 THEN 18 G

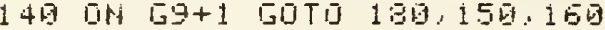

15G OH REY\# 1. "CHG ETL" GOSUE 30 Dê

160 GH KEY\# 2. "GAS DH" GOSUB 350 DH KEY\# 3. "GAS DFF" GOSUE 3 501

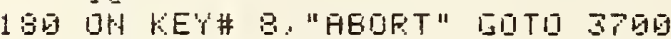

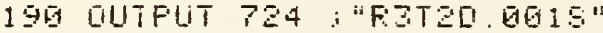

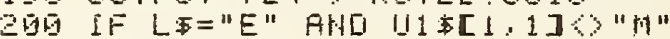
THEW 220

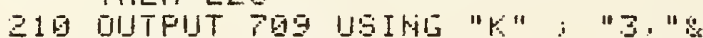
EIF

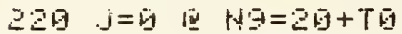

230 DH TIMEF\# 1, 3600 GOTO 260

249 IOTO 240

250 FEM PEFIOL E:

259 LLEAR E KE' $Y$ 'ABEL

270 FUF $1=\overline{1}$ TO 9

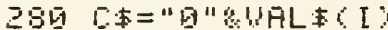

290 CUUTFUT 709 USIML "K"; CE

309 EHTER P24; VCI?

316 HEXT I

320 UISF "MASS IN= ":4C3

उउप UISF "MASS DUT= ":W61

349 DISF "TEIP IH= "IU64

בSE OISF "TEMF DUT= ". "UC

360 GISF "MAIN GAL FTE= "UCO

37日 UISF M5: W5

380 LISF "SEF TUEE= "UCE

39Q BISF "BSM PTE= "UC

490 OISP "DSM FTE= ":168
41U LIEF" "EST TUEE= "MC

$420 \quad 1=1+3$

430 IISF "TIME: ": 1; "EER"

440 IF SUIZ THEN 240

450 IF 13120 THEH 480

460 DX KE'\# Q. "AEOFT" GOTO 4EDE

470 EEEF Q UE tment Feriod"

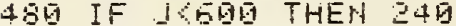

4 GI FEM FER IOD [i

50 CLEAR E KE" LAEEL Q DISP "PU. n $1 \equiv 1$ d dats taking $\equiv$ t.

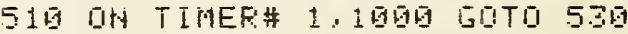

5206070520

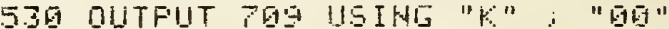
E EHTEF P $\mathrm{P}+\mathrm{HQ}$

54日 OUTFUT 7日9 USISI "K" ; "91"

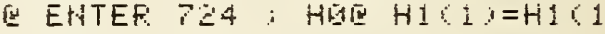
$\mathrm{Y}+\mathrm{HB}$

550 OUTPUT 709 USIHE "K゙" "G2"

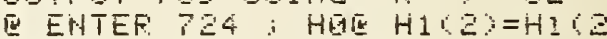
$\gamma+M \bar{G}$

56 GUTPUT 7 G9 USIS "K" " E ENTEF TCA ; HGE HIC $y+H \overline{1}$

57 DUTFUT 759 USIHE "K"; "G4" E EHTEF T24; HGQ H1 $49=\mathrm{H} 1 \mathrm{C}$ $+\mathrm{HQ}$

5S日 OUTFUT 7 OQ HEIHG "K" : "GS" E ENTEF 724 ; HEQ H1C5) $=H 1<5$ $\mathrm{Y}+\mathrm{Hig}$

5马E OUTFUT 7 7 G USING "K" "GE" Q ENTEF: T24; HQE H1CG)=H1CE $Y+H \bar{b}$

EOG OUTFUT 709 HSING "K" " E ENTEF: PEA : HQG HIST $=H 1 C \vec{C}$ $1+\mathrm{HB}$

E19 DUTFUT 7Q9 JSING "K" : "GG" Q ENTEF 724 ; HGE H168\%=H1 $\therefore+\mathrm{H} \underline{\mathrm{G}}$

E2G DUTFUT PQS USING "K" "EG" E EHTEF 724 ; HG H169) $=H 1(9$ $1+\mathrm{HE}$

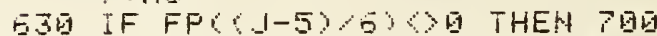

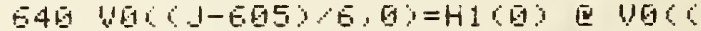

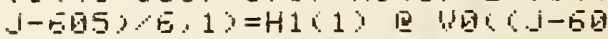
$5,0,2>=H I ? 2$

E50 $10(3-605)(5,3)=H 1(3)$

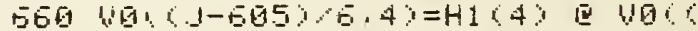
$J-605,6,5)=H 1(5)$ Q $5)(E, 6)=H 1(6)$

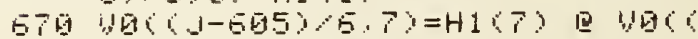

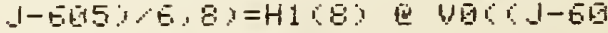
$5) \cdot 5,9=H 1(9)$

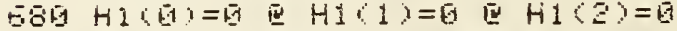
Q $H_{1}(3)=0$ Q $H_{1}(4)=$ 可 $\mathrm{E} H 1\langle 5\rangle=$ E E $H$ i $(E)=$

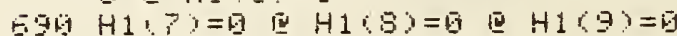




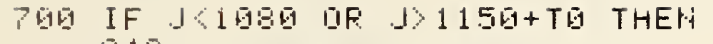
940

710 IF JP1130 THEH 830

72 IF $J<1$ Q

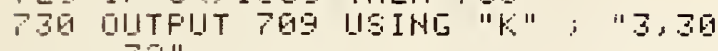
: 31

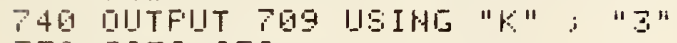

756 15010

7 EG IF 1211 THEN BG日

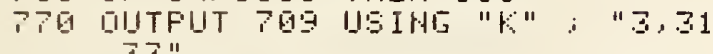
, 3.3

780 DUTFIT 7 G9 ISIHE "K"; "3"

790 10T0 950

G6日 IF J1128 THEH 950

810 OUTFUT 四事

82日 GOTO 950

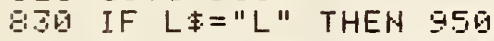

84E CUTPUT 709 USIHE "K": "1日"

850 EHTER $724 ;$ I $1(1-1131$ )

SER CIUTFUT FES ISIHI "K" : "12"

ETE EHTEE 724; W1 I-1 131 \%

886 IF $J<1140+T$ THEN 910

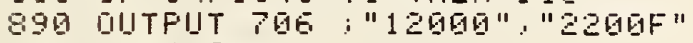

960 GTTO

910 IF 131140 THEH 950

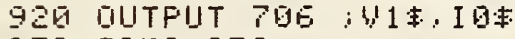

930 GOTO 950

940 IF $J>1651$ THEN 978

$550 \quad J=1+1$

96E GBTO 520

970 DFF TIMER\# 1 Q INE "K"; "Z"

98E DUTFITT 724; "FET1[1.1S" E LDE: HL 724

995 DITFUT 7G9 ISIHE "K" ; "14"

1 GEG EEEF Q LLEFF Q DISF "RIDH EH II DHELKK LIST" QISF

1019 IISF "IHELK LALQFINETEF HHL EHWIFOHS FOF CIAMAGE" Q $F$

1920 IISF "FFEHEATEF SHOULLI EE T UFHE[ DFF" IO [IISF

1 Q 30 DISF "TIIFH DFF WALUES DH GA S ELIHLEF:" Q LISF

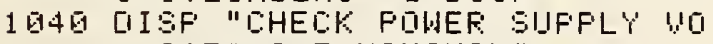
LTAEES HFE HOMIHAL"

1950 IF LF="L" THEH 1979

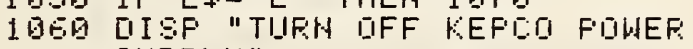
SIIFFLY"

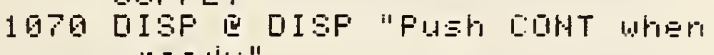
re.gd $\% "$

1 可可 FAIISE

16日G ELEAF E [ISF "LATH-SIIM FALK ETS BEIHE AWEFALE["

1. 1 QG FGR $K=0$ TD $G$

1116 FOF $I=6$ TO 175

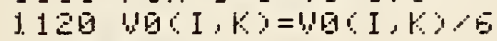

113 GEXT I

1140 HEXT K
115.5 IF LF="L" THEH 12 Q

1150 [ISF "Lal ibration 'G]

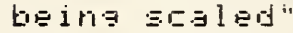

1170 F I I = $Y$ IE EEEALISE OF CIIUICIEF IH U-I Elig

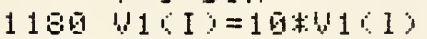

1196 HEXT I

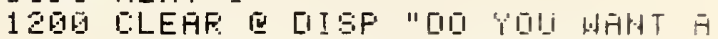
FRIIT QIIT OF THE FESULTS (U OF H"

1210 IHFIIT FE

1220 IF $F=" \% "$ THEH $12 E$

123 IF FE="H" THEH 19 G

124 EEEF Q LISP Q [IISF "WHAT"

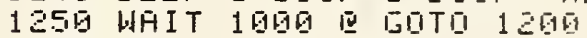

1260 IF LT="L" THEH 157 G

1270 FFIHT E FFIHT "ELEI: CIATH" E F'F:IHT

$12 B$ FEIHT "HO. WDLTS AHF:"

1290 IMALE $3[1,3 x, 50 z, 20,2 x, 502,2$ [1

13日E FDF I=日 TO $H 9-1$

131 FFIHT ISIHI 128 ; I I I. I I $\therefore$ I 1 CI

1 ZZQ HEXT I

1330 IF LF="[" THEH 1576

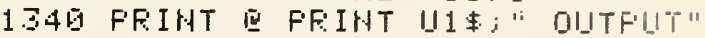
E F'FIHT

1350 IMADE $3[1,3 X, 5[2,4[1$

1.

137 F FEIHT

$1380 \quad .11=10-111$

1390 GOSUE 45E日

1460 BOTI 1960

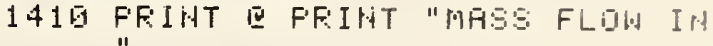

1420 J1=3 E FFIHT

1430 GOSUE 45日日

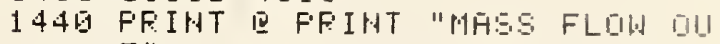
$T$ "

145 FFIHT E. $11=1$

1450 DOSUE 45 G

1476 FFIHT E FFIHT "TEMF" IN"

148 FFIHT E J1=4

1496 BDISE 450 G

15 GE FEIHT E FEIHT "TEMF DUT"

151 GPIHT I $11=2$

1520 BOSUE 450日

15.35 FFIHT Q PFIHT "EFL FTO"

154 PFIHT Q $11=0$

1550 G0SIJE 4500

$156 \bar{G}$ GOTO 1960

157 FUF $I=0$ TO

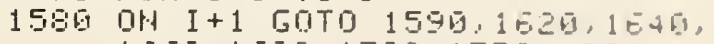
$1560,1550,1760,1735,1750.17$ 76,1790

1590 FFIHT "MAIH DAL FITO"

1606 12=E.

1E1日 GOTO 1816 


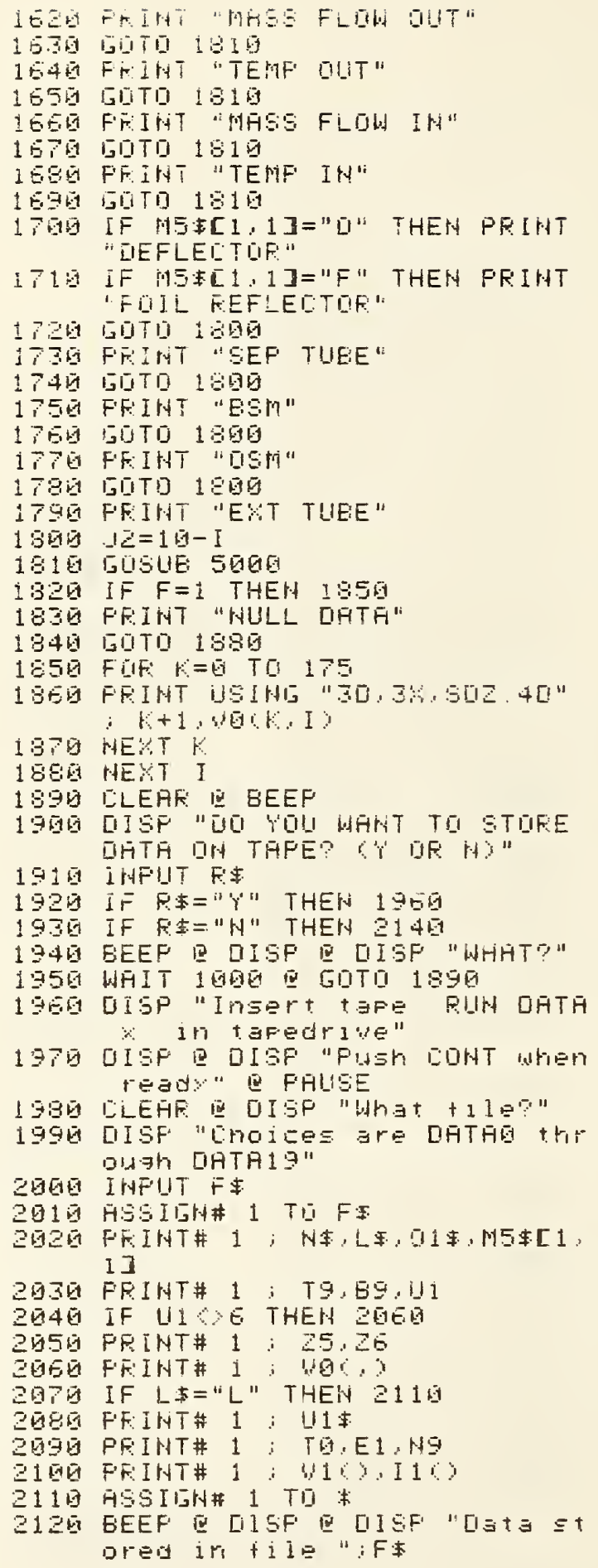

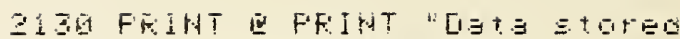

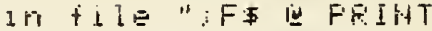

2I4U WHIT 1 GIGE E CLEHE

2150 OISP "FUH HU: "; IH: " COMPLE TE[ T: UISF

21SG UISF "INDICATE CHEICE"

217G LISF " 1 ENL RUIS"

21GE UIJP " 2 . NEH RUN"

2196 [ISF "3. FEFD [ITTF FILE"

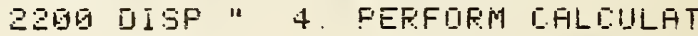
intis:"

2219 UISP " 5. TFRHEFEF DRTA GH F.5232

222G OISP " 5. FFIHT DUT E!IFEEH T FUHA [IATF"

2ZJE पISP " 7 . LOP' CUFEEHT [IAT ATO FILE⿰

2240 OISP Q DISF "EHTEF LIHE NO

2ZSG INPITT R

2200 IF $\mathrm{R}=1$ AHI $\mathrm{P}<=7$ AHO FP(R)= G THE ZUY 290

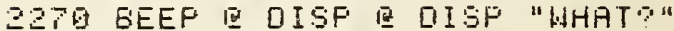

2ESE GUTO 214E

2230 ort $R$ G0T0 2530.23010.2310.23 $46,2406,126,1960$

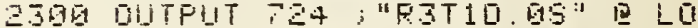
IAL $T 24$ E HERTTIO 7 E EHAIT "नं

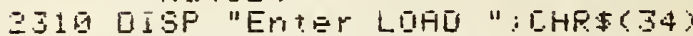

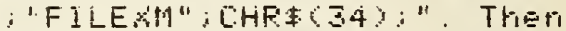
PISh EHIL LINE.

2320 [ISF "LAUTIUH-ThIS ki11 wi Pe out Eurrent Frogram and data from memory e EEEF

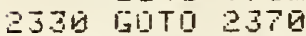

2346 ELEHF E [ISP "M.Jie sure t.jF e CLLCIF iS in taFe drive."

2345 EEEF Q [ISF "Push LOHT when ready :

235E IISP USIHT "K": "TYFE LOAO ":CHF⿻ 34 ): "CALC"; CHF⿻ $(34)$ ; " and Fush EHC LIHE key"

23E GISF "Writh laading is EamFl Ete. Fush RUH."

ZZTE FHUSE

23BG EEEP Q OISP "ERROR!--Do not FUSh [DITT!"

3390 G0TO 2370

24 OIS OISP "PFOURAM HEELS TO EE D EWELUFEI TO SUIT FAFTICULAF SERIAL TRANSFER SYSTEM."

2410 WFIT 200 E GOTO 2140

$243 \mathrm{FEH}========$

2430 REE SPAIE

244 RिEW

2456 REM

$24 E$ FEE

247W REM

ZUE FEM
FIR

FUTURE 


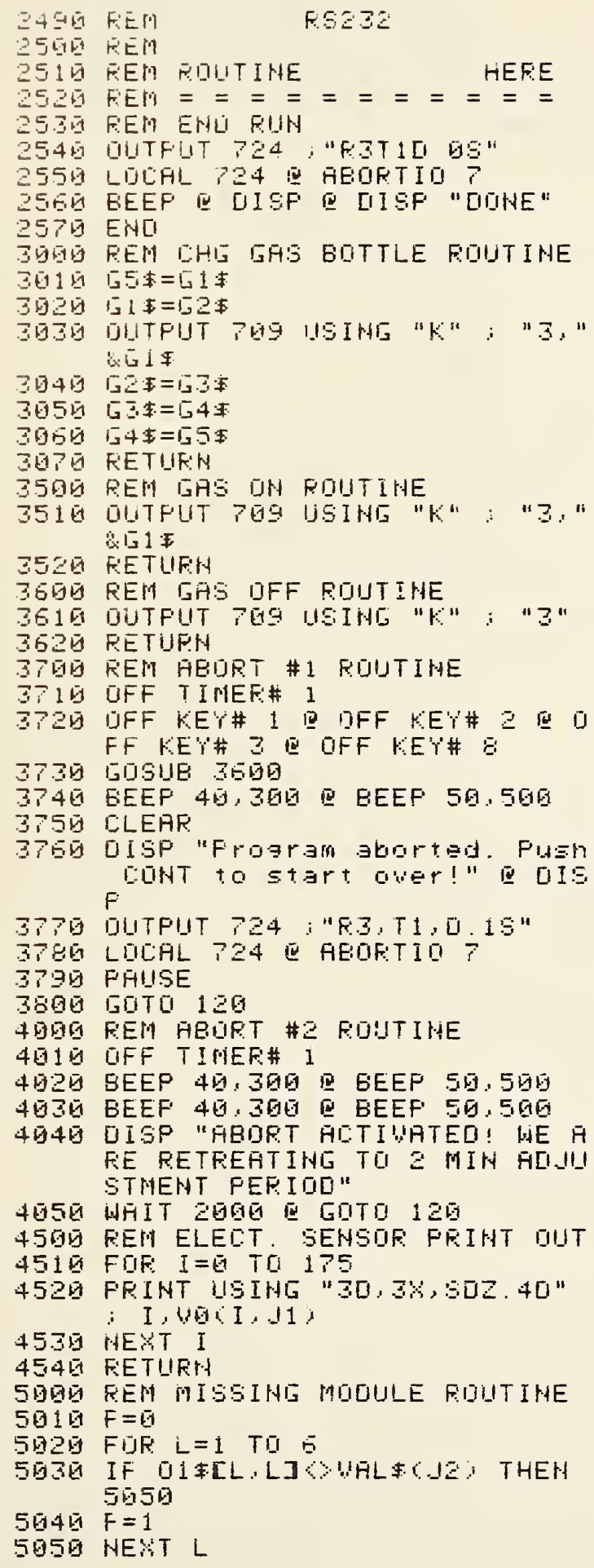


Variable Map

Proyram: CLUP'2

Vate: 831118

B9 - barometric pressure in $\mathrm{mm}$ of $\mathrm{Hy}$

C\$ - scanner channel command for switching sensor channels

El - nominal electrical energy input

F - flay to look for unit missiny from calorimeter confi guration

$\mathrm{F} \$$ - name of file in which run data is to be stored

G9 - method of gas supply $(1=$ low press. manifold, $2=$ high press. manifold)

G1\$ - electrical valve channel for primary gas cylinder (LP and HP supply)

G2\$ - electrical valve channel for \#1 back-up gas cylinder (LP supply)

G3\$ - electrical valve channel for \#2 back-up gas cylinder (LP supply)

G4\$ - electrical valve channel for \#3 back-up yas cylinder (LP supply)

Gb\$ - temporary string variable for changing order of gas cylinders in LP supply

$\mathrm{Hl}$ - array for acyuiring by summiny sensor output data packets

$\mathrm{H} \varphi$ - measured sensor output voltage to be summed to $\mathrm{Hl}$

1 - counter

11 - array containing electrical calibration current readinys

Iy\$ - current limit command to calibration power supply

$J$ - counter

J1 - index indicatiny sensor data being handled

$\mathrm{J} 2$ - index indicating unit being searched for missing module routine

K - counter

L - counter

$L \$$ - run type ( $L=$ laser, $C=$ combination, $E=$ electrical $)$

M5\$ - deflector-type name display messaye during monitor period

N9 - number of $V 1$ (and 11 ) readings

N\$ - run number

U1\$ - calorimeter configuration descriptor

$R \quad$ - numeric answer to yuestions

$R \$$ - alpha answer to questions

T9 - ambient temperature in degrees $\mathrm{C}$

$T \varphi$ - electrical energy injection period duration in seconds

U1 - numeric indicator of unit receiving electrical eneryy

U1\$ - name of unit being calibrated

$V \quad$ - array for storing sensor output readings duriny monitor period

V1 - array containing electrical calibration voltage readings

$V \varphi$ - matrix for storing all data packets acquired through $\mathrm{HI}$

V1\$ - voltage command to calibration power supply 

21 - mass flow in zero readiny
22 - mass flow out zero reading
$\angle 3$ - temperature in zero readiny
24 - temperature out zero readiny
$2 b$ - main calorimeter RTU dial setting
20 - temperature out dial settiny

$(c)$
$(c)$
$(c)$
$(c)$
$(c)$
$(c)$ 


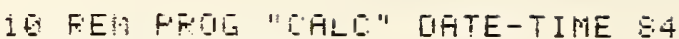
9221 I $15: 45$

2 GIF IOH EFSE

3日 GHOE , TG, ES, F11.1G, Z Z . ZE

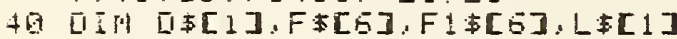

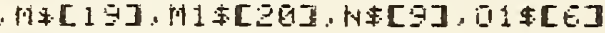
PRE[1].U1क[1:3]

5 [I I Y Y

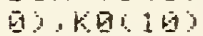

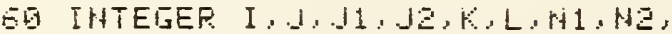
H马, M4, NE, TE

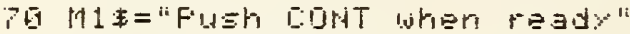

Q6 CLEAF TEEEF

96 DISF "InSERt tapE RUN DATA $x$

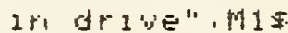

1 GE PHUSE

110 CLEAF

12日 OISF "WHAT FILE OD YOUU WISH TO ALCESSO

136 IHFUT $F$

140 ASEIGN\# 1 TO F.

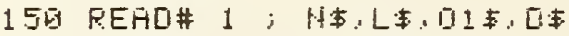

16 FEAL\# 1 ; TS.EG,U1

170 IF $113-$ THEH 19日

15 REFII\# 1 ; Z5.ZE

195 REFO\# $1 ; \| 6,3$

200 IF L\$="L" THEH 24 E

210 REFD\# $1 ;$

220 FEFF[\# $1 ;$; $9 . E 1, N 5$

230 PEFC\# 1 : V1C.I16

240 ASSIGN\# 1 TO

250 DLEAR 巴E EEEF

260 IISF "Contents of tile "iF年; "are in memary"

270 [ISF "Fun NO: ":N\$ E IISF

2GQ UISF "Re-ingert taFe LLOF in drive", Ml1

290 PAISE

3ES CLEAF

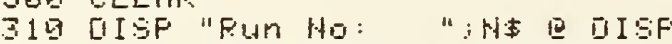

320 [I ISF "Ruri TYFe: "L L T UISF

330 0ISP "Lalor contia: ";010

349 IF $L q=" L "$ THEN 2006

350 DISP G UISP "Unit regeiuirg elec eriergy"

J5ด OISF U1\$ Q OISF

zre LISF "NominaI Energy: ",E1," \lrcorner .

38日 IF LF="C" THEH 20日日

390 IF U1\$[1.1] "M" THEN 45日 EL SE $N 1=Q$ Q

$4 \overline{4}$ IF U1\$[1; I] "E" THEN $419 \mathrm{EL}$ SE H $1=9$ Q $N 2=9$ Q $M=U 1$ \& $F 1$ \$="EKTUE:" E J1=

419 IF U1क[1, 1]>"G" THEN $42 \overline{E L}$ SE HI=S E H $2=8$ E Plt=U1\% E F1 F="OSMDN米" $\mathrm{E} J 1=8$

480 IF UI\$[1,1] "E" THEN 430 EL

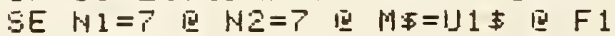

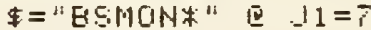

43日 IF U1S[1.1] "E" THEN 44. EL SE H1=6 Q $H 2=5$ IQ F= SFTLEA:"

44 IF U1F[1.1]く" "F" THEH 45日 EL SE MI=5 ¿ $\$=" F D R E F 末 "$ Q $\$ 1=5$

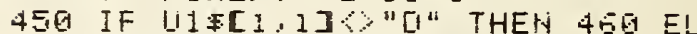

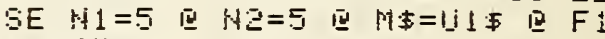
F= "DEFLE: 速" $11=5$

456 GDSU8 36B日

470 GOSUE 3596

43 REM LET EHL FHETOE

465 TE=1 + ND HEAT FLOIW WHILE SH UTTEE I 3 OPEH

490 FOFE $I=H 1$ TO $H E$

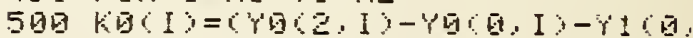
I)

510 HEXT I

520 FEM DUTFUT ELEL FESULTS

$53 \sqrt{1} M=1$

549 ERT IS M

559 CLEAF E EEEF

55R DISF "RLIN NO: "IN\$ DISF

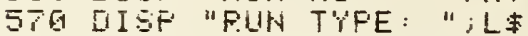

550 UISF "INIT EHLIE: ":U17

590 [IISF "CALDE CLINFIG: ":01\$

6日G DISF E UISP USING "13A.3\%.SD 4 LIE, $2 A^{\prime \prime}:$ "ELECT EHERG' $Y$ " :

51日 [ISP USING "12A.4K, 20,4R";

$520 \square I 5 P$

639 IF U1क[1.1]く" "M" THEH B

646 [IISF "Fetel dial Eettina: " : Z:5

5.56 OISF "TEMF UIJT dial इetting I: $2 E$

650 [ISF Q IF M=2 THEN 690

ET UISF MIF E BEEF ¿ FAUSE

Бउ. IMATE $12 \mathrm{H}, 1 \mathrm{~K} . \mathrm{SO}$. उDE

S9G FOF: $I=H I$ TO NZ

FU日 IF I $=$ I THEN M

715 IF $I=1$ THEH M\#="MASS FLOU OU $T "$

PQ日 IF I= THEH M

PSB IF I=3 THEN M\$="MASS FLOW IN

740 IF I=4 THEN M娄 "TEMP IN"

TSE IISF E [ISF M\$ Q [ISF

780 DISF "ZERO RATIHE PERIOO" E [II $\subseteq$ F "==========ニ======"

P7G QISF USING BSD: "日th MONENT "YG:C I

FB日 OISF USING 6B日: "1St MOMENT 13, $Y 1: 0, T:$

P9E DISP USING EBQ : "ZNA MOMENT

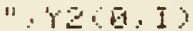

B日E

81日 IF $M=2$ THEN 340

8 EUISF MIF E EEEF E FHUSE 


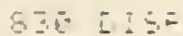

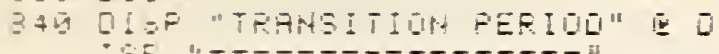

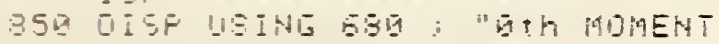

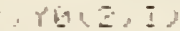

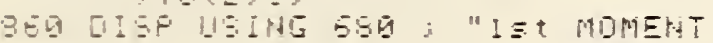

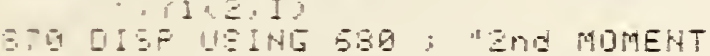

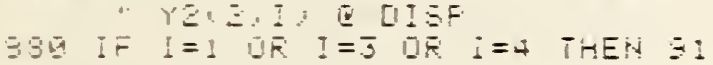

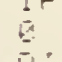

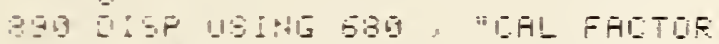
$=1, k, 14 ?$ ?

ำ 1500026

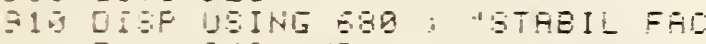

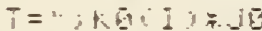

$390 \quad[1] \mathrm{F}$

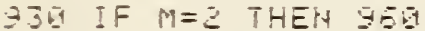

G4 UIEF MIS E EEEF Q FRUSE

$350015 \mathrm{~F}$

356 UISF "FINAL RATING FERIDU" IE

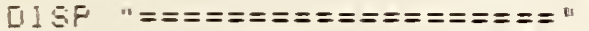

马7ด EISF USING 680 ; WT MOMENT , YBisis

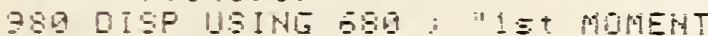
1.,, $1(1, I)$

G5G OISF LISING 58Q; "ZRA MOMENT

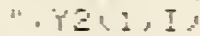

1 1956 UISF

101 IF $P=2$ THEH 1 G

1020 [ISF MIS E BEEF E FHLISE

$15.35 \square I 5 \%$

1 G4 NEAT I

1950 IF $M=2$ THEH 1120

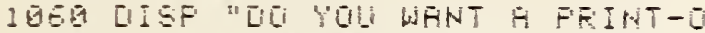
UT DF THE RESULTS? CY OF HY

$197 \overline{1}$ INPUIT $R$ E

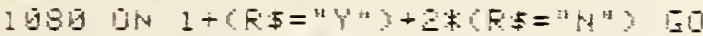

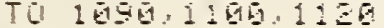

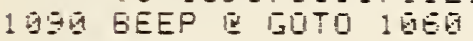

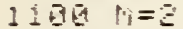

1116 G⿴囗十 540

$1120 \mathrm{M}=1$ Q CRT IS M I LLEFR

IIJE IISF "IO HOU WHFT TO STOFE

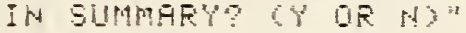

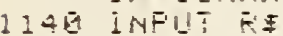

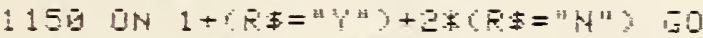
TU $1186.1176,2520$

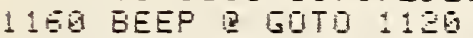

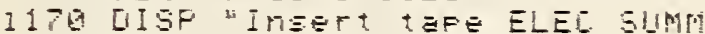
ARY in taFe drIte"

IISQ UISF MIF

113 F FUSE

1300 FUR I=N1 TO HE

$121 \mathrm{H} H \mathrm{H}=1 \mathrm{Z}$

1220 IF $I=0$ TIF $I=2$ THEN ME=1:

130 IF $I=G$ THEN FiS="MCETEI:

1248 IF $I=1$ THEH FIE=

I 35 IF I=E THES FIE= "TEQUTW"

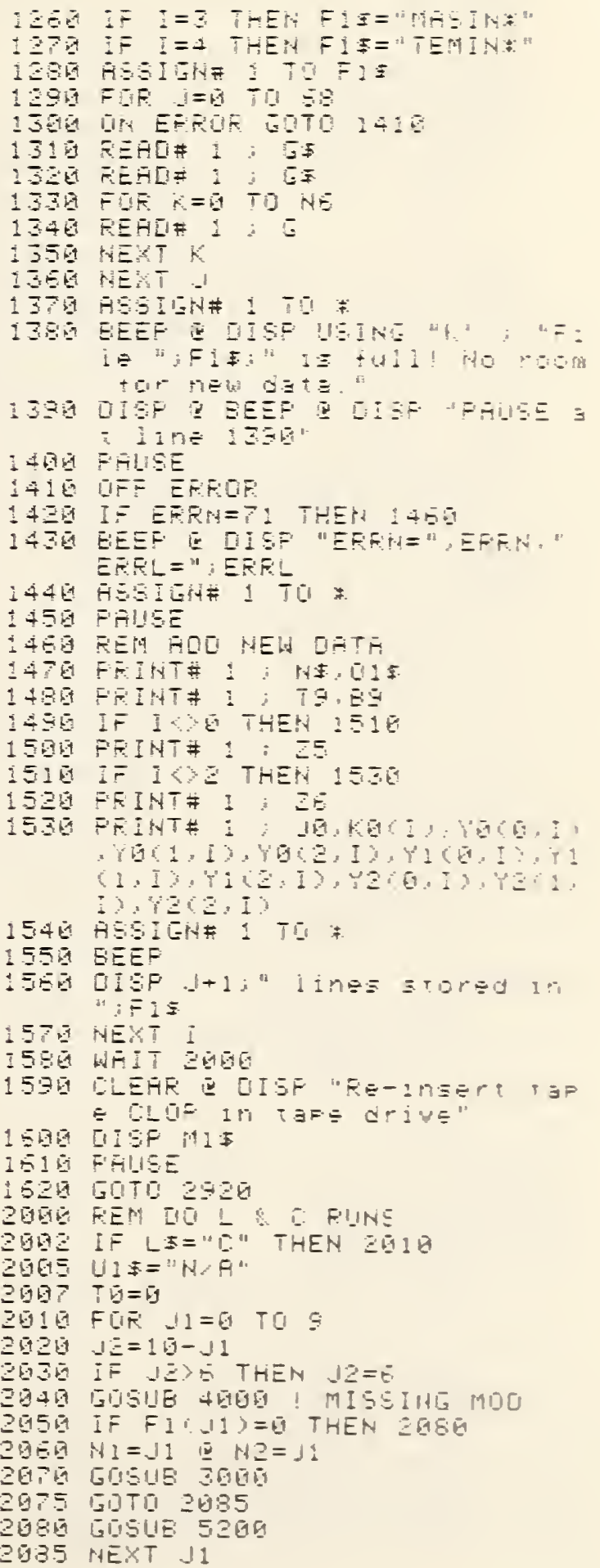




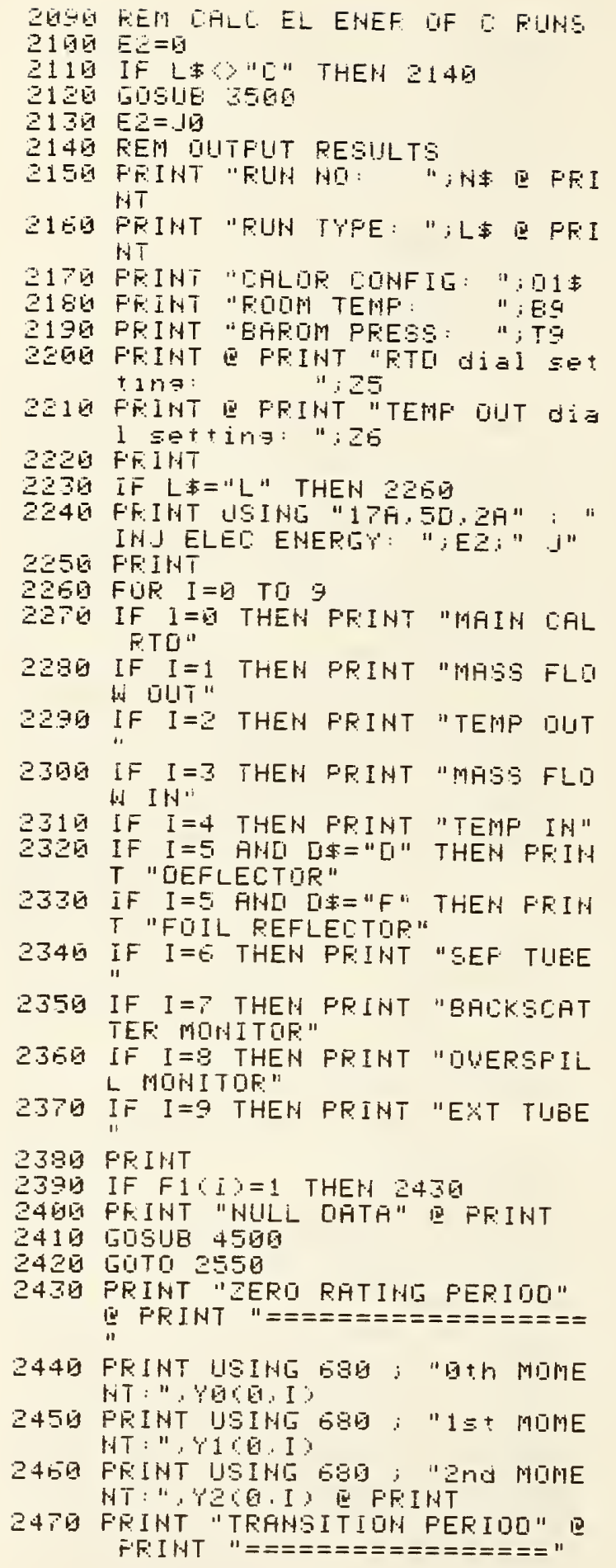

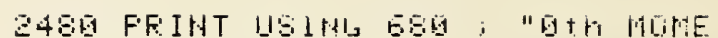
HT: " YG

2496 FFIHT USIHE EBS; "1Et MOME HT: " Y ' $12 . \mathrm{I}$

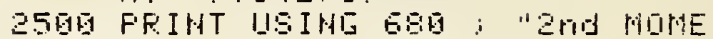
HT: " $T 2 C Z I D$ E FFIHT

2510 FFINT "FINHL FITTINI FEFIOD"

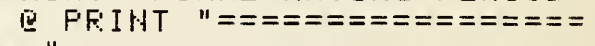
$=="$

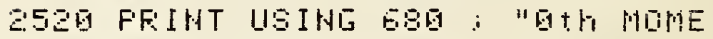
$H T: ", H \in(1 . I)$

25.5 FFIHT USIHE ESE; "1Et MOHE HT: " $\because 181, I ?$

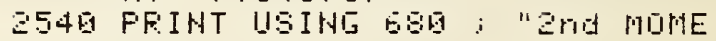
$H T: ", Y Z 1, I)$

$25.5 \mathrm{G}$ FRIHT

ZTE LLEAR E EEEF

257G [ISF "[IO YOUI WHAT TI SAWE ESULTS ONN THFE? Y"YF HO"

258日 IHFUT RE

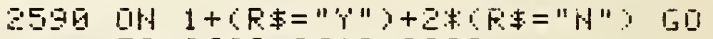

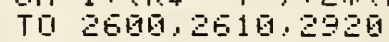

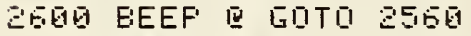

2E1G [ISF E [ISF "InSErt taFe LA SER Full $x$ iri taFe drive" E F.FIHT W1: E FHIISE

2E. ou w $3 \equiv h$ to

2E.0 IHFUT F1米

264 HSSIGH\# 1 TO FI I LOOK FOR EDF

$2 E .5 \bar{G}$ FOR $I=0$ TO 27

ZEEG ON EFFOF GOTO 2790

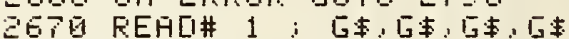

25EG FIEAC\# 1 ; G.G.5.G

26日6 READ\# 1 ; G

270 GOE $J=0$ TL 91

:71日 FEHE\# $1: 5$

27ER HEKT I

273G HEXT I

274 EEEF Q E tull. InFut shother tile n.jme ":

2750 INFUT F1t.

27GE LISF "FHUSE to Ereate "iF1क ;" if necessary. Fush Cont Nitien ready."

277G FHISE

2780 GOTO 2640

27G日 DFF ERROF:

2806 IF ERFN=P1 THEH 2840

2919 EEEF I [ISP "ERRH=": ERRH: "E FR:L = ":ERRL

ZQZU ASSIGN\# 1 TO

2BIG PALSE

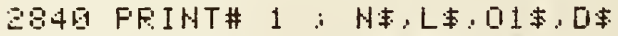

2850 FRINT\# 1 ; T9.B9.25.25

285日 FFINT\# 1 :

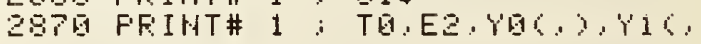
अ 1209 


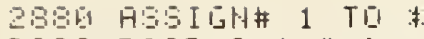

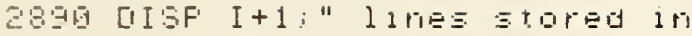
": F 1 F EEEF

可可 WHIT ZUG

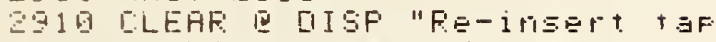
ELLOF if t $\exists F$ do

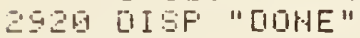

2930 EHC

J1GD FEM IELEUILATE MONEHT:

3日19 $4=30$ Q

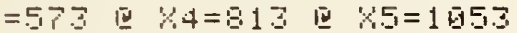

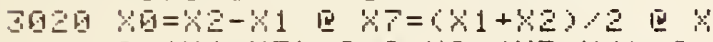

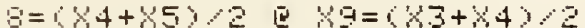

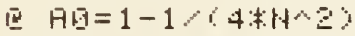

उ可哥

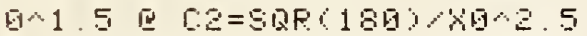

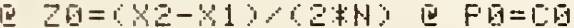

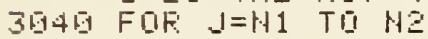

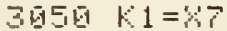

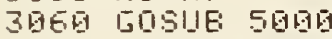

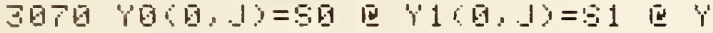
$2(1,1)=52$

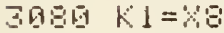

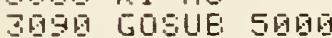

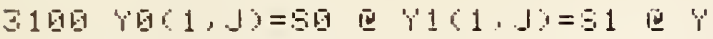
$3(1,1)=53$

$3110 k 1=x 9$

3126 GOSUE 50.

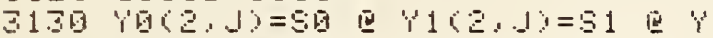
$363,1)=52$

314 G HEXT I

3. 15 FETIIRN

356E FEM ELEL: ENEFI'Y IH.I

$3519 \quad U 2=0$

$35263=0$

3530 I $2=1$

354 I $I=0$

355 Flife I=日 TO

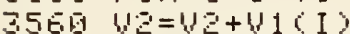

$3570 \quad 43=W 3+11(1+T 0+10)$

$3586 \quad I 2=I 2+I 1(I)$

359 I $I=I 3+I 1(I+T E+10)$

BEDG HEXT I

$3619 \quad W 2=42>10$

उ.

$3630 \quad I 2=I 210$

3649 I $=1310$

उE 50 过

3EG FQR I=日 TO H5-1

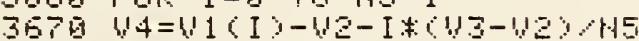

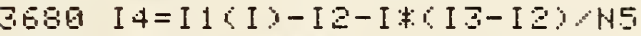

$3590 \quad 10=J 0104$ 政 4

3706 NEKT I

3710 F:ETILRH

400 REN WISSINI MUE DETECT

$4010 F 1611 \%=0$

4 Q 2 GQ FR $L=1$ TO

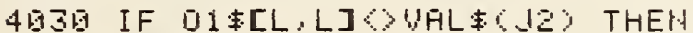
465

$4040 F 1(11)=1$
4Q5日 HEYT L

4 GE FETIETH

45GG FEEH FILL HILL DIATH SLITS

451 FIF $\quad I=0$ TO

452 国

$45.351<1.1 . I)=-I H F$

4546 Y I, I = I HF

455 HEXT I

$45 E$ FETIJES

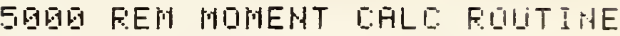

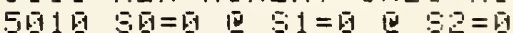

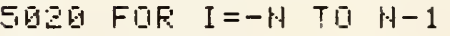

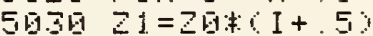

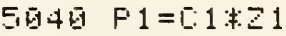

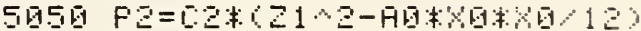

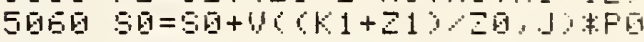

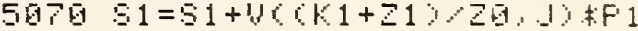

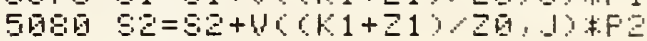

5090 HEXT I

51 G FETUFI

52GE FEM FILL HIILL [IATA FOER L FIII 15

51 目

$52 E$ E $1=-I H F$

$52 \Xi \bar{G} \quad E=-I H F$

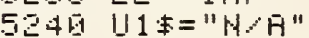

5 ESETUFH 
Variable Map

Proyram: CALC

Date: $\quad 840227$

Al - first order correction factor to get orthoyonality between moments

By - barometric pressure in $\mathrm{mm}$ of $\mathrm{Hy}$

C1 - normalization factor for lst moment

C2 - normalization factor for 2nd moment

Cø - normalization factor for Uth moment

U\$ - deflector type descriptor ( $D=$ mirror deflector, $F=$ foil reflector)

E1 - nominal electrical eneryy injected

E2 - energy injected during C run

F1 - array containiny flays indicating missing modules

F\$ - name of file containing raw run data

FI\$ - name of file in which results are to be stored

G - throw away numeric variable

G\$ - throw away string variable

I - counter

11 - array containing electrical calibration current readings

12 - average zero reading of I1 before injection

13 - average zero readiny of I1 after injection

14 - $I 1$ readings corrected for drift

$\mathrm{J}-$ counter

$J 1$ - index of sensor data in $V$ being processed

$\mathrm{J} 2$ - number indicating unit being searched for

in missiny mod test

$J \emptyset$ - electrical eneryy injected during calibration run

K1 - midpoint of period beiny calculated

$K D$ - calibration factor

L - counter

$L \$$ - run type ( $L=$ laser, $C=$ combination, $E=$ electrical)

$M$ - results output type descriptor ( $1=$ display, $2=p$ rint)

$M \$$ - temporary label for printing name of unit

M1\$ - -messaye- "Push CONT when ready"

$\mathrm{N}$ - number of data packets in nalf duration of any time period

N1 - lower sensor index of data to be processed

N2 - upper sensor index of data to be processed

N5 - number of V1 (and I1) readinys

N6 - number of throw away numerical variables

N\$ - per line in number

U1\$ - calorimeter configuration descriptor

P1 - lst moment function

P2 - 2nd moment function

$P \emptyset$ - Uth moment function

$R \$$ - alpha answer to yuestions

S1 - lst moment summiny variable

$\mathrm{SL}$ - 2nd moment summiny variable

Sy - Uth moment summiny variable 
T'L - factor representiny ratio of temp after

shutter closes to temp before shutter opens

Ty - ambient temperature in deyrees $\mathrm{C}$

Ty - duration in seconds of electrical energy

injection period

Ul - numeric indicator of unit receiviny eneryy

(electrical or laser)

Ul\$ - narne of unit receiviny electrical eneryy

$V \quad$ - array $(176 \times 10)$ containiny voltaye output

readinys for 10 sensors

array containiny electrical calibration voltage readinys

averaye zero readinys of $V l$ before injection

averaye zero reading of $V l$ after injection

Vl readinys corrected for drift

time in seconds of starting point of zero rating period

time in seconds of endiny point of zero ratiny period

time in seconds of startiny point of transition period

time in seconds of endiny point of transition period

time in seconds of endiny point of final ratiny period

midpoint of zero ratiny period in seconds

midpoint of transition period in seconds

miduoint of final ratiny period in seconds

period duration in seconds

Y1 - array containing 1st moments of 3 time periods

for all sensors

Y2 array containing 2nd moments of 3 time periods

for all sensors

array containing Uth moments of 3 time periods

for all sensors

21 - time coordinate of the point under yuestion

25 - main calorimeter RTU dial setting

26 - temperature out dial settiny

Zy number of readings averayed to get one data packet 
IE FEM FEG "ELSEAH" UHTE-TIME

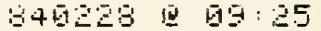

Z6 TFT IGIH EHEE

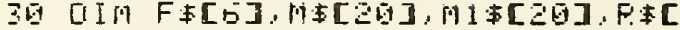

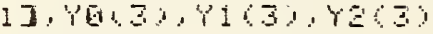

4 SHIRT B.

SE IHTELEF I. MI. F

b. M1

7 ELEAF E CIISF "InEETt TAFE EL

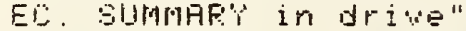

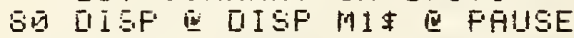

9 SLEEAF

I HSUF IS TUEE FILEESELI"

11 [ISF " 1. MAIH ERL RTO"

IZG UISF" 2 . MASS FLQW OUT"

1.3日 1 ISF" 3. TEMFEFATURE DUT"

140 [ISF " 4. MASS FLEW IH"

150 IISF" 5. TEMFEFATURE IM"

160 [ISF" "E. DEFLECTOF"

170 OISF" "7. FOIL FEFLECTOR"

$189015 F "$ "S. SEFRRATIOH TLEE"

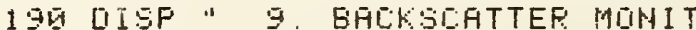
[IF:"

20日 UISF " 1日. OUERSPILL MOHITUR

219 UISP "11. EKTEHSIOH TUBE"

20 LISF Q LISF "ENTEF LIHE HI

236 INFIIT F

240 IF FO=1 AHD $R=11$ THEW $27 \bar{G}$

250 EEEF Q [ISF E "ISF "WHAT?"

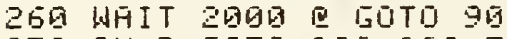

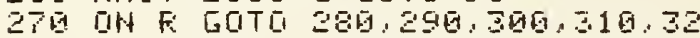
ㅁ. $350,346,350,360,376,380$

ZBE FF="MLETL\#"Q M\$="MAIN EFLUF IMETER RTO" Q LOTO JEG

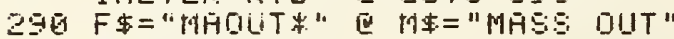
E $10 T 0 \quad 390$

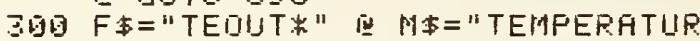
E UUT" E GETTO $\$ 90$

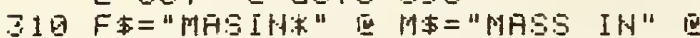
$50 T 0 \quad \Xi 90$

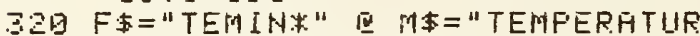
E IN" IQ GUTO 390

330 $F \$="[I E F L E * "$ Q M\$="MIRROR UEF LECTUF" E GOTO 390

340 F⿻二"FDREF*" Q $M=" F D I L$ REFLE C:T [IF:" E GOTD 396

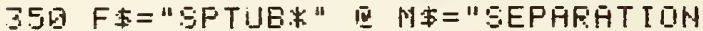
TLEE" E GOTE J9E

36日 F来="BSMON*" Q F MCNITUE" E GQTA 390

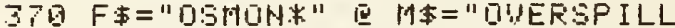
MUNITLF:" ए GUTO उ9G

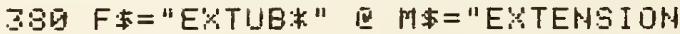
TUEE"

$390 \quad M=1$

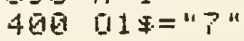

41 CET IS M
420 ELEAF 0 UISF MF

$43 \bar{D}$ IMALE $12 \bar{H} \cdot 1 \mathrm{X}, \mathrm{SU}$. S[E

440 FSEIGH\# 1 TO F

459 FDR $I=D \quad T D B S$

466 UIS EREOAF: GOTO 960

47. REHC\# 1 : H\$, 015

436 REHL\# 1 : TS, BS

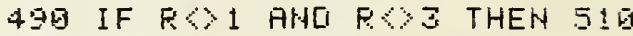

50 GE FEO\# 1 : $2 \mathrm{~B}$

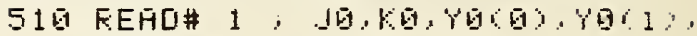

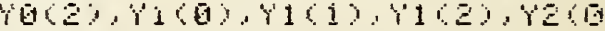
$\therefore+2(1)+20<2$

5 [IISF "LIHE ":I+1 世 [IISF

530 DISP "PUH NO: ":NH Q UISF

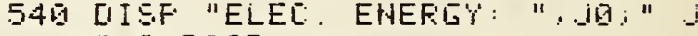
13 E $[I S F$

55 QISF "DHL CONFIG ": G1:

560 [ISF "PUGM TENF: "TS: "IEL E:"

57Q DISF "BRROM FRESS: ": BS:" mm $H F "$ ¿ [ISF

$5 B$ IF $F$ C 1 THEH BDG

599 [IISF "PTE [IHL SETTIHE: ":ZE E $[I S P$

EEG IF F 3 THEH 620

E1D OISF "TEMF DUT OIAL SETTINE: ": ZZ Q DISF

520 IF $M=2$ THEN 550

G.3̄ EEEF E LISF MI\$ E FHUSE

E4⿴囗十 OISF

65日 UISF "ZERQ RATIHG FERIGU" Q

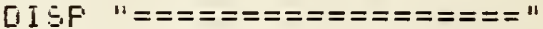

65日 OISF USING 439; "DTh MONENT 11, You

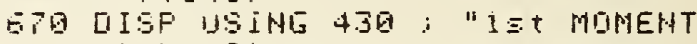
1. 1200

ESG DISF USIHG $430:$ "ZNA MOMEFT ". 20 is

59日 0 ISF

700 IF $M=2$ THEN 730

719 EEEF E UISF MIF E FHUSE

720 UISF

730 IISF "TRAHSITIOH FERIDO" $\bar{Q} 0$ I SF" $=============="$

74 DISF USING $430:$ "Gth MOMENT ", $Y$ G

75 [ISP USINE 4.30: "1ET MOMEHT "Y Y Y :

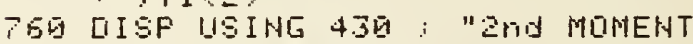
" Y Y 20 E IISF

770 IF $F=2$ OR $R=4$ GR $R=5$ THEH $B Q$ E

78日 UISF USIHE 43日: "EAL FACTOF ". $\mathrm{R} \theta$

79 GDTE BIO

806 OISF USINE 4.30: "STABIL FAC

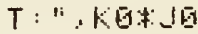

Q1日 $[1 \mathrm{ISP}$

32 IF $M=2$ THEH 85.

830 EEEF E 


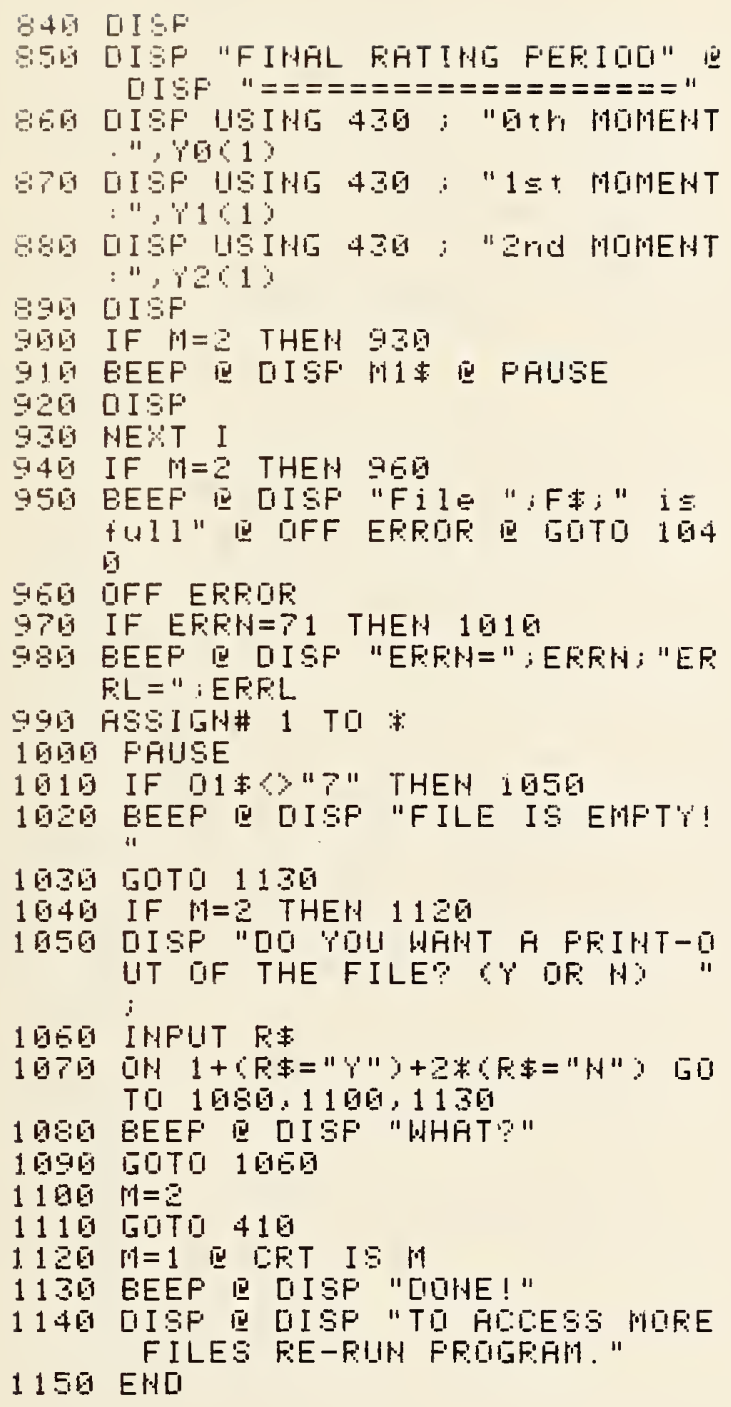


Variable Map

Proyram: ELSCAN

Date: 840228

B9 - barometric pressure in $\mathrm{mm}$ of $\mathrm{Hg}$

$F \$$ - name of summary file to be accessed

I - counter

Jy - injected electrical energy in joules

Kض - calibration or stability factor as appropriate

$M \quad$ - data output method descriptor (1=display, $2=p r i n t)$

$M \$$ - name of unit in $F \$$

M1\$ - - messaye- "Push CUNT when ready"

N\$ - run number

UI\$ - calorimeter configuration descriptor

$k \quad$ - numeric answer to questions

$\mathrm{K} \$$ - alpha answer to yuestions

Ty - ambient temperature in deyrees C

Yl - array containing lst moments for zero rating, transition, and final rating periods

Y2 - array containing 2nd moments for zero rating, transition, and final rating periods

$Y \varphi$ - array containing Uth moments for zero ratiny, transition, and final rating periods

Zy - dial settiny for either main calorimeter RTD or temp out sensor 
10 FEM FFIIL "FAETRE" [IATE-TIME

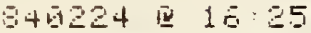

EQ FEP AFFLIES CDFE FUF LIFIFT F FOM DUT:IIUE AMEIENT TQ FETL A HEI TEMF LULT FEF: OTHEF: MOIUL ES

3. FEM AUERAGES ELEETFIEAL FESU LTS NU FFUUISIUNS FIF MASS IN OR OUT OR TEMF IH

4 LIFTIGH EHSE G

5 ILEAR.

5. II HO $59,42169), N \$[9],[1 \mp[6], I 1+[$

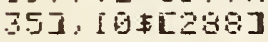

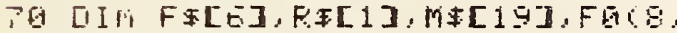
$4,0.50 \%$

3日 DISF "Insert taFe ELEL. SUUM HFi 1 in

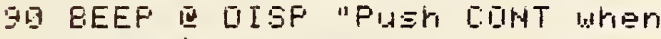

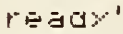

109 FIHISE

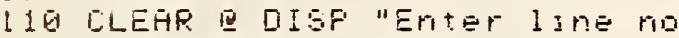
at aerisar desired"

120 DISF " 1. Mझin E. BI RTL"

13 [ISF " $"$. TEMF [itt"

140 OISP " I. Fail Fetiertor"

150 [ISF" 4. Murgr [letiectoot:

169 OISF "5. SEparation Tube"

17ब UISP i E. Eackscatter Monit art

180 [IJF" F. OUErEFill Monitor

190 [IJF"

20日 पISF E LISF "Enter IJ ne no.

210 INFUT PE REIHTSR

220 IF $F\rangle=1$ QIF $F<=8$ THEH 240

230 OISF E EEEF E पISP "WHAT?" GLTO 215

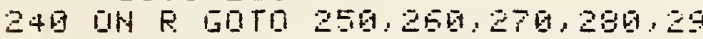
[0, $306,310,30$

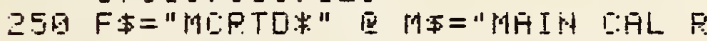

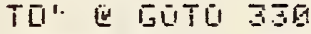

250 FE="TEQUT:"

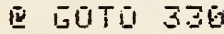

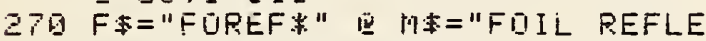
CTUE:" E GOTO 330

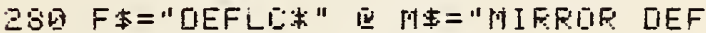
LELTOF" EQTO 330

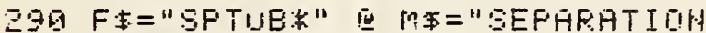
TUEE " E GOTO $\$ 30$

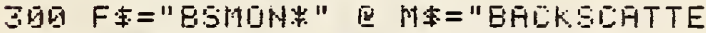
F. NÜHTOF:" E GUTO 330

$310 \mathrm{FF}=" \mathrm{OSM}$ OIH MUNITUF:" EGTO

320 F\$="EXTHE*" E MF="EXTEHSTDN TUEE म1

33日

335 H. $1=$

34 FOR I=日 TO 53

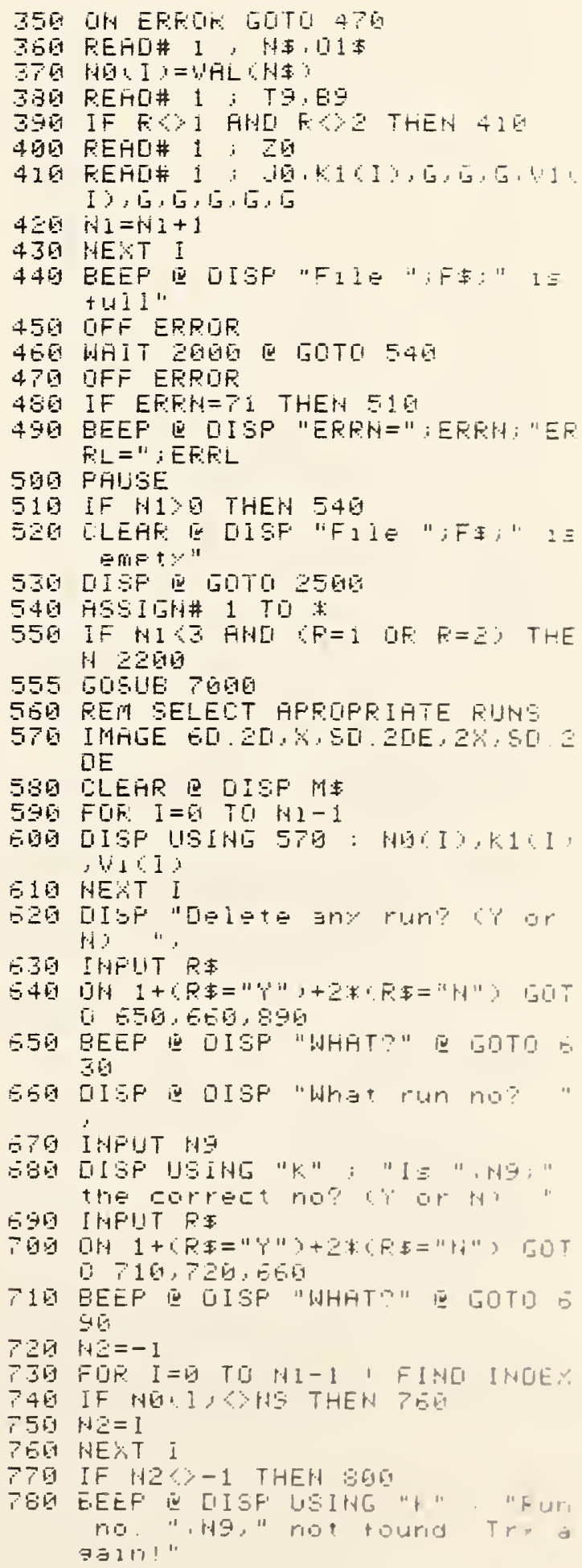




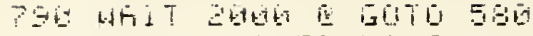

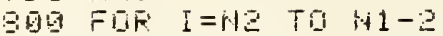

SIE IF HE=H-I THEH $85 \mathrm{G}$

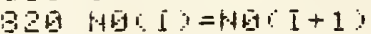

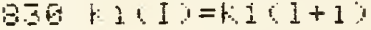

B十日 U1 $12=1(1+1)$

BES WEXT I

950 $+1=+1-1$

8T IF H120 THEH 5 G

BTS LLEAR Q EEEF Q GISF "Ho valu Es iett to be consióted"

806 G0T0 250日

89Q IF H1<3 AHE $C R=1$ DF $F=2$ ? THE Ii 200

G9G IF HIOI OF $R=1$ OF $R=2$ THEH 9 36

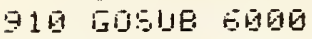

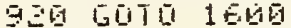

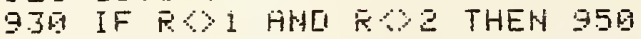

94. IOSUE 5060

950 IF $P=1$ DR $R=2$ THEN 97

960 IDSUE 4EDG

979 GDSUB 5096

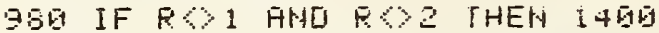

99G REM OUTFUT RTD \& TEMF GIIT FE SULTS

1 GEG IMHEE 15H.

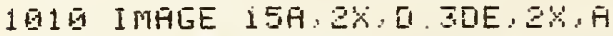

$192 \bar{M} M=1$ Q CLEAR

1030 CFT IS HE UISF M⿻ UIEF

1949 LISP USIHI IG⿴囗十⺝ ; "Lalib Fa ctor: ". . K

1959 UISF Q OISF USINE 1900; "S to [UU1

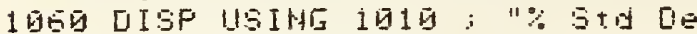

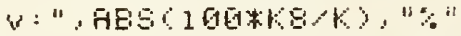

1979 UISP Q DISF USING 1019: "g

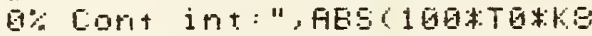
(k), "\%"

1080 USF USIHI $1910 ; 195 \%$ Eont

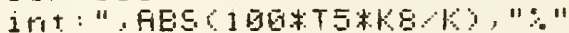

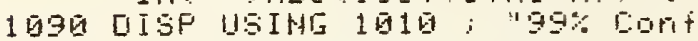
lnt: ", RES 1 G日్

$119 \bar{Q}$ IF $M=2$ THEN $113 \mathrm{~B}$

$111 \mathrm{~A}$ BEEF \& [ISF "Fust C.QHT when ready"

1120 PHIISE

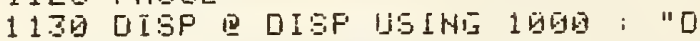
ritt CoEt:".Ai

1145 UISP 巴 OISF USINE 1EG0: "S to. [IEW: ". FE

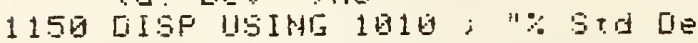

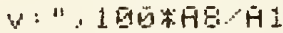

1150 015P 巴 DISF USING 1919:

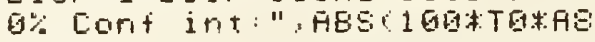
G1) " $"$ "

1179 UISP USIHE 1 Q19 . "95\% Cont

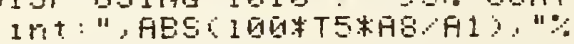

1139 OISP USIHE 1910 ; "99\% Lant

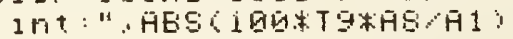

1190 UISF E [ISF "HO Ot FOITTE ". It

120 UISF Q OISF II

$121 \mathrm{G}$ IF $M=2$ THEH $13 \mathrm{~S}$

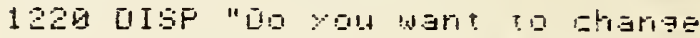
inta rote? is ar ij it

1230 IYPUT FO

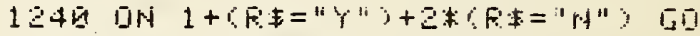
TU $125 \mathrm{Q}, 12 \mathrm{E}, 12 \mathrm{GQ}$

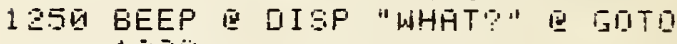
$1 \sum 26$

1260 G0SUE 7505

1270 50T0 1 128

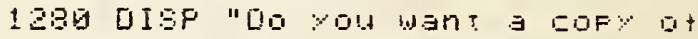

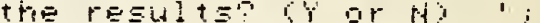

1290 INFUT EF

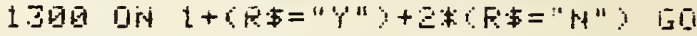
T0 $1316,1320,1350$

1319 EEEF Q DISF "WHAT?" 1290

1320 M=2 Q

1330 H $M=1$ ERT IS

1349 50T0 2009

$146 G$ REM DUTPUT HHEILLAR'Y MODULE 5

$1416 \quad n=1$ Q L LEAF

142 CFT IS M E UISF MT E UISF

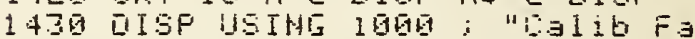
Et:": $: 1$

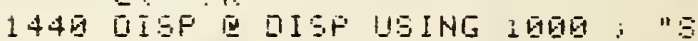
ta [1Ewiation: ". KE

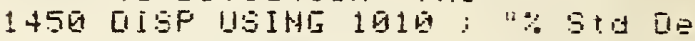
$\forall: "$, HESCIEA

14EG UISP Q UISF USINE $1010 ; "$ "

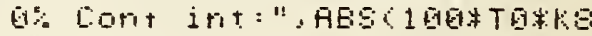
사, "\%"

1476 UISP JSIHE 1016; "95\% Cont Int: ". HES(1ER.T5*KBK) "\% "

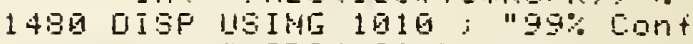

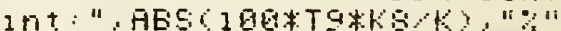

149 UISP Q DISF "No at Fuints: "N1

15 GI 0 ISF Q

1510 IF $M=E$ THEN $1 E 36$

1.526 uIsf "[ro pou want to Enange

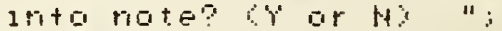

15.36 IAPUT FE

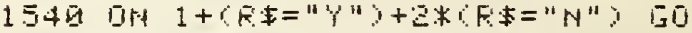
$T 61550,1560,1550$

1559 БEEP Q DISF "WHAT?" Q GITD i $52 \mathrm{G}$

1560 G05UE 7506

1570 GUTO 1420

1580 UISF "UD You want a LOP af the resulte? ir ar in 1 :

15马E INPUT RT

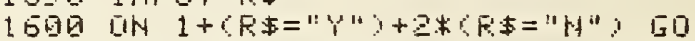
T61616,1620,1630

1519 BEEF Q DISP "WHAT" Q GOTO 1590 
I 250 M

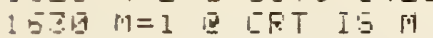

164 G日丁

?

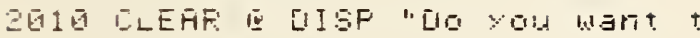
a gar r or H:"

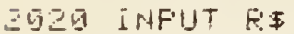

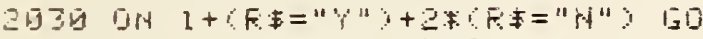
T $31040,2656,2506$

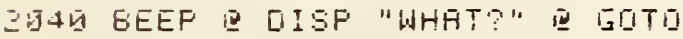
2020

20.5 FGCR, 1 $=6$

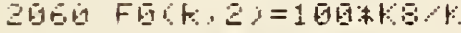

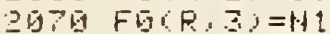

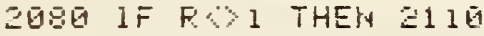

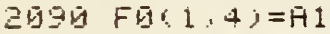

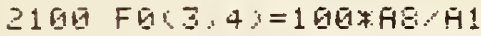

211 I IF $R<2$ THEH $214 \overline{0}$

212 F $12: 4 \geqslant=\mathrm{H} 1$

$213 \bar{F} \mathrm{~F}(4,4)=1$ 西术AB, $\mathrm{H} 1$

214G HSSIGNA 2 TO "IALFAX"

215日 FRINT\# $2 ; F G C ;$

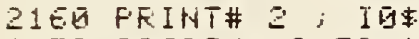

य179 ASSIDH ב TU 末

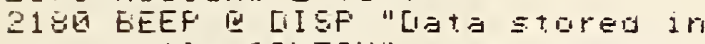
+IIE CALFAY"

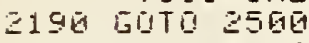

22BG BEEP Q UISP Q UISF "HOT EHD ULH FUNS FITE LEFET SQUAFES FIT"

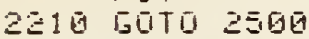

2505 EEEF Q UISF "[IINE"

251 is EMLI

3.J日 FEM LIN LST SIE FIT GHATEEL $L \bar{H}$ :

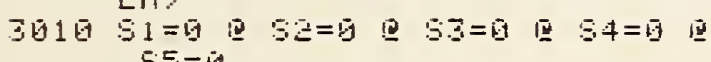
$5: 5=0$

302B FIR I=日 TO $M I-1$

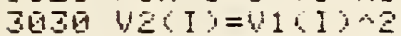

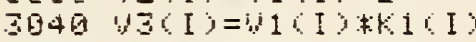

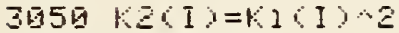

$3050 \quad 51=51+11<I$ ?

$367 \bar{B} \quad 52=53+1213$

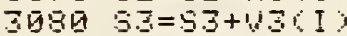

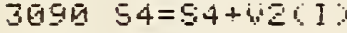

310 $55=55+k 3(2)$

$311 \mathrm{G}$ NEXT I

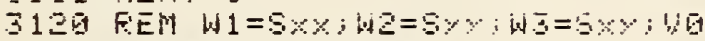

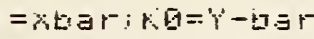

3130 แ $3=53-31 * 52 \% 1$

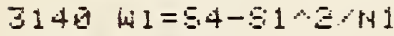

31.56 W2 $=55-52$ - $3+41$

$316.96=51 \times 11$

$3170 \quad K 5=S B N 1$

31EU FEM HI=SLUFE:K=Y-1HT

$3190 \quad A 1=W 3.151$

$3200 \quad k=r 0-A 1$ 情

3219 EEM $44=56 \%+2: 45=36 \% 3$

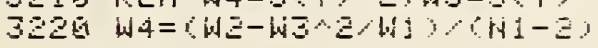

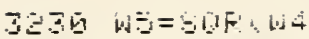

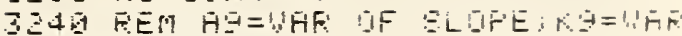
IIF $Y-2 r^{4}$

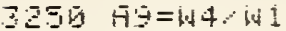

SE FE=SQR AOS

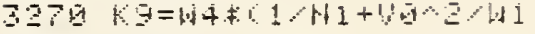

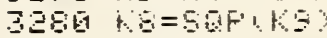

ZEG FETURA

460 FED HUE 5 .

401 要

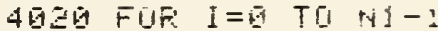

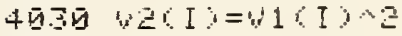

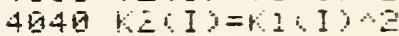

$40.5051=51+11 . I$.

$466 \overline{3} 2=52+1.1 \div 1$

$457054=54+42(1)$

$468055=55+126 \mathrm{I}$

4 प日G HEXT I

41 던

$4119 k=52<1$

4120 y

4150 V8=56F?

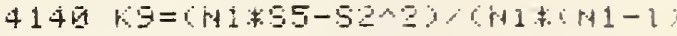

$415 \mathrm{AB}=\mathrm{B}=\mathrm{BF}(\mathrm{F})$

$41 E$ FETIJFN

596 F F $T 5=99 \%$

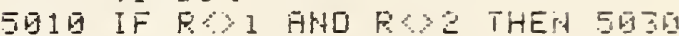

5620 H

5025 G

5056 H $15=1$

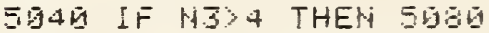

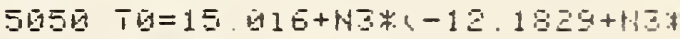
5.894.5- . 413.5 .7 .5$)$

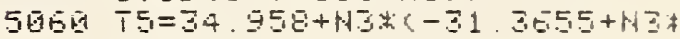
$19.203-1.945 * 15)$

507日

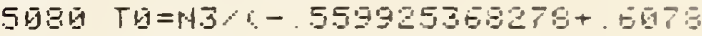
$44692534.43+$.

5596 T5=N3 - 6115593191+.519110

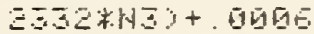

51 IG IF $43 \% 1$ THEW 51 .

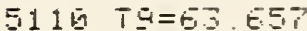

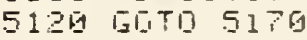

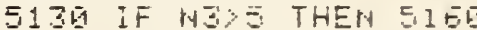

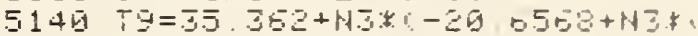
$4.595-5 E 367+2.5 y$

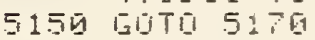

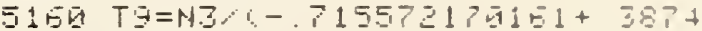

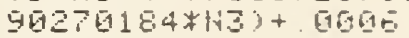

517 F FETUFH

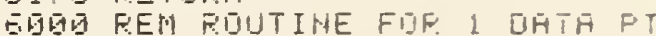

E旦过 $k=k 1$.

Eดวด $\times 3=\overline{9}$

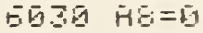

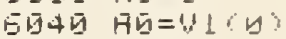

EGE $T \bar{B}=1$

可可的 T. $=1$

E.

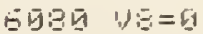




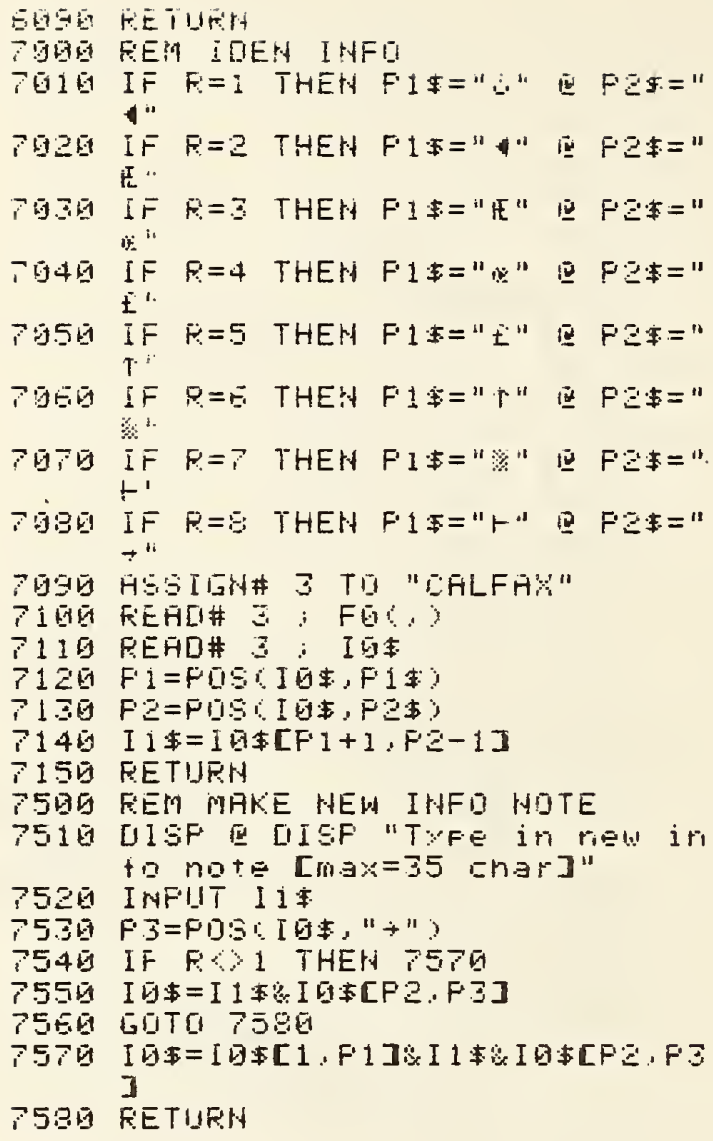




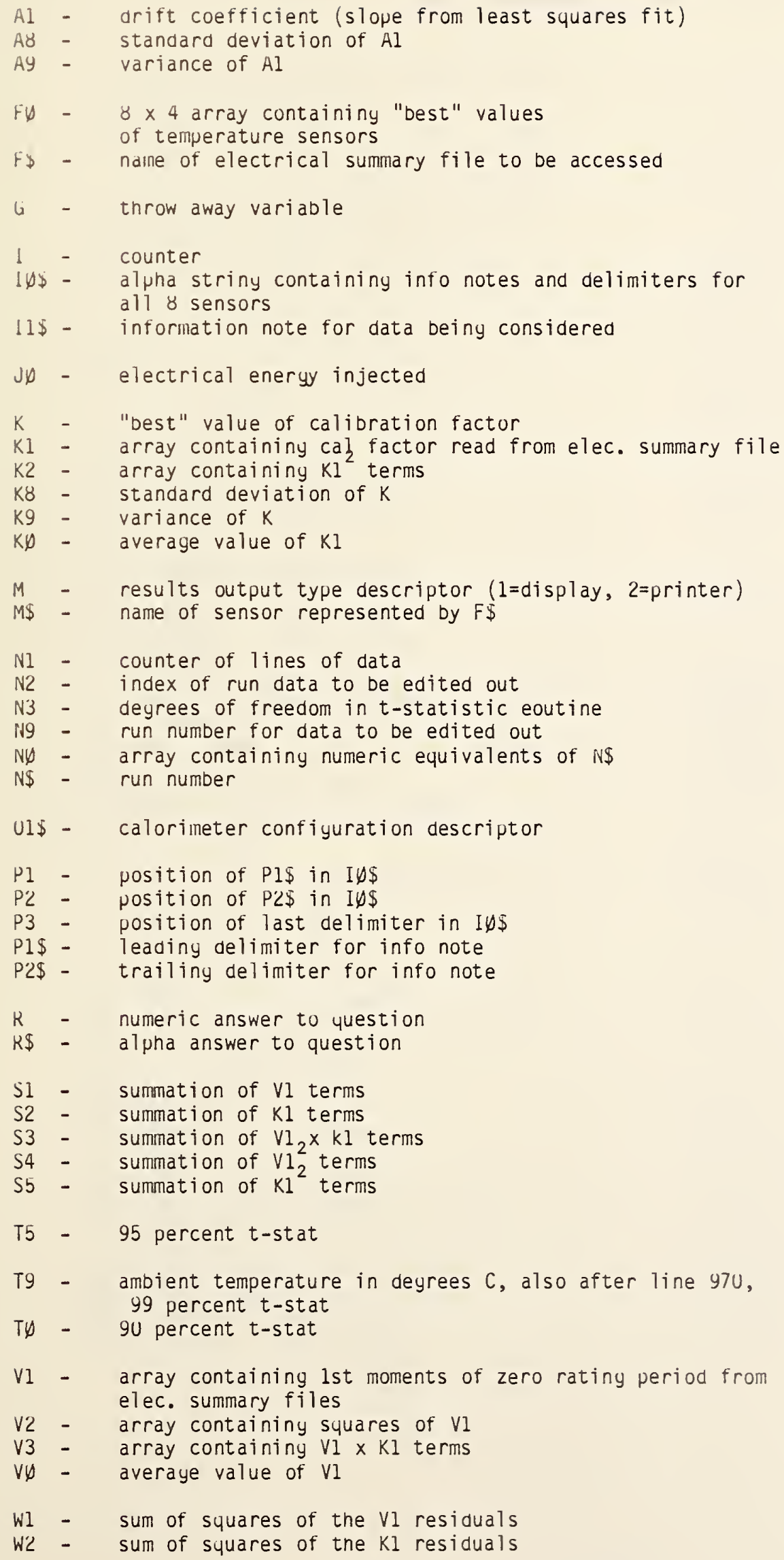


W3 - sum of squares of the $V 1 \times K l$ residuals

W4 - $\left(W 3^{2} / W^{2}\right) \times(N 1-2)$

Wb - square root of $w 4$

ZV - dial setting of main calorimeter RTD or temperature out (as appropriate) 
1 FEM FEIII "FILEXM" [IATE-TIME 340220 \& $12: 35$

E UFTIDH DESE BO

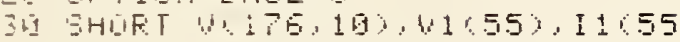

4

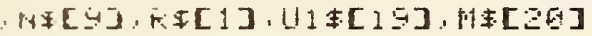

5. INTEGEP I, HS, 111, I1

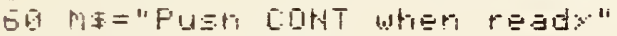

TG ILEAR Q SEEF

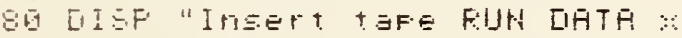

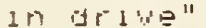

3ด [ISF MIT E FHIJSE

1 GE LEAP

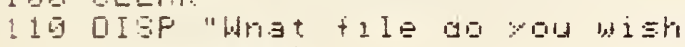
T.

12 IHFUT $F$ F

13 GESIGHZ 1 TO F

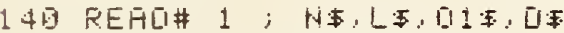

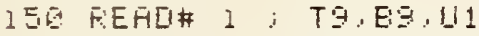

160 IF 1135 THEH 1 SG

17. FEALI\# 1 ; Z5. ZE

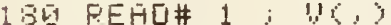

198 IF $L \$=" L "$ THEH 230

20日 FEAO\# $1 ; 111 \mathrm{E}$

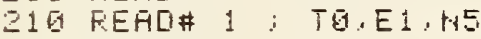

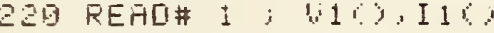

236 ASEIGNA I T日

24 CLEAR E DISP USING "K" : "E ntente of tile ":Fq:" memory"

250 WHET 20106

250 $M=1$

27G LLEAR Q E.FET IS B

2EQ [ISF "Fut NO: "HA

2马G [ISF Q UISF "PUn TYFE:

3G DISF i il

I19 DISF "RIDU TEMF: "IT'

3. [IEG C

Z20 QI i) min $\mathrm{H} \equiv$ ":

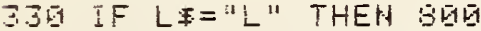

346 UISF E LISF USIHE "I5F. 5 I , ZA "; "Hom EnErэ\%:" E1;" J"

350 IF $M=3$ THEN 380

35 OISP Q UISF 饾

379 FHILSE

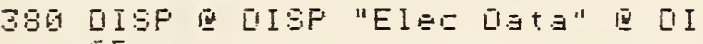
$\Xi F$

396 IISF "LIRE UOITE HIIFE"

486 FEIF $I=G$ TO $H 5-1$

419 IISF HSING "30,3\%,MEO.20, $2 \%$

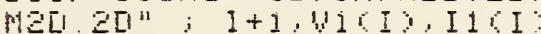

420 HEST I

430 IF $M=Z$ THEH $4 E 6$

448 OISF Q OISP MF Q UISP

45 FFIUSE

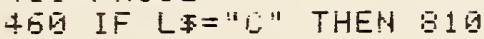

47 DISF [I ISF

450 IMAGE "UIAL SETTIHE" \& MEL I 2

490 IF UI\$[1,1]="M" THEH 540

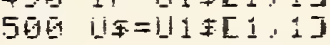

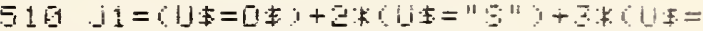

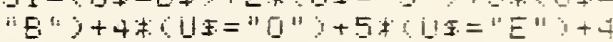

520 505UE 25日日

5395010 i 149

540 पISP "MHSS FLO!. IH" E

$5=69$ i1 =

550 1050 256

57G पISF E LISF "MASE FLIB DUT. E $[I I S F$

530 . $11=1$

550 GUEIJE 2500

6.0 [ISF E OISF "TEMFEFATIEE IY" Q $[1] S \mathrm{~F}$

$5+11=4$

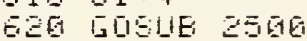

5.J日 IISF I UISF "TEMFEFATLIRE DUT

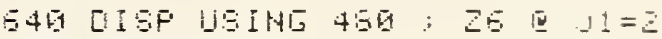

550 G0SUE 2506

GEG UISP W LISP "CALDETMETER RTU

670 [ISF USING $430: 25$ Q J $1=$

EST TOSLE 250

69G GOTO $11+9$

GGE REM DUTFUT $L$ \& L FULHE

81日 FDF J1=日 TO

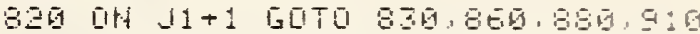

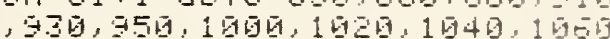

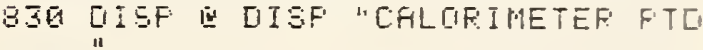

34D [ISF USING $489 ; 25$ E $2=6$

B56

B5日 DISF 世 UISF "MASS FLDW BUT" 更

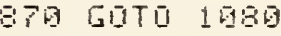

GSE DISF IQ UISF "TEMFERATURE DIT

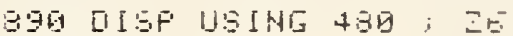

प905 5010 1500

G19 UISF E UISF "MASS FLLIU IA" E [IS IF

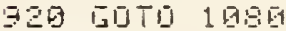

IJE DISF Q UISP "TEMFERATIJPE IF" E $[1 I S F$

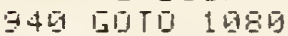

950 IF $U F=$ "F" THEH YBE?

96日 UISF E UISP "UEFLECTDF" E [I] S.F

974 G0T

93日 OISF Q DISF "FOIL REFLESTOF"

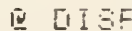

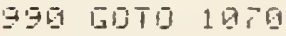

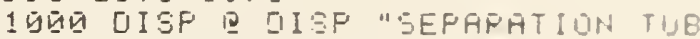
$E^{1}$ \& 


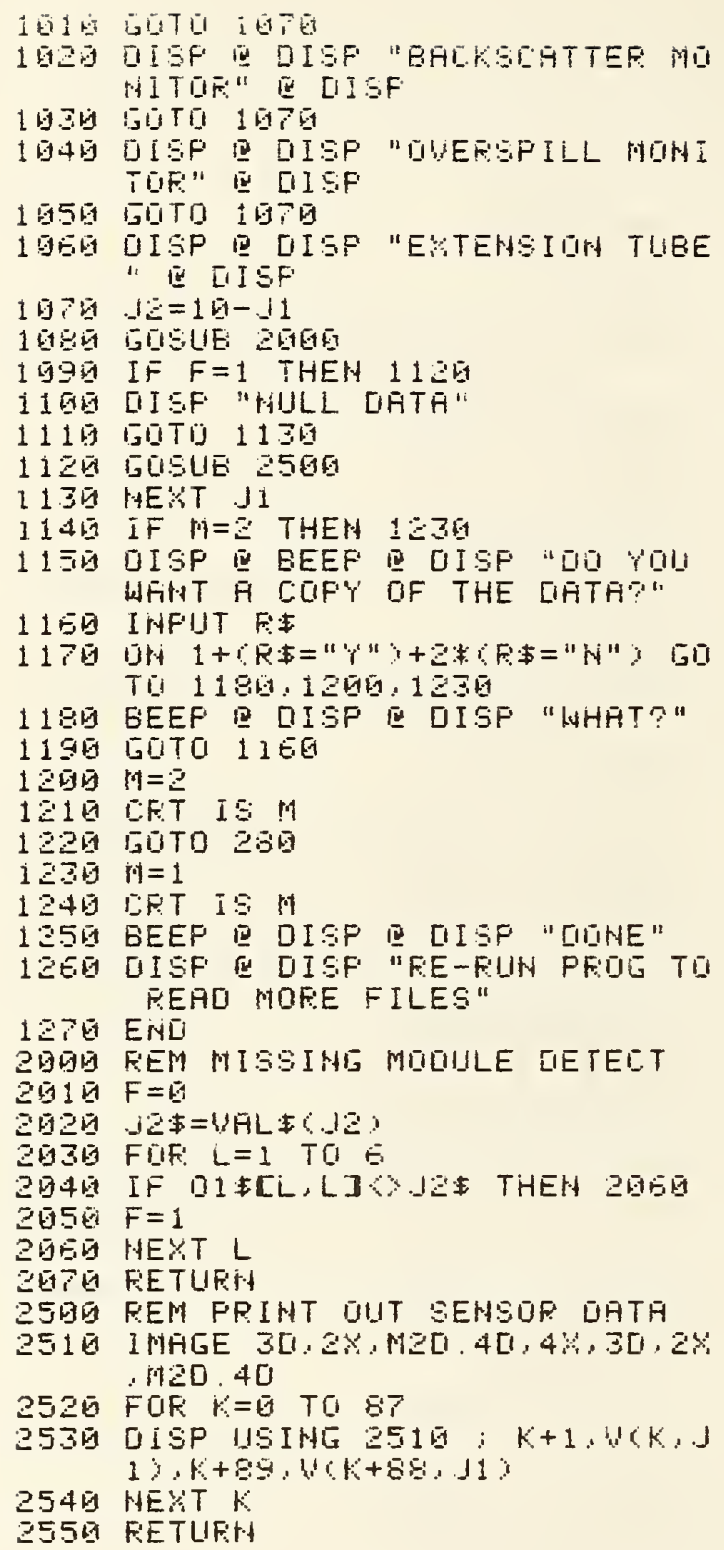


By - barometric pressure in $\mathrm{mm}$ of $\mathrm{Hg}$

U\$ - deflector type descriptor ( $D=$ mirror deflector, $F=$ foil reflector)

El - noninal electrical energy injected

$F \quad$ - flay in missing module routine ( $0=$ missing, $1=$ present)

F\$ - name of temporary data file to be accessed

1 - counter

11 - array containing electrical calibration current readings

$J 1$ - column index in V indicatiny particular sensor

$\mathrm{J}^{2}$ - numeric indicator of module

J2\$ - string eyuivalent of 32 for comparing in missing inodule routine

K - counter

L $\quad$ - counter

$L \$$ - run type ( $L=1$ aser, $C=$ combination, $E=$ electrical)

M - results output type descriptor (1=display, 2=printer)

M\$ - -message- "Push CONT when ready"

N5 - number of V1 (and II) data points

N\$ - run number

$01 \$$ - calorimeter configuration descriptor

R\$ - alpha answer to questions

Ty - ambient temperature in deyrees $C$

Ty - duration of injection period in seconds

U1 - number of module receiving energy (1aser or electrical)

U\$ - one letter descriptor of unit receiving electrical eneryy

UI\$ - name of module receiviny electrical eneryy

$V \quad$ - matrix $(176 \times 10)$ containiny output values

for all sensors

V1 - array containing electrical calibration voltage readinys

Zb - main calorimeter RTO dial settiny

Z6 - temperature out dial setting 
C7. "CHMUN"

Proyran Listiny

5 FEM FFGL "EHMGR" IHTE-TIME E

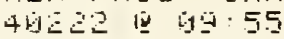

1 II:LEAF

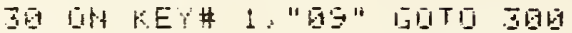

4 G

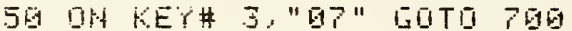

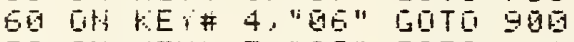

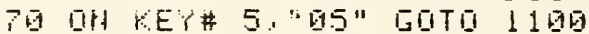

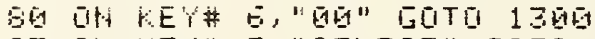

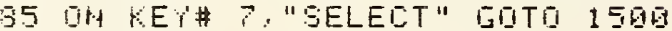

9日 GH tE'Y S, "STOF" GOTO 140

$\because 1$ LLEAR

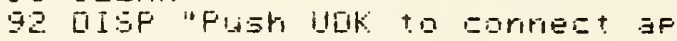

Frofrlate Eganer charinel to [u⿻卄. "Q UISF

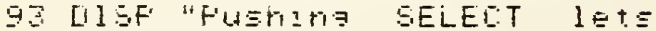
You chooseary Eharine i"

I 1 GE KE' LAEEEL

110 FiE IOLING LOUP

12 FEEH

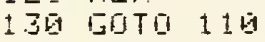

¿4G LISF "PFIGPAM TEFMIHATED"

15 EEEF

150 EHEI

BดD OUTFUT 799 HSIHE "K" ; "QG"

310 GOTO 91

500 DUTFUT 70G USIHE "K" "GS"

510 GOTO

PQ日

716 G0T0 91

9日0 DUTFUT PQS USIHE "K" , "GE"

Q10 GUTO

1109 DUTPIT 799 USIHG "K" :

1110 G日T

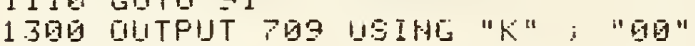

1316 GUTO 91

1500 GLEAF Q OISF "UHAT DHAHNEL"

151 I INFUT I:

152G DUTPUT 7GE HSIHE "K" : E.

1536 GUTO 91

Variable Map

C\$ - channel command to scanner 

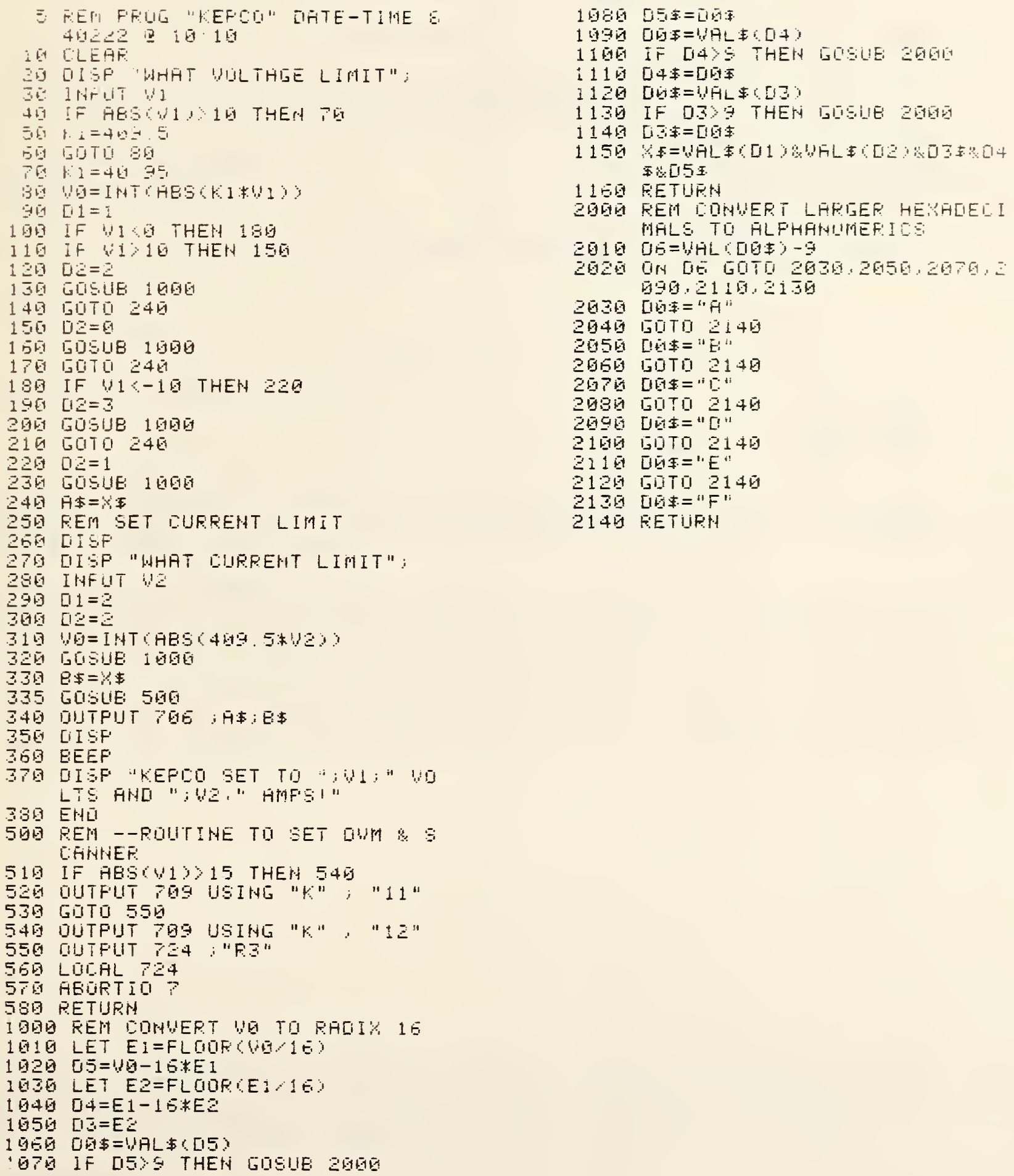
Variable Map

Program: KEPCU

Vate: 840222

A\$ - voltaye command to power supply

B\$ - current coinmand to power supply

U1 - number indicating SN488 channel (1=voltage, 2=current)

U' - number indicatiny SN488 ranye

D3 - lst nexadecimal diyit (MSU) of power supply command

U4 - Znd hexadecimal diyit of power supply command

Ub - 3rd hexadecimal diyit (LSU) of power supply command

Uo - amount hexadecimal number exceeds $y$

U3\$ - 3rd character in power supply command (MSU)

U4\$ - $\quad 4$ th character in power supply command (2nd hexadecimal digit)

DS\$ - bth character in power supply command (LSD)

$D Q \$$ - temporary string variable for converting hexadec digits to string variables

El - quotient derived during hexadecimal conversion

K1 - scaling constant for calculating power supply command

V1 - voltage limit

V2 - current limit

$V \emptyset$ - decimal equivalent of hexadecimal number part of power supply command

X\$ - transfer striny variable for calculating power supply commands 
NBS.114A (REV. 2-8C)

U.S. DEPT. OF COMM.

BIBLIOGRAPHIC DATA

SHEET (See in structions)

1. PUBLICATION OR REPORT NO.

NBSIR 84-3008

2. Performing Organ. Report No.

3. Publication Date

October 1984

4. TITLE AND SUBTITLE

A Calorimeter for Measuring High-Energy Optical Pulses

5. AUTHOR(S)

P. A. Simpson, E. G. Johnson, Jr., S. M. Etze1

6. PERFORMING ORGANIZATION (If joint or other than NBS, see instructions)

NATIONAL BUREAU OF STANDARDS

DEPARTMENT OF COMMERCE

WASHINGTON, D.C. 20234

9. SPONSORING ORGANIZATION NAME AND COMPLETE ADDRESS (Street. City, State, ZIP)

7. Contract/Grant No.

Newark AFB

Newark, Ohio

10. SUPPLEMENTARY NOTES

[.] Document describes a computer program; SF-185, FIPS Software Summary, is attached.

11. ABSTRACT (A 200-word or less factual summary of most significant information. If document includes a significant

bibliography or literature survey, mention it here)

Two similar calorimeters for measuring laser pulses in the range $1 \mathrm{~kJ}$ to $15 \mathrm{~kJ}$ are described. The calorimeters, which are electrically calibrated, can be operated anywhere from the ultraviolet to infrared by selecting the proper materials for the volume absorber and deflecting mirror. Operation of each calorimeter is controlled by a dedicated desk-top computer. The theoretical basis for the calorimeters is given as are the constructional and operational details. The computer programs that are used are included in the appendices.

12. KEY WORDS (Six to twelve entries; alphabetical order; capitalize only proper names; and separate key words by semicolons) calorimeter; computer-controlled calorimeter; electrically calibrated calorimeter; high energy calorimeter; laser pulse; volume absorbing calorimeter.

13. AVAILABILITY

$\mathrm{X}$ Unlimited

For Official Distribution. Do Not Release to NTIS

Order From Superintendent of Documents, U.S. Government Printing Office, Washington, D.C. 20402.

X] Order From National Technical Information Service (NTIS), Springfield, VA. 2216I

\begin{tabular}{|} 
14. NO. OF \\
PRINTED PAGES \\
170 \\
\hline 15. Price \\
$\$ 16.00$
\end{tabular}




